DOE/RW- 0472 Rev. 1

Office of Civilian Radioactive Waste Management

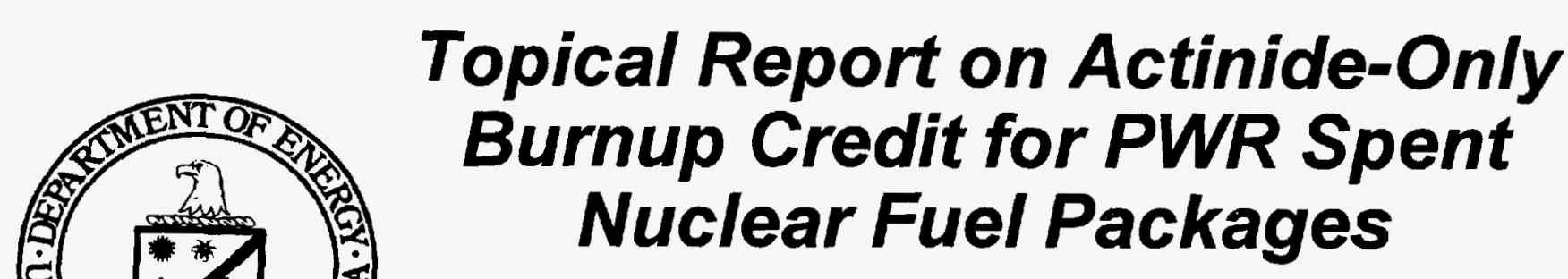

Revision 1

April 1997 


\section{Topical Report on Actinide-Only Burnup Credit for PWR Spent Nuclear Fuel Packages}

Revision 1

April 1997 


\begin{abstract}
A methodology for performing and applying nuclear criticality safety calculations, for PWR spent nuclear fuel (SNF) packages with actinide-only burnup credit, is described. The changes in the U234, U-235, U-236, U-238, Pu-238, Pu-239, Pu-240, Pu-241, Pu-242, and Am-241 concentration with burnup are used in burnup credit criticality analyses. No credit for fission product neutron absorbers is taken. The methodology consists of five major steps.
\end{abstract}

1. Validate a computer code system to calculate isotopic concentrations of SNF created during burnup in the reactor core and subsequent decay. A set of chemical assay benchmarks is presented for this purpose as well as a method for assessing the calculational bias and uncertainty, and conservative correction factors for each isotope.

2. Validate a computer code system to predict the subcritical multiplication factor, $\mathrm{k}_{\mathrm{eff}}$, of a spent nuclear fuel package. Fifty-seven $\mathrm{UO}_{2}, \mathrm{UO}_{2} / \mathrm{Gd}_{2} \mathrm{O}_{3}$, and $\mathrm{UO}_{2} / \mathrm{PuO}_{2}$ critical experiments have been selected to cover anticipated conditions of SNF. The method uses an upper safety limit on $\mathrm{k}_{\text {eff }}$ (which can be a function of the trending parameters) such that the biased $\mathrm{k}_{\mathrm{eff}}$ when increased for the uncertainty is less than 0.95 .

3. Establish bounding conditions for the isotopic concentration and criticality calculations. Three bounding axial profiles have been established to assure the "end effect" is accounted for conservatively.

4. Use the validated codes and bounding conditions to generate package loading criteria (burnup credit loading curves). Burnup credit loading curves show the minimum burnup required for a given initial enrichment. The utility burnup record is compared to this requirement after the utility accounts for the uncertainty in its record. Separate curves may be generated for each assembly design, various minimum cooling times and burnable absorber histories.

5. Verify that SNF assemblies meet the package loading criteria and confirm proper assembly selection prior to loading. A measurement of the average assembly burnup is required and that measurement must be within $10 \%$ of the utility burnup record for the assembly to be accepted. The measurement device must be accurate to within $10 \%$.

Each step is described in detail for use with any computer code system and is then demonstrated with the SCALE 4.2 computer code package using 27BURNUPLIB cross sections. 


\section{INTENTIONALLY LEFT BLANK}


TABLE OF CONTENTS

Page

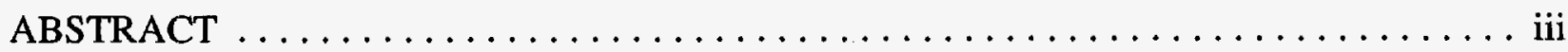

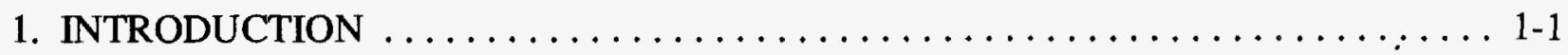

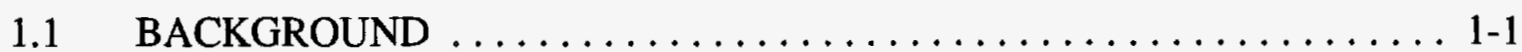

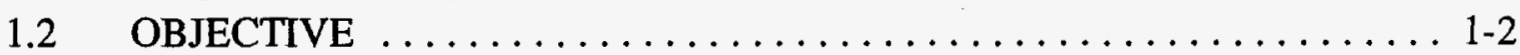

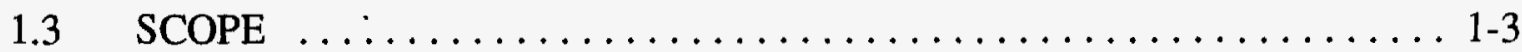

1.4 REGULATORY REQUIREMENTS $\ldots \ldots \ldots \ldots \ldots \ldots \ldots \ldots \ldots \ldots, 1-4$

1.4.1 Criticality Safety Design Criteria $\ldots \ldots \ldots \ldots \ldots \ldots \ldots \ldots . \ldots \ldots$

1.4.2 Applicable Regulatory Guides and Standards $\ldots \ldots \ldots \ldots \ldots \ldots$ 1-4

1.5 QUALITY ASSURANCE $\ldots \ldots \ldots \ldots \ldots \ldots \ldots \ldots \ldots \ldots \ldots \ldots \ldots$

1.6 OVERVIEW OF THE BURNUP CREDIT

CRITICALITY ANALYSIS METHODOLOGY $\ldots \ldots \ldots \ldots \ldots \ldots \ldots 1-6$

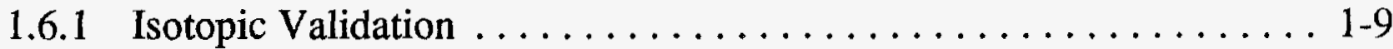

1.6.2 Criticality Validation $\ldots \ldots \ldots \ldots \ldots \ldots \ldots \ldots \ldots \ldots \ldots \ldots \ldots$

1.6.3 Analysis and Modeling Parameters . ............... 1-10

1.6.4 Spent Nuclear Fuel Package Loading Criteria $\ldots \ldots \ldots \ldots \ldots$ 1-11

1.6.5 Physical Implementation and Controls $\ldots \ldots \ldots \ldots \ldots \ldots \ldots$ 1-12

1.7 ORGANIZATION OF THE REPORT $\ldots \ldots \ldots \ldots \ldots \ldots \ldots \ldots \ldots \ldots \ldots \ldots$

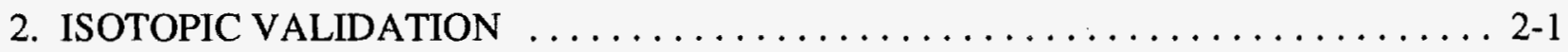

$2.1 \quad$ ISOTOPIC SELECTION FOR SPENT FUEL REPRESENTATION $\ldots \ldots .2-1$

2.2 ISOTOPIC VALIDATION DATA $\ldots \ldots \ldots \ldots \ldots \ldots \ldots \ldots \ldots \ldots$

2.2.1 Isotopic Validation Measurements $\ldots \ldots \ldots \ldots \ldots \ldots \ldots \ldots .2-5$

2.2.2 Range of Applicability of Measured Data ............. 2-10

2.2.3 Qualification of Isotopic Measurement Data .............. 2-14

2.2.4. Summary of Approval Requests on Isotopic Validation Data . . . . 2-15

2.3 ISOTOPIC CALCULATIONAL BIAS AND UNCERTAINTIES $\ldots \ldots \ldots 2-15$

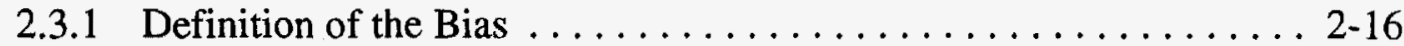

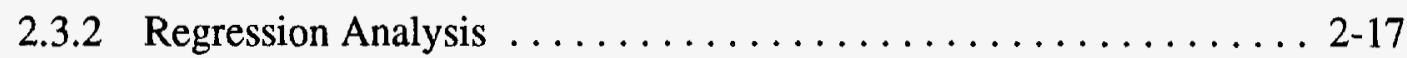

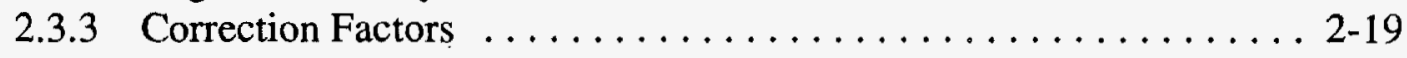

v $\quad$ March 31, $1997(2: 33 \mathrm{pm})$ 


\section{TABLE OF CONTENTS (Continued)}

2.3.4 Summary of Approval Requests for Isotopic Calculational Methodology .................... 2-21

2.4 DEMONSTRATION WITH SCALE 4.2 AND 27BURNUPLIB

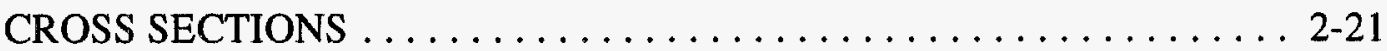

$2.5 \quad$ SUMMARY OF ISOTOPIC VALIDATION $\ldots \ldots \ldots \ldots \ldots \ldots \ldots 2-23$

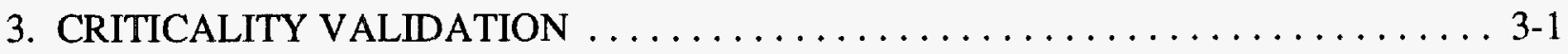

3.1 CRITICALITY VALIDATION DATA $\ldots \ldots \ldots \ldots \ldots \ldots \ldots \ldots \ldots, 3-2$

3.1.1 Validation Experiments $\ldots \ldots \ldots \ldots \ldots \ldots \ldots \ldots \ldots \ldots \ldots \ldots \ldots \ldots \ldots, 2$

3.1.1.1 $\mathrm{UO}_{2}$ Fuel Critical Experiments $\ldots \ldots \ldots \ldots \ldots \ldots \ldots .3-2$

3.1.1.2 $\mathrm{UO}_{2}$-Gadolinium Critical Experiments ............ 3-3

3.1.1.3 Mixed-Oxide Fresh Fuel Critical Experiments ........ . 3-6

3.1.2 Range of Validation Experiment Conditions . . . . . . . . . 3-7

3.1.3 Qualification of Data ...................... 3-7

3.2 CALCULATIONAL BIAS AND UNCERTAINTIES $\ldots \ldots \ldots \ldots \ldots . \ldots 3-12$

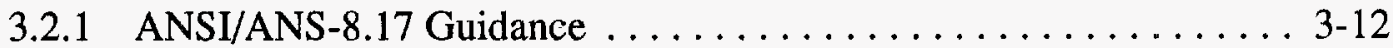

3.2.2 Bias and Uncertainty From Critical Experiments $\ldots \ldots \ldots \ldots \ldots$ 3-13

3.2.2.1 Lower Prediction Band Technique ............ 3-13

3.2.3 Calculational Requirements $\ldots \ldots \ldots \ldots \ldots \ldots \ldots \ldots \ldots . \ldots \ldots$ 3-17

3.3 METHODOLOGY DEMONSTRATION WITH SCALE $4.2 \ldots \ldots \ldots 3-19$

3.4 SUMMARY AND CONCLUSION $\ldots \ldots \ldots \ldots \ldots \ldots \ldots \ldots \ldots, 23$ 


\section{TABLE OF CONTENTS (Continued)}

Page

4. ANALYSIS AND MODELING PARAMETERS $\ldots \ldots \ldots \ldots \ldots \ldots \ldots \ldots \ldots$

4.1 LIMITING PARAMETERS IN THE CALCULATION

OF ISOTOPIC CONCENTRATIONS $\ldots \ldots \ldots \ldots \ldots \ldots \ldots \ldots \ldots$. $\ldots \ldots \ldots$

4.1.1 Specific Power $\ldots \ldots \ldots \ldots \ldots \ldots \ldots \ldots \ldots \ldots \ldots \ldots$ 4-1

4.1.2 Dissolved Boron Effects . . . . . . . . . . . . . . . . . 4-5

4.1.3 Reactor Coolant Temperature and Density . . . . . . . . . . . 4-6

4.1.4 Fuel Pellet Temperature . . . . . . . . . . . . . . . . . . . . 4-7

4.1.5 Summary of Limiting Parameters . . . . . . . . . . . . . 4-8

4.2 SNF PACKAGE DESIGN SPECIFIC EFFECTS $\ldots \ldots \ldots \ldots \ldots \ldots \ldots$

4.2 .1 Moderator Density $\ldots \ldots \ldots \ldots \ldots \ldots \ldots \ldots \ldots \ldots \ldots . \ldots \ldots$

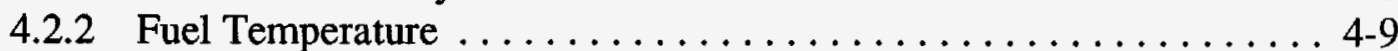

4.2 .3 Axial Burnup Profile $\ldots \ldots \ldots \ldots \ldots \ldots \ldots \ldots \ldots \ldots \ldots . \ldots \ldots$

4.2.3.1 Limiting Axial Burnup Profile . . . . . . . . . . . . . . . . . 4-9

4.2.3.2 Axial Modeling Requirements .............. 4-11

4.2.3.3 Simplified Axial Modeling . . . . . . . . . . . 4-13

4.2.3.3.1 Axial Reflector $\ldots \ldots \ldots \ldots \ldots \ldots$. . . 13

4.2.3.3.2 Cask Configuration ............ 4-13

4.2.3.3.3 Fuel Assembly Length . . . . . . . . . . . . 4-14

4.2.3.3.4 Cooling Time ............... 4-14

4.2.3.3.5 $\mathrm{k}_{\mathrm{eff}}$ Bias Curves $\ldots \ldots \ldots \ldots \ldots \ldots \ldots \ldots$ 4 14

4.2.3.4 Summary of Axial Burnup Profile . . . . . . . . . . 4-18

4.2.4 Horizontal Burnup Profile $\ldots \ldots \ldots \ldots \ldots \ldots \ldots \ldots$. . $\ldots \ldots$

4.3 CONCLUSIONS $\ldots \ldots \ldots \ldots \ldots \ldots \ldots \ldots \ldots \ldots \ldots \ldots \ldots \ldots \ldots$

5. LOADING CRITERIA $\ldots \ldots \ldots \ldots \ldots \ldots \ldots \ldots \ldots \ldots \ldots \ldots \ldots \ldots \ldots \ldots$

5.1 FRESH FUEL CALCULATIONS $\ldots \ldots \ldots \ldots \ldots \ldots \ldots \ldots \ldots \ldots$

5.2 GENERATION OF THE BURNUP CREDIT LOADING CURVE . . . . . . 5-1 


\section{TABLE OF CONTENTS (Continued)}

Page

5.2.1 Find the Limiting Burnup for Each Initial Enrichment $\ldots \ldots \ldots \ldots$ 5-1

5.2.2 Plot the Burnup Credit Loading Curve $\ldots \ldots \ldots \ldots \ldots \ldots \ldots .5-4$

5.2.3 Burnup Records Adjustment $\ldots \ldots \ldots \ldots \ldots \ldots \ldots \ldots \ldots, 5-4$

5.3 LIMITATIONS ON THE BURNUP CREDIT LOADING CURVES $\ldots . .5$ 5-6

5.3.1 Assembly Design Type $\ldots \ldots \ldots \ldots \ldots \ldots \ldots \ldots \ldots \ldots$ 5-6

5.3.2 Assemblies Loaded With Removable Burnable Absorber Rods .... 5-7

5.3.3 Cooling Time $\ldots \ldots \ldots \ldots \ldots \ldots \ldots \ldots \ldots \ldots \ldots \ldots \ldots \ldots \ldots$

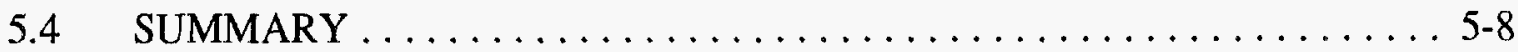

6. PHYSICAL IMPLEMENTATION AND CONTROLS $\ldots \ldots \ldots \ldots \ldots \ldots \ldots .6$ 6-1

6.1 BURNUP CREDIT PACKAGE LOADING PROCESS $\ldots \ldots \ldots \ldots \ldots, 6-1$

6.1.1 Fuel Assembly Classification Procedure . . . . . . . . . . . 6-4

6.1.2 Independent Burnup Verification Procedure ............. 6-5

6.1.3 Package Loading Procedure $\ldots \ldots \ldots \ldots \ldots \ldots \ldots \ldots \ldots .6 .5$

6.2 FUEL ASSEMBLY MISLOAD $\ldots \ldots \ldots \ldots \ldots \ldots \ldots \ldots \ldots \ldots \ldots$

6.3 BURNUP VERIFICATION REQUTREMENTS $\ldots \ldots \ldots \ldots \ldots \ldots \ldots \ldots 6-6$

6.4 MEASUREMENT SYSTEM DESIGN REQUIREMENTS $\ldots \ldots \ldots \ldots \ldots 6-7$

6.4.1 Accuracy Requirement $\ldots \ldots \ldots \ldots \ldots \ldots \ldots \ldots \ldots \ldots \ldots \ldots$

6.4.1.1 Dependent Measurement Systems . . . . . . . . . . 6. 6-7

6.4.1.2 Independent Measurement Systems $\ldots \ldots \ldots \ldots \ldots \ldots$ 6.9 6

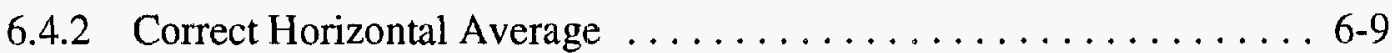

6.4 .3 Operational Considerations ..................... 6-9

6.4.4 Characteristics of Assemblies To Be Measured . . . . . . . . . . . . . 6-9

6.4 .5 Analysis Tools . . . . . . . . . . . . . . . . . . . 6-10

6.4 .5 Pool Compatibility ....................... $6-10$

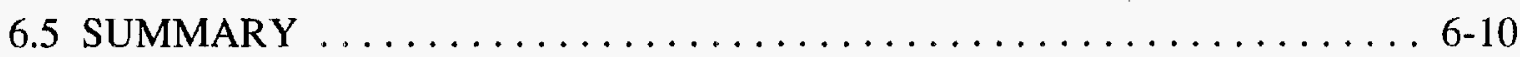




\section{TABLE OF CONTENTS (Continued)}

7. SUMMARY OF THE BURNUP CREDIT PROCESS $\ldots \ldots \ldots \ldots \ldots \ldots \ldots \ldots \ldots .7-1$

7.1 OVERVIEW $\ldots \ldots \ldots \ldots \ldots \ldots \ldots \ldots \ldots \ldots \ldots \ldots \ldots \ldots \ldots \ldots, 1$

7.2 REVIEW OF THE BURNUP CREDIT STEPS $\ldots \ldots \ldots \ldots \ldots \ldots \ldots \ldots 7-1$

7.2.1 Validation of a Code System for Calculation of

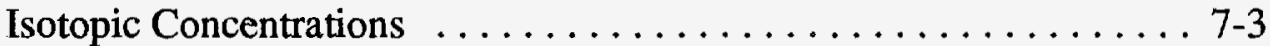

7.2.2 Validation of a Code System for Calculation of Criticality in an SNF Package .................... 7-3

7.2.3 Limiting Conditions for Analysis $\ldots \ldots \ldots \ldots \ldots \ldots \ldots \ldots \ldots \ldots$

7.2.4 Generation of Burnup Credit Loading Curves . . . . . . . . . . 7-7

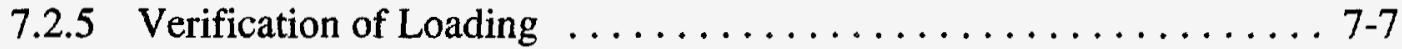

7.3 RANGE OF APPLICABILITY $\ldots \ldots \ldots \ldots \ldots \ldots \ldots \ldots \ldots \ldots \ldots . .7$

7.4 CONSERVATISM IN THE BURNUP CREDIT METHOD $\ldots \ldots \ldots \ldots .7-9$

7.5 SUMMARY OF NRC APPROVALS SOUGHT $\ldots \ldots \ldots \ldots \ldots \ldots \ldots$ 7-11

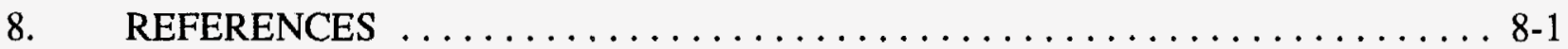

APPENDIX A - EXAMPLE OF BURNUP CREDIT ANALYSIS $\ldots \ldots \ldots \ldots \ldots \ldots$ A-1

APPENDIX B - BURNUP MEASUREMENT SYSTEMS $\ldots \ldots \ldots \ldots \ldots \ldots \ldots \ldots$ B-1

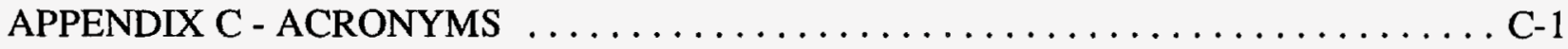

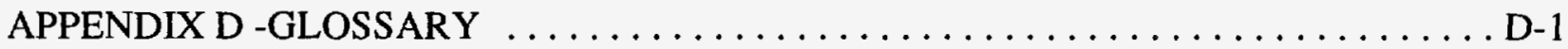


INTENTIONALLY LEFT BLANK 


\section{LIST OF FIGURES}

Page

1-1. Fresh Fuel Assumption Procedure $\ldots \ldots \ldots \ldots \ldots \ldots \ldots \ldots \ldots \ldots \ldots \ldots \ldots \ldots \ldots \ldots \ldots$

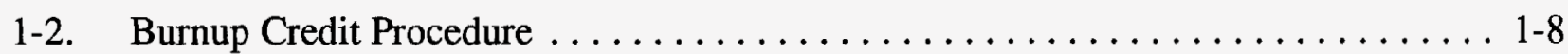

2-1. Fractions of Neutrons Absorbed by Major Actinides at Various Cooling Times, $3.6 \mathrm{wt} \% \mathrm{U}-235,10 \mathrm{GWd} / \mathrm{MTU} \ldots \ldots \ldots \ldots \ldots \ldots \ldots \ldots \ldots . \ldots \ldots .2$

2-2. Fractions of Neutrons Absorbed by Major Actinides at Various Cooling Times, $3.6 \mathrm{wt} \% \mathrm{U}-235,30 \mathrm{GWd} / \mathrm{MTU} \ldots \ldots \ldots \ldots \ldots \ldots .2-3$

2-3. Fractions of Neutrons Absorbed by Major Actinides at Various Cooling Times, $3.6 \mathrm{wt} \% \mathrm{U}-235,50 \mathrm{GWd} / \mathrm{MTU} \ldots \ldots \ldots \ldots \ldots \ldots .2-4$

3-1. MOX Benchmark Experiment Composition Summary (against Low Burnup) ... . 3-10

3-2. MOX Benchmark Experiment Composition Summary (against High Burnup) ... . . 3-11

3-3. Illustration of the Lower Prediction Band Technique for the Determination of an Upper Safety Limit (USL) . . . . . . . . . . . . . 3-14

3-4. Upper Safety Limit (USL) for $\mathrm{UO}_{2}$ Experiment Subset $\ldots \ldots \ldots \ldots \ldots \ldots \ldots$ 3-21

3-5. Upper Safety Limit (USL) for MOX Experiment Subset $\ldots \ldots \ldots \ldots \ldots \ldots \ldots$ 3-22

3-6. Final Upper Safety Limit (USL) $\ldots \ldots \ldots \ldots \ldots \ldots \ldots \ldots \ldots \ldots \ldots \ldots \ldots \ldots \ldots \ldots$

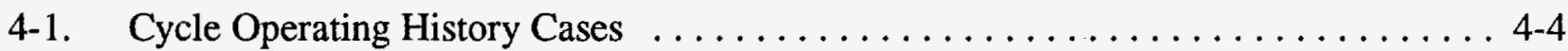

4-2. $\quad \mathbf{k}_{\text {inf }}$ versus Boron Concentration $\ldots \ldots \ldots \ldots \ldots \ldots \ldots \ldots \ldots \ldots \ldots \ldots \ldots \ldots \ldots \ldots$

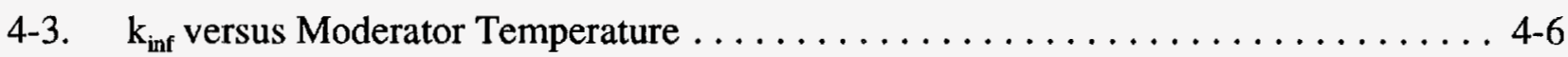

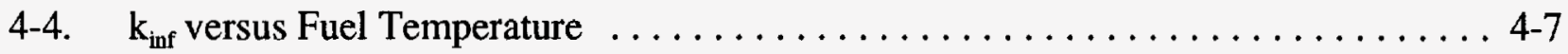

4-5. Burnup Profile Measurement by Gamma Scan ................. 4-10

4-6. End Effect Reactivity versus Burnup $\ldots \ldots \ldots \ldots \ldots \ldots \ldots \ldots \ldots \ldots \ldots, 4-11$

4-7. $\mathrm{k}_{\mathrm{eff}}$ Bias Curves for 5 Year Cooling Time $\ldots \ldots \ldots \ldots \ldots \ldots \ldots \ldots \ldots$ 


\section{LIST OF FIGURES (Continued)}

\section{Page}

4-8. $\quad k_{\text {eff }}$ Bias Curves for 10 Year Cooling Time $\ldots \ldots \ldots \ldots \ldots \ldots \ldots \ldots \ldots \ldots$

4-9. $\quad \mathbf{k}_{\mathrm{eff}}$ Bias Curves for 15 Year Cooling Time $\ldots \ldots \ldots \ldots \ldots \ldots \ldots \ldots \ldots \ldots$

4-10. Maximum Quadrant Deviation versus Assembly Average Burnup .......... 4-19

5-1. Development of Burnup Credit Loading Curve for a Specific $\ldots \ldots \ldots \ldots \ldots \ldots .5-2$

5-2. Determination of Required Minimum Burnups for a Specific $\ldots \ldots \ldots \ldots \ldots \ldots$ 5-3

5-3. $\mathrm{k}_{\text {infinity }}$ versus Cooling Time $(3.0 \mathrm{wt} \% \mathrm{U}-235,30 \mathrm{GWd} / \mathrm{MTU}$ Burnup) $\ldots \ldots \ldots \ldots .5-9$

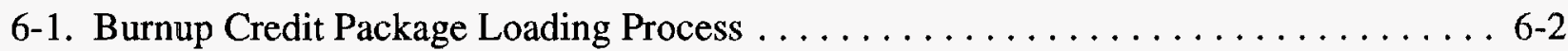

7-1. Burnup Credit Loading Curve $\ldots \ldots \ldots \ldots \ldots \ldots \ldots \ldots \ldots \ldots \ldots \ldots \ldots \ldots \ldots \ldots \ldots \ldots \ldots$ 


\section{LIST OF TABLES}

Page

2-1. Calculated and Measured Values for the Selected Actinides $\ldots \ldots \ldots \ldots \ldots \ldots$. 2-7

2-2. Comparison of Physical Parameters Between Benchmark and Anticipated Burnup Credit Assemblies . . . . . . . . . . . . . . . . . 11

2-3. Range of Applicability Matrix for Isotopic Validation $\ldots \ldots \ldots \ldots \ldots \ldots \ldots \ldots$

2-4. Bias, Uncertainty, and Isotopic Correction Factors for Burnup Credit Nuclides for Use with SCALE 4.2 and 27BURNUPLIB Analyses . . . . . . . . 2-24

3-1. Critical Benchmark Experiments for Burnup Credit Method Validation with CSAS/27BURNUPLIB Calculated Results . . . . . . . . . . . . . . 3-4

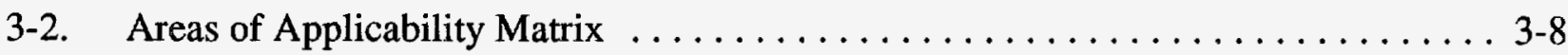

3-3. Trending Analyses Results for $\mathrm{UO}_{2}$-only Subset $\ldots \ldots \ldots \ldots \ldots \ldots \ldots \ldots \ldots$

3-4. Trending Analyses Results for MOX Subset $\ldots \ldots \ldots \ldots \ldots \ldots \ldots \ldots \ldots$. $3-19$

3-5. Parameters Used in Upper Safety Limit (USL) Calculations for $\mathrm{UO}_{2}$-only Subset . 3-20

3-6. Parameters Used in Upper Safety Limit (USL) Calculations for MOX Subset $\ldots$ 3-21

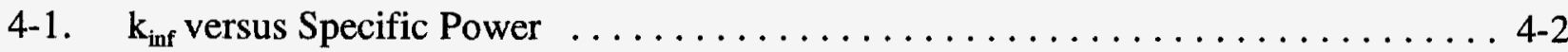

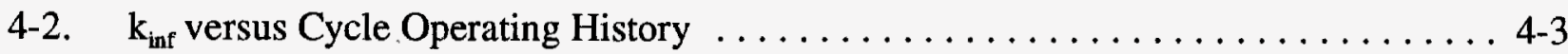

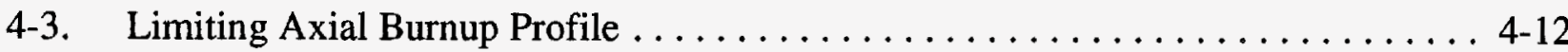

4-4. $\quad \mathrm{k}_{\mathrm{eff}}$ Bias Values for 5 Year Cooled Assembly .................. 4-16

4-5. $\mathrm{k}_{\mathrm{eff}}$ Bias Values for 10 Year Cooled Assembly $\ldots \ldots \ldots \ldots \ldots \ldots \ldots \ldots \ldots \ldots \ldots$

4-6. $\mathrm{k}_{\text {eff }}$ Bias Values for 15 Year Cooled Assembly . . . . . . . . . . . . . . 4-17

4-7. Conservative Horizontal Burnup Gradients in PWR Assemblies . . . . . . . . . 4-19

4-8. Limiting Values of Modeling Parameters $\ldots \ldots \ldots \ldots \ldots \ldots \ldots \ldots \ldots \ldots, 4-20$ 


\section{LIST OF TABLES}

Page

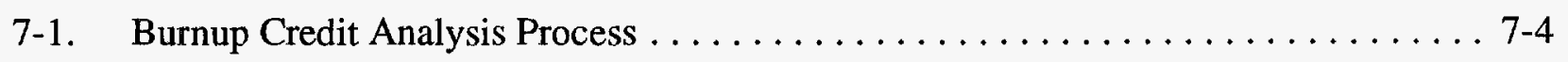

7-2. Conservatisms in the Actinide-Only Burnup Credit Methodology $\ldots \ldots \ldots \ldots \ldots 7-10$

7-3. Conservatisms in the Change in Reactivity as a Function of Burnup $\ldots \ldots \ldots \ldots$ 7-10 


\section{INTRODUCTION}

This chapter provides introductory information on burnup credit and gives an overview of the burnup credit methodology.

\subsection{BACKGROUND}

The Nuclear Waste Policy Act of 1982 (NWPA), as amended, ${ }^{1-1}$ assigns to the United States Department of Energy (DOE) the responsibility for managing the disposal of civilian spent nuclear fuel (SNF) and high-level radioactive waste (HLW). To fulfill this responsibility, the DOE Office of Civilian Radioactive Waste Management (OCRWM) is developing a Civilian Radioactive Waste Management System (CRWMS) to accept, transport, and permanently dispose of the waste. The waste packages that will be used to transport the SNF from commercial utility reactor sites to the HLW repository will be licensed by the United States Nuclear Regulatory Commission (NRC) in accordance with the requirements of Title 10 to the Code of Federal Regulations (CFR) Part $71^{1-2}$ (Transportation).

To meet 10 CFR Part 71 requirements, SNF transportation packages must be designed to ensure criticality safety. Criticality safety is ensured by package design features, such as maintaining SNF geometry and the use of supplemental neutron absorbing materials, as well as administrative controls. Administrative controls are required to ensure SNF loaded into a transportation package meets design basis fuel requirements and applicable licensing conditions. Design basis fuel requirements and licensing conditions typically include limits on fuel design and initial enrichment.

Historically, safety analyses of criticality control systems for transportation packages include an assumption that the SNF loaded into the package is "fresh" or unirradiated. In other words, the spent fuel is assumed to have its original, as-manufactured U-235 isotopic content. The "fresh fuel" assumption is very conservative since the potential reactivity of the nuclear fuel is substantially reduced after being irradiated in the reactor core. The concept of taking credit for this reduction in nuclear fuel reactivity due to burnup of the fuel, instead of using the fresh fuel assumption in the criticality safety analysis, is referred to as "Burnup Credit." Burnup credit uses the actual physical composition of the fuel and accounts for the net reduction of fissile material and the buildup of neutron absorbers in the fuel as it is irradiated. Neutron absorbers include actinides and other isotopes generated as a result of the fission process. Using only the change in actinide isotopes in the burnup credit criticality analysis is referred to as "Actinide-Only Burnup Credit."

Although the fresh fuel assumption represents a conservative design approach, which substantially simplifies the criticality safety analysis and associated administrative controls, it results in a significant reduction in SNF capacity for a given package weight. Analyses performed by DOE and its contractors have indicated that using burnup credit to maximize SNF transportation cask capacities is a justifiable concept that would result in public risk benefits and cost savings. ${ }^{1-3}$ Similar benefits would be realized for SNF storage and disposal packages. The use of burnup credit in the design of criticality control systems enables more spent fuel to be placed in a package. Increased package capacity in turn results in a reduced number of storage, shipping, and disposal containers for a given number of SNF assemblies. Several public and rate payer benefits result from an overall reduction in the number of packages because the total number of packages drive both cost and risk. Fewer shipments result in a lower risk of accidents associated with the handling and 
transportation of spent fuel, thus reducing both radiological and non-radiological risk to the public. The economic benefits of burnup credit result from lower storage, shipping, and disposal costs and reduced package handling operations at storage, shipping, and receiving facilities. Given the large

I quantity of SNF there are substantial incentives for using burnup credit in the design of SNF storage, transportation, and disposal packages.

This topical report describes a methodology, to be used as guidance, for validating analytical methods and for applying burnup credit in the design of criticality control systems for pressurized water reactor (PWR) spent fuel transportation packages. The report references technical data, analyses, and results that have been developed over the years by OCRWM contractors in support of burnup credit. The topical report uses and organizes these data and analyses to develop validation and analysis methodologies as well as operational processes necessary for implementation of burnup credit.

\subsection{OBJECTIVE}

The objective of this topical report is to present to the NRC for review and acceptance a methodology for using burnup credit in the design of criticality control systems for PWR spent fuel transportation packages, pursuant to the requirements of 10 CFR Part 71. This methodology is also applicable to SNF storage packages and could also be used by commercial SNF cask and canister designers in the criticality analysis of those packages. The proposed methodology consists of five major steps as summarized below:

1. Validate a computer code system to calculate isotopic concentrations in SNF created during burnup in the reactor core and subsequent decay

2. Validate a computer code system to predict the subcritical multiplication factor, $k_{\text {eff }}$, of a spent nuclear fuel package

3. Establish bounding conditions for the isotopic concentration and criticality calculations

4. Use the validated codes and bounding conditions to generate package loading criteria (burnup credit loading curves)

5. Verify that SNF assemblies meet the package loading criteria and confirm proper fuel assembly selection prior to loading.

I When reviewed and accepted by the NRC, this topical report will serve as a criteria document for criticality control analysts and provide steps for the use of actinide-only burnup credit in the design of criticality control systems. The NRC accepted burnup credit methodology will be used by

1 commercial SNF storage and transportation package designers. Design specific burnup credit criticality analyses will be defined, developed, and documented in the Safety Analysis Report (SAR)

I for each specific storage or transportation package that uses burnup credit. These SARs will then be submitted to the applicable review branch of the NRC for review and approval. This topical report is expected to be referenced in a number of storage and transportation cask applications to

I be submitted by commercial cask and canister designers to the NRC. Therefore, NRC acceptance of this topical report will result in increased efficiency of the review process for these SNF storage 
and transportation cask applications. The DOE will also reference NRC-accepted topical reports in its license application for a geologic repository.

There are three general areas where the DOE is requesting NRC acceptance of the actinide-only burnup credit methodology. First, that the data presented are sufficient to validate the burnup credit criticality analysis methodology presented in this topical report. This includes the chemical assay data used to validate the spent fuel isotopic concentration calculations and the 57 critical experiments used to validate the burnup credit criticality calculations. Second, that the burnup credit methodology presented is acceptable. This includes the analytical techniques and the burnup credit loading procedures. Third, that the SCALE-4.2 $2^{1-4}$ computer code package utilizing the 27BURNUPLIB has been validated and is acceptable for performing burnup credit criticality analyses. A detailed breakdown of what the DOE is specifically seeking NRC acceptance of is presented in Section 1.6.

\subsection{SCOPE}

This topical report presents a methodology for using actinide-only burnup credit in the design of PWR spent fuel transportation packages. It also provides guidance on loading S.NF into a transportation package that has been licensed for burnup credit. Actinide-only burnup credit only addresses the reduced reactivity of SNF due to changes in actinide isotopes. The negative reactivity effect of fission products is not included in the scope of this report. The DOE plans to submit another topical report in the future to address the additional negative reactivity effect from the buildup of fission product neutron absorbers.

The actinide-only burnup credit methodology presented in this report has a wide applicability. It applies to all current generation commercial PWR fuel, with the following restrictions:

- Burnup credit benefits can be gained from fuel burned from 1 to $50 \mathrm{GWd} / \mathrm{MTU}$. SNF with an assembly average burnup greater than $50 \mathrm{GWd} / \mathrm{MTU}$ shall be treated as having a burnup of $50 \mathrm{GWd} / \mathrm{MTU}$ for the purposes of this methodology.

- Enrichments above 5 weight percent U-235 are excluded.

- Assemblies with integral fuel burnable absorbers (IFBAs) are excluded.

- The methodology applies to SNF with cooling times ranging from 1 to 100 years.

- Mixed oxide (MOX) initial enrichment fuel is excluded.

- Reconstituted or disassembled fuel is excluded. Also excluded is fuel which has had any of its original rods removed or replaced.

Criticality validation covers all current SNF packages but the package vendor should confirm that their design is covered by the features in the criticality experiments. For example, hafnium absorbers are not included in the current set of criticals recommended in this report. 
There are analysis and modeling parameters that affect criticality, which are not unique to burnup credit. None of these parameters or effects impact the proposed burnup credit methodology; therefore, they are not included in this topical. A licensee's Safety Analysis Report is required to address these parameters in the usual manner. Examples include:

- Material and fabrication tolerances.

- Uncertainties due to limitations in the geometric or material representations used in the computational method.

- Effects of symmetric or asymmetric fuel assembly clustering within the spent fuel basket.

\subsection{REGULATORY REQUIREMENTS}

Compliance with NRC regulatory requirements is accomplished by applying available regulatory guidance, industry standards, and regulatory precedent established by previous license applications. Criticality safety design criteria are set forth in the NRC's Code of Federal Regulations. In addition to the NRC regulations, NRC Regulatory Guides (RGs) address criticality safety. These RGs have been considered for applicability to the burnup credit methodology discussed in this report. The RGs typically accept the procedures and methodologies developed in ANSI/ANS Standards. ANSI/ANS Standards provide basic requirements that can be referenced or used with other safety standards or regulations to address criticality safety requirements. The sections below discuss the specific NRC regulatory requirements and industry guidance upon which the burnup credit topical report is based.

\subsubsection{Criticality Safety Design Criteria}

I The NRC regulatory requirements for transportation of SNF are established in 10 CFR Part 71. A design criteria which is key to this regulation is nuclear criticality safety. Nuclear criticality safety criteria for the design and certification of Type $\mathrm{B}(\mathrm{U})$, Fissile Class I transportation packages are set forth in $10 \mathrm{CFR} \S 71.55(\mathrm{~b}),(\mathrm{d})$, and (e) and $\$ 71.57$.

The burnup credit methodology presented in this topical report is consistent with the general design criteria specified in 10 CFR Parts 71. Section 1.3 discusses the scope and specific restrictions imposed on the proposed burnup credit methodology.

\subsubsection{Applicable Regulatory Guides and Standards}

Outlined below are the Regulatory Guides and ANSI/ANS Standards whose guidance has been incorporated into the burnup credit methodology.

- Regulatory Guide 3.4, Nuclear Criticality Safety in Operations with Fissionable Materials at Fuels and Material Facilities. ${ }^{1-5}$ This Regulatory Guide endorses ANSI/ANS-8.1, Nuclear Criticality Safety in Operations with Fissionable Materials Outside Reactors. ${ }^{1-6}$ The 
burnup credit topical report complies with guidance provided in RG 3.4 and ANSI/ANS-8.1 as discussed in Chapter 3 of this report.

- Regulatory Guide 3.58, Criticality Safety for Handling, Storing, and Transporting LWR Fuel at Fuels and Materials Facilities. ${ }^{1-7}$ This Regulatory Guide endorses ANSI/ANS-8.17, Criticality Safety Criteria for the Handling, Storage, and Transportation of LWR Fuel Outside Reactors ${ }^{1-8}$ with the following exception. The Regulatory Guide states that credit for fuel burnup may be taken only when the amount of burnup is confirmed by reactivity measurements that are appropriate for each type of fuel assembly in the environment in which it is to be stored. The burnup credit topical report complies with the guidance provided in RG 3.58, but not with regard to this exception. Instead, the burnup credit topical report complies with the guidance of ANSI/ANS-8.17, which allows credit for fuel burnup by analysis, as discussed in Chapters $2,3,4$, and 5 and by verification of the exposure history of each fuel assembly, as discussed in Chapter 6 of this report.

- Regulatory Guide 3.60, Design of an Independent Spent Fuel Storage Installation (Dry Storage). ${ }^{1-9}$ The Regulatory Guide endorses ANSI/ANS-57.9, Design Criteria for an Independent Spent Fuel Storage Installation (Dry Storage Type). ${ }^{1 \cdot 10}$ Consideration has been given to the guidance in Regulatory Guide 3.60 and ANSI/ANS 57.9 in the development of the burnup credit topical report. With regard to Criticality Safety, 57.9 endorses ANSI/ANS-8.17, which allows credit for fuel burnup by analysis and verification of the exposure history. Therefore, the burnup credit topical report complies with the applicable guidance provided in RG 3.60 and ANSI/ANS-57.9

- Draft Regulatory Guide 1.13, Proposed Revision 2 to Regulatory Guide 1.13 Spent Fuel Storage Facility Design Basis. ${ }^{1-11}$ This draft Regulatory Guide endorses ANSI/ANS-57.2, Design Requirements for Light Water Reactor Spent Fuel Storage Facilities at Nuclear Power Plants, ${ }^{1-12}$ subject to several clarifications and modifications. The burnup credit topical report complies with the applicable guidance contained in draft RG 1.13 and ANSI/ANS-57.2 as discussed in Chapter 6 of this report.

\subsection{QUALITY ASSURANCE}

The Quality Assurance Requirements and Description (QARD) document is the principal quality assurance document for the Civilian Radioactive Waste Management program. ${ }^{1-13}$ The QARD meets the applicable QA program requirements in 10 CFR Part 50, Appendix B; 10 CFR Part 71; 10 CFR Part 72; 10 CFR Part 60; and NQA-1. The QARD establishes the QA requirements for OCRWM, contractors, subcontractors, national laboratories, and other Government agencies performing activities for OCRWM that are quality affecting.

The key elements of the QARD are standard. They require planning, identification of inputs, identification of assumptions, thorough analysis by qualified analysts, checking, and documentation. Analyses performed are sufficiently detailed as to the purpose, method, assumptions, input, and references such that a person technically qualified in the subject can understand the analysis and verify its adequacy without recourse to the originator. Technical analysis outputs specify the appropriate level of inspection and testing necessary to ensure technical adequacy. Technical document reviews are performed to ensure that the inputs are correctly selected for their 
incorporation into the analysis. Assumptions are described, reasonable and where applicable, identified as requiring additional confirmation as the design proceeds. The technical outputs are reasonable compared to the inputs and necessary technical input for interfacing organizations are specified in the documents. QA records are legible, accurate and completed appropriate to the work accomplished. Records are indexed for ease in retrieval. Records are distributed, handled and controlled in accordance with the QA procedures. This includes proper indentification, classification, distribution, storage, retreival and disposition. The process is subject to QA audit to ensure compliance with the applicable procedures.

Much of the analysis in support of this document was performed by the M\&O following the procedures written to support Section 3.0, Design Control, of the QARD. No tests or experiments were performed by the $\mathrm{M} \& \mathrm{O}$.

This topical report references technical data, analyses, and results that have been developed by OCRWM contractors. Where applicable, these reference documents have been developed under the respective contractor QA programs in compliance with OCRWM's QA program. Some data used in the development of the burnup credit criticality analysis procedure are derived from reports, experiments, or records that are not subject to the requirements of OCRWM's QA program. The qualification of these data is addressed in the appropriate sections of the topical report.

\subsection{OVERVIEW OF THE BURNUP CREDIT CRITICALITY ANALYSIS METHODOLOGY}

The burnup credit criticality analysis procedure has been developed to be consistent with the criticality analysis procedure currently accepted by the NRC for which the fresh fuel assumption is made. The generic criticality safety analysis procedure using the fresh fuel assumption is illustrated in Figure 1-1. The purpose of the criticality safety analysis using the fresh fuel assumption is to develop a cask loading criterion that establishes the maximum initial enrichment of an SNF assembly design that can be loaded into a cask. Figure 1-2 illustrates the generic burnup credit criticality analysis procedure recommended in this topical report. The burnup credit criticality analysis procedure builds upon the fresh fuel procedure. The burnup credit procedure results in a spent nuclear fuel package loading criteria that specify minimum burnups necessary for a range of initial enrichment values for a specific fuel assembly design. These results are presented as burnup credit loading curves.

The key elements in Figure 1-2 that distinguish the burnup credit procedure from the fresh fuel procedure are shaded. NRC acceptance is sought for these key elements of the burnup credit procedure, which are briefly described in the following subsections. Detailed descriptions of each of these elements and their relevance to the regulatory requirements are provided in the body of the topical report. In the following discussion, refer to Figure 1-2 for an understanding of where these key elements fit into the overall burnup credit criticality analysis procedure. 


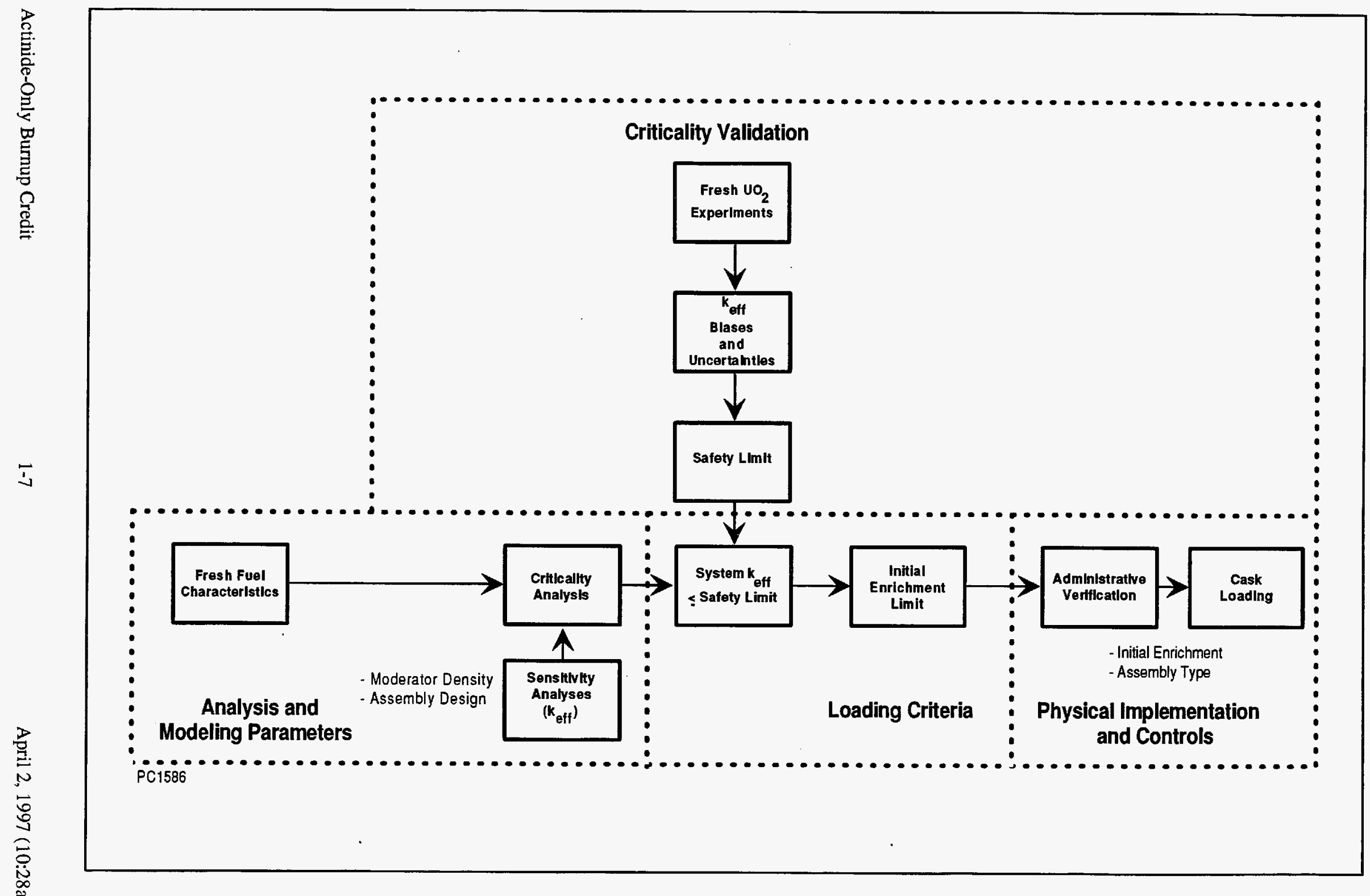

Figure 1-1. Fresh Fuel Assumption Procedure 


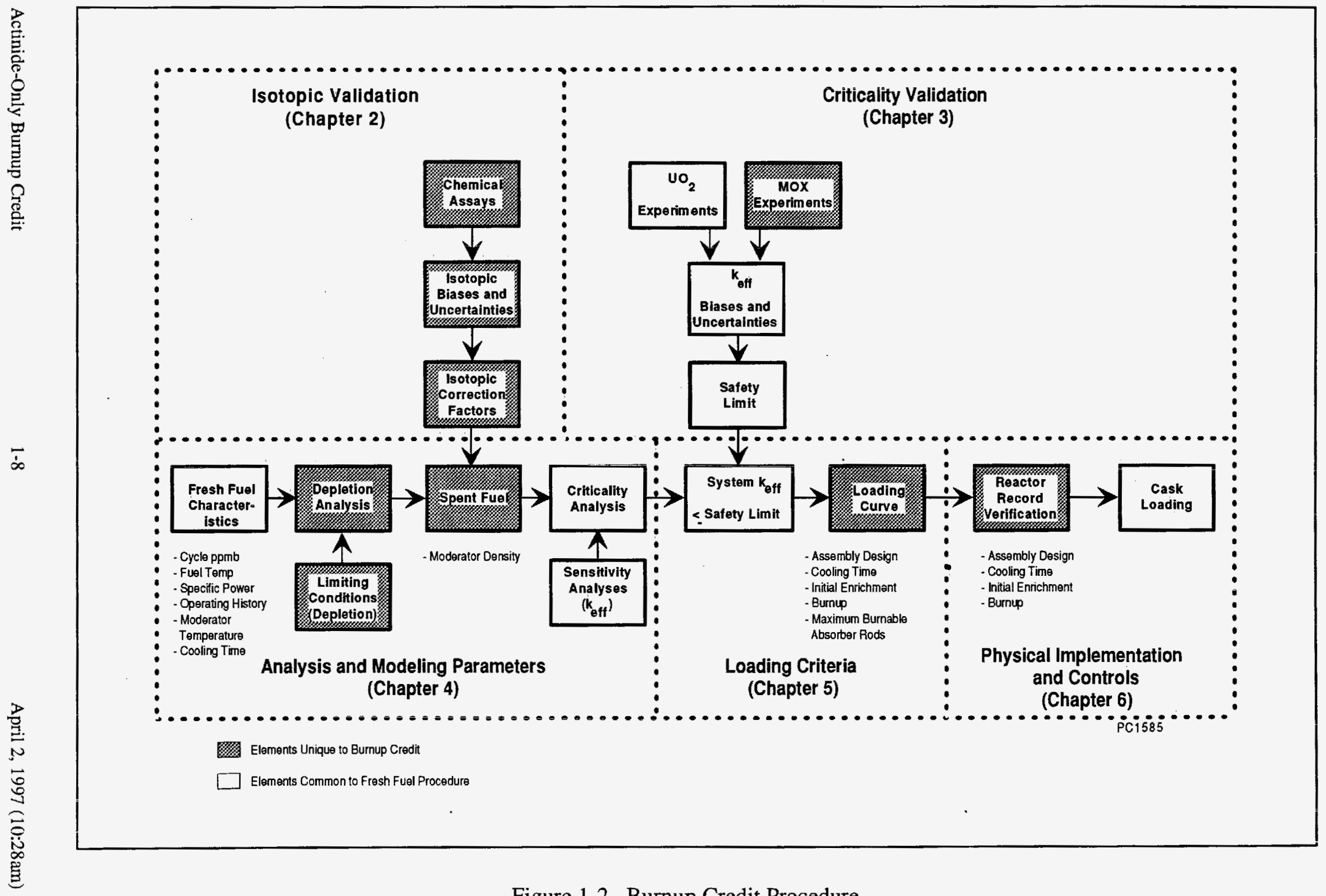

Figure 1-2. Burnup Credit Procedure 


\subsubsection{Isotopic Validation}

The isotopic composition of fresh fuel is well known through extensive, routine measurements by fuel manufacturers. However, after fuel is irradiated in a reactor, the isotopic composition of the spent fuel must be determined through analysis. Routine measurement of the isotopic.content of discharged fuel using chemical assays would not be practical due to dose, safety, and cost concerns. Confidence in the analytical capabilities is high due to the good agreement between the analytical predictions used for core reload analyses and the constant measurements of reactivity and power distributions at power plants. Source terms generated for thermal and shielding analyses have also shown good agreement with experiments.

For the burnup credit methodology presented in this topical report, the code system used for predicting isotopic content must be validated. The recommended validation method uses a set of chemical assays for spent fuel. These assays represent benchmarks for which best estimate predictions are computed with the code. The ratio of the measured benchmarks and the computed best estimate predictions are used to determine multiplicative biases and uncertainties. The biases and uncertainties for each isotope are combined in a conservative manner into a correction factor for each isotope. The correction factors are calculated and applied conservatively to ensure that criticality safety evaluations employing the burnup credit method result in a neutron multiplication factor that is conservative for the system being evaluated.

The isotopic validation method is applicable to any computer code system. For the purpose of demonstrating the method, the SAS2H sequence of SCALE 4.2 was used. This demonstration resulted in validation of this computer code system for actinide-only burnup credit.

This topical report is specifically seeking NRC acceptance of the following:

- That the PWR fuel post irradiation examination assay data selected for isotopic inventory bias and uncertainty determination are sufficient for validating the selected actinide composition in spent fuel.

- That the statistical procedure proposed for establishing isotope-specific biases and correction factors is a conservative method to account for isotopic concentration changes during burnup

- That the SAS2H sequence of the SCALE 4.2 code system using 27BURNUPLIB cross sections has been validated and that appropriate isotopic correction factors have been determined.

\subsubsection{Criticality Validation}

Criticality analysis methods applied in fresh fuel assumption design evaluations are validated by performing benchmark calculations using well-characterized criticality experiments. The burnup credit criticality analysis method is also validated using well-characterized criticality experiments. The criticality validation establishes the validity of the best-estimate calculational method used to 
determine the effective multiplication factor $\left(\mathrm{k}_{\mathrm{eff}}\right)$ of a system and for deriving the subcritical safety limit consistent with ANSI/ANS-8.1 and ANSI/ANS-8.17 criteria.

The criticality experiment benchmark validation calculations are used to establish method bias and uncertainty over a specific range of package and fuel characteristics. Fresh fuel assumption methods for evaluating PWR applications are typically benchmarked against low enrichment, unirradiated heterogeneous $\mathrm{UO}_{2}$ fueled systems with similar characteristics to the package being evaluated. The burnup credit method is also benchmarked against $\mathrm{UO}_{2}$ fueled systems that contain the important $\mathrm{U}-235$ and $\mathrm{U}-238$ burnup credit isotopes. The burnup credit criticality validation also includes low enrichment, unirradiated heterogeneous mixed oxide (MOX) fueled systems. MOX experiments provide benchmark data for other transuranic isotopes present in spent fuel and included in the burnup credit analysis procedure. Burnup credit method bias and uncertainty results are used to establish the subcritical safety limit to be applied in criticality safety evaluations employing the burnup credit methodology. The subcritical safety limit is calculated based on a statistically determined magnitude of the method biases, uncertainties, and administrative safety margins.

This topical report is specifically seeking NRC acceptance of the following:

- That the 57 criticality experiments selected are sufficient for validating computer codes for actinide-only burnup credit analysis.

- That the selected trend analyses requirements on the criticality experiment analysis are adequate.

- That the method of determining the upper safety limit assures criticality safety.

- That the use of the developed USL with CSAS/27BURNUPLIB code system and with a $0.05 \Delta \mathrm{k}_{\mathrm{m}}$ administrative safety margin is acceptable to perform actinide-only burnup credit criticality safety calculations in SNF package design.

\subsubsection{Analysis and Modeling Parameters}

Analyses performed for validation use best-estimate values to simulate specific experimental conditions. Design basis analyses are more generic and must address a range of parameters. Therefore, all of the key reactor operating parameters in the burnup analysis such as moderator density, soluble boron level, fuel temperature, specific power, and operating history must be conservatively selected at bounding values for actinide-only criticality analysis. These values will serve as limits to the applicability of a given burnup credit design application.

The $\mathbf{k}_{\text {eff }}$ analysis of the spent nuclear fuel package requires conservatism in the moderator density in the package and the axial profile used for the burnup. The designer is required to perform the package analysis at the most reactive moderator density and is required to prove that the density I selected is the most reactive. 
This topical report is specifically seeking NRC acceptance of the following:

- That a single cycle burnup at a specific power of $60 \mathrm{MW} / \mathrm{MTU}$ conservatively bounds the effects of specific power and operating history on isotopic concentrations

- That the use of the maximum cycle average dissolved boron concentration conservatively accounts for soluble boron effects on isotopic concentrations

- That the reactivity of the spent fuel is maximized by setting the fuel temperature to the maximum pellet averaged temperature

- That the use of the maximum core outlet temperature in determining the moderator density for depletion produces conservative isotopic concentrations

- The method presented for determining optimum moderation in the SNF package

- That the use of the selected limiting axial burnup profiles for burnup credit adequately capture the end effects

- That the selected horizontal gradients and use of the most limiting arrangement in the package sufficiently model horizontal burnup effects.

\subsubsection{Spent Nuclear Fuel Package Loading Criteria}

The result of performing a burnup credit criticality analysis is the development of burnup credit loading curves. The curves specify the loading criteria, by indicating the minimum burnup necessary for a fuel assembly with a specific initial enrichment and minimum cooling time to be placed in a burnup credit package. Multiple curves may be necessary due to variations in fuel assembly designs (i.e., Westinghouse versus BW designs). Also, separate curves can be generated for fuel that was burned with removable burnable absorbers.

The development of a burnup credit loading curve is accomplished by performing a set of criticality analyses for a range of initial enrichment. First, the criticality analysis is performed to determine the $k_{\text {eff }}$ value for a given initial enrichment and an initial estimate of the required burnup. Then, the burnup is adjusted and the criticality analysis is repeated until a $k_{\text {eff }}$ value equal to or less than the allowable value is obtained. The minimum burnup, which results in an acceptable $k_{\text {eff }}$ value for the given initial enrichment, is the required minimum burnup. The procedure is repeated for a range of initial enrichments.

This topical report is seeking NRC acceptance of the above method used to generate two-parameter loading curves (i.e., burnup and initial enrichment) for specifying package burnup credit loading requirements. 


\subsubsection{Physical Implementation and Controls}

I The loading of spent nuclear fuel transportation packages designed for burnup credit requires the implementation of additional controls during loading to ensure design basis fuel requirements and licensing conditions are met. These controls are in addition to those that are already being implemented for fresh-fuel based packages. ANSI/ANS-8.17 indicates that credit may be taken for fuel burnup by establishing a maximum spent fuel reactivity and ensuring that each fuel assembly has a reactivity no greater than the maximum established by "analysis and verification of the exposure history of each fuel unit." The previous sections introduced the methodology for determining a conservative reactivity for the SNF assemblies. In addition, this topical report presents a generic loading procedure that enhances the administrative controls with a physical measurement to verify the reactor records for loading burnup credit packages.

This burnup verification includes measurements of neutron and gamma emissions from spent fuel 1 assemblies using any measurement system which meets specific guidelines. These measurements are correlated to the SNF assembly burnup data obtained from the reactor records. Any anomaly in the declared burnup, initial enrichment, and cooling time of the assembly would be detected in this burnup verification technique.

I This topical report is seeking NRC acceptance of the burnup verification procedure and guidelines described in Chapter 6.

\subsection{ORGANIZATION OF THE REPORT}

The contents of the report are organized following the sequence described in the preceding section and illustrated in Figure 1-2. Chapter 1 provides introductory information on burnup credit and gives an overview of the burnup credit methodology.

Chapter 2 addresses isotopic validation in detail. The available chemical assays of spent fuel isotopics are presented. The actual statistical approach to yield biases and correction factors is then discussed. The SAS2H sequence of the SCALE 4.2 code package with 27BURNUPLIB is used to demonstrate the validation procedure. This chapter also presents the biases and correction factors that result from using the code package.

1 Chapter 3 presents 57 criticality benchmark experiments to be used to validate burnup credit criticality calculations. Then it develops the method to convert analysis of critical experiments to an upper safety limit on $k_{\text {eff }}$. The technique seeks a correlation of the data to a parameter that influences $k_{\text {eff. }}$ The parameter used for illustration is the average energy group in which fission occurs. The CSAS sequence of the SCALE 4.2 code package with 27BURNUPLIB is used to demonstrate this process.

Chapter 4 develops guidelines to determine default or bounding values of physical parameters to be used in the analysis of spent fuel compositions and reactivity. The appropriate treatment of the axial burnup is developed in this chapter. 
The analytical methods and parameters presented in the previous chapters are combined in Chapter 5 where the generation of burnup credit loading curves is presented. This chapter describes how the loading curves are actually generated.

Chapter 6 illustrates the steps and procedures for selecting SNF for loading into a burnup credit package. The use of reactor records to qualify spent fuel assemblies for loading into a burnup credit package is discussed. Guidelines are established for measurement systems to be used for verification of reactor record burnup values, and examples of measurement systems which could potentially meet the guidelines are described.

Chapter 7 summarizes the topical report and reviews the steps for implementing burnup credit.

Chapter 8 provides bibliographic information for references.

Appendix A demonstrates the application of the burnup credit methodology by providing sample calculations performed by cask vendors using the methodology presented in this report.

Appendix B provides discriptions of burnup measurement systems provided by the measurement system vendors.

Appendix C contains an acronym list and Appendix D is a Glossary of Terms. 
INTENTIONALLY LEFT BLANK 


\section{ISOTOPIC VALIDATION}

As illustrated in Figure 1-2, it is SNF depletion analysis that differentiates the burnup credit approach from the traditional fresh fuel approach in designing the criticality control systems of spent fuel packages. The depletion analysis simulates the burnup of the fuel under reactor operating conditions. The result of the depletion analysis is the predicted isotopic composition of the discharged spent fuel assembly.

The primary focus of this chapter is on developing a methodology for validating isotopic depletion/generation computer codes used in predicting the quantities of actinide isotopes in SNF. The validation is performed by comparing the calculated to the measured isotopic values. A bias and uncertainty determined from this comparison is then established for each isotope. Subsequently, the bias and uncertainty terms are used to calculate a set of conservative correction factors to be used to modify the isotopic inventory for criticality analysis.

In summary, this chapter describes the process for determining a conservative estimate of concentrations of selected actinide isotopes for use in criticality safety analyses. The major discussions in this chapter are: 1) selecting isotopes to represent spent fuel for criticality analyses; 2) the measured chemical assay data used in the validation of the calculational method; and 3) the method used to establish calculational bias, uncertainty, and correction factors.

\subsection{ISOTOPIC SELECTION FOR SPENT FUEL REPRESENTATION}

Approximately 1,300 different isotopes are generated in the spent fuel. Representing all these isotopes in an analytical model for criticality analysis is neither practical nor essential. Therefore, a limited set of radionuclides is proposed for the analysis of SNF reactivity.

In making a conservative selection of isotopes to represent the spent fuel composition, the neutron absorption properties of the isotopes should be considered. The concentration and hence the contribution of these isotopes to neutron absorption, resulting in either fission or simple neutroncapture reactions, is dependent on cooling time. Figures 2-1 through 2-3 provide the results of a sensitivity study ${ }^{2-1}$ showing the fractional absorption rate as a function of time for the key actinide isotopes.

The isotopes that have a significant positive reactivity worth (U-235, Pu-239, and Pu-241) must be included in the burnup credit methodology. Factors to be considered in conservatively eliminating isotopes with negative worth are the chemical form, physical form and characteristics, solubility, volatility, and verifiability of the isotope by comparison to physical measurements. These factors do not disqualify any of the selected actinides. Np-237 is conservatively not considered at this time due to large deviations between the calculated and measured values. Therefore, the selected actinide isotopes to be included in the burnup credit criticality analysis methodology are U-234, U-235, U-236, U-238, Pu-238, Pu-239, Pu-240, Pu-241, Pu-242, and Am-241. 


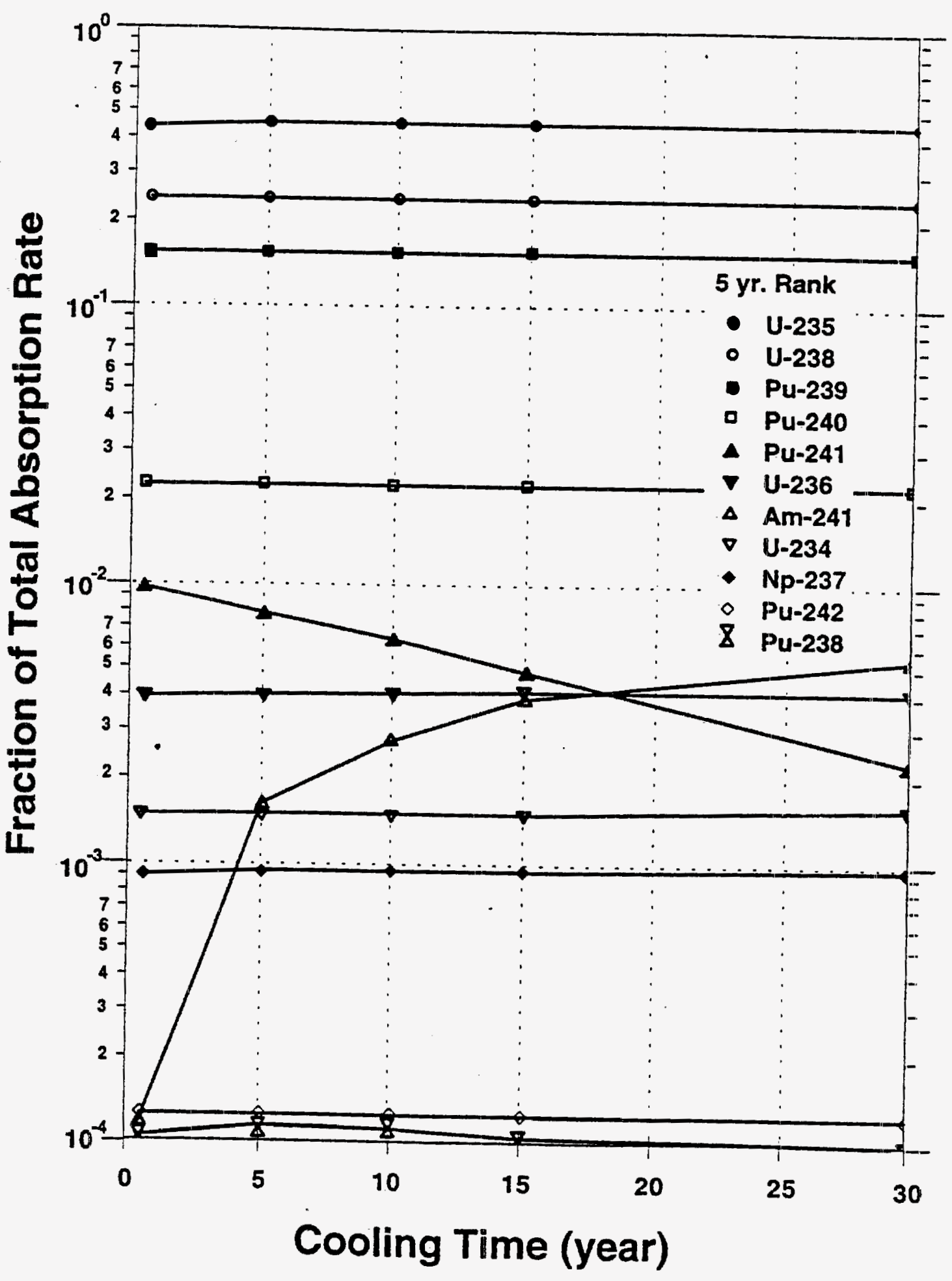

Figure 2-1. Fractions of Neutrons Absorbed by Major Actinides at Various Cooling Times, $3.6 \mathrm{wt} \% \mathrm{U}-235,10 \mathrm{GWd} / \mathrm{MTU}$ 


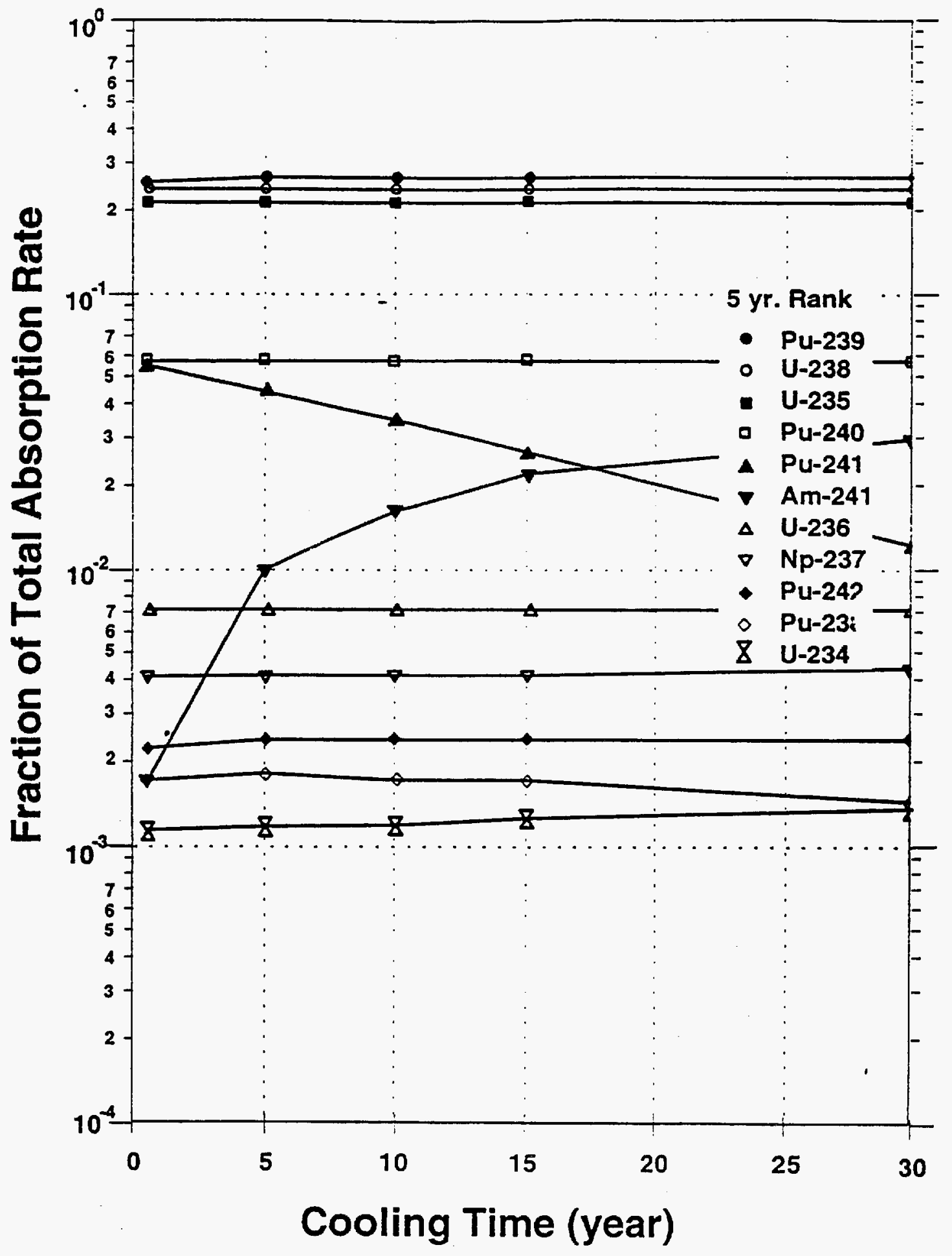

Figure 2-2. Fractions of Neutrons Absorbed by Major Actinides at Various Cooling Times, $3.6 \mathrm{wt} \% \mathrm{U}-235,30 \mathrm{GWd} / \mathrm{MTU}$ 


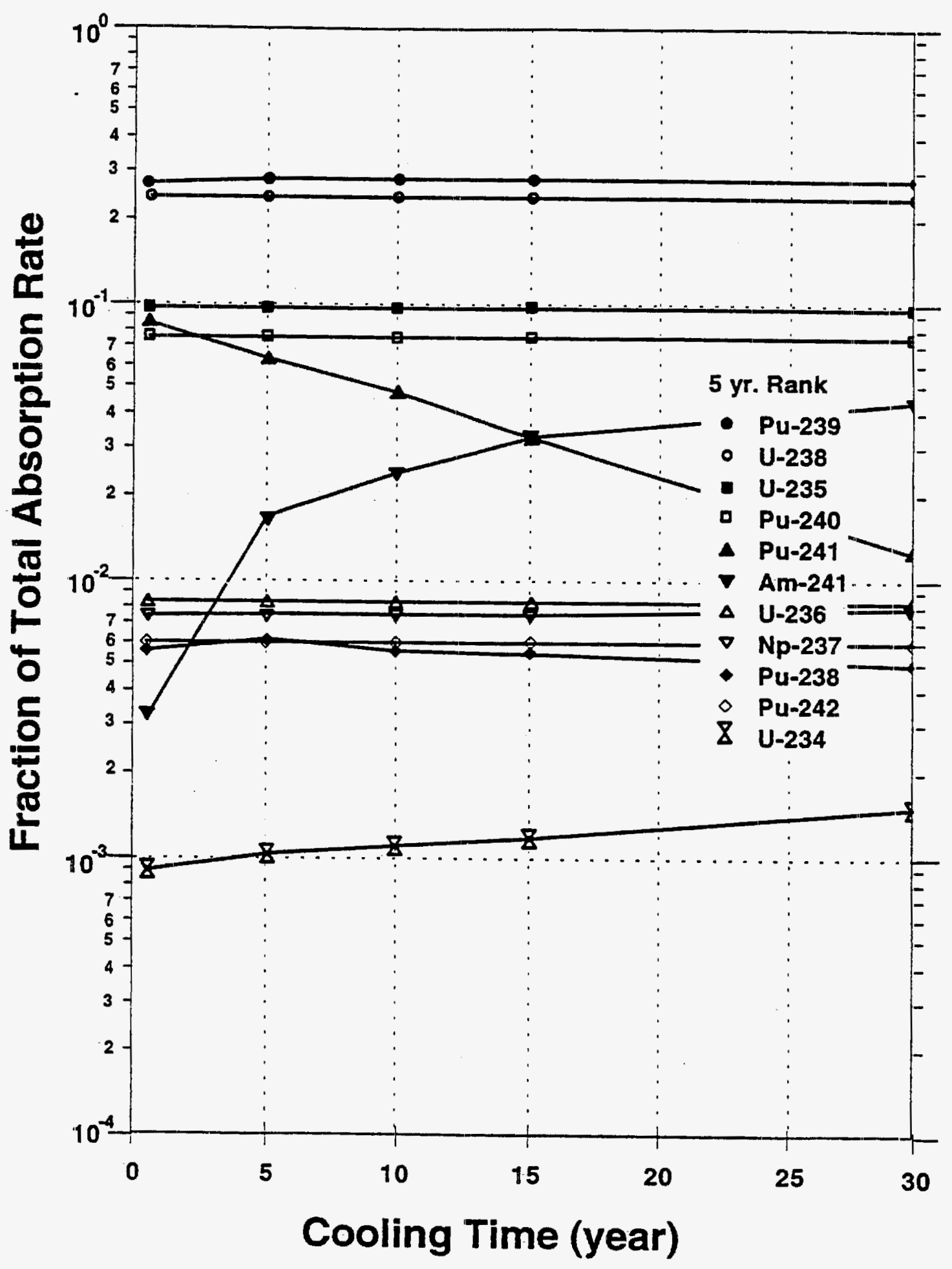

Figure 2-3. Fractions of Neutrons Absorbed by Major Actinides at Various Cooling Times, $3.6 \mathrm{wt} \% \mathrm{U}-235,50 \mathrm{GWd} / \mathrm{MTU}$ 


\subsection{ISOTOPIC VALIDATION DATA}

To ensure the accuracy of any computational tool used to predict the isotopic composition in spent fuel, the tool must be validated against a set of measurements performed on spent fuel samples. These samples should test the capabilities of the computational tool over a wide range of parameters important to the isotopic changes in the fuel assemblies. The following sub-sections present: 1) the isotopic measurement data to be used to validate isotopic computational tools for predicting the selected actinide inventories in spent fuel, 2) an examination of the range of applicability of the data, and 3 ) the qualification of the data.

\subsubsection{Isotopic Validation Measurements}

This subsection presents the experimental data recommended for use in validating the calculation of selected actinides in spent fuel. The sources of these data are the Materials Characterization Center (MCC) at the Pacific Northwest Laboratories (PNL), ${ }^{2-2,2-3,2-4,2-5}$ data from the German Obrigheim reactor fuel assemblies, ${ }^{2-6,2-7}$ data from Mihama-3, Yankee Rowe, Trino Vercelles, and Turkey Point fuel assemblies published in Reference 2-8. A compilation of all the measurements along with details of benchmark calculations are provided in References 2-9 and $2-10$, and 2-11. The following paragraphs provide a summary discussion of the chemical assays data.

The fuel assemblies analyzed at the MCC, which was part of the OCRWM program to collect information on spent fuel for the Yucca Mountain Repository Project, consisted of three 14x14 Combustion Engineering (CE) assemblies from the Calvert Cliffs Unit 1 reactor and one $15 \times 15$ Westinghouse assembly from $\mathrm{H}$. B. Robinson Unit 2 reactor. From each assembly, a specific fuel pin was selected for study. The data from the MCC on these assemblies include detailed fuel information collected before the assemblies were destructively assayed. These data included reactor, assembly, and fuel pin specifications; irradiation histories; a description of unusual events that occurred during each assembly's lifetime; burnup measurements; and detailed axial scans using gamma spectroscopy. The radiochemical assays were performed on individual fuel pellets taken from multiple axial positions in each fuel rod to evaluate a distribution of burnups. For each pellet, measurements were performed for the major actinides, cesium isotopes, and Tc-99. The uncertainty for each type of analytical measurement was included in the data documentation. Although a few of the isotopic measurements had large uncertainties, the measurement uncertainties for the selected actinides were around 1.6\%. The complete description of Calvert Cliffs and H. B. Robinson spent fuel samples and their calculational models are provided in Reference 2-11.

The Obrigheim data were chosen because they represented assembly-averaged data. Five fuel assemblies were physically divided into full-length halves. Each 12-foot half-section was then dissolved and assayed. Since the MCC provides pellet-specific data, it was decided to use the Obrigheim assembly-averaged data for benchmarking. The results from the dissolved assembly analyses provide "assembly-averaged" isotopic values. Obrigheim data are based on samples that were independently evaluated at four different European laboratories. The complete description of Obrigheim spent fuel samples and calculational models are also provided in Reference 2-11. 
In the mid 1960's extensive post-irradiation examinations, including radiochemical analyses, were performed on a selected set of spent fuel assemblies, with relatively high enrichment (i.e., $3.4 \mathrm{wt} \%$ U-235), discharged from Yankee Rowe Cores I, II, and IV. The overall purpose of the program was to further the knowledge of physical processes that occur within an operating reactor; and, thereby contribute to the advancement of competitive atomic power. The program was carried out under three phases. Under Phase I, 56 fuel rods were removed from 14 Core I fuel assemblies, and in Phase II post-irradiation examinations 7 fuel rods were removed from a two-cycled burned assembly. The burnup for the rods from Core I and II ranged from 13 to 18 and 10 to $31 \mathrm{GWd} / \mathrm{MTU}$, respectively. Under Phase III, 8 rods from one assembly which had been cycled in Cores I, II, and IV were selected for post-irradiation examinations. The maximum burnup of these rods was $46 \mathrm{GWd} / \mathrm{MTU}$. Therefore, because of the relatively high burnup and enrichment, it was decided to use the Yankee Rowe measurement data from a selected number of rods from the assembly which had been cycled in Cores I, II, and IV for this isotopic validation. In addition, Yankee Core design is significantly different from the typical PWR. Therefore, data from fuel assemblies exposed to a non-typical spectrum is included in the benchmark set. The complete description of spent fuel samples and calculational models is provided in Reference 2-9.

As part of an effort "to obtain quantitative data concerning the characteristics of the high burnup spent fuel dissolution for reprocessing," 2-8 spent fuel samples from Mihama-3 fuel assembly had been analyzed and reported in Reference 2-8. These samples provide data points at enrichment of $3.2 \mathrm{wt} \%$. Eight Mihama-3 samples with a burnup range of $6.9-34.2 \mathrm{GWd} / \mathrm{MTU}$ were used as part of benchmark set for this isotopic validation. The complete description of spent fuel samples and calculational models is provided in Reference 2-9.

Fourteen spent fuel samples obtained from three spent fuel assemblies discharged from the Trino Vercelles PWR (Italy) also were used as part of the benchmark set. The purpose of the Trino Vercelles program was to provide data for isotopic benchmarking purposes. Data from Trino Vercelles was selected for this study because of the relatively high (3.9 wt \%) enrichment of one fuel sample and because of its significantly different core design (similar to Yankee Rowe). The isotopic measurements for Trino Vercelles spent fuel were conducted by the Ispara (Italy) and Karlsruhe (Germany) facilities of the European Joint Research Center. The complete description of spent fuel samples and calculational models is provided in Reference 2-10.

As part of the pre-test characterization of the assemblies for the Climax - Spent Fuel Test which involved storage of spent fuel assemblies in a granite formation, five fuel rods from the Turkey Point Unit 3 reactor were destructively examined. The results of isotopic measurements made on the five samples taken from the five fuel rods are used as part of this isotopic validation benchmark set. Turkey Point was selected simply because of detailed data that were readily available. Burnup analyses for the five samples were performed by Battle Columbus Laboratory. (BCL) with direction provided by the Hanford Engineering Development Laboratory (HEDL). The complete description of the fuel samples and calculational models is provided in Ref. 2-10.

A total of 54 samples representing eighteen different fuel assemblies discharged from seven different reactors have been used as the benchmark set for actinide-only isotopic validation. Table 2-1 presents the results of the measurements for nine actinides. 
Table 2-1. Calculait i and Measured Values for the Selected Actinides

\begin{tabular}{|c|c|c|c|c|c|c|c|c|c|c|c|c|c|c|c|c|c|c|c|c|}
\hline & & Calvert $\mathrm{C}$ & $\begin{array}{r}\text { (mgig U02) } \\
\text { ms Unit I DO4 } \\
\text { (ATM 104) } \\
\end{array}$ & MKP109 & Calven Cliffs & 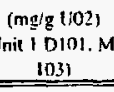 & A098 (ATM & Falvert Ctifrs & $\begin{array}{c}\text { ing/g Un2) } \\
\text { nit I BT03. NE } \\
\text { (06) } \\
\end{array}$ & 107 (ATM- & & Robinson B & $\begin{array}{l}\text { U02) } \\
\text { 5. N-9 (ATM-1 }\end{array}$ & & & & $\begin{array}{r}(\mathrm{mg} \\
\text { gheim } 170.172\end{array}$ & $\begin{array}{l}g \text { (1) } \\
176,168,171\end{array}$ & & \\
\hline \multirow{5}{*}{ Istorpe } & Reference & 2.3 & 2.3 & $2-3$ & $2-2$ & 2.2 & $2-2$ & $2-4$ & 2.4 & $2-4$ & $2-5$ & $2-5$ & $2-5$ & 2.5 & $2-622-7$ & $2-6 \& 2-7$ & $2-6 \& 2.7$ & $2-6 \& 2-7$ & $2-6 \& 2-7$ & $2-6 \& 2.7$ \\
\hline & $\begin{array}{c}\text { Cooling Time } \\
\text { (days) }\end{array}$ & 1870 & 1870 & 1870 & 2374 & 2374 & 2374 & 2447 & 2447 & 2447 & 3936 & 3936 & 3631 & 3631 & 0 & 0 & 0 & 0 & 0 & 0 \\
\hline & $\begin{array}{c}\begin{array}{c}\text { Enrichment } \\
\text { (wt-\%o U-235) }\end{array} \\
\end{array}$ & 3.03 & 3.03 & 3.03 & 2.72 & 2.72 & 2.72 & 2.45 & 2.45 & 2.45 & 2.56 & 2.56 & 2.56 & 2.56 & 3.13 & 3.13 & 3.13 & 3.13 & 3.13 & 3.13 \\
\hline & $\begin{array}{c}\text { Axinl Location } \\
\text { (cm) }\end{array}$ & 13.2 & 27.7 & 165.22 & 8.9 & 24.3 & 161.7 & 11.28 & 19.92 & 161.21 & 11.00 & 26.00 & 199.00 & 226.00 & $\mathrm{~N} / \mathrm{A}$ & NiA & $\mathrm{N} / \mathrm{A}$ & $\mathrm{N} / \mathrm{A}$ & $N / A$ & N/A \\
\hline & $\begin{array}{c}\text { Bumup } \\
\text { (GWd/MTU) } \\
\end{array}$ & 27.35 & 37.12 & 14.34 & 18.68 & 26.62 & 33.17 & 31.4 & 37.27 & 46.46 & 16.02 & 23.81 & 28.47 & 31.66 & 25.93 & 26.54 & 27.99 & 28.40 & 29.04 & 29.52 \\
\hline \multirow[t]{2}{*}{ U. 234} & \multirow{2}{*}{$\begin{array}{l}\mathrm{C} \\
\mathrm{M} \\
\end{array}$} & $1.610 c-01$ & $1.3900-01$ & $1.260<-01$ & $1.600 x-0 !$ & 1. $120 e-01$ & $1.2900-01$ & $1.210 e-01$ & $1.110 \mathrm{e}-01$ & $9.8400=-02$ & 40 & 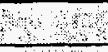 & Wro & 37, & 40,3 & $3 \%$ & $8 x_{3}$ & 3 & 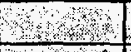 & 3 \\
\hline & & $1.600 x=01$ & 1.400e.-01 & $1.200 e-01$ & 1.400e-01 & $1.2\left|k_{-}-0\right|$ & $1.200 e-01$ & $1.530 e-01$ & $1.270 \mathrm{c}-01$ & $7.490 \times-02$ & tothe? & & $3^{2}=4$ & S18\%? & सेख? & $180 \%$ & 40 & 80 & +3ro & 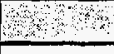 \\
\hline \multirow[t]{2}{*}{01.235} & \multirow{2}{*}{$\begin{array}{l}\mathrm{c} \\
\mathrm{M} \\
\end{array}$} & $8.000 e+00$ & $4.720 e+\infty 0$ & $3.200 k+00$ & $1.010 e+01$ & $6.640 c+00$ & $4.660 x+00$ & $3.820 e+00$ & $2.5900+00$ & $1.430 c+00$ & $1.073 e+01$ & $7.271 e+00$ & $5.821 e+00$ & $4.967 e+00$ & $9.420 e+00$ & $1.060 e+01$ & $9.130 e+00$ & $1.030 e+01$ & $9.600 e+00$ & $8.920 e+00$ \\
\hline & & 8. $4700+00$ & $5.170 c+\infty 0$ & $3.540 e+00$ & $1.025 e+01$ & $6.940 e+100$ & $4.780 e+00$ & $3.86 n+00$ & $2.710 c+\infty 0$ & $1.406 e+00$ & $1.070 e+01$ & $7.210 e+00$ & $5.180 e+00$ & $4.860 e+00$ & $9.680 e+00$ & $1.095 e+01$ & $9.580_{t+00}$ & $1.058 \varepsilon+01$ & $9.850_{e}+00$ & $9.180 e+00$ \\
\hline \multirow[t]{2}{*}{0.236} & \multirow{2}{*}{$\begin{array}{l}c \\
4\end{array}$} & $3.240++00$ & $3.630 e+00$ & $3.750 e+00$ & $2.480 x+00$ & $2.980 c+00$ & $3.2200+00$ & $2.900 e+00$ & $3.000 c+00$ & $3.020 c+00$ & $2.166 e+00$ & $2.682 c+00$ & $2.881 \mathrm{e}+00$ & $2.980<+00$ & $3.790 e+00$ & $3.630 e+00$ & $3.830 e+00$ & $3.6700+00$ & $3.770 x+\infty 0$ & $3.860 e+00$ \\
\hline & & $34+4 n+00$ & $2530 x+00$ & $3690+0+00$ & $25000+00$ & $200 n+100$ & $32600+00$ & $2.860+200$ & $3.030 x+00$ & $3040+\infty n$ & $2100 x+00$ & $2740 n+m$ & $2820 k+00$ & $3,000+000$ & $+3200+00$ & $35001+00$ & $3258+20$ & $3620=+00$ & $3700 k+00$ & $3810 \mathrm{e}+00$ \\
\hline \multirow[t]{2}{*}{ U. $23 R$} & \multirow{2}{*}{$\begin{array}{l}\mathrm{C} \\
\mathrm{M} \\
\end{array}$} & $8.370 c+02$ & $8.300 x+02$ & $8.240 e+02$ & $8.450 c+02$ & $8.400 e+02$ & $8.340 e+02$ & $8.380 e+02$ & $8.330 e+02$ & $8.240 e+02$ & $8.483 e+02$ & $8.424 c+02$ & $8.384 c+02$ & $8.344 e+02$ & & 30 & Broly & $3 \%$ & 4.4 & 48 \\
\hline & & $8.425 e+02$ & $8.327 e+02$ & $8.249 e+02$ & $8.551 e+02$ & $8.538 c+02$ & $8.422 e+02$ & 8. $446 e+02$ & $8.438 c+02$ & $8.272 e+02$ & $8.470 e+02$ & $8.470 c+02$ & $8.340 x+102$ & $8.420 c+02$ & 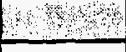 & 3. & 13ror & 30 & H'? & 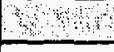 \\
\hline \multirow[t]{2}{*}{$\mathrm{Pu}-238$} & \multirow{2}{*}{$\begin{array}{l}\mathrm{C} \\
\mathrm{M} \\
\end{array}$} & $9.7900-02$ & $1.8800-01$ & $2.690 e-01$ & $3.9900,02$ & 9.010e 02 & $1.470 \mathrm{e}-01$ & $1.470 e-01$ & $2.010 \mathrm{e}-01$ & $2.900 x-01$ & $2.841 \mathrm{C}-02$ & $6.953 \mathrm{e}-02$ & $1.059 \mathrm{e}-01$ & $1.323 e-01$ & $1.060 \mathrm{c} .01$ & $8.520 \mathrm{e}-02$ & $1.1100-01$ & $9.1400-02$ & $1.030 \mathrm{e}-01$ & $1.1600=01$ \\
\hline & & $1.010 e-01$ & $1.890 \mathrm{e}-01$ & $2.6900-01$ & $4.850 \mathrm{e}-02$ & 9.6900 .02 & $1.483 e-01$ & $1.426 e-01$ & $1.947 \mathrm{e}-01$ & $2.842 e-01$ & $2.8300-02$ & $6.950 \mathrm{e}-02$ & $1.140 x-01$ & $1.3000-01$ & $1.054 t e-01$ & $8.010 e-02$ & $1.013 e-01$ & $8.890 \mathrm{e}-122$ & $9.480 \mathrm{e}-02$ & $1.071 \mathrm{E}-01$ \\
\hline \multirow[t]{2}{*}{ Pu-239 } & $c$ & $4.280 e+100$ & $4.410 e+\infty 0$ & $4.5600+00$ & $3.890 e+00$ & $+.220 e+00$ & $4.420 c+00$ & $4.040 e+00$ & $4.080 e+00$ & $4.210 c+00$ & $3.854 e+00$ & $4.291 e+00$ & $4.589 e+00$ & $4.689 e+00$ & $5.100 e+00$ & $5.020 x+00$ & $5.120 x+00$ & $5.040 c+00$ & $5.090 e+00$ & $5.130 e+00$ \\
\hline & M & $4.264 c+00$ & $4.357 e+00$ & $1.357 e+100$ & $3.94 S_{e}+00$ & $4.252 e+100$ & $4.187 c+\infty 0$ & $3.314 c+00$ & $3.835 e+00$ & $3.766 e+00$ & $3.640 e+00$ & $4.020 e+00$ & $4.3900+00$ & $4.200 c+00$ & $5.013 e+00$ & $4.805 e+00$ & $4.957 \mathrm{e}+00$ & $4.713 e+00$ & $4.925 e+00$ & $4.943 e+00$ \\
\hline \multirow[t]{2}{*}{$P 11-240$} & \multirow{2}{*}{$\begin{array}{l}\mathrm{C} \\
\mathrm{M}\end{array}$} & $1.610 c+00$ & $2.070 x+00$ & $2.320 e+00$ & $1.160 x+100$ & $1.630 e+00$ & $1.950 c+00$ & $1.950 e+00$ & $2.180 e+\infty$ & $2.450 e+00$ & $1.067 e+00$ & $1.591 \mathrm{le}+00$ & $1.862 e+00$ & $2.026 e+00$ & $1.860 e+00$ & $1.710 e+\infty 0$ & $1.890 e+00$ & $1.750 e+00$ & $1.840 e++00$ & $1.920 e+00$ \\
\hline & & $1.719 e+00$ & $2.2399_{e+00}$ & $2.543 e+00$ & $1.243 e+\infty 0$ & $1.766 e+00$ & $2.111 e+\infty$ & $2.067 e+00$ & $2.321 \mathrm{e}+00$ & $2.599++00$ & $1.0900+00$ & $1.670 e+00$ & $1.970 x+50$ & $2.120 e+00$ & $2.020 c+00$ & $1.800 e+00$ & $2.0000+00$ & $1.830 e+00$ & $1.920 e+00$ & $2.040 e+00$ \\
\hline \multirow[t]{2}{*}{$P_{11-241}$} & \multirow{2}{*}{$\begin{array}{l}\mathrm{C} \\
\mathrm{M}\end{array}$} & $7.090 \times-01$ & 9.330e-01 & $1.0600+00$ & $4.500 \mathrm{e}-01$ & $6.9700-01$ & $8.55 x-01$ & $7.3900-01$ & $8.3100-01$ & $9.440=-01$ & $3.199 e-01$ & $5.304=-01$ & $6.814=-01$ & $7.5100-01$ & $1.160 t+00$ & $1.050 c+00$ & $1.180 e+00$ & $1.070 x+00$ & $1.140 c+00$ & $1.200 e+100$ \\
\hline & & $6.810 e-01$ & $9.030 \mathrm{e}-01$ & $1.020 x+\infty 0$ & $4.542 e-01$ & $6.822 \mathrm{e}-01$ & $8.125 \mathrm{e} \cdot 01$ & $7.260 \mathrm{e}-01$ & $8.130 \mathrm{e}-01$ & $8.862 e-01$ & $3.040 \mathrm{e}-01$ & $5.040 x-01$ & $6.810 e-01$ & $6.920 \mathrm{e}-01$ & $1.103 e+00$ & $9.780 \mathrm{e}-01$ & $1.107 e+00$ & $9.780 \mathrm{e}-04$ & $1.058 e+00$ & $1.128 e+00$ \\
\hline \multirow[t]{2}{*}{$\mathrm{Pu}-242$} & \multirow{2}{*}{$\begin{array}{l}\mathrm{C} \\
\mathrm{M}\end{array}$} & $2.770 \mathrm{e}-01$ & $5.550 e-01$ & $7.860 x-01$ & $1.240 e-01$ & $3.0400=01$ & $4.9800-01$ & $4.8900-01$ & $6.8900-01$ & $1.010 e+00$ & $3+$ & 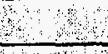 & 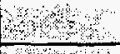 & +3 & $3.420 \mathrm{e}-01$ & $2.750 \mathrm{e}-01$ & $3.610 \mathrm{e} \cdot 01$ & $2.890 \mathrm{e}-01$ & $3.300 e-01$ & $3.740 \mathrm{e}-01$ \\
\hline & & $2.8900-01$ & $5.760 \mathrm{e} \cdot 01$ & 8. $400 x-01$ & 1.3940 .01 & 3.30le.01 & $5.4746-01$ & $5.463 \mathrm{e}-\Omega 1$ & $7.753 \mathrm{e}-01$ & $1.169 e+00$ & 3 & 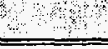 & $x^{2}$ & 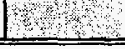 & $4.000<-01$ & $3.1200-01$ & 4.0500 .01 & $3.2800-01$ & $3.7200-01$ & $4.380 e-01$ \\
\hline
\end{tabular}


Table 2-1. Calculated and Measured Values for the Selected Actinides (Continued)

\begin{tabular}{|c|c|c|c|c|c|c|c|c|c|c|c|c|c|c|c|c|c|c|c|c|}
\hline & & \multicolumn{5}{|c|}{ Turkey Poin (mq $/ \mathrm{Q} U)$} & \multicolumn{14}{|c|}{ rino vercelles (meg/g U) } \\
\hline \multirow{5}{*}{ Isorope } & Reference & 2.10 & 2.10 & $2-10$ & 2.10 & 2.10 & 2.8 & 2.8 & 2.8 & 2.8 & 2.8 & 2.8 & 2.8 & $2-8$ & 2.8 & $2-8$ & 2.8 & 2.8 & 2.8 & $2-8$ \\
\hline & $\begin{array}{c}C \text { Cooling Time } \\
\text { (days) }\end{array}$ & 927 & 927 & 927 & 927 & 927 & 10 & 10 & 10 & 10 & 10 & 10 & 10 & 10 & 10 & 10 & $n$ & 10 & 10 & 10 \\
\hline & 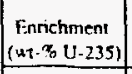 & 2.556 & 2.556 & 2.556 & $2.55 \mathrm{k}$ & $2.55 \%$ & 3.897 & 3.13 & 3.13 & 3.13 & 3.13 & 3.13 & 3.13 & 3.13 & 3.13 & 3.13 & 3.13 & 3.13 & 3.13 & 3.13 \\
\hline & $\begin{array}{c}\text { Axial" } \\
\text { Lxxation }(\mathrm{cm})\end{array}$ & 167.6 & 167.0 & 167.0 & 167.6 & 167.0 & 79.2 & 158.5 & 79.2 & 26.4 & 237.7 & 211.3 & 158.5 & 79.2 & 158.5 & 79.2 & 188.5 & 79.2 & 158.5 & 79.2 \\
\hline & $\begin{array}{c}\text { Burnup } \\
\text { (GWdMTU) }\end{array}$ & 30.72 & 30.51 & $31 . .96$ & 31.26 & 31.31 & 12.042 & 15.377 & 15.898 & 11.529 & 12.859 & 20.602 & 23718 & 24.304 & 23.867 & 24.548 & 23.928 & 24,362 & 24.33 & 24.313 \\
\hline \multirow[t]{2}{*}{ U.234 } & \multirow[t]{2}{*}{$c$} & $1.3800 \cdot .01$ & $1.3800-01$ & $1.360 x-91$ & $1.3770 .-01$ & $1.3600 \cdot .81$ & & . & 8 & $68 \mathrm{n}$ & $3 \times$ & 29 & She & 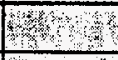 & $4+48$ & 101 & 3 & 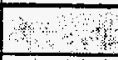 & 2 & Lo \\
\hline & & $1.321<.01$ & $1.321 \mathrm{e}-01$ & $1.225 \mathrm{se}-01$ & $1.131 \mathrm{l} e-131$ & $1.3200-01$ & & : & 5 & 853 & nestro & Who & 88.4 & 4,3 & $x^{4}$ & P. & $x$ & $20+4$ & $3+2$ & 6ys \\
\hline \multirow[t]{2}{*}{ U.2.235 } & \multirow[b]{2}{*}{$M$} & $5.450 x+\infty 0$ & $5.510 e+(x)$ & $5.191 k++00$ & $5.280++00$ & $5.270 e_{e}+10$ & $2.699 x+01$ & $1.780 e+01$ & 1.. & $2.040 e+01$ & $1.950 e+01$ & $1.460 c+01$ & $1.290 e+01$ & $1.250 e+01$ & $1.280 e+01$ & $1.240 x+01$ & $1.280 x+01$ & $1.250 x+01$ & $1.260 e+01$ & $1.2500_{e+11}$ \\
\hline & & $5.865 \mathrm{se}+00$ & $5.676 c+\infty 0$ & $5.5846+00$ & $5.509 e_{t+00}$ & $5.662 e+00$ & $2.6600+01$ & $1.728 c+01$ & $1.661 e+01$ & $2.017 e+01$ & $1.946 e+01$ & $1.436 x+01$ & $1.248 c+01$ & $1.23 s_{e}+01$ & $1.291 \mathrm{e}+01$ & $1.221 e+01$ & $1.282 e+01$ & $1.225 \mathrm{e}+01$ & $1.297 e+01$ & $1.231++01$ \\
\hline \multirow[t]{2}{*}{$\mathrm{U}-236$} & \multirow[b]{2}{*}{$M$} & $3.350 e+\infty 0$ & $3.350 e+00$ & $3.3800+00$ & $3.370 x+00$ & $3.370 k+\infty n$ & $2.450 x+\infty 00$ & $2.6200++00$ & $2.6700+00$ & $2.1400 \div+00$ & $2.3200+00$ & $3.1500+00$ & $3.410 c++0$ & $3.460 e+\infty 0$ & $3.420 e+00$ & $3.480 x+\infty 0$ & $3.430 e+00$ & $3.4600+00$ & $3.460 e+100$ & $3.4600+000$ \\
\hline & & $3.254 e+00$ & $3.255 e+00$ & $3.178 e+00$ & $3.156 e+00$ & $3.252 e+00$ & $2.7360+00$ & $2.834 \mathrm{e}+00$ & $2.739 e+10$ & $2.502 e+00$ & $2.453 e+00$ & $3.317 e+\infty 0$ & $3.610 e+00$ & $3.638 e+00$ & $3.520 c+00$ & $3.540 e+00$ & $3.753 e+00$ & $3.465 \mathrm{e}+00$ & $3.4711+00$ & $3.569 \mathrm{e}+00$ \\
\hline \multirow[t]{2}{*}{$\mathrm{U} \cdot 238$} & \multirow[t]{2}{*}{ C } & $9.490 e+02$ & $9.500 e+02$ & 9.49le +02 & 9.490xe+02 & $9.490 e+02$ & $95200+02$ & $9.5600+02$ & $9.560 \mathrm{e}+02$ & $9.590 e+02$ & $9.580 x+02$ & $9.520 e+02$ & $9.490 x+02$ & $9.490 e+02$ & $9.490 e+02$ & $9.490 x+02$ & $9.490 k+02$ & $9.490<+102$ & $9.490 e+02$ & $9.4900+122$ \\
\hline & & $9.502 e+02$ & $9.506 e+02$ & $9.495 \mathrm{e}+122$ & $9.499 e_{+}+02$ & $9.498 c+02$ & $9.513 e+02$ & $9.558 \mathrm{e}+02$ & $9.558 c+02$ & $9.595 \mathrm{e}+022$ & $9.587 \mathrm{e}+02$ & $9.518 e+02$ & $9.493 e+02$ & $9.492 \mathrm{e}+02$ & $9.4922+02$ & $9.483 e+02$ & 9. $485 \mathrm{e}+02$ & $9.482 e+02$ & $9.486 e+02$ & $9.472 e+02$ \\
\hline \multirow[t]{2}{*}{ Pu. 238} & \multirow[b]{2}{*}{ 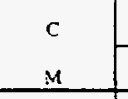 } & $1.466 n e-01$ & $1.44 a x=01$ & $1.5<n e-01$ & $1.520 \mathrm{e}-01$ & $1.5200-01$ & & $\mathrm{BO}_{\mathrm{B}}$ & 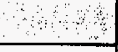 & $\mathrm{L}^{2}$ & 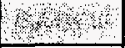 & 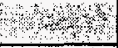 & 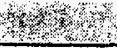 & Writy & Hints & D... & B.to & 3rots & 40 & 20 \\
\hline & & $1.365 \mathrm{se}-01$ & $1.3606-01$ & $1 .+265 \mathrm{e}-01$ & $1.382 \mathrm{e}-01$ & $1.372 \mathrm{e}-01$ & & 3 & $\therefore \quad$ & mats & 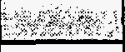 & 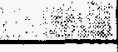 & H & $3, x_{2}$ & Int & W & $y^{2}$ & $3+4$ & 4,3 & 3 \\
\hline \multirow[t]{2}{*}{$\mathrm{Pu}-239$} & \multirow{2}{*}{$\begin{array}{l}c \\
M\end{array}$} & $5.080 \mathrm{e}+\mathrm{m}$ & S.080e+mo & $500 x_{e}+10$ & $5000 x+n 0$ & $5.090 x+00$ & $4.391 k+\infty 0$ & $5.160 x+\infty 0$ & $5.130 e++\infty)$ & $4.310 e+00$ & $4.680++\infty 0$ & $5.790 x+00$ & $6.010 e+00$ & $5.920 \mathrm{e}+00$ & $6.030 e+00$ & $5.9400+00$ & $6.030 e+00$ & $5.920 e++00$ & $6.06(1)+100$ & $5.920++\infty 0$ \\
\hline & & $1.8 .88 c+(19)$ & $.8 .850+00$ & $4.930 c+0)$ & $4.94 l e+100$ & $4.788 e+00$ & $4.586 x+100$ & $5.2666++00$ & $5.234 \mathrm{e}+100$ & $4.418 c+00$ & $4.580 e++00$ & $5.7558+00$ & $5.895 \mathrm{e}+00$ & $6.0700+00$ & $5.950 e+\infty 0$ & $5.980 e+00$ & $6.0600 \mathrm{e}+10$ & $5.995 \mathrm{e}+00$ & $6.060+100$ & $5.970 e++00$ \\
\hline \multirow[t]{2}{*}{ Plit-24n } & \multirow{2}{*}{$\begin{array}{l}\mathrm{C} \\
\mathrm{M}\end{array}$} & 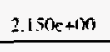 & 2.1.44x+10 & $2.199 x+1+0$ & $2.170 x+100$ & $2.180 x+(x)$ & $6.600 x=011$ & $1.0600+00$ & $1.090 x+e+00$ & 1.370e.01 & $8.400 e-01$ & $1.460 x+00$ & 1. $.6800++\infty$ & $1.700 x+10$ & $1.690 x++00$ & $1.7200+100$ & $1.6900+\mathrm{etn}$ & $1.710 x+100$ & $1.7200++10$ & $1.7000++00$ \\
\hline & & $2.266<+00$ & $2.29 \operatorname{se}+\infty 0$ & $2.295 \varepsilon+\infty 0$ & $2.320 x+00$ & $2.278 e+100$ & $7.165 c .01$ & $1.118 e+00$ & $1.137 e+00$ & $7.7500-01$ & $8.4000=-01$ & $1.520 e++00$ & $1.755 \mathrm{e}+00$ & $1.825 \mathrm{e}+00$ & $1.760 c+00$ & $1.785 \mathrm{e}+00$ & $1.7900++00$ & $1.810 e+00$ & $1.770 e++00$ & $1.790 c+00$ \\
\hline \multirow[t]{2}{*}{$P_{n n: 241}$} & \multirow{2}{*}{$\begin{array}{l}\mathrm{C} \\
\mathrm{M} \\
\end{array}$} & $1.160 \mathrm{e}+00$ & $1.15(0+0)$ & $1.1910+n$ & $1.180+00$ & $1.1800+00$ & $3.280 \mathrm{e}-\mathrm{n} 1$ & $6.250 e-01$ & $6.460 \mathrm{e}-01$ & $3.6400-.01$ & 4.280e 01 & $9.0800-01$ & $1.090 k+10$ & $1.100 e++00$ & $1.100 e+\infty$ & $1.120 e+00$ & 1. $100 x+\infty 0$ & $1.110 c+\infty 0$ & $1.130 e+\infty 0$ & $1.1000++(x)$ \\
\hline & & $1.061 \mathrm{e}+00$ & $1.068 \mathrm{Ce}+(0)$ & $1.204 x+100$ & 1.124 $4 c_{+}+00$ & $1.072 e+00$ & $3.475 \mathrm{c} .01$ & $6.140 e-01$ & $6.1808=01$ & $3.6900-01$ & 4.0000 .01 & $8.850 e-01$ & $1.030 e+00$ & $1.060 e+00$ & $1.050 x+00$ & $1.055 e+00$ & $1.050 e+00$ & $1.05 s e+00$ & $1.060 e+\infty 0$ & $1.0600+00$ \\
\hline \multirow[t]{2}{*}{$P=212$} & \multirow{2}{*}{$\begin{array}{l}\mathrm{c} \\
\mathrm{M}\end{array}$} & $5.150 e-n 1$ & s.n7ke.n1 & $5.4500-01$ & 5.3400 .01 & $5.360 \mathrm{er}-01$ & $2.500 x-12$ & 7.570 e. 02 & $8.230 e-02$ & $3.280 \mathrm{e}-12$ & 4.410e-. 02 & $1.5700-01$ & $2.2200-01$ & 2.3500 .01 & $2.250 \mathrm{e}-01$ & $2.4000-.01$ & $2.260 \mathrm{E}-\mathrm{n1}$ & $2.3696 \mathrm{e} \cdot .11$ & $2.350 e_{e .01}$ & $2.350 e-n 1$ \\
\hline & & $5.020 \mathrm{e}-01$ & $5.248 \mathrm{c} \cdot 01$ & $5.477 \mathrm{e}-01$ & $5.428 \mathrm{e}-01$ & $5.235 \mathrm{e}-01$ & $3.135 \mathrm{e} \cdot 02$ & $8.638 \mathrm{e}-02$ & $9.487 \mathrm{e}-02$ & $3.803 e .02$ & $4.600 \mathrm{Re}-02$ & $1.7200=01$ & $2.435 \mathrm{~s}-01$ & $2.575 \mathrm{e}-01$ & $2.400 \mathrm{e}-01$ & $2.5400-01$ & 2.4700 .01 & $2.5900-01$ & $2.400 \mathrm{c}-01$ & $2.5000-.01$ \\
\hline
\end{tabular}




\begin{tabular}{|c|c|c|c|c|c|c|c|c|c|c|c|c|c|c|c|c|c|}
\hline & & \multicolumn{8}{|c|}{ Mihama (g'assembly) } & \multicolumn{8}{|c|}{ Yankee Rowe (g/assembly) } \\
\hline \multirow{5}{*}{ Isotope } & Reference & $2-8$ & 2.8 & $2-8$ & $2-8$ & 2.8 & $2-8$ & $2-8$ & 2.8 & $2-8$ & 2.8 & 2.8 & $2-8$ & $2-8$ & $2 \cdot 8$ & 2.8 & $2-8$ \\
\hline & $\begin{array}{c}\text { Contling Time } \\
\text { (days) }\end{array}$ & 1825 & 1825 & 1825 & 1825 & 1825 & 1825 & 1825 & 1825 & 281.5 & 281.5 & 281.5 & 281.5 & 281.5 & 281.5 & 281.5 & 281.5 \\
\hline & $\begin{array}{c}\text { Enrichment } \\
\text { (wt:\% U. -235) }\end{array}$ & 3.208 & 3.208 & 3.203 & 3.203 & 3.21 & 3.21 & 3.21 & 3.21 & 3.4 & 3.4 & 3.4 & 3.4 & 3.4 & 3.4 & 3.4 & 3.4 \\
\hline & $\begin{array}{c}\text { Axial lencation" } \\
(\mathrm{cm})\end{array}$ & 18.6 & 316.7 & 142.6 & 236.7 & 16.7 & 107.2 & 32.9 & 240.2 & 86.7 & 54.7 & 22.7 & 6.7 & 54.7 & 22.7 & 54.7 & 22.7 \\
\hline & $\begin{array}{c}\text { Burnup } \\
\text { (GWUMTU) } \\
\end{array}$ & 8.30 & 6.90 & 15.30 & 21.20 & 29.44 & 32.30 & 33.70 & 34.10 & 15.95 & 30.39 & 31.33 & 20.19 & 32.03 & 31.41 & 35.97 & 35.26 \\
\hline \multirow[t]{2}{*}{$1 J .234$} & \multirow{2}{*}{$\begin{array}{l}\mathrm{C} \\
\mathrm{M} \\
\end{array}$} & $1.140 e+02$ & & 7 & 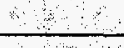 & 2 & $8.300 e+01$ & $8.1300+01$ & 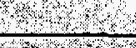 & $4.320 e+01$ & $3.510 e+01$ & $3.420 e+01$ & $4.070 e+01$ & $3.370 e+01$ & $3.410 e+01$ & $3.170 e+01$ & $3.220 c+01$ \\
\hline & & $1.193 \mathrm{e}+02$ & & & re? & 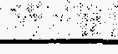 & $7,767 e+01$ & $7.758 \mathrm{e}+01$ & 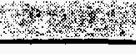 & $4.280 e+01$ & $3.914 e+01$ & $3.236 e+01$ & $3.967 e+01$ & $3.132 e+01$ & $3.184 c+01$ & $3.262 e+01$ & $3.314 e+01$ \\
\hline \multirow[t]{2}{*}{$1+235$} & \multirow{2}{*}{$\begin{array}{l}c \\
\mathrm{~N}\end{array}$} & $1.040 c+04$ & $1.100 c+04$ & $7.850 x+03$ & $6.170 x+03$ & $4.160 e+03$ & $3.680 x+03$ & $3.380 e+03$ & $3.420 e+03$ & $5.430 t+03$ & $3.280 e+03$ & $3.150 e+03$ & $4.660 x+03$ & $3.090 e+03$ & $3.140 e+03$ & $2.680 e+03$ & $2.720 e+03$ \\
\hline & & $10060+04$ & & $82730+03$ & $6.489 e+03$ & $-4.3660+03$ & $+044 c+03$ & $3512 e+03$ & 3.584 .03 & $5.462 c+03$ & $3463 e+03$ & $3.284 \cot 03$ & $4.7360+03$ & $3250 x+03$ & $3.268 \mathrm{c}+03$ & $2697 e+03$ & $2713 e+03$ \\
\hline \multirow[t]{2}{*}{ (1.2.3. } & \multirow{2}{*}{$\begin{array}{l}c \\
y\end{array}$} & $7.820 c+02$ & $6.860 x+02$ & $1.180 e+03$ & $1.460 e+03$ & $1.830 e+03$ & $1.890 x+03$ & $1.920 e+03$ & $1.930 e+03$ & $7.870 e+02$ & $1.130 e+03$ & $1.150 e+03$ & $9.130 e+02$ & $1.160 c+03$ & 1. $150 e+03$ & $1.210 e+03$ & $1.200 e+03$ \\
\hline & & $7344 x+02$ & $6521+0+02$ & $1 \mathrm{Hele+03}$ & $1+60 R+03$ & $1708 e+03$ & $-283 z e+03$ & $1.865 e+03$ & $1871=03$ & $2949+02$ & $1124 e+03$ & Lلد & $2.107 e+02$ & $115 x=03$ & $1 \sqrt{22}+03$ & $1,226 x+103$ & $1.224+03$ \\
\hline \multirow[t]{2}{*}{1238} & \multirow{2}{*}{$\begin{array}{l}\mathrm{C} \\
\mathrm{M}\end{array}$} & $4.290++05$ & $4.290 k+05$ & $1.270 x+05$ & $4.250 e+05$ & $4.220 c+105$ & $4.210 e+05$ & $4.200 e+05$ & $4.200 e+05$ & $2.630 e+05$ & $2.590 e+05$ & $2.5900+05$ & $2.620 e+05$ & $2.590 c+05$ & $2.590 e+05$ & $2.580 e+05$ & $2.580 e+05$ \\
\hline & & $4.291 \mathrm{l}+05$ & $4.293 e+05$ & $4.266 c+05$ & $4.249 e+0 s$ & $4.223 e+05$ & $1.211 e+05$ & $4.211 \mathrm{e}+05$ & $4.20 s_{e+05}$ & $2.618 \mathrm{e}+05$ & $2.584 e+05$ & $2.579 e+05$ & $2.581 \mathrm{e}+05$ & $2577 e+05$ & $2.580 e+05$ & $2572 e+05$ & $2.575 \mathrm{c}+0 \mathrm{~s}$ \\
\hline \multirow[t]{2}{*}{$P n-2.38$} & \multirow{2}{*}{$\begin{array}{l}c \\
4\end{array}$} & $2.200 x+(x)$ & $1.600 e+00$ & $1.060 x+01$ & $2.410 e+01$ & $5.530 e+0 t$ & $6.790 x+01$ & $7.400 x+01$ & $8.120 e+01$ & $1.120 e+01$ & $5.030 e+01$ & $5.220 e+01$ & $1.910 e+01$ & $5.530 e+01$ & $5.250 e+01$ & $7.060=+01$ & $6.700 e+01$ \\
\hline & & $20011 e+00$ & $1,500+00$ & Lل15set & $2552 e+01$ & $5840<+01$ & $2098 \mathrm{c}+01$ & $7477 \mathrm{en}+1 \mathrm{l}$ & $8.2760+01$ & $1.3040+01$ & $4846 e+01$ & s.gesetoL & $2212 c+01$ & $6.230 x+01$ & $5016 x+01$ & $6.9376+01$. & $6728 c+01$ \\
\hline \multirow[t]{2}{*}{$P_{1-2.239}$} & \multirow{2}{*}{$\begin{array}{l}\mathrm{c} \\
\mathrm{u} \\
\end{array}$} & $1.390 x+03$ & $1.280 c+03$ & $1.930 e+03$ & $2.270 x+03$ & $2.300 c+03$ & $2.360 e+03$ & $2.350 e+03$ & $2.500 c+03$ & $1.570 e+03$ & $2.030 e+03$ & $2.010 e+03$ & $1.700 e+03$ & $2.060 e+03$ & $2.010 e+03$ & $2.120 e+03$ & $2.070 e+03$ \\
\hline & & $1.3+2+0+03$ & $1.261 e+03$ & $2.075 x+03$ & $2.267 e+03$ & $2.363 e+03$ & $2.441 e+03$ & $2.217_{e+03}$ & $2.371 e+03$ & $1.642 e+03$ & $2.170 e+03$ & $2.186 e+03$ & $1.821 e+03$ & $2.202 \varepsilon+03$ & $2.116 e+03$ & $1.916 e+03$ & $1.882 e+03$ \\
\hline \multirow[t]{2}{*}{$\mathrm{Pu} \cdot 2 \mathrm{An}$} & \multirow{2}{*}{$\begin{array}{c}c \\
y\end{array}$} & $1.840 c+02$ & $1.450 c+12$ & $4.270 e+02$ & $6.280 c+02$ & $8.500 x+02$ & $9.190 e+02$ & $9.510 e+02$ & $9.780 e+12$ & $2.900 e+02$ & $5.650 e+02$ & $5.770 e+02$ & $3.750 e+02$ & $5.910 e+02$ & $5.790 e+02$ & $6.480 e+02$ & $6.360 \mathrm{c}+02$ \\
\hline & & $1882 e+02$ & $1=35=+02$ & $16160+02$ & $6645 e+02$ & $2,358 \mathrm{et}+02$ & 2010 & $-1024=+03$ & $1083 e+03$ & $3,078 e+12$ & $5.839 e+02$ & $6.210+102$ & $3961 e+02$ & $6.5312+102$ & $626 x k+12$ & $2003 x+02$ & $6.825 c+102$ \\
\hline \multirow[t]{2}{*}{ P11-2*11 } & \multirow{2}{*}{$\begin{array}{l}c \\
4 \\
\end{array}$} & $5.220 e+01$ & $3.790 e+0 t$ & $1.750 c+02$ & $3.010 e+02$ & $4.170 t+02$ & $4.610 e+02$ & $4.760 e+02$ & $5.090 c+02$ & $1.700 e+02$ & $3.860 e+02$ & 4. $170 \mathrm{e}+02$ & $2.360 e+02$ & $4.330 e \pm 02$ & $4.180 e+02$ & $4.870 e+02$ & $4.710 e+02$ \\
\hline & & $4843 e+01$ & $3.695 e+01$ & $1820 x+02$ & $2005 x+02$ & $4260+02$ & $4.712 e+02$ & $43840+02$ & $4.802+102$ & $1828 e+02$ & $4.247 e+02$ & $4,4892+02$ & $2.524 c+12$ & $4596 x+10$ & $4.354 k+102$ & $4,623 e+02$ & $-4.462 c+02$ \\
\hline \multirow[t]{2}{*}{$\mathrm{PU}-2 \mathrm{d2}$} & \multirow[t]{2}{*}{ c } & $4.170 e+00$ & $2.43 n++00$ & $2.890 x+01$ & $7.240 e+01$ & $1.590 x+02$ & $1.950 c+02$ & $2.170 e+02$ & $2.240 c+02$ & $1.960 e+01$ & $9.780 e+01$ & $1.050 e+02$ & $3.660 \mathrm{c}+01$ & $1.100 e+02$ & $1.050 e+02$ & $1.400 e+02$ & $1.340 e+02$ \\
\hline & & $4.235 e+00$ & $2.695 \mathrm{e}+100$ & $3.298 \mathrm{c}+01$ & $7.830 c+01$ & $1.820 x+02$ & $2.187 e+02$ & $2.384 c+02$. & $2.541 e+02$ & $2.213 e+01$ & $9.555 e+01$ & $1.088 e+02$ & $3.995 e+01$ & $1.163 e+02$ & $1.104 t+02$ & $1.522 e+02$ & $1.457 e+102$ \\
\hline
\end{tabular}

$C-$ Calculated value
$M-$ Measured value

'Height of sample above bottom of fuel

$\mathrm{N} / \Lambda$ - Not Applicable. Isotopic measurements were performed by assaying full length halves of fuel 
Since almost all the Am-241 in SNF with at least five years cooling time comes from post irradiation decay of Pu-241, the predicted Am-241 values will be biased based on Pu-241 measurements. Therefore, no Am-241 measurements were used to determine the bias associated with predicting Am-241. In some cases, specific isotopic measurements were not performed or were not reported on all the nine isotopes in a given sample. Thus, the measured data range from 25 to 54 samples per actinide isotope. Reference 2-9 summarizes the complete set of the isotopic measurements for the selected actinides.

\subsubsection{Range of Applicability of Measured Data}

As prescribed in ANSI/ANS-8. $1,{ }^{2-12}$ the validation of a computational method requires that the area of applicability of the data be defined. This area of applicability is dependent on the range of material compositions and geometric arrangements within which the bias of the calculational method is established. Table 2-2 provides the range of values for spent fuel assembly dimensions and composition from which the 54 chemical assays were taken. However, since a number of design options affect the isotopic production in the same way, this section identifies the appropriate parameters to use to establish trends and the range of applicability.

The isotopic concentrations are determined by the following differential equation:

$$
\mathrm{d} \mathbf{N}^{\mathrm{i}} / \mathrm{dt}=\mathrm{N}^{\mathrm{i}-1} \sigma_{\mathrm{c}}^{\mathrm{i}-1} \phi+\lambda^{j} \mathrm{~N}^{\mathrm{j}}-\mathrm{N}^{\mathrm{i}} \sigma_{\mathrm{a}}^{\mathrm{i}} \phi-\lambda^{\mathrm{i}} \mathrm{N}^{\mathrm{i}}
$$

where:

$\mathrm{N}^{\mathrm{i}} \quad$ is the isotope of concern (e.g., U-236)

$\mathrm{N}^{\mathrm{i}-1} \quad$ is the isotope preceding the isotope of concern in a capture chain (e.g., U-235)

$\mathrm{N}^{\mathrm{j}} \quad$ is the decay parent for the isotope of concern (e.g., Pu-240)

$\sigma_{\mathrm{c}}$ and $\sigma_{\mathrm{a}}$ are the capture and absorption cross section, respectively, and

$\phi \quad$ is the flux

$\lambda$ decay constant.

The concentration of isotopes in spent fuel depends on:

- Initial concentration

- Cross sections

- Fission

- Capture

- Scattering

- Specific Power

- Irradiation Time

- Decay constants and branching ratios

- Cooling time. 
Table 2-2 Comparison of Physical Parameters Between Benchmark and Anticipated Burnup Credit Assemblies

\begin{tabular}{|c|c|c|}
\hline $\begin{array}{c}\text { Key } \\
\text { Parameters }\end{array}$ & $\begin{array}{l}\text { Anticipated Burnup } \\
\text { Credit Spent Fuel } \\
\text { Assemblies }\end{array}$ & 54 Benchmark Samples \\
\hline $\begin{array}{l}\text { Assembly Characteristics } \\
\text { Type }\end{array}$ & All types & $\begin{array}{l}\text { CE } 14 \times 14 \\
\text { WE } 17 \times 18,15 \times 15,14 \times 15 \\
\text { Siemens } 14 \times 14\end{array}$ \\
\hline Fuel Rod Characteristics & & \\
\hline Pitch $(\mathrm{cm})$ & $1.07-1.47$ & $1.07-1.47$ \\
\hline Outside Diameter $(\mathrm{cm})$ & $0.79-1.12$ & $0.86-1.12$ \\
\hline Gap (cm) & $0.005-0.017$ & $0.005-0.015$ \\
\hline Pellet Diameter $(\mathrm{cm})$ & $0.71-0.99$ & $0.75-0.96$ \\
\hline Pellet Density $\left(\mathrm{g} / \mathrm{cm}^{3}\right)$ & $10.0-10.4$ & $10.08-10.57$ \\
\hline Moderator/Fuel Volume & $1.3-1.9$ & $1.3-1.7$ \\
\hline Clad Material & $\begin{array}{l}\text { Zircaloy } \\
\text { Stainless Steel }\end{array}$ & $\begin{array}{l}\text { Zircaloy } \\
\text { Stainless Steel }\end{array}$ \\
\hline Cooling Time (years) & 5 to 100 & $0-10$ \\
\hline
\end{tabular}

The isotopic concentration dependency on the above is obvious except for two parameters; specific power and the scattering cross section. The specific power sets the magnitude of the flux by the following relation:

Specific Power $=($ Energy per Fission $) \times($ Macroscopic Fission Cross Section $) \times($ Flux $)$ Fuel Density

Burnup and specific power are related by:

Specific Power $=$ Burnup/Irradiation Time 
Now let us review the parameters from the above list that influence the isotopic concentration. The initial concentration, irradiation time, decay constants (including branching ratios), and cooling time are generally well known. Since burnup is measured by use of Nd-148, this implies that the specific power is known to the accuracy of the measurement. Hence, this only leaves the crosis sections. There are two sources of potential error in the cross sections. The first is the direct error in the multi group or continuous energy library (e.g., 27BURNUPLIB or ENDF(B-V). The other is an indirect error in the cross sections caused by the cross section processing in collapsing the energy dependent cross sections to one energy group. This indirect error could be due to a direct error in a scatter cross section or in the processing technique itself.

The isotopic validation will consider four parameters: burnup, spectrum, enrichment, and specific power. These four parameters will cover the major independent ways of creating errors in isotopic concentrations. Each will be described below.

The isotopic concentration changes are directly proportional to burnup. In general, any error in cross section will create an increasing error in isotopic concentration with burnup. It is possible to have errors that will compensate each other but it is unlikely that they will have the same dependence on burnup so an absorption cross sectional error is expected to demonstrate itself in a trend with burnup. This parameter will expose problems with both the direct capture and absorption cross sections from the library (e.g., 27BURNUPLIB) as well as the processing technique.

The following items affect the neutron energy spectrum in a PWR:

- Fuel design (there is a little variation of the hydrogen to uranium ratio between assembly designs)

Moderator density (temperature is the measured parameter)

- Soluble boron concentration

Presence of burnable absorbers

- Burnup

- Specific Power

- Enrichment.

Changes in the values of the above parameters cause the neutron spectrum to be softer (less energetic) or harder (more energetic) than a nominal neutron spectrum. This change in neutron spectrum impacts the cross sections and hence the isotopic production in the spent fuel. For example, high average boron concentration in the reactor causes the spectrum to be harder and therefore impacts the isotopic inventory in the spent fuel assembly. Since the collapse of the cross sections depends on the spectrum, trends on spectrum will be sought. The magnitude of the effect of a 
spectral error will depend on the quantity of burnup so the trend sought will actually be the product of the spectral index and the burnup.

The macroscopic fission cross section impacts the magnitude of the flux for a given specific power. At the beginning of life the macroscopic fission cross section is proportional to the enrichment. A review of equations presented in this section reveals that as the enrichment increases the flux decreases and it takes a greater burnup to achieve the same production of some isotopes, such as $\mathrm{Pu}-$ 239. By seeking a trend on enrichment, deviations in isotopic production caused by errors in the fission cross section can be identified. Once again, the observed quantity of this error will increase with burnup so the trending analysis will seek a trend on the product of burnup times enrichment.

Knowing the specific power and burnup sets the irradiation time. For some isotopes their concentration depends on the competition of absorption and decay. Most isotopes produced in a reactor decay to their daughters in a time frame that is too short to be influenced by magnitude of the flux. Other isotopes have long half lives so that decay during irradiation is negligible. There are some exceptions. Xe-135 reaches an equilibrium concentration that depends on the level of the flux. A higher specific power will result in a slightly harder spectrum due to the Xe-135 content and the spectral index should catch this effect. Pm-149 content increases with higher specific power but it has a small cross section so does not affect the spectrum in the reactor but does affect the reactivity of spent fuel by higher Sm-149 content. This effect is ignored in actinide-only burnup credit. Np-238 concentration increases with specific power. Since Np-238 has a large absorption cross section, the increased concentration results in more absorption and hence less production of $\mathrm{Pu}-238$. One more isotope of concern is $\mathrm{Pu}-241$ which has a 14.4 year half life. A trend in isotopic concentration of $\mathrm{Pu}$ 238 with specific power would indicate an error in the absorption cross section of Np-238. A trend in the isotopic concentration of $\mathrm{Pu}-241$ indicates an error in the decay constant of $\mathrm{Pu}-241$ which is used in the actinide-only methodology for the production of Am-241. The magnitude of these errors depends on the burnup so a search for a trend on $\mathrm{Pu}-238$ and $\mathrm{Pu}-241$ as a function of burnup times specific power would be appropriate. It is inappropriate to seek a trend on specific power for any of the other actinides.

Only the four parameters; burnup, spectrum, enrichment, and specific power will be used to establish the range of applicability. Table 2-3 represents the range of applicability that can be supported by the data. Extrapolation of data range via trending analysis is permitted in ANSI/ANS-8.1 and is used here. In Table 2-3 the spectral index is given as the Average Lethargy of Absorption (ALA). Any spectral index is acceptable but this is the recommended parameter. Equation 2-2 below defines the ALA.

$$
A L A=\frac{\sum_{i=1}^{27} \Phi_{i} \Sigma_{i} \bar{u}_{i}}{\sum_{i=1}^{27} \Phi_{i} \Sigma_{i}}
$$

Where,

$$
\begin{aligned}
& \bar{u}_{i}=\text { average lethargy for group } \mathrm{i} \\
& \Phi_{i}=\text { the flux of the } \mathrm{i}^{\text {th }} \text { lethargy group } \\
& \Sigma_{i}=\text { the absorption cross section of the } \mathrm{i}^{\text {th }} \text { lethargy group }
\end{aligned}
$$


Table 2-3. Range of Applicability Matrix for Isotopic Validation

\begin{tabular}{|l|l|l|}
\hline \multicolumn{1}{|c|}{ Key Parameters } & \multicolumn{1}{c|}{$\begin{array}{c}\text { Range of 54 Benchmark } \\
\text { Experiments }\end{array}$} & \multicolumn{1}{c|}{ Range of Applicability } \\
\hline Burnup (GWd/MTU) & $6.9-46.46$ & $0-50$ \\
Spectrum* & $15.4-16.5$ & $15-17$ \\
$\begin{array}{l}\text { Initial Enrichment } \\
\text { (wt \% U-235) }\end{array}$ & $2.45-3.90$ & $0.71-5.0$ \\
Specific Power(MW/MTU) & $10.7-39.6$ & $0-60$ \\
\hline
\end{tabular}

*The spectral index is the Average Lethargy of Absorption with a reference energy of $20 \mathrm{Mev}$.

The ALA values calculated using Equation 2-2 for the 54 benchmarks range between 15.4 and 16.5. The data points around 15.6 belong to Yankee Rowe samples, which indicate a hard neutron spectrum. This is confirmed by the fact that the samples come from rods with smallest pitch and stainless steel cladding. All the data between 16 and 16.5 belong to samples which came from typical commercial PWR (Calvert Cliffs, H. B. Robinson, Obrigheim, etc.). Therefore, the 54 benchmarks considered for isotopic validation covers a wide range of neutron spectrum, and it even covers fuel with hard spectrum (Yankee Rowe) which are not usually seen among typical PWR.

\subsubsection{Qualification of Isotopic Measurement Data}

The radiochemical analyses of spent fuel isotopic composition samples from the Calvert Cliffs and H. B. Robinson reactors were analyzed by the MCC at PNL. The MCC is responsible for providing spent fuel Approved Testing Materials (ATMs) for radiochemical measurements conducted by PNL for the Department of Energy's Office of Civilian Radioactive Waste Management. The activities at PNL were performed according to QA procedures developed using the QA program, which included ASME/ANSI NQA-1 requirements.

Although the programs under which measurements on the samples from Obrigheirn, Trino Vercelles, Yankee Rowe, Turkey Point, and Mihama have not been performed under DOE CRWM QA program, the production and handling of radioactive materials, especially fissile materials, is heavily controlled by both national and international regulatory bodies. Detailed procedures and documentation are required for activities utilizing these materials. One of the primary purposes of a formal QA program is to establish written policies and procedures to ensure good scientific principles are utilized. The nature of material used in these studies (solutions containing fissionable materials) provides assurance that stringent requirements for formal procedures and documentation were imposed on the experiments. Further assurance of the technical quality of the test results on most of the samples is provided through multiple 
radiochemical analyses performed by independent laboratories. For example, fuel samples from the Obrigheim PWR in Germany were analyzed independently by four European laboratories; European Institute for Transuranic Elements, Institute for Radiochemistry, Karlsruhe Reprocessing Plant, and the International Atomic Energy Agency. The isotopic measurement for Trino Vercelles spent fuel were conducted by Ispara and Karlsruhe. The Yankee Rowe samples were analyzed by TRACELAB, GE-Vallecitos, and New Brunswick laboratories.

\subsubsection{Summary of Approval Requests on Isotopic Validation Data}

Section 2.2.1 described the results of the measurements for the selected actinides to be used in validation of depletion computer codes for burnup credit analysis. Section 2.2.2 provided the justification for the acceptability of the measurement data in terms of the range of applicability for the validation purposes. Based on the above discussions, acceptance of the measurement data, summarized in Table 2-1, for the selected actinides is requested.

\subsection{ISOTOPIC CALCULATIONAL BIAS AND UNCERTAINTIES}

Any validated depletion computer code can be used to perform isotopic depletion/generation for burnup credit. In order to validate the code, each of the 54 cases shown in Table 2-1 must be analyzed. The analysis technique must be the same as that which will be used for the burnup credit package analysis.

The requirement of using the same technique for both validation and package analysis is not expected to be very restrictive, but an example violation may help in understanding this requirement. In any depletion code an approximation of the energy distribution of the flux must be made. In a point depletion code, such as SAS2H, the geometric data that can be handled is limited so a general algorithm is set up and validated. The algorithm selected for assembly models performed for this study is:

1) Divide the assembly cross sectional area by the number of removable burnable absorber rods (or by the number of guide tubes plus one for the instrumentation tube if there are no burnable absorbers).

2) Model the assembly with concentric rings to preserve the volume of each component of that fraction of the assembly.

3) The central rings will be related to the cell associated with a burnable absorber (or a guide tube). This would then be surrounded by the appropriate quantity of homogenized fuel cells. The next ring will contain the appropriate volume of guide tube cell material. The final ring will contain the assembly gap material.

The resulting energy spectrum of the flux is dependent on this algorithm. Although a number of the chemical assay points are taken from positions in the assembly that are not well represented by this algorithm, it is inappropriate to use a different algorithm for the assembly and point calculation. Hence, a violation of the modeling requirement would result if the analyst attempts to model a chemical assay by rings around the particular assayed pellet. If a $2 \mathrm{D}$ computer code such as CASMO, PHOENIX, or HELIOS is used, data can be obtained from the appropriate point in the assembly 
without modifying the assembly homogenization algorithm. With that type of code the actual energy spectrum associated with the chemical assay point can be used in the validation process.

After the isotopic inventory for the 54 benchmarks are calculated, a statistical method is used, to determine the bias along with the uncertainties in terms of a set of correction factors. These correction factors are then used to adjust the future isotopic values calculated by the code for which the correction factors were developed. The following subsections present the statistical method to be used in developing the correction factors.

\section{| 2.3.1 Definition of the Bias}

Given the calculated and measured values for isotopic concentrations, this section defines a bias to be used for adjusting the calculated isotopic concentrations to the best estimate isotopic concentrations. The bias approach selected for isotopics is a multiplicative bias, $x$, which is the ratio of measured to calculated values. The bias and uncertainty are then used to determine a set of correction factors for adjusting the future isotopic values calculated by the particular code.

To use the bias in determining the correction factors by which the calculated isotopic values can be simply multiplied, the bias should be calculated in terms of the ratio between the measured and the calculated values:

$$
x=\frac{M}{C}
$$

where:

$$
\begin{aligned}
x & =\text { multiplicative bias } \\
\mathbf{M} & =\text { measured isotopic concentration value } \\
\mathbf{C} & =\text { calculated isotopic concentration value. }
\end{aligned}
$$

If multiple measurements are performed on a sample, the average of all the measurements were used for M. For example, for Obrigheim, Yankee Rowe, and Trino Vercelles average value of the multiple independent measurements were used for $M$.

The relationship between the measured-to-calculated ratio and the input parameters is assumed to be as follow:

$$
\mathrm{x}_{\mathrm{fit}}=(\mathrm{M} / \mathrm{C})_{\mathrm{fit}}=1 \cdot 0+\mathrm{b}_{1}{ }^{*} \mathrm{~B}+\mathrm{b}_{2}{ }^{*} \mathrm{~B} * \mathrm{~S}+\mathrm{b}_{3}{ }^{*} \mathrm{~B} * \mathrm{E}+\mathrm{b}_{4}{ }^{*} \mathrm{~B} * \mathrm{P} \quad \text { Eq. } 2-4
$$


where:

$$
\begin{aligned}
& x_{\text {fit }}=\text { predicted bias as a function of input parameters } \\
& B=\text { burnup } \\
& b_{1}=\text { slope for burnup } \\
& S=\text { a spectral index } \\
& b_{2}=\text { slope for burnup*spectrum } \\
& E=\text { initial enrichment } \\
& b_{3}=\text { slope for burnup*initial enrichment } \\
& P=\text { specific power } \\
& b_{4}=\text { slope for burnup*specific power }
\end{aligned}
$$

As seen, the burnup variable appears in each of the terms on the right side of the equation. This is because the degree of change on each of the independent variables is related to the level of burnup. The $\mathrm{x}_{\mathrm{fit}}$ value at zero burnup is one because the calculated value becomes the initial condition measured value if there is no burnup.

\subsubsection{Regression Analysis}

For simplicity, the slopes for each of the independent variables, $b_{1}, b_{2}, b_{3}, b_{4}$, are determined one by one sequentially and a test is performed to show whether the slopes are significant or not. For example, to determine $b_{1}$, equation $2-4$ is first assumed to be a function of burnup only.

$$
x_{\text {fit }}=1+b_{1}^{* B}
$$

Using the single-parameter regression model shown by Eq. $2-5$, the slope $b_{1}$ is determined. The value for $b_{1}$ is calculated by minimizing the following equation: ${ }^{2-14}$

$$
S S_{R}=\sum_{i=1}^{n}\left(x_{i}-1-b_{1} * B_{i}\right)^{2}
$$

where,

$\mathrm{n}=$ number of data points

$\mathrm{SS}_{\mathrm{R}}=$ the sum of the squares of differences

$x_{i}=$ measured-to-calculate value for the $i^{\text {th }}$ data point

$\mathrm{B}_{\mathrm{i}}=$ burnup value for the $\mathrm{i}^{\mathrm{ith}}$ data point

Setting partial derivative of $\mathrm{SS}_{\mathrm{R}}$ with respect to $\mathrm{b}_{1}$ to zero, and solving for $\mathrm{b}_{1}$ results in the following equation:

$$
b_{1}=\frac{\sum_{i=1}^{n} B_{i} * x_{i}-\sum_{i=1}^{n} B_{i}}{\sum_{i=1}^{n} B_{i}^{2}}
$$


Then a test is performed to determine if the value for parameter $b_{1}$ is significant. The null hypothesis in this test is $b_{1}=0$.

The test statistic is: $:^{2-9}$

$$
\mathrm{v}=\left|b_{1}\right| \sqrt{\frac{(n-1) \sum_{i=1}^{n} B_{i}^{2}}{S S_{R}}}
$$

After calculation of the test statistic, it is compared to the Student's t-value (found in Appendix A. 3 of Reference 2-15), for the particular sample size (i.e., n-1) and level of significance. The null hypothesis is justified if the calculated test statistic is less than the Student's t-value. The level of significance for this test has been selected at $95 \%$ confidence. Therefore, the trend will be rejected unless there is $95 \%$ confidence that the slope is not zero.

If the test indicates that the value is not significant, the burnup term is eliminated (i.e., $b_{1}=0$ ) and a regression with respect to burnup*spectral index is performed, with the intercept value still being one, and the value for $b_{2}$ is calculated similar to equation 2-7. This process is repeated and each time a test is performed to determine whether the value for the respective slope is significant or not.

If the trending test indicates the value for the slope associated with burnup is significant, the burnup term is kept in the equation, and Eq. 2-5 for burnup*spectral index becomes as follow:

$$
x_{\text {fit }}=1+b_{1}^{*} B+b_{2}^{*} B^{*} S
$$

The regression procedure, as before, calls for minimizing the following equation.

$$
S S_{R}=\sum_{i=1}^{n}\left(x_{i}-1-b_{1} * B_{i}-b_{2} * B_{i} * S_{i}\right)^{2}
$$

Taking the partial derivative of Eq. 2-10 with respect to $b_{2}$ and setting it equal to zero, yields the following equation.

$$
b_{2}=\frac{\sum_{i=1}^{n} B_{i} * S_{i} * x_{i}-\sum_{i=1}^{n} B_{i} * S_{i}-b_{1} * \sum_{i=1}^{n} B_{i} * S_{i} * B_{i}}{\sum_{i=1}^{n}\left(B_{i} * S_{i}\right)^{2}}
$$

As before, the trending test is applied to $b_{2}$. The trending test formula for $b_{2}$ turns out to be similar to Equation 2-8 for testing $b_{1}$ except $b_{1}$ and $B_{i}$ are replaced with $b_{2}$ and $B_{i}{ }^{*} S_{i}$.

Again, if the trending test indicates the value for the slope associated with burnup*spectral index is significant, the burnup*spectral index term is kept in the equation, and Eq. 2-9 becomes as follow: 


$$
\mathrm{x}_{\mathrm{fit}}=1+\mathrm{b}_{1}{ }^{*} \mathrm{~B}+\mathrm{b}_{2}{ }^{*} \mathrm{~B} * \mathrm{~S}+\mathrm{b}_{3}{ }^{*} \mathrm{~B}^{*} \mathrm{E}
$$

As before, in order to determine $b_{3}$, the sum of the squares of the residuals which is:

$$
S S_{R}=\sum_{i=1}^{n}\left(x_{i}-1-b_{1} * B_{i}-b_{2} * B_{i} * S_{i}-b_{3} * B_{i} * E_{i}\right)^{2}
$$

is minimized by setting the partial derivative of Eq. 2-13 with respect to $b_{3}$ to zero. This results in the following equation for $b_{3}$.

$$
b_{3}=\frac{\sum_{i=1}^{n} B_{i} * E_{i} * x_{i}-\sum_{i=1}^{n} B_{i} * E_{i}-b_{1} * \sum_{i=1}^{n} B_{i} * E_{i} * B_{i}-b_{2} * \sum_{i=1}^{n} B_{i} * E_{i} * B_{i} * S_{i}}{\sum_{i=1}^{n}\left(B_{i} * E_{i}\right)^{2}}
$$

The trending test formula for $b_{3}$ is again similar to Equation 2-8 for testing $b_{1}$; but with replacement of the appropriate parameters, which in this case are $b_{3}$ and $B_{i}{ }^{*} E_{i}$. If the test indicates the value of $b_{3}$ is significant, Equation 2-4 becomes the final equation with $b_{1}, b_{2}$, and $b_{3}$ values given by Equations 2-7, 2-11, and 2-14. However, for Pu-238 and Pu-241, trending analysis with respect to a fourth parameter, burnup*specific power is also performed using a similar procedure to that above. The Equation for $b_{4}$ can be determined by inspecting Equation 2-7, 2-11, and 2-14. The test statistic for testing $b_{4}$ is similar to Equation 2-8, but with $b_{4}$ and $B_{i}{ }^{*} P_{i}$ as the independent variables.

\subsubsection{Correction Factors}

Having established the trends associated with the isotopic data, the correction factor for each isotope can now be determined. The correction factor for each isotope is determined to assure that the isotopic concentration is conservative. This implies adding an appropriate uncertainty to the fissile isotopes and subtracting the uncertainty in the absorber isotopes. The appropriate uncertainty is found using the prediction interval technique. This technique establishes an interval around the mean prediction in which there is $95 \%$ confidence that the next observation will be within the interval. For this application only one side of the interval is of interest. Therefore, the uncertainty is established in a way that there is a $95 \%$ confidence that the next observation being above (absorbers) or below (fissile isotopes) the corrected isotopic concentration.

The correction factor for those isotopes which do not exhibit any trends is: $:^{2-16}$

$$
f=1.0 \pm \hat{\sigma} t_{95, n-1} \sqrt{1+1 / n}
$$


where,

$$
\hat{\sigma}=\sqrt{\frac{1}{n-1} \sum_{i=1}^{n}\left(x_{i}-1\right)^{2}}
$$

and $t_{95, n-1}$ is the Student- $t$ value for $95 \%$ confident with $n-1$ data points. The sign between the bias and the total uncertainty depends on the type of isotope. For positive worth isotopes the correction factor is calculated by adding 1.0 to the total uncertainty as follow:

$$
f_{b u c}=f_{p o s}=1.0+\hat{\sigma} t_{95, n-1} \sqrt{1+1 / n}
$$

The correction factors for negative worth isotopes (neutron absorbers) are calculated in a similar but converse manner.

$$
f_{b u c}=f_{\text {neg }}=1.0-\hat{\sigma} t_{\mathrm{gs,n-1}} \sqrt{1+1 / n}
$$

The generic correction factor formula for isotopes which exhibit trends with respect to one or more of the four parameters (burnup, burnup*spectrum, burnup*initial enrichment, and burnup*specific power) is also determined based on prediction interval. Therefore, the $95 \%$ confidence correction factor is:

$$
f=1.0+\sum_{j=1}^{m} b_{j} * H_{j} \pm t_{95, n-m} \sqrt{\left(1+\frac{\sum_{j=1}^{m} H_{j}^{2}}{\sum_{i=1}^{n} H_{j i}}\right) \frac{S S_{R}}{n-m}}
$$

where:

$m=$ number of parameters $(1,2,3$, or 4$)$ against which the specific isotope exhibited trends $b_{j}=$ slope for the trending parameter

$\mathrm{H}_{\mathrm{j}}=$ trending parameter (burnup, burnup*spectral index, burnup*initial enrichment, or burnup*specific power)

$$
S S_{R}=\sum_{i=1}^{n}\left(x_{i}-1-\sum_{j=1}^{m} b_{j} * H_{j}\right)^{2}
$$

$\mathbf{n}=$ number of data points

Similar to the non-trended case, the sign between the bias and the total uncertainty depends on the type of isotope. Furthermore, a level of conservatism is added to this process by ignoring the correction factor when its value is below unity. Hence, for a positive worth isotope whose calculated isotopic concentration is greater than the measured value, the calculated value is not 
lowered (i.e., $f=1.0$ ). This would ensure that the maximum amount of positive worth isotopes is included in the criticality calculations. Based on this conservatism, the correction factor for positive worth isotopes which exhibit trends with respect to one or more of the four parameters is:

$$
f_{b u c}=f_{p o s}=\max \left[1.0+\sum_{j=1}^{m} b_{j} * H_{j}+t_{95, n-m} \sqrt{\left(1+\frac{\sum_{j=1}^{m} H_{j}^{2}}{\sum_{i=1}^{n} H_{j i}}\right) \frac{S S_{R}}{n-m}}, 1.0\right]
$$

The correction factors for negative worth, non-trended isotopes are calculated by subtracting the total uncertainty from the bias term represented by a linear equation. The conservative assumption on disallowing any compensating effects is considered by setting the correction factor equal to unity if the calculated correction factor is greater than one. This approach ensures that the future calculated inventory for negative worth isotopes is not increased if the chemical assay indicated a higher measured value than the corresponding calculated value. Therefore, the correction factor for negative worth isotopes which exhibit trends with respect to one or more of the four parameters is:

$$
f_{b u c}=f_{n e g}=\min \left[1.0+\sum_{j=1}^{m} b_{j} * H_{j}-t_{95, n-m} \sqrt{\left(1+\frac{\sum_{j=1}^{m} H_{j}^{2}}{\sum_{i=1}^{n} H_{j i}}\right) \frac{S S_{R}}{n-m}}, 1.0\right]
$$

\subsubsection{Summary of Approval Requests for Isotopic Calculational Methodology}

Section 2.3 describe methodology requirements for performing fuel depletion calculations and presented a statistical approach for calculating biases, uncertainties, and correction factors, based on calculated and measured isotopic values that can be used to bias future calculated isotopic values. Therefore, Section 2.3 of this topical report seeks the NRC acceptance of the methodology for fuel depletion calculation and the proposed statistical approach in calculating biases, uncertainties, and correction factors.

\subsection{DEMONSTRATION WITH SCALE 4.2 AND 27BURNUPLIB CROSS SECTIONS}

The computational tool used to demonstrate the isotopic validation methodology, described in Sections 2.1 through 2.3 , is the SAS2H calculational sequence from the SCALE 4.2 computer code package with the 27BURNUPLIB cross section library. ${ }^{2-13}$ SAS2H/27BURNUPLIB invokes 
a series of cross section processing codes and a 1-D transport cell model that allows problem-specific (assembly type including water holes) cross sections to be used as a function of burnup. The core of the calculational sequence is the ORIGEN-S point depletion/decay code. ORIGEN-S requires nuclide data such as cross section data, fission product yields, decay data, and branching fractions (the probability associated with a particular mode of decay). ORIGEN-S also requires system data such as initial fuel composition, fuel geometry, and the operating history of the fuel (e.g., specific power, exposure time, and down time). Nuclide data are supplied to ORIGEN-S by libraries within the SCALE system, while the system data are problem specific and user specified. As the calculation proceeds through the exposure history, cross section data are updated by the 1-D transport code based on revised (as calculated by ORIGEN-S) isotopic concentrations to capture the effects of shifts in the energy spectrum. The output of such a calculation provides the calculated isotopic concentration for user-specified nuclides. SAS2H modeling details for each experiment are described in References 2-9, 2-10, and 2-11. Table 2-1 provides the calculated values for each of the measured isotopic samples.

Based on the methodology described in Sections 2.3.1 through 2.3.3 and the data provided in Table 2-1, trending analyses were performed for the nine isotopes with respect to burnup, burnup*spectrum, and burnup*enrichment. Trending test with respect to burnup*specific power was performed only for Pu-238 and Pu-241. The results of trending analyses for U-234, U-236, $\mathrm{U}-238$, and $\mathrm{Pu}-238$ did not indicate any trends with any of the parameters. However, $\mathrm{U}-235, \mathrm{Pu}-$ 239, $\mathrm{Pu}-240, \mathrm{Pu}-241$, and $\mathrm{Pu}-242$ exhibited trends with respect to burnup only. Since the Am241 correction factor is determined based on $\mathrm{Pu}-241$, a correction factor with the same burnup trend is assigned to Am-241 (of course, the sign for the uncertainty term changes). The correction factor equations for those parameters which exhibited trends with respect to burnup (in GWd/MTU) is provided in the following.

$$
f_{b u c}^{U-235}=\max \left[1.0+0.00103 * B+1.6741 \sqrt{\left(1.0+\frac{B^{2}}{41086}\right) \frac{0.05543}{54-1}}, 1.0\right]
$$

1

$$
f_{b u c}^{P u-239}=\max \left[1.0-0.00067 * B+1.6741 \sqrt{\left(1.0+\frac{B^{2}}{41086}\right) \frac{0.10832}{54-1}}, 1.0\right]
$$

$$
\left\{\begin{array}{l}
f_{b u c}^{P u-240}=\min \left[1.0+0.00225 * B-1.6741 \sqrt{\left(1.0+\frac{B^{2}}{41086}\right) \frac{0.02674}{54-1}}, 1.0\right] \\
f_{b u c}^{P u-241}=\max \left[1.0-0.00103 * B+1.6741 \sqrt{\left(1.0+\frac{B^{2}}{41086}\right) \frac{0.1172}{54-1}}, 1.0\right]
\end{array}\right.
$$


$f_{b u c}^{P u-242}=\min \left[1.0+0.00300 * B-1.6766 \sqrt{\left(1.0+\frac{B^{2}}{38450}\right) \frac{0.2276}{50-1}}, 1.0\right]$

$f_{b u c}^{A m-241}=\min \left[1.0-0.00103 * B-1.6741 \sqrt{\left(1.0+\frac{B^{2}}{41086}\right) \frac{0.1172}{54-1}}, 1.0\right]$

Table 2-4 provides the mean biases, uncertainties, and the correction factors $\left(f_{\text {buc }}\right)$ for each selected actinide. The $f_{\text {buc }}$ values are the only numbers that should be used in adjusting the calculated values for selected actinides, representing spent fuel composition, when performing burnup credit criticality analyses. The adjustment is performed by multiplying the number density for each of the selected actinide isotopes by the corresponding correction factor. This table is valid only with use of the SAS2H/27BURNUPLIB of SCALE 4.2 computer code system. A similar table should be generated if another code system or cross section set is selected.

\subsection{SUMMARY OF ISOTOPIC VALIDATION}

In this chapter three main components of isotopic validation were discussed: 1) the experimental data, 2) validation methodology, and 3) validation of SAS2H/27BURNUPLIB of the SCALE 4.2 computer code package. It is the purpose of this chapter to seek the acceptance of these three components of the isotopic validation.

The experimental data component presented in Section 2.2 was developed by performing chemical assays on selected rods from many spent fuel assemblies. The data cover a wide range of the parameters important to isotopic concentrations during fuel depletion in reactors. The validation methodology consists of best-estimate analysis for determining isotopic concentrations computationally, and the statistical approach in determining biases, uncertainties, and correction factors. The above validation methodology was demonstrated using the experimental data and SAS2H/27BURNUPLIB of the SCALE 4.2 computer code package. Using this specific code, data, and methodology, a set of isotopic correction factors was developed that can be used directly in modifying future calculated inventory of the selected actinides.

Therefore, this section requests acceptance of the chemical assay data for the selected actinides as summarized in Table 2-1, the method for calculating isotopic correction factors for the selected actinides, and the use of SAS2H/27BURNUPLIB as a computational tool in calculating the quantity of the selected actinides in spent fuel assemblies. 
Table 2-4. Bias, Uncertainty, and Isotopic Correction Factors for Burnup Credit Nuclides for Use with SCALE 4.2 and 27BURNUPLIB Analyses

\begin{tabular}{|c|c|c|c|c|c|}
\hline Isotope & $n$ & $\begin{array}{c}\text { Mean } \\
\text { Bias }\end{array}$ & Uncertainty & $f$ & $f_{b u c}$ \\
\hline $\mathrm{U}-234$ & 25 & 1.000 & 0.186 & 0.814 & 0.814 \\
\hline$*$ U-235 & 54 & 1.031 & 0.055 & 1.086 & 1.086 \\
\hline U-236 & 53 & 1.000 & 0.065 & 0.935 & 0.935 \\
\hline U-238 & 48 & 1.000 & 0.009 & 0.991 & 0.991 \\
\hline $\mathrm{Pu}-238$ & 40 & 1.000 & 0.137 & 0.863 & 0.863 \\
\hline${ }^{*} \mathrm{Pu}-239$ & 54 & 0.980 & 0.076 & 1.056 & 1.056 \\
\hline${ }^{*} \mathrm{Pu}-240$ & 54 & 1.068 & 0.038 & 1.030 & 1.000 \\
\hline${ }^{*} \mathrm{Pu}-241$ & 54 & 0.970 & 0.079 & 1.049 & 1.049 \\
\hline$* \mathrm{Pu}-242$ & 50 & 1.090 & 0.116 & 0.974 & 0.974 \\
\hline${ }^{*} \mathrm{Am}-241^{* *}$ & N/A & 0.970 & 0.079 & 0.889 & 0.889 \\
\hline
\end{tabular}

*Evaluated at $30 \mathrm{Gwd} / \mathrm{MTU}$

**Since the vast majority of Am-241 is created after shutdown by Pu-241, Am-241 was biased based on Pu-241

Note: The mean bias for isotopes without a trend is 1.0 by definition. The mean of the samples for U-234, U-236, U-238, and Pu-238 are 0.971, 0.9998, 1.000977, 1.010087, respectively. 


\section{CRITICALITY VALIDATION}

The design of spent fuel packages using burnup credit imposes unique requirements for criticality analysis method validation. Many components of the burnup credit criticality analysis method proposed in this topical report have been widely used in the design and licensing of conventional transportation and storage system packaging using the fresh fuel assumption. These methods must be shown to be valid for use in burnup credit applications. American National Standards ANSI/ANS-8.1 $1^{3-1}$ and $8.17^{3-2}$ provide criteria for nuclear criticality safety in away-from-reactor spent fuel handling, storage, and transportation activities. ANSI/ANS-8.1 applicability is specifically focused on criteria for validating analysis methodologies. Validation consistent with ANSI/ANS-8.1 requires:

- Use of "adequate" calculational techniques and nuclear data

- Correlation of analytical results with experimental data to establish analysis method bias

- Establishment of reactivity margin consistent with uncertainties.

ANSI/ANS-8.1 also requires documentation of validation results and allows for the use of trends to extend the criticality analysis method bias beyond the range of experiment conditions evaluated to establish the bias. The burnup credit criticality analy is validation described in this report follows the guidance provided in ANSI/ANS 8.1 and 8.17.

The criticality analysis method validation process described in this chapter is intended to be generically applicable to any criticality analysis code system. Criticality analysis validation is accomplished primarily through correlation of analytical results to benchmark critical experiments for systems containing $\mathrm{UO}_{2}$ and mixed oxide fuel (MOX). A representative set of benchmark experiments suitable for use in burnup credit method validation is presented and a procedure for combining benchmark calculation results and deriving a subcritical safety limit is described.

The validation process is demonstrated with specific codes and nuclear data libraries. Criticality analysis calculational techniques and nuclear data used in this chapter are included in Version 4.2 of the SCALE modular code system. ${ }^{3-3}$ SCALE is a well-established code system that has been used widely in away-from-reactor applications for criticality safety analyses via its CSAS (Criticality Safety Analysis Sequence) analysis sequences. CSAS sequences invoke standardized procedures to provide appropriate neutron cross sections for use in criticality $\left(\mathrm{k}_{\text {eff }}\right)$ calculations. Cross section processing is performed by the SCALE 4.2 NITAWL-II and BONAMI modules. Where specific problems require cell-weighting of cross sections prior to the criticality calculation, the CSAS2X sequence is used in which the 1-D discrete ordinates code XSDRNPM is invoked. Criticality calculations are performed via three-dimensional (3-D) Monte Carlo calculations using KENO V.a. The CSAS sequences, and the 27BURNUPLIB neutron cross section library (henceforth referred to as the CSAS/27BURNUPLIB code systems), are used to demonstrate the generic validation process. 
In summary, this chapter presents, for review and approval, a generic validation methodology for actinide-only burnup credit criticality calculational methods. The validation methodology includes: 1) the selection of a set of benchmark critical experiments for spent nuclear fuel package design, 2) the trending analyses of the calculated multiplication factors against selected parameters, and 3) the determination of an acceptance criterion for the calculated maximum value of $k_{\text {eff }}$ referred to as an upper safety limit. Based on the validation results presented in this chapter, the review and approval of the validation of the CSAS/27BURNUPLIB code system for actinide-only burnup credit are requested.

\subsection{CRITICALITY VALIDATION DATA}

Current practice for validating criticality safety computational methods relies primarily on measured data from well characterized critical experiments using fresh fuel. Available benchmark data include a diverse set of low-enrichment heterogeneous rod lattice systems designed to test computational method capabilities over a wide range of parameters important to criticality safety. A large number of $\mathrm{UO}_{2}$ critical experiments have been performed that are useful in validating specific non-burnup related parameters, such as variations in rod pitch, moderation, presence of soluble neutron absorbers, reflector effects, and external fixed and integral neutron absorbers. Criticality benchmark experinents containing MOX fuel are also available for validating the effect of higher order actinides cu spent nuclear fuel system reactivity.

\subsubsection{Validation Experiments}

Burnup credit criticality analysis methods proposed for use in spent nuclear fuel package design should be validated against a diverse set of critical experiments covering the range of design features and operating conditions anticipated for the specific package design application. A reference set of

157 critical experiments has been selected to demonstrate the generic validation methodology. This generic reference set of experiments measures method accuracy over a wide range of conditions for systems containing low enrichment, fresh fuel rod lattices similar to light water reactor fuel 1 assemblies. The experiment set includes $19 \mathrm{UO}_{2}, 2 \mathrm{UO}_{2}$-Gadolinium, and $36 \mathrm{MOX}$ configurations. A brief description of the experiments and effective neutron multiplication factor $\left(\mathrm{k}_{\mathrm{eff}}\right)$ results calculated using the CSAS/27BURNUPLIB code system are presented in Table 3-1. More detailed

information can be found in the original references listed or the technical reports generated in I support of this project. ${ }^{3-15,3-16}$

\subsubsection{1 $\mathrm{UO}_{2}$ Fuel Critical Experiments}

The $19 \mathrm{UO}_{2}$ critical experiments from 8 references are selected to examine 6 different aspects of spent nuclear fuel package criticality:

- Neutron interaction between PWR type fuel assemblies

- Effectiveness of neutron flux traps between fuel assemblies

- Effect of voiding on the effectiveness of flux traps 
- Effectiveness of neutron absorber plates and rods to reduce interaction between fuel assemblies

- Reactivity effect of commonly used package shielding materials

- Neutron spectra shift or relative neutron moderation caused by dissolved boron.

Table 3-1 lists the experiments and their distinctive characteristics as related to the aspects of criticality listed above. The experiments are water moderated and reflected, unless otherwise noted.

The experiments included in the $\mathrm{UO}_{2}$ experiment subset are typical of experiments used in fresh fuel assumption package applications. The specific experiments included in this subset were selected to cover a broad range of features found in SNF package designs. Five experiments are specifically included as comparison cases for $\mathrm{UO}_{2}$-Gadolinium and $\mathrm{MOX}$ experimental arrangements to identify potential trends. The $\mathrm{UO}_{2}$ subset is designed to provide a comprehensive test of the neutronics calculational ability. The specific $\mathrm{UO}_{2}$ experiments included in Table 3-1 are proposed as an integral component of the generic reference set of 57 critical experiments. However, specific package design applications may not incorporate features included in the $\mathrm{UO}_{2}$ subset (e.g., depleted uranium shielding) or may incorporate features not included in the subset (e.g., hafr.ium supplemental absorber materials). Package designers should confirm that the generic reference set covers the significant criticality control package design features prior to applying the $\mathrm{UO}_{2}$ subset without modification.

\subsubsection{2 $\mathrm{UO}_{2}$-Gadolinium Critical Experiments}

Spent fuel contains significant neutron absorbing isotopes that result in "hardening" of the neutron spectrum relative to nuclear fuel systems containing fresh fuel only. The spectrum hardening, or the increase in average neutron energy, results from increased competition for thermal neutrons within the system due to the presence of fission product and higher order actinide neutron absorbers, which are not present in fresh fuel systems. The addition of large thermal neutron absorption cross section isotopes, such as $\mathrm{Gd}-155$, in significant concentrations integral with the $\mathrm{UO}_{2}$ fuel matrix, can also result in hardening of the neutron spectrum relative to pure $\mathrm{UO}_{2}$ systems of comparable initial enrichment. Therefore, the $\mathrm{UO}_{2}$-gadolinium critical experiments are included in the set of critical experiments to account for the effects that may arise because of neutron spectrum hardening in $\mathrm{UO}_{2}$ systems.

The two $\mathrm{UO}_{2}$-Gadolinium experiments are included in the reference set of benchmark experiments to provide criticality analysis method validation data for applications where significant absorbers are assumed present integral to the fuel matrix. Since these experiments represent fresh fuel with a small variation (inclusion of $\mathrm{Gd}_{2} \mathrm{O}_{3}$ ), they are considered part of the $\mathrm{UO}_{2}$-only subset. These experiments are applicable to any analysis that references this topical report as a basis for actinideonly burnup credit criticality analysis method validation. 
Table 3-1. Critical Benchmark Experiments for Burnup Credit Method Validation with CSAS/27BURNUPLIB Calculated Results

\begin{tabular}{|c|c|c|c|c|c|c|}
\hline Experiment Case & $\begin{array}{c}\text { Enrichment } \\
\text { U.235 } \\
\text { (wt \%) } \\
\end{array}$ & Description & $\begin{array}{l}\text { Original } \\
\text { Reference }^{1}\end{array}$ & $\begin{array}{c}\text { Lattice } \\
\text { Water/Fuel } \\
\text { Volume } \\
\end{array}$ & $\mathrm{AlLA}^{2}$ & $k_{\text {arf }} \pm$ std. dev. \\
\hline \multicolumn{7}{|c|}{ LWR UO, Fuel Pin Lattices - 19 Experiments } \\
\hline $\begin{array}{l}\text { Absorber plates: } \\
\text { Experiment } 1 \\
\text { Experiment } 2 \\
\text { Experiment } 3 \\
\text { Experiment } 4 \\
\end{array}$ & $\begin{array}{l}2.35 \\
2.35 \\
2.35 \\
2.35 \\
\end{array}$ & $\begin{array}{l}\text { Exp. 005: No Absorber }\left(\mathrm{H}_{2} \mathrm{O}\right) \\
\text { Exp. 017: Boral } \\
\text { Exp. 024: Aluminum plates } \\
\text { Exp. 028: Stainless steel }\end{array}$ & $\begin{array}{l}\text { Ref. 3-4 } \\
\text { Ref. 3-4 } \\
\text { Ref. 3-4 } \\
\text { Ref. 3-4 } \\
\end{array}$ & $\begin{array}{l}2.92 \\
2.92 \\
2.92 \\
2.92 \\
\end{array}$ & $\begin{array}{l}19.0 \\
18.9 \\
19.0 \\
19.0 \\
\end{array}$ & $\begin{array}{l}0.9908 \pm 0.0013 \\
0.9930 \pm 0.0010 \\
0.9925 \pm 0.0014 \\
0.9936 \pm 0.0014 \\
\end{array}$ \\
\hline $\begin{array}{l}\text { Reflecting walls: } \\
\text { Experiment } 5 \\
\text { Experiment } 6 \\
\text { Experiment } 7 \\
\end{array}$ & $\begin{array}{l}4.31 \\
4.31 \\
4.31 \\
\end{array}$ & $\begin{array}{l}\text { Uranium walls } \\
\text { Lead walls } \\
\text { Steel walls } \\
\end{array}$ & $\begin{array}{l}\text { Ref. 3-5 } \\
\text { Ref. 3-5 } \\
\text { Ref. 3-6 } \\
\end{array}$ & $\begin{array}{l}1.60 \\
1.60 \\
1.60 \\
\end{array}$ & $\begin{array}{l}17.4 \\
18.2 \\
17.9 \\
\end{array}$ & $\begin{array}{c}. \\
0.9980 \pm 0.0016 \\
0.9978 \pm 0.0016 \\
0.9979 \pm 0.0016 \\
\end{array}$ \\
\hline $\begin{array}{l}\text { Soluble Boron: } \\
\text { Experiment } 8 \\
\text { Experiment } 9 \\
\text { Experiment } 10 \\
\text { Experiment } 11 \\
\end{array}$ & $\begin{array}{l}4.31 \\
4.31 \\
4.31 \\
4.31 \\
\end{array}$ & $\begin{array}{l}\text { Exp. 173: no boron } \\
\text { Exp. 177: } 2550 \text { ppmb } \\
\text { Exp. 178: no boron } \\
\text { Exp. 181: } 2550 \text { ppmb } \\
\end{array}$ & $\begin{array}{l}\text { Ref. 3-7 } \\
\text { Ref. 3-7 } \\
\text { Ref. 3-7 } \\
\text { Ref. 3-7 } \\
\end{array}$ & $\begin{array}{l}1.59 \\
1.59 \\
1.09 \\
1.09 \\
\end{array}$ & $\begin{array}{l}18.3 \\
17.3 \\
17.7 \\
16.7 \\
\end{array}$ & $\begin{array}{l}0.9947 \pm 0.0011 \\
0.9937 \pm 0.0012 \\
0.9950 \pm 0.0011 \\
0.9831 \pm 0.0013 \\
\end{array}$ \\
\hline $\begin{array}{l}\text { Flux traps: } \\
\text { Experiment } 12 \\
\text { Experiment } 13\end{array}$ & $\begin{array}{l}4.31 \\
4.31\end{array}$ & $\begin{array}{l}\text { Exp. 214R: flux traps } \\
\text { (no voids) } \\
\text { Exp. 214V3: flux traps } \\
\text { (with voids) } \\
\end{array}$ & $\begin{array}{l}\text { Ref. 3-8 } \\
\text { Ref. 3-8 }\end{array}$ & $\begin{array}{l}1.60 \\
1.60\end{array}$ & $\begin{array}{l}17.5 \\
17.4\end{array}$ & $\begin{array}{l}0.9943 \pm 0.0016 \\
0.9933 \pm 0.0010\end{array}$ \\
\hline $\begin{array}{l}\mathrm{UO}_{2} \text { triangular } \\
\text { lattices: } \\
\text { Experiment } 14 \\
\text { Experiment } 15\end{array}$ & $\begin{array}{l}2.35 \\
2.35\end{array}$ & $\begin{array}{l}\text { EPRI MOX Comparison } \\
\text { EPRI MOX Comparison }\end{array}$ & $\begin{array}{l}\text { Ref. 3-11 } \\
\text { Ref. 3-11 }\end{array}$ & $\begin{array}{l}1.20 \\
3.69\end{array}$ & $\begin{array}{l}17.9 \\
19.2\end{array}$ & $\begin{array}{l}0.9909 \pm 0.0013 \\
0.9960 \pm 0.0013\end{array}$ \\
\hline $\begin{array}{l}\mathrm{UO}_{2} \text { square } \\
\text { lattices: } \\
\text { Experiment } 16 \\
\text { Experiment } 17 \\
\text { Experiment } 18 \\
\end{array}$ & $\begin{array}{l}2.46 / 4.02 \\
5.74 \\
5.74 \\
\end{array}$ & $\begin{array}{l}\mathrm{UO}_{2} / \mathrm{Gd}_{2} \mathrm{O}_{3} \text { Comparison } \\
\text { SAXTON MOX Comparison } \\
\text { SAXTON MOX Comparison } \\
\end{array}$ & $\begin{array}{l}\text { Ref. 3-10 } \\
\text { Ref. 3-12 } \\
\text { Ref. 3-12 } \\
\end{array}$ & $\begin{array}{l}1.87 \\
1.93 \\
5.07 \\
\end{array}$ & $\begin{array}{l}17.5 \\
18.2 \\
19.2 \\
\end{array}$ & $\begin{array}{c}\cdot \\
0.9930 \pm 0.0011 \\
0.9931 \pm 0.0019 \\
0.9955 \pm 0.0012 \\
\end{array}$ \\
\hline $\begin{array}{l}3 \times 3 \text { assy arrays } \\
\text { w/absorbers: } \\
\text { Experiment } 19\end{array}$ & 2.46 & $\begin{array}{l}\text { Core IV: } 84 \mathrm{~B}_{4} \mathrm{C} \text { pins- } \\
1 \text { pitch between assemblies }\end{array}$ & Ref. 3-9 & 1.84 & 17.8 & $0.9898 \pm 0.0010$ \\
\hline & & UO,-Gadolinium & ttices - 2 Experime & & & \\
\hline $\begin{array}{l}\mathrm{UO}_{2} / \mathrm{Gd}_{4} \mathrm{O}, \text { fuel rods: } \\
\text { Experiment } 20 \\
\text { Experiment } 21\end{array}$ & $\begin{array}{l}1.94 / 2.46 / 4.02 \\
1.94 / 2.46 / 4.02 \\
\end{array}$ & $\begin{array}{l}\text { Core 14: } 12 \mathrm{Gd} \text { fuel rods } \\
\text { Core 16: } 16 \mathrm{Gd} \text { fuel rods }\end{array}$ & $\begin{array}{l}\text { Ref. 3-10 } \\
\text { Ref. 3-10 }\end{array}$ & $\begin{array}{l}1.88 \\
1.88 \\
\end{array}$ & $\begin{array}{l}17.5 \\
17.5 \\
\end{array}$ & $\begin{array}{l}0.9905 \pm 0.0011 \\
0.9923 \pm 0.0011\end{array}$ \\
\hline
\end{tabular}




\begin{tabular}{|c|c|c|c|c|c|c|}
\hline Experiment Case & $\begin{array}{c}\text { Eurichment } \\
\text { U.235 } \\
(\mathbf{w t} \%) \\
\end{array}$ & Description & $\begin{array}{c}\text { Original } \\
\text { Reference }^{1}\end{array}$ & $\begin{array}{c}\text { Lattice } \\
\text { Water/Fuel } \\
\text { Volume }\end{array}$ & $\mathbf{A L A}^{2}$ & $k_{\text {err }} \pm$ std. dev. \\
\hline \multicolumn{7}{|c|}{ LWR Mixed Oxide Criticals-36 Experiments } \\
\hline $\begin{array}{l}\text { EPRI } \\
\mathrm{UO}_{2} / \mathrm{PuO}_{2} \\
2 \mathrm{wt} \% \mathrm{PuO}_{2} \\
7.8 \mathrm{wt} \% \mathrm{Pu}-240: \\
\\
\text { Experiment } 22 \\
\text { Experiment } 23 \\
\text { Experiment } 24 \\
\text { Experiment } 25 \\
\text { Experiment } 26 \\
\text { Experiment } 27 \\
\end{array}$ & $\begin{array}{l}0.71 \\
0.71 \\
0.71 \\
0.71 \\
0.71 \\
0.71 \\
\end{array}$ & $\begin{array}{l}0.700 \text {-in. pitch, } 0 \text { ppmb } \\
0.700 \text {-in. pitch, } 688 \text { ppmb } \\
0.870 \text {-in. pitch, } 0 \text { ppmb } \\
0.870 \text {-in. pitch, } 1090 \text { ppmb } \\
0.990 \text {-in. pitch, } 0 \text { ppmb } \\
0.990 \text {-in. pitch, } 767 \text { ppmb } \\
\end{array}$ & $\begin{array}{l}\text { Ref. 3-11 } \\
\text { Ref. 3-11 } \\
\text { Ref. 3-11 } \\
\text { Ref. 3-11 } \\
\text { Ref. } 3-11 \\
\text { Ref. 3-11 } \\
\end{array}$ & $\begin{array}{l}1.20 \\
1.20 \\
2.53 \\
2.53 \\
3.64 \\
3.64 \\
\end{array}$ & $\begin{array}{l}17.5 \\
17.1 \\
18.6 \\
18.1 \\
18.9 \\
18.6 \\
\end{array}$ & $\begin{array}{l}0.9960 \pm 0.0014 \\
0.9977 \pm 0.0013 \\
1.0032 \pm 0.0011 \\
1.0050 \pm 0.0013 \\
1.0048 \pm 0.0014 \\
1.0073 \pm 0.0009 \\
\end{array}$ \\
\hline $\begin{array}{l}\mathrm{SAXTON} \\
\mathrm{UO}_{2} / \mathrm{PuO}_{2} \\
6.6 \mathrm{wt} \% \mathrm{PuO}_{2} \\
8.6 \mathrm{wt} \% \mathrm{Pu}-240: \\
\\
\text { Experiment } 28 \\
\text { Experiment } 29 \\
\text { Experiment } 30 \\
\text { Experiment } 31 \\
\text { Experiment } 32 \\
\text { Experiment } 33 \\
\end{array}$ & $\begin{array}{l}0.71 \\
0.71 \\
0.71 \\
0.71 \\
0.71 \\
0.71 \\
\end{array}$ & $\begin{array}{l}0.52 \text {-in. pitch } \\
0.56 \text {-in. pitch } \\
0.56 \text {-in. pitch, } 337 \text { ppmb } \\
0.735 \text {-in. pitch } \\
0.792 \text {-in. pitch } \\
1.04 \text {-in. pitch }\end{array}$ & $\begin{array}{l}\text { Ref. } 3-12 \\
\text { Ref. } 3-12 \\
\text { Ref. } 3-12 \\
\text { Ref. } 3-12 \\
\text { Ref. } 3-12 \\
\text { Ref. } 3-12 \\
\end{array}$ & \begin{tabular}{|l|}
1.68 \\
2.16 \\
2.16 \\
4.70 \\
5.67 \\
10.75 \\
\end{tabular} & $\begin{array}{l}17.5 \\
17.9 \\
17.7 \\
18.8 \\
19.0 \\
19.3 \\
\end{array}$ & $\begin{array}{l}1.0025 \pm 0.0012 \\
1.0035 \pm 0.0017 \\
0.9998 \pm 0.0016 \\
1.0046 \pm 0.0017 \\
1.0063 \pm 0.0017 \\
1.0076 \pm 0.0016 \\
\end{array}$ \\
\hline $\begin{array}{l}\text { PNL4976 } \\
\text { MOX and } \mathrm{UO}_{2} \\
2 \mathrm{wt} \% \mathrm{PuO}_{2} \\
7.9 \mathrm{wt} \% \mathrm{Pu}-240: \\
\text { Experiment } 34\end{array}$ & $\begin{array}{l}\text { MOX } 0.71 \\
\text { UO, 4.31 }\end{array}$ & $\begin{array}{l}\mathrm{MOX} \text { and } \mathrm{UO}_{2} \text { rods in } \\
\text { uniform pattern }\end{array}$ & Ref.3-13 & 0.49 & 15.5 & $0.9864 \pm 0.0012$ \\
\hline $\begin{array}{l}\mathrm{PUP} \\
\mathrm{UO}_{2} / \mathrm{PuO}_{2} \text { triangular } \\
2 \mathrm{wt} \% \mathrm{PuO}_{2} \\
8 \mathrm{wt} \% \mathrm{Pu}-240 \text { : } \\
\\
\text { Experiment } 35 \\
\text { Experiment } 36 \\
\text { Experiment } 37 \\
\text { Experiment } 38 \\
\text { Experiment } 39 \\
\text { Experiment } 40 \\
\end{array}$ & $\begin{array}{l}0.71 \\
0.71 \\
0.71 \\
0.71 \\
0.71 \\
0.71 \\
\end{array}$ & $\begin{array}{l}0.80 \text {-in lattice spacing } \\
0.93 \text {-in lattice spacing } \\
1.05 \text {-in lattice spacing } \\
1.143 \text {-in lattice spacing } \\
1.32 \text {-in lattice spacing } \\
\text { 1.386-in lattice spacing }\end{array}$ & $\begin{array}{l}\text { Ref. } 3-14 \\
\text { Ref. } 3-14 \\
\text { Ref. } 3-14 \\
\text { Ref. } 3-14 \\
\text { Ref. } 3-14 \\
\text { Ref. } 3-14 \\
\end{array}$ & $\begin{array}{l}1.211 \\
1.987 \\
2.808 \\
3.513 \\
5.019 \\
5.635 \\
\end{array}$ & \begin{tabular}{|l|}
17.9 \\
18.6 \\
18.9 \\
19.1 \\
19.3 \\
19.3 \\
\end{tabular} & $\begin{array}{l}0.9882 \pm 0.0010 \\
0.9960 \pm 0.0011 \\
0.9909 \pm 0.0010 \\
1.0003 \pm 0.0010 \\
1.0034 \pm 0.0010 \\
1.0005 \pm 0.0010 \\
\end{array}$ \\
\hline $\begin{array}{l}\mathrm{PUP} \\
\mathrm{UO}_{2} / \mathrm{PuO}_{2} \text { triangular } \\
2 \mathrm{wt}_{\mathrm{O}} \mathrm{PuO} \\
16 \mathrm{wt} \% \mathrm{Pu}-240:\end{array}$ & & 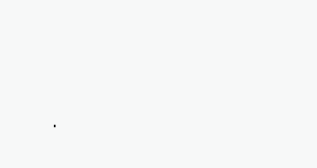 & 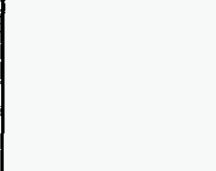 & & & 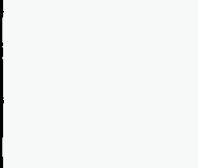 \\
\hline $\begin{array}{l}\text { Experiment } 41 \\
\text { Experiment } 42 \\
\text { Experiment } 43 \\
\text { Experiment } 44 \\
\end{array}$ & $\begin{array}{l}0.71 \\
0.71 \\
0.71 \\
0.71 \\
\end{array}$ & $\begin{array}{l}0.93 \text {-in lattice spacing } \\
1.05 \text {-in lattice spacing } \\
\text { 1.143-in lattice spacing } \\
1.32 \text {-in lattice spacing }\end{array}$ & $\begin{array}{l}\text { Ref. 3-14 } \\
\text { Ref. 3-14 } \\
\text { Ref. 3-14 } \\
\text { Ref. 3-14 }\end{array}$ & $\begin{array}{l}1.987 \\
2.808 \\
3.513 \\
5.019\end{array}$ & $\begin{array}{l}18.5 \\
18.8 \\
19.0 \\
19.2 \\
\end{array}$ & $\begin{array}{l}0.9997 \pm 0.0010 \\
0.9983 \pm 0.0010 \\
1.0032 \pm 0.0010 \\
1.0025 \pm 0.0009\end{array}$ \\
\hline
\end{tabular}


Table 3-1. Critical Benchmark Experiments for Burnup Credit Method Validation with CSAS/27BURNUPLIB Calculated Results (Continued)

\begin{tabular}{|c|c|c|c|c|c|c|}
\hline Experiment Case- & $\begin{array}{c}\text { Enrichment } \\
\text { U.235 } \\
\text { (wt \%) } \\
\end{array}$ & Description & $\begin{array}{c}\text { Original } \\
\text { Reference' }^{\prime}\end{array}$ & $\begin{array}{c}\text { Lattice } \\
\text { Water/Fuel } \\
\text { Volume } \\
\end{array}$ & $A L A^{2}$ & $k_{a} \pm$ std. dev. \\
\hline $\begin{array}{l}\mathrm{PUP} \\
\mathrm{UO}_{2} / \mathrm{PuO}_{2} \text { triangular } \\
2 \mathrm{wt} \% \mathrm{PuO}_{2} \\
24 \mathrm{wt} \% \mathrm{Pu}-240 \text { : } \\
\text { Experiment } 45 \\
\text { Experiment } 46 \\
\text { Experiment } 47 \\
\text { Experiment } 48 \\
\text { Experiment } 49 \\
\text { Experiment } 50\end{array}$ & $\begin{array}{l}0.71 \\
0.71 \\
0.71 \\
0.71 \\
0.71 \\
0.71\end{array}$ & $\begin{array}{l}0.80 \text {-in lattice spacing } \\
0.93 \text {-in lattice spacing } \\
\text { 1.05-in lattice spacing } \\
\text { 1.143-in lattice spacing } \\
1.32 \text {-in lattice spacing } \\
1.386 \text {-in lattice spacing }\end{array}$ & $\begin{array}{l}\text { Ref. 3-14 } \\
\text { Ref. 3-14 } \\
\text { Ref. 3-14 } \\
\text { Ref. 3-14 } \\
\text { Ref. 3-14 } \\
\text { Ref. 3-14 } \\
\end{array}$ & $\begin{array}{l}1.211 \\
1.987 \\
2.808 \\
3.513 \\
5.019 \\
5.635 \\
\end{array}$ & $\begin{array}{l}17.7 \\
18.4 \\
18.8 \\
19.0 \\
19.2 \\
19.2 \\
\end{array}$ & $\begin{array}{l}0.9902 \pm 0.0009 \\
0.9949 \pm 0.0009 \\
0.9985 \pm 0.0009 \\
1.0023 \pm 0.0009 \\
1.0051 \pm 0.0009 \\
1.0072 \pm 0.0009 \\
\end{array}$ \\
\hline $\begin{array}{l}\mathrm{PUP} \\
\mathrm{UO}_{2} / \mathrm{PuO}_{2} \text { triangular } \\
4 \mathrm{wt} \% \mathrm{PuO}_{2} \\
18 \mathrm{wt} \% \mathrm{Pu}-240 \text { : } \\
\\
\text { Experiment } 51 \\
\text { Experiment } 52 \\
\text { Experiment } 53 \\
\text { Experiment } 54 \\
\text { Experiment } 55 \\
\text { Experiment } 56 \\
\text { Experiment } 57\end{array}$ & $\begin{array}{l}0.71 \\
0.71 \\
0.71 \\
0.71 \\
0.71 \\
0.71 \\
0.71 \\
\end{array}$ & $\begin{array}{l}0.85 \text {-in lattice spacing } \\
0.93 \text {-in lattice spacing } \\
1.05 \text {-in lattice spacing } \\
1.143 \text {-in lattice spacing } \\
1.386 \text {-in lattice spacing } \\
1.60 \text {-in lattice spacing } \\
1.70 \text {-in lattice spacing }\end{array}$ & $\begin{array}{l}\text { Ref. } 3-14 \\
\text { Ref. 3-14 } \\
\text { Ref. 3-14 } \\
\text { Ref. 3-14 } \\
\text { Ref. } 3-14 \\
\text { Ref. 3-14 } \\
\text { Ref. 3-14 }\end{array}$ & $\begin{array}{l}1.500 \\
1.993 \\
2.815 \\
3.521 \\
5.647 \\
7.859 \\
9.000\end{array}$ & $\begin{array}{l}18.0 \\
18.4 \\
18.8 \\
19.0 \\
19.2 \\
19.4 \\
19.4\end{array}$ & $\begin{array}{c}\cdot \\
0.9982: 50.0010 \\
0.9945: \pm 0.0011 \\
1.0007: \pm 0.0011 \\
1.0007: 0.0011 \\
1.0082: 50.0010 \\
1.0086: 0.0009 \\
1.0096: 00.0009\end{array}$ \\
\hline
\end{tabular}

1 This table summarizes experiments analyzed and documents results provided in Reference 3-16.

12 Average Lethargy for Absorption (ALA). Used to assess relative energy spectra for each critical configuration.

\subsubsection{Mixed-Oxide Fresh Fuel Critical Experiments}

Spent fuel contains many actinides and fission products that are not present in fresh fuel. In addition to the U-235 and U-238 isotopes present in spent fuel, the set of burnup credit isotopes considered in this topical report includes other actinide isotopes that are important in the neutronics modeling of spent fuel systems. Important actinide isotopes include the fissile isotopes Pu-239 and Pu-241, and major neutron absorbing isotopes such as Pu-240. Although laboratory critical experiment measured $k_{\text {eff }}$ data are not available for irradiated nuclear fuel, experiments have been performed I with mixed oxide (MOX) fuel. Thirty-six MOX fuel critical experiments have been selected to use I for validating burnup credit analysis methodologies and are included in the benchmark set. Four sources of MOX critical experiments are used. In addition, four $\mathrm{UO}_{2}$ critical experiments are included from two of the MOX critical experiment series to identify any trends that may exist between $\mathrm{UO}_{2}$ and MOX fuel in similar configurations. ${ }^{3-11,3-12}$

1 The 36 MOX experiments are included in the reference set of benchmark experiments to provide criticality analysis method validation data for the selected actinide-only burnup credit isotopes. Since the $\mathrm{UO}_{2}$ and $\mathrm{UO}_{2}$-Gadolinium experiments provide benchmark data for U-235 and U-238 only, the MOX experiments are necessary to provide validation data for the other fissile and neutron 
absorbing actinide isotopes. The MOX experiments are applicable to any analysis that references this topical report as a basis for actinide-only burnup credit criticality analysis method validation.

\subsubsection{Range of Validation Experiment Conditions}

The range of material compositions and geometric arrangements representative of conditions expected in a spent fuel package must be characterized to establish requirements for the burnup credit criticality analysis method validation. Column 1 of Table 3-2 summarizes key criticality analysis parameters. The range of conditions that can be anticipated for spent fuel packages is provided in column 2 of the table. Two sets of critical experiments (i.e., $\mathrm{UO}_{2}$ and $\mathrm{MOX}$ ) from several experimental sources have been selected for burnup credit criticality analysis method validation. Column 3 of Table 3-2 provides the range of spent fuel composition and physical system characteristics that are covered by the critical experiments selected. The experiments cover a wide range of fuel compositions and anticipated spent fuel package physical conditions.

Validation of burnup credit criticality analysis methodologies requires consideration of a larger number of isotopes than is necessary with the fresh fuel assumption. In addition to the uranium in spent fuel, the set of burnup credit isotopes considered in this topical report include significant actinide isotopes. The set of $36 \mathrm{MOX}$ experiments selected provides the experimental measurement data necessary to validate burnup credit analysis method treatment of all $1 . \times$ actinide isotopes included in the methodology. The MOX fuel benchmark experiments are st. ungly influenced by the key fissile isotopes (U-235, $\mathrm{Pu}-239$, and $\mathrm{Pu}-241$ ) and major neutron absorbing isotopes (U-238 and $\mathrm{Pu}-240$ ). Figures 3-1 and 3-2 provide a comparison of fuel compositions for each MOX validation experiment series relative to spent fuel compositions for two levels of fuel burnup. The five key actinides listed above, in addition to U-234, Pu-238, Pu-242 and Am-241, are represented adequately in the MOX benchmarks. The concentrations of U-236 in the experiments are not comparable to the representative SNF values; nevertheless, it has been demonstrated that it is acceptable to include this isotope in criticality calculations due to good agreement in the chemical assays. $^{3-16}$

\subsubsection{Qualification of Data}

The critical experiments included in the generic reference set are recognized "benchmark standard" experiments performed specifically for reactor core design and criticality analysis method benchmarking purposes. Each experiment has been formally documented in reports issued by the organizations involved in the measurements. These reports were reviewed prior to publication, and have been further reviewed by their intended audience. Finally, the number of criticality calculations performed at the time of the experiments and subsequently by various organizations and individuals applying the data in validation work serves as a confirmation of the measurements under the specified conditions. Many of the $\mathrm{UO}_{2}$ benchmark experiments included in the reference set have been previously used and accepted for such purposes in numerous fresh fuel storage and transportation package design and licensing applications. In addition, the use of a comprehensive set of experimental data from a number of independent experimental facilities provides a high degree of assurance that potential inaccuracies, errors, or omissions in any one experiment or group of experiments will not significantly affect the overall criticality analysis method bias result derived from the application of the entire set of experimental data. 
Table 3-2. Areas of Applicability Matrix

\begin{tabular}{|c|c|c|}
\hline $\begin{array}{c}\text { Key } \\
\text { Parameters } \\
\end{array}$ & $\begin{array}{c}\text { Anticipated SNF Package } \\
\text { Conditions }\end{array}$ & 57 Critical Experiments \\
\hline \multicolumn{3}{|l|}{$\begin{array}{l}\text { Fuel Rod } \\
\text { Parameters }\end{array}$} \\
\hline $\begin{array}{l}\text { Fuel Composition } \\
\text { Isotopic Composition }\end{array}$ & Spent Fuel & $\begin{array}{llll}\text { U-234 } & \text { U-235 } & \text { U-236 } & \text { U-238 } \\
\text { Pu-238 } & \text { Pu-239 } & \text { Pu-240 } & \text { Pu-241 } \\
\text { Pu-242 } & \text { Am-241 } & & \end{array}$ \\
\hline Burnup & 0 to $56 \mathrm{GWd} / \mathrm{MTU}$ & Unirradiated $\mathrm{UO}_{2}$ and $\mathrm{MOX}$ fuel \\
\hline $\begin{array}{l}\text { Initial } \\
\text { enrichment } \\
\text { (wt. \% U-235) }\end{array}$ & 0.71 to $5.00 \%$ & $\begin{array}{l}\mathrm{UO}_{2}: 2.35 \text { to } 5.74 \% \\
\mathrm{UO}_{2}-\mathrm{Gd}_{2} \mathrm{O}_{3}: 1.94 \text { to } 4.02 \% \\
\mathrm{MOX}: 0.71 \text { to } 4.31 \%(\mathrm{wt} \% \mathrm{U}-235) \\
\\
\left.2 \text { to } 6.6 \% \text { (wt } \% \mathrm{PuO}_{2}\right)\end{array}$ \\
\hline Cooling Time & 5 to 100 Years & N/A \\
\hline $\begin{array}{l}\text { Euel Material Nuclear } \\
\text { Properties }\end{array}$ & & \\
\hline $\begin{array}{l}\text { Fuel } \\
\text { Temperature }\end{array}$ & $70^{\circ} \mathrm{F}$ & $70^{\circ} \mathrm{F}$ \\
\hline Fuel Material Form & $\begin{array}{l}\text { Fuel: Irradiated } \mathrm{UO}_{2} \\
\text { Cladding: Zircaloy } \\
\text { Stainless Steel }\end{array}$ & $\begin{array}{ll}\text { Fuel: } & \mathrm{UO}_{2} \\
& \mathrm{UO}_{2}-\mathrm{Gd}_{2} \mathrm{O}_{3} \\
& \mathrm{MOX} \\
\text { Cladding: } & \text { Zircaloy } \\
& \text { Stainless Steel } \\
& \text { Aluminum } \\
\end{array}$ \\
\hline Fuel Material Density & $\begin{array}{l}10.0 \text { to } 10.4 \mathrm{~g} / \mathrm{cm}^{3} \\
\text { ( } 91 \% \text { to } 95 \% \text { of theoretical } \\
\text { density) }\end{array}$ & $\begin{array}{l}\mathrm{UO}_{2}: 9.2 \text { to } 10.4 \mathrm{~g} / \mathrm{cm}^{3} \\
\mathrm{UO}_{2}-\mathrm{Gd}_{2} \mathrm{O}_{3}: 9.5 \text { to } 10.2 \mathrm{~g} / \mathrm{cm}^{3} \\
\text { MOX: } 9.5 \text { to } 10.4 \mathrm{~g} / \mathrm{cm}^{3}\end{array}$ \\
\hline $\begin{array}{l}\text { Fuel Rod } \\
\text { Geometry }\end{array}$ & & $\begin{array}{l}\text { Square and triangular lattices, } \\
\text { heterogeneous }\end{array}$ \\
\hline & $\begin{array}{l}0.71 \text { to } 0.99 \mathrm{~cm} \text { pellet dia } \\
0.005 \text { to } 0.017 \mathrm{~cm} \text { gap } \\
0.79 \text { to } 1.12 \mathrm{~cm} \text { cladding OD }\end{array}$ & $\begin{array}{l}0.86 \text { to } 1.28 \mathrm{~cm} \text { pellet dia } \\
0 \text { to } 0.009 \mathrm{~cm} \text { gap } \\
0.99 \text { to } 1.44 \mathrm{~cm} \text { cladding } \text { OD }\end{array}$ \\
\hline Fuel rod spacing & 1.07 to $1.47 \mathrm{~cm}$ pitch & $\begin{array}{l}\mathrm{UO}_{2}: 1.42 \text { to } 2.21 \mathrm{~cm} \text { pitch } \\
\mathrm{UO}_{2}-\mathrm{Gd}_{2} \mathrm{O}_{3}: 1.64 \mathrm{~cm} \text { pitch } \\
\mathrm{MOX}: 1.32 \text { to } 4.32 \mathrm{~cm} \text { pitch }\end{array}$ \\
\hline
\end{tabular}




\begin{tabular}{|c|c|c|}
\hline $\begin{array}{c}\text { Key } \\
\text { Parameters } \\
\end{array}$ & $\begin{array}{c}\text { Anticipated SNF Package } \\
\text { Conditions }\end{array}$ & 57 Critical Experiments \\
\hline \multicolumn{3}{|l|}{ Array Parameters } \\
\hline Fixed Neutron absorbers & $\begin{array}{l}\text { Borated materials (e.g., } B_{4} C \text {, } \\
\text { borated stainless steel, boral, etc.) }\end{array}$ & $\begin{array}{l}\text { External } \mathrm{B}_{4} \mathrm{C} \text { rods } \\
\text { Boral, stainless steel, and } \\
\text { aluminum plates }\end{array}$ \\
\hline $\begin{array}{l}\text { Materials of construction } \\
\text { within array }\end{array}$ & Guide tubes & Water gaps \\
\hline \multicolumn{3}{|l|}{$\begin{array}{l}\text { Moderator } \\
\text { Conditions } \\
\end{array}$} \\
\hline Water Density & $1 \mathrm{~g} / \mathrm{cm}^{3}$ & $1 \mathrm{~g} / \mathrm{cm}^{3}$ \\
\hline $\begin{array}{l}\text { Water } \\
\text { Temperature }\end{array}$ & $70^{\circ} \mathrm{F}$ & $70^{\circ} \mathrm{F}$ \\
\hline $\begin{array}{l}\text { Moderator to Fuel Volume } \\
\text { Ratio }\end{array}$ & 1.3 to 1.9 & $\begin{array}{l}\mathrm{UO}_{2}: 1.09 \text { to } 5.07 \\
\mathrm{UO}_{2}-\mathrm{Gd}_{2} \mathrm{O}_{3}: 1.88 \\
\mathrm{MOX}: 0.49 \text { to } 10.75\end{array}$ \\
\hline Soluble Boron Concentration & $0 \mathrm{ppm}$ & $\begin{array}{l}\mathrm{UO}_{2}: 0 \text { to } 2550 \mathrm{ppm} \\
\mathrm{UO}_{2}-\mathrm{Gd}_{2} \mathrm{O}_{3}: 1579 \text { to } 1654 \\
\text { MOX: } 0 \text { to } 1090 \mathrm{ppm}\end{array}$ \\
\hline \multicolumn{3}{|l|}{$\begin{array}{l}\text { Reflector and Interaction } \\
\text { Conditions }\end{array}$} \\
\hline $\begin{array}{l}\text { Reflector } \\
\text { Composition }\end{array}$ & $\begin{array}{l}\text { Water, depleted uranium and } \\
\text { stainless steel reflectors }\end{array}$ & $\begin{array}{l}\text { Water, depleted uranium, stainless steel } \\
\text { and lead reflectors }\end{array}$ \\
\hline $\begin{array}{l}\text { Interaction with other fissile } \\
\text { material }\end{array}$ & $\begin{array}{l}\text { Fissile uranium and plutonium } \\
\text { isotopes in SNF }\end{array}$ & $\begin{array}{l}\text { Fissile uranium and plutonium isotopes } \\
\text { in MOX fuel pins }\end{array}$ \\
\hline
\end{tabular}




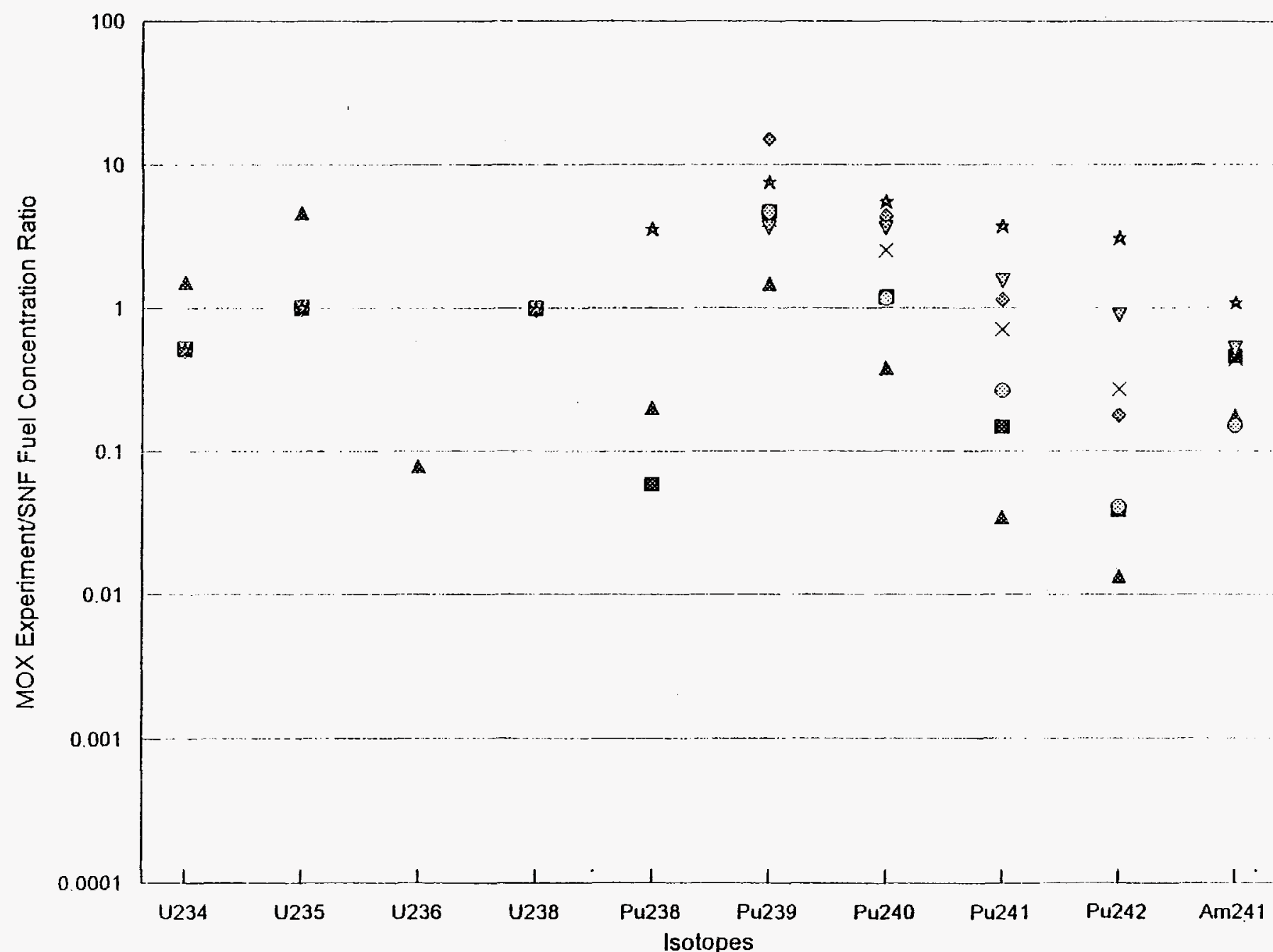

\section{圆 EPRI}

- SAXTON

A PNL4976

- $\operatorname{PUP}(2,8)$

$\times \operatorname{PUP}(2,16)$

\& PUP $(2,24)$

\& PUP $(4)$ 


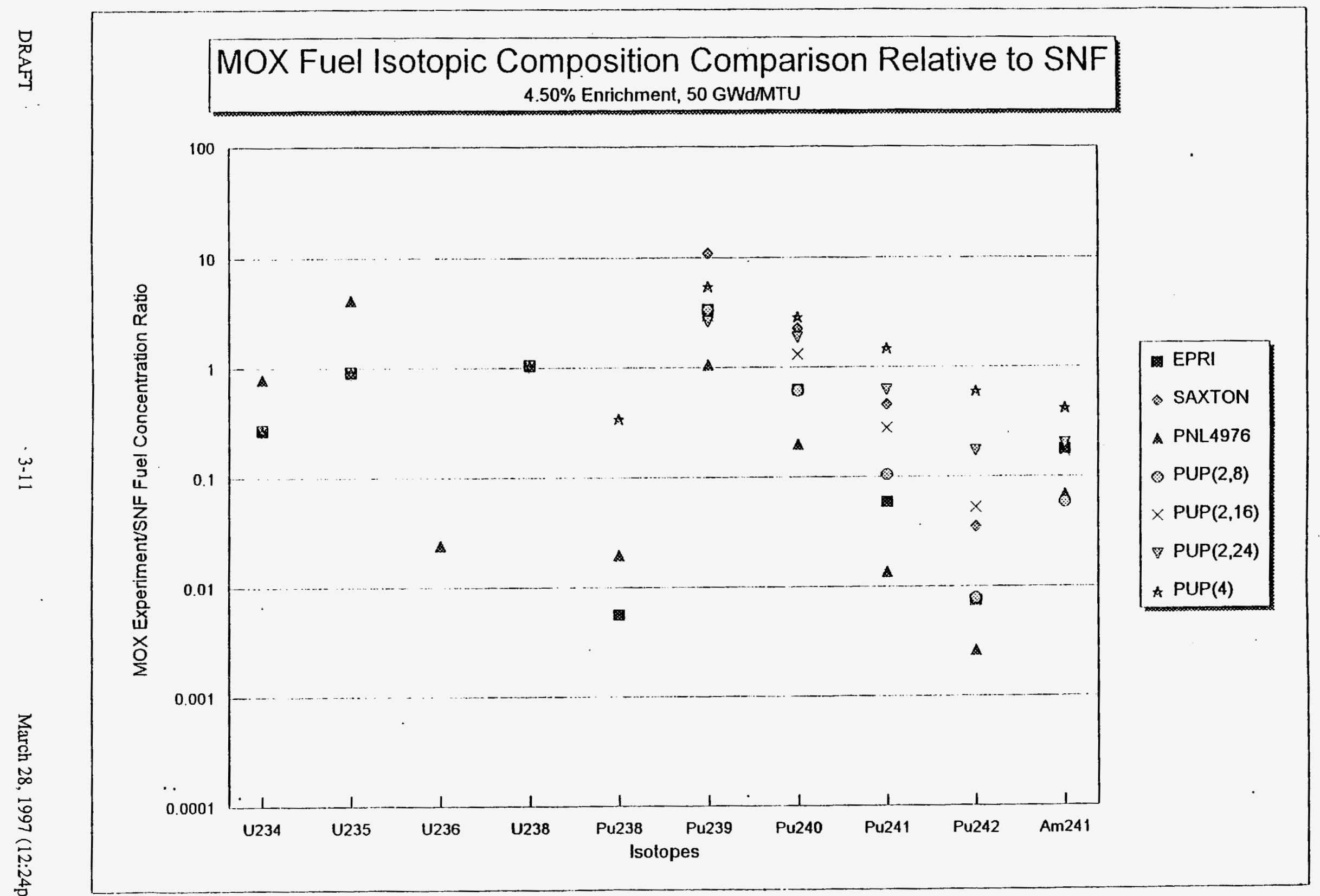

Figure 3-2. MOX Benchmark Experiment Composition Summary (against High Burnup) 


\subsection{CALCULATIONAL BIAS AND UNCERTAINTIES}

Specific guidance for use of calculational methods in the analysis of LWR Fuel is provided in ANSI/ANS-8.1. The Standard specifies that "bias shall be established by correlating the results of criticality experiments with results obtained for these same systems by the method being validated." Based on this Standard, this section describes the recommended approach and statistical methods

1 for determining the bias in the calculation of $k_{\text {eff }}$, along with uncertainties associated with that bias.

\subsubsection{ANSU/ANS-8.17 Guidance}

The approach to be taken in demonstrating subcriticality based on the numerical calculation of the effective neutron multiplication factor is prescribed in Section 5.1 of ANSI/ANS 8.17. The following paragraphs describe the recommended approach as set forth in the Standard. The criterion to establish subcriticality requires that the calculated multiplication factor, $\mathrm{k}_{\mathrm{s}}$, be less than or equal to an established maximum allowable multiplication factor based on benchmark calculations and uncertainty terms, i.e.,

where

$$
k_{s} \leq k_{c}-\Delta k_{s}-\Delta k_{c}-\Delta k_{m}
$$

$$
\begin{aligned}
& \mathrm{k}_{\mathrm{s}}=\begin{array}{l}
\text { calculated allowable maximum multiplication factor, } \mathrm{k}_{\mathrm{eff}} \text {, for the system being } \\
\text { evaluated }
\end{array} \\
& \mathrm{k}_{\mathrm{c}}=\begin{array}{l}
\text { the mean value of } \mathrm{k}_{\text {eff }} \text { resulting from the calculation of benchmark criticality } \\
\text { experiments using a specific calculational method }
\end{array} \\
& \Delta \mathrm{k}_{\mathrm{s}}=\text { uncertainty in the value of } \mathrm{k}_{\mathrm{s}} \\
& \Delta \mathrm{k}_{\mathrm{c}}=\text { uncertainty in the value of } \mathrm{k}_{\mathrm{c}} \\
& \Delta \mathrm{k}_{\mathrm{m}}=\text { an arbitrary administrative margin to ensure subcriticality. }
\end{aligned}
$$

ANSI/ANS-8.17 provides additional detailed guidance describing analysis considerations included in each term of Equation 3-1. The uncertainty in method bias, $\Delta \mathrm{k}_{\mathrm{c}}$, connected with the calculation of $k_{c}$ may include uncertainties in the critical experiments, statistical and/or convergence uncertainties in the benchmark calculations, uncertainties due to extrapolation beyond the range of experimental data, and uncertainties due to limitations or weaknesses in the geometrical or nuclear modeling of the critical experiments. Similarly, for a given subcritical system, there is the uncertainty $\Delta \mathrm{k}_{\mathrm{s}}$ associated with the calculated $\mathrm{k}_{\text {eff }}$ value for the system, $\mathrm{k}_{\mathrm{s}}$. This uncertainty includes any statistical/convergence uncertainty related to the analysis method (i.e., Monte Carlo uncertainties) and modeling uncertainties related to basket construction (i.e., material composition, material thickness, and fabrication tolerances) not accounted for with worst-case treatments in the computational model. Each of the various uncertainties is combined statistically if independent or combined additively if statistically correlated. 


\subsubsection{Bias and Uncertainty From Critical Experiments}

The criticality analysis method bias is calculated as a direct additive measure of systematic disagreement between the calculated and the measured experimental data for direct application of the ANSI/ANS-8.17 subcriticality safety criteria. The ANSI/ANS-8.17 form of the subcriticality safety criteria, Equation 3-1, is rearranged to define the criticality analysis method bias and bias uncertainty in more directly recognizable terms. If the method bias is defined as $\beta$, where $\beta=1$ $\mathrm{k}_{\mathrm{c}}$, and the uncertainty in bias is defined as $\Delta \beta$, where $\Delta \beta=\Delta \mathrm{k}_{c}$, the subcriticality safety criteria can be rewritten as follows:

$$
\mathrm{k}_{\mathrm{s}} \leq 1.0-\beta-\Delta \mathrm{k}_{\mathrm{s}}-\Delta \beta-\Delta \mathrm{k}_{\mathrm{m}}
$$

The value $k_{c}$ and thus the method bias $\beta$ are not necessarily a constant over the full range of variable parameters of interest. If trends exist that cause the benchmark values of $k_{\text {eff }}$ to vary with one or more parameters (e.g., enrichment, fuel-to-moderator ratio, etc.), then $\beta$ is most appropriately determined from a best fit for the calculated $k_{\text {eff }}$ values, as a function of the parameter upon which it is dependent. A statistical approach is presented in the following subsection that can be applied to perform trend analysis on benchmark calculation results and calculate a method bias as a function of a single barameter. A method for determining the uncertainty, $\Delta \beta$, connected with the calculation of $\beta$ is also presented.

\subsubsection{Lower Prediction Band Technique}

Based on the criteria for subcriticality set forth in ANSI/ANS 8.17, a statistical technique has been developed for the determination of subcritical limits using the prediction interval method. ${ }^{3-17} \mathrm{~A}$ similar statistical technique has been previously applied for the determination of subcritical limits in validation studies for the CSAS/27BURNUPLIB code system. ${ }^{3-18,3-19}$ This approach is a single-sided, statistical method for the determination of an upper safety limit (USL) based on the statistical analysis of a number of critical systems. The USL is determined such that there is a high degree of confidence that a calculated result is subcritical; a system is considered acceptably subcritical if a calculated $k_{\text {eff }}$ plus calculational uncertainties lies at or below this limit (i.e., $k_{s}+\Delta k_{s}$ $\leq$ USL). Thus, based on Equation 3-2, the USL is the statistically determined magnitude of the sum of the biases, uncertainties, and administrative safety margin applied to a set of critical benchmarks, such that with a high degree of confidence,

$$
\text { USL } \leq 1.0-\beta-\Delta \beta-\Delta \mathrm{k}_{\mathrm{m}}
$$

Based on a given set of critical experiments, the USL can be determined as a function of key system parameters, such as the average energy group causing fission (AEG), average lethargy for absorption (ALA), fuel enrichment, or fuel/moderator ratio. Because both $\beta$ and $\Delta \beta$ can vary with a given parameter, the USL is typically expressed as a function of the parameter. This approach is conceptually illustrated in Figure 3-3. In this figure, the upper line $\left[k_{c}(x)\right]$ represents a linear regression fit of a set of benchmark experiment calculation results plotted as a function of the trended parameter, $\mathrm{x}$. The difference between the linear regression fit and $\mathrm{k}_{\mathrm{eff}}=1.0$ is the calculational bias. The middle line $\left[k_{c}(x)-\Delta k_{c}(x)\right]$ represents the lower prediction band.(LPB) for 


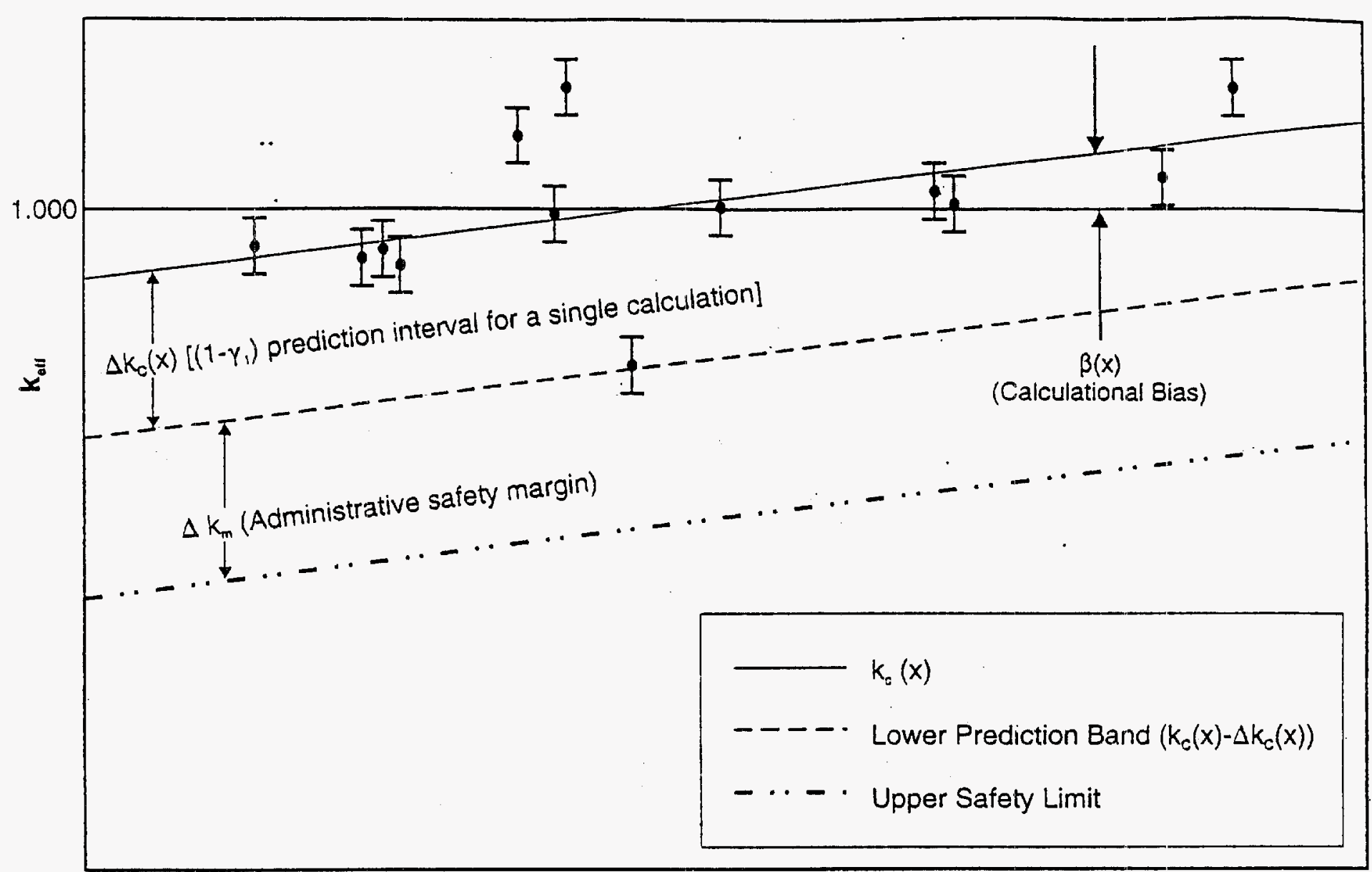

\section{Trended Parameter $\mathrm{X}$ Increasing Value $\longrightarrow$}

Figure 3-3. Illustration of the Lower Prediction Band Technique for the Determination of an Upper Safety Limit (USL)

a single additional calculation; e.g., the user can be $95 \%$ confident $\left(1-\gamma_{1}=0.95\right)$ that the next 1 calculated value of $k_{\text {eff }}$ for a critical experiment will be greater than $\left[k_{c}(x)-\Delta k_{c}(x)\right]$. The prediction band is determined statistically based on the existing data and a specified level of confidence; the greater the standard deviation in the data or the larger the confidence desired, the larger the band

I width will be. The prediction band accounts for uncertainties in the experiments, 'calculational approach, and calculational data (e.g., neutron cross sections), and is therefore a statistical basis for $\Delta \beta$, the uncertainty in the value of the bias, $\beta$. The bottom line in the figure represents the upper safety limit for subcriticality, based on an additional margin of subcriticality. This safety margin provides further assurance of subcriticality and represents the quantity $\Delta \mathrm{k}_{\mathrm{m}}$ defined earlier.

Based on Equation 3-3 and the definitions provided above, the limiting USL condition (i.e., USL $\left.=1.0-\beta-\Delta \beta-\Delta \mathrm{k}_{\mathrm{m}}\right)$ is defined as:

$$
\mathrm{USL}=1.0-\bar{\beta}-\Delta \beta-\Delta \mathrm{k}_{\mathrm{m}}
$$


for cases when the calculated multiplication factors do not show a trend with any parameter ( $\bar{\beta}$ is the mean bias), or

$$
\mathrm{USL}(\mathrm{x})=1.0-\beta(\mathrm{x})-\Delta \beta(\mathrm{x})-\Delta \mathrm{k}_{\mathrm{m}}
$$

when the calculated values show a statistically significant trend against parameter $x$. In the unlikely event that the calculated values show trends against more than one parameter, multiple linear regression would have to be employed to compute both the bias and uncertainty as a function of the multiple parameters. To determine if the calculated values exhibit a significant trend against parameter $\mathrm{x}$, the data is fitted through linear regression to obtain the equation

$$
k_{c}(x)=a+b x
$$

and a slope test ${ }^{3-20}$ (variation of the Student's $t$ test) is performed. The test requires obtaining the test statistic, $\mathrm{T}$,

$$
T=b \sqrt{\frac{(n-2) S_{x x}}{S S_{i}}}
$$

where

$$
S_{x x}=\sum_{i=1, n}\left(x_{i}-\bar{x}\right)^{2}
$$

and

$$
S S_{R}=\sum_{i=1, n}\left(k_{i}-a-b x_{i}\right)^{2}
$$

The test statistic is then compared to the Student's t-distribution with $95 \%(\alpha=0.05)$ confidence and $\mathrm{n}-2$ degrees of freedom. Given a null hypothesis of "no statistically significant trend exists (slope is zero)," the hypothesis is accepted for $|\mathrm{T}|<\mathrm{t}_{\alpha / 2, \mathrm{n}-2}$, and rejected otherwise.

The bias, $\beta$, is treated as a function of zero, one, or multiple parameters, based on the linear regression and trend testing on the calculated multiplication factors. Figure 3-3 presents the case when the bias depends on one trending parameter, $\beta(x)=1.0-k_{c}(x)$. 
I Next, the confidence band for an additional calculation, $\Delta \beta$, may be determined using the I relationship:

$$
\Delta \beta=t_{\gamma_{1}, n-1} s_{p}\left[1+\frac{1}{n}\right]^{1 / 2}
$$

I for cases with no trend, and

$$
\Delta \beta(x)=t_{\gamma_{1}, n-2} s_{p}\left[1+\frac{1}{n}+\frac{(x-\bar{x})^{2}}{S_{x x}}\right]^{1 / 2}
$$

I for the one trend cases, where

$\mathrm{n}=$ the number of critical calculations used in establishing $\mathrm{k}_{\mathrm{c}}(\mathrm{x})$

$\mathrm{t}_{\gamma 1, \mathrm{~m}}=$ the Student-t value for $\gamma_{1}$ and $\mathrm{m}$ degrees of freedom

$\overline{\mathrm{x}}=$ the mean value of parameter $\mathrm{x}$ in the set of calculations

$s_{\mathrm{p}}=$ the pooled standard deviation for the set of criticality calculations.

1 The pooled standard deviation is obtained from the pooled variance, $s_{\mathrm{p}}^{2}$. Pooled variance is given by:

$$
s_{p}^{2}=s^{2}+s_{w}^{2}
$$

1 for the no trend cases, and

$$
\mathrm{s}_{\mathrm{p}}^{2}=\mathrm{s}_{\mathrm{k}(\mathrm{x})}^{2}+\mathrm{s}_{\mathrm{w}}^{2}
$$

1 for the one trend cases. The $\mathrm{s}^{2}$ represents the variance of the calculated values around the mean, 1 while the $s_{k}^{2}(x)$ is the variance (or mean square error) of the regression fit, and is given by:

$$
s_{k(x)}^{2}=\frac{1}{(n-2)}\left[\sum_{i=1, n}\left(k_{i}-\bar{k}\right)^{2}-\frac{\left[\sum_{i=1, n}\left(x_{i}-\bar{x}\right)\left(k_{i}-\bar{k}\right)\right]^{2}}{\sum_{i=1, n}\left(x_{i}-\bar{x}\right)^{2}}\right]
$$


which can also be written as

$$
s_{k(x)}^{2}=\frac{\sum_{i=1, n}\left[k_{i}-k_{c}\left(x_{i}\right)\right]^{2}}{n-2}
$$

The $s_{w}^{2}$ is the within-variance of the data:

$$
s_{w}^{2}=\frac{1}{n} \sum_{i=1, n} \sigma_{i}^{2}
$$

The term $\sigma_{i}$ in Equation 3-16 is the standard deviation associated with $k_{i}$ for a Monte Carlo calculation. Although not required to be included in the calculational uncertainty, the within variance is used to augment the calculational variance. For deterministic codes, which do not have a standard deviation associated with a computed value of $\mathrm{k}$, this standard deviation is zero.

Substituting for $\beta(x)$ in Equation 3-5, an expression for the upper safety limit (for the case when the bias exhibits a trend with one parameter) may be written as:

$$
\mathrm{USL}(\mathrm{x})=1.0-\mathrm{a}_{0}+\mathrm{bx}-\Delta \beta(\mathrm{x})-\Delta \mathrm{k}_{\mathrm{m}} \text {, }
$$

The $a_{0}$ (where $a_{0}=1-a$ ) and $b$ parameters are determined from the linear regression, while $\Delta \beta(x)$ is computed from Equation 3-11. The administrative safety margin, $\Delta \mathrm{k}_{\mathrm{m}}$, is typically assigned a value of 0.05 in safety analyses.

The Equation 3-17 function is represented by the lowermost line of Figure 3-3. As previously discussed, this line represents an upper bound to ensure subcriticality for a given configuration when the calculated $k_{\text {eff }}$ plus uncertainty for the configuration is less than the USL. USLs may be calculated for a number of independent parameters for a given system.

Besides providing a statistically valid methodology to establish criticality calculational method bias and bias uncertainty over a defined range of experimental conditions, the lower prediction band technique provides a mechanism to justify extending the range of applicability. As discussed earlier, ANSI/ANS-8.1 allows the range of applicability to be extended beyond this range by extrapolating the trends established for the bias. However, no precise guidelines are specified for the limits of extrapolation.

\subsubsection{Calculational Requirements}

ANSI/ANS-8.1 requires that a reactivity safety margin be prescribed that is sufficient to ensure subcriticality. The safety margin shall include allowances for uncertainties in the bias and for uncertainties in any extensions of the area(s) of applicability. The proper statistical tools for the calculation of the safety margin (USL) have been presented in the previous section. Specific requirements for actinide-only burnup credit criticality validation have been determined and are stated and discussed here. 
All analyses must be performed individually on the two subsets $\left(\mathrm{UO}_{2}, \mathrm{MOX}\right)$ of critical experiments encompassing the benchmark set of critical experiments. An independent USL must be determined for each subset of critical experiments, and then combined conservatively by selecting the lower of the two at any value of the trending parameter(s). This combination method bounds a USL computed with the entire benchmark set, which may or may not be statistically valid due to the combination of the two independent subsets.

The range of experimental conditions included in the benchmark experiments selected for validating burnup credit criticality analysis methods establishes the areas of applicability over which the calculated method bias, included in the USL, can be applied. Table 3-2 and Figures 3-1 and 3-2 summarize the extent to which the benchmark experiment set covers the range of anticipated SNF package conditions. Although a limited set of experimental data exists for burnup credit analysis method benchmark purposes, the level of extrapolation beyond that typically required for fresh fuel analysis methods is not large. Extrapolations are limited to covering the range of isotopic compositions and neutron spectrum anticipated for systems containing spent nuclear fuel. Benchmark data provided by the MOX critical experiment set provide a strong validation of analysis method treatment of the key actinide fissile and neutron absorber isotopes. Trending the validation results to a spectral parameter over a diverse group of experiments containing many neutron absorbing materials provides a sound validation basis to address spectrum issues without significant extrapolation. It provides an integral trending basis for many parameters affecting neutron energy spectra, including fissile material content, fuel-to-moderator ratio, and presence of absorbers. The spectral parameter could be the average energy group causing fission (AEG), average lethargy for absorption (ALA), fission (ALF), capture (ALC), or other global spectral parameter.

In addition to trending the calculated multiplication factors against a spectral parameter, trending against initial enrichment (for the $\mathrm{UO}_{2}$ subset), fuel outside diameter and soluble boron concentration must also be performed. Although those three parameters affect the neutron spectrum, they could also account for other deficiencies. For example, a direct error in the cross section values of U-235 or U-238 in the ENDF/B library would be observed in the initial enrichment trending, while the boron concentration trending does similarly for errors in the boron cross section values. The trending against the fuel outside diameter aids in noticing deficiencies in the resonance and cell treatment. Trending against plutonium isotopic concentrations to observe direct errors in the ENDF/B library is not necessary since the most limiting USL is taken from cases with no plutonium and those with plutonium concentrations greater than that seen in SNF.

To determine the USL for each subset, trending analyses against the four parameters must be performed. A linear regression fit of the calculated multiplication factors against each of the trending parameters, followed by a slope test on each computed regression slope, shall be performed. For cases when no statistically significant trends are found, Equations 3-4 and 3-10 would be used to compute the USL; if one trend is found, Equations 3-5 and 3-11 would be used. For cases when more than one trend is found, multiple regression analysis ${ }^{3-20}$ must be followed.

A $0.05 \Delta \mathrm{k}_{\mathrm{m}}$ administrative safety margin is typically assigned for spent nuclear fuel package applications using the fresh fuel assumption. This margin is also acceptable for use in burnup credit design applications since the magnitude of uncertainty in calculation bias and the level of extrapolation from experimental conditions are consistent with fresh fuel assumption applications. 


\subsection{METHODOLOGY DEMONSTRATION WITH SCALE 4.2}

A USL to establish definitive bias and uncertainty terms for use in burnup credit analyses is derived using the results summarized in Table 3-1 for the CSAS/27BURNUPLIB system. This example may be used for guidance in performing similar calculations with a different criticality code or code system, or cross section set. For this analysis, the average lethargy for absorption was selected as the spectral trending parameter. Table 3-1 provides ALA values computed from the CSAS/27BURNUPLIB code system outputs. ${ }^{3-16}$

Benchmark calculation $\mathrm{k}_{\text {eff }}$ results were evaluated against the four trending parameters. Statistical trending analyses were performed on each experiment subset $\left(\mathrm{UO}_{2}\right.$ and $\mathrm{MOX}$ experiments) individually. Only one statistically significant trend was observed. This was a trend against the average lethargy for absorption for the MOX subset. Results for the trending analyses are presented in Tables 3-3 and 3-4 for the $\mathrm{UO}_{2}$ and MOX subsets, respectively. The bias and spectral trending results for the plutonium-bearing MOX critical experiments are consistent with previously observed trends relating to current plutonium cross section data and are not limited to the CSAS/27BURNUPLIB criticality analysis method. ${ }^{3-21,3-22}$

Table 3-3. Trending Analyses Results for $\mathrm{UO}_{2}$-only Subset

\begin{tabular}{|l|c|c|c|c|c|c|c|}
\hline \multicolumn{1}{|c|}{ Parameter } & $\mathbf{N}$ & slope & $\mathbf{S}_{\mathbf{x z}}$ & $\mathbf{S S}_{\mathbf{R}}$ & $\mathbf{T}$ & $\mathbf{t}_{\alpha / 2, \mathrm{n}-2}$ & TREND \\
\hline ALA & 21 & $4.09 \mathrm{E}-4$ & $1.06 \mathrm{E} 1$ & $1.66 \mathrm{E}-4$ & 0.451 & 2.09 & NO \\
\hline Initial Enrichment & 18 & $9.61 \mathrm{E}-4$ & $2.41 \mathrm{E} 1$ & $1.30 \mathrm{E}-4$ & 1.656 & 2.12 & NO \\
\hline Clad Outside Diameter & 18 & $5.59 \mathrm{E}-3$ & $3.21 \mathrm{E}-1$ & $1.42 \mathrm{E}-4$ & 1.060 & 2.12 & NO \\
\hline Boron Concentration & 21 & $-6.38 \mathrm{E}-7$ & $1.69 \mathrm{E} 7$ & $1.61 \mathrm{E}-4$ & 0.901 & 2.09 & NO \\
\hline
\end{tabular}

Table 3-4. Trending Analyses Results for MOX Subset

\begin{tabular}{|l|c|c|c|c|c|c|c|}
\hline \multicolumn{1}{|c|}{ Parameter } & $\mathbf{N}$ & slope & $\mathbf{S}_{\mathbf{\alpha}}$ & $\mathbf{S S}_{\mathbf{R}}$ & $\mathbf{T}$ & $\mathbf{t}_{\alpha / 2, \mathrm{n}-2}$ & $\mathbf{T R E N D}$ \\
\hline ALA & 36 & $4.55 \mathrm{E}-3$ & $2.28 \mathrm{E} 1$ & $7.05 \mathrm{E}-4$ & 4.771 & 2.03 & YES \\
\hline Clad Outside Diameter & 35 & $-7.93 \mathrm{E}-3$ & $9.89 \mathrm{E}-1$ & $9.04 \mathrm{E}-4$ & 1.506 & 2.03 & NO \\
\hline Boron Concentration & 36 & $3.41 \mathrm{E}-6$ & $2.13 \mathrm{E} 6$ & $1.15 \mathrm{E}-3$ & 0.855 & 2.03 & NO \\
\hline
\end{tabular}

Using the approach described in the previous section, the various terms required to determine the USL for each subset are computed. Tables 3-5 and 3-6 summarize the intermediate results and the final USL computed for each subset of critical experiments. The benchmark calculation $k_{\text {eff }}$ results 
1 and USL calculation parameters are plotted in Figure 3-4 for the $\mathrm{UO}_{2}$ subset and Figure 3-5 for the 1 MOX subset.

I Although plotted against the ALA in Figure 3-4, the $\mathrm{UO}_{2}$ subset did not exhibit a statistically significant trend against any of the required trending parameters. The uncertainty for this subset was $0.0056 \Delta \mathrm{k}$, much lower than the administrative margin of $0.05 \Delta \mathrm{k}_{\mathrm{m}}$. For the MOX subset, the uncertainty observed was lower than $0.01 \Delta \mathrm{k}$ for the ALA range of interest.

Table 3-5. Parameters Used in Upper Safety Limit (USL) Calculations for $\mathrm{UO}_{2}$-only Subset

\begin{tabular}{l|l|l|}
\cline { 2 - 3 } \multicolumn{1}{|c|}{ Parameter } & \multicolumn{1}{c|}{ Value } \\
\cline { 2 - 3 } 1 & $\mathrm{n}$ & 21 \\
$\mathrm{I}$ & Average multiplication factor $\left[\overline{\mathrm{k}}_{\mathrm{c}}\right]$ & 0.9938 \\
$\mathrm{I}$ & Average Bias $[\bar{\beta}]$ & 0.0062 \\
$\mathrm{I}$ & Variance around mean $\left[\mathrm{s}^{2}\right]$ & $8.380 \mathrm{E}-6$ \\
$\mathrm{I}$ & Within-data variance $\left[\mathrm{s}_{\mathrm{w}}{ }^{2}\right]$ & $1.719 \mathrm{E}-6$ \\
1 & Pooled standard deviation $\left[\mathrm{s}_{\mathrm{p}}\right]$ & $3.178 \mathrm{E}-3$ \\
1 & $\mathrm{t}_{\mathrm{\gamma} 1, \mathrm{n}-1}$ & 1.725 \\
1 & Uncertainty $[\Delta \beta]$ & $5.611 \mathrm{E}-3$ \\
1 & Safety margin $\left[\Delta \mathrm{k}_{\mathrm{m}}\right]$ & 0.05 \\
1 & USL & 0.9381 \\
\hline
\end{tabular}


Table 3-6. Parameters Used in Upper Safety Limit (USL) Calculations for MOX Subset

\begin{tabular}{|c|c|}
\hline Parameter & Value \\
\hline $\mathrm{n}$ & 36 \\
\hline Linear regression fit $[k(A L A)]$ & $0.9163+0.004550 * \mathrm{ALA}$ \\
\hline $\operatorname{Bias}[\beta(\mathrm{ALA})]$ & $0.0837-0.004550 *$ ALA \\
\hline Average ALA & 18.54 \\
\hline Variance of fit $\left[\mathrm{s}_{\mathrm{k}(\mathrm{x})}^{2}\right]$ & $2.072 \mathrm{E}-5$ \\
\hline Within-data variance $\left[\mathrm{s}_{\mathrm{w}}^{2}\right]$ & $1.347 \mathrm{E}-6$ \\
\hline Pooled standard deviation $\left[\mathrm{s}_{\mathrm{p}}\right]$ & $4.698 \mathrm{E}-3$ \\
\hline $\mathrm{t}_{\gamma 1, \mathrm{n}-2}$ & 1.691 \\
\hline $\mathrm{S}_{\mathrm{xx}}$ & 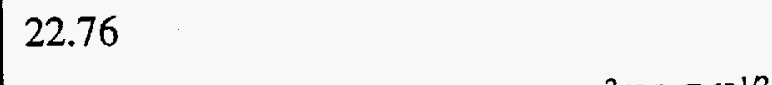 \\
\hline Uncertainty $[\Delta \beta(\mathrm{ALA})]$ & $7.944 \mathrm{E}-3 *\left[1.028+(\mathrm{ALA}-18.54)^{2} / 22.76\right]^{1 / 2}$ \\
\hline Safety margin $\left[\Delta \mathrm{k}_{\mathrm{m}}\right]$ & 0.05 \\
\hline USL & $\begin{array}{l}0.8663+0.004550 * \text { ALA }-0.001665 * \\
{\left[23.402+(\mathrm{ALA}-18.54)^{2}\right]^{1 / 2}}\end{array}$ \\
\hline
\end{tabular}

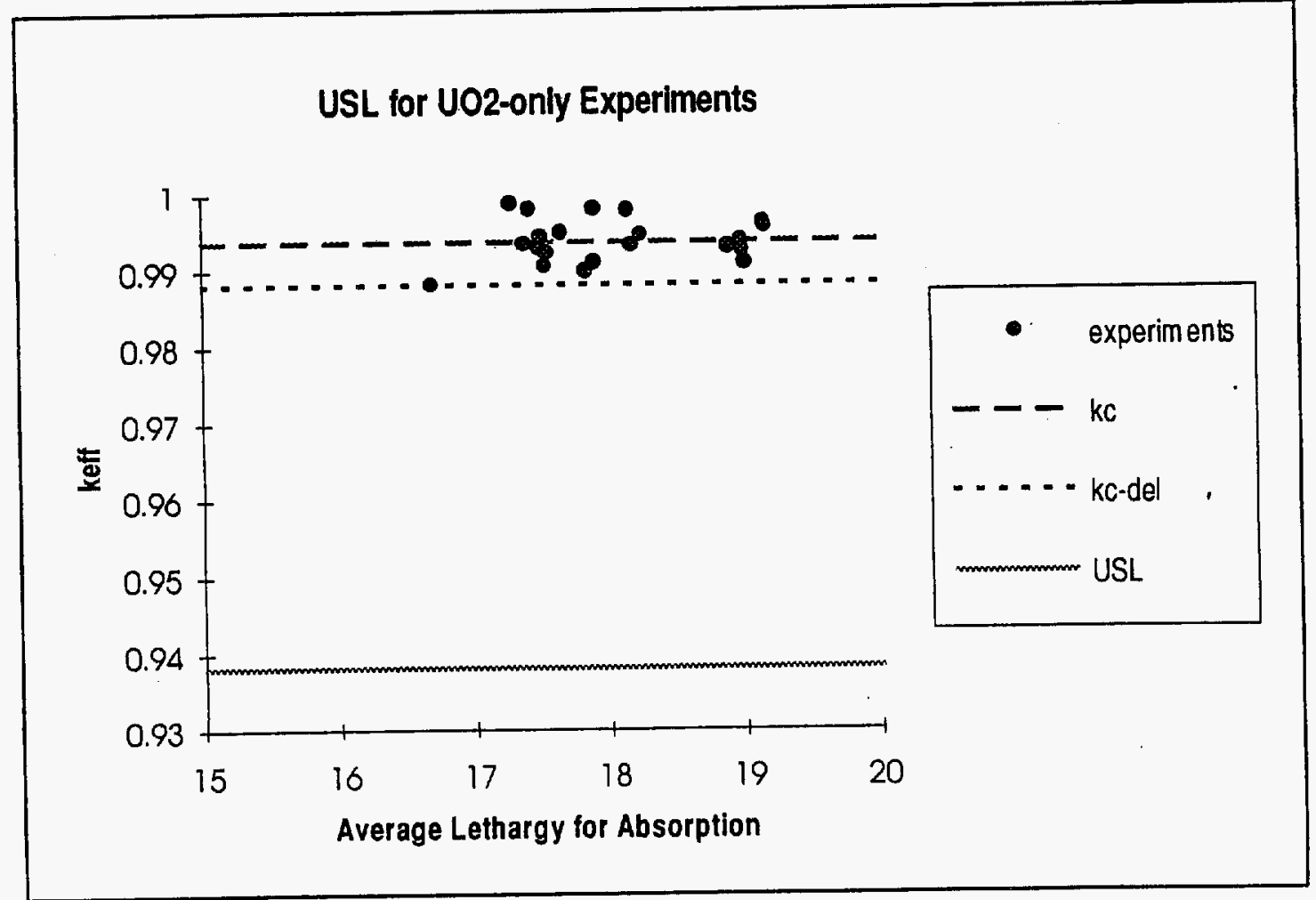

Figure 3-4. Upper Safety Limit (USL) for $\mathrm{UO}_{2}$ Experiment Subset 


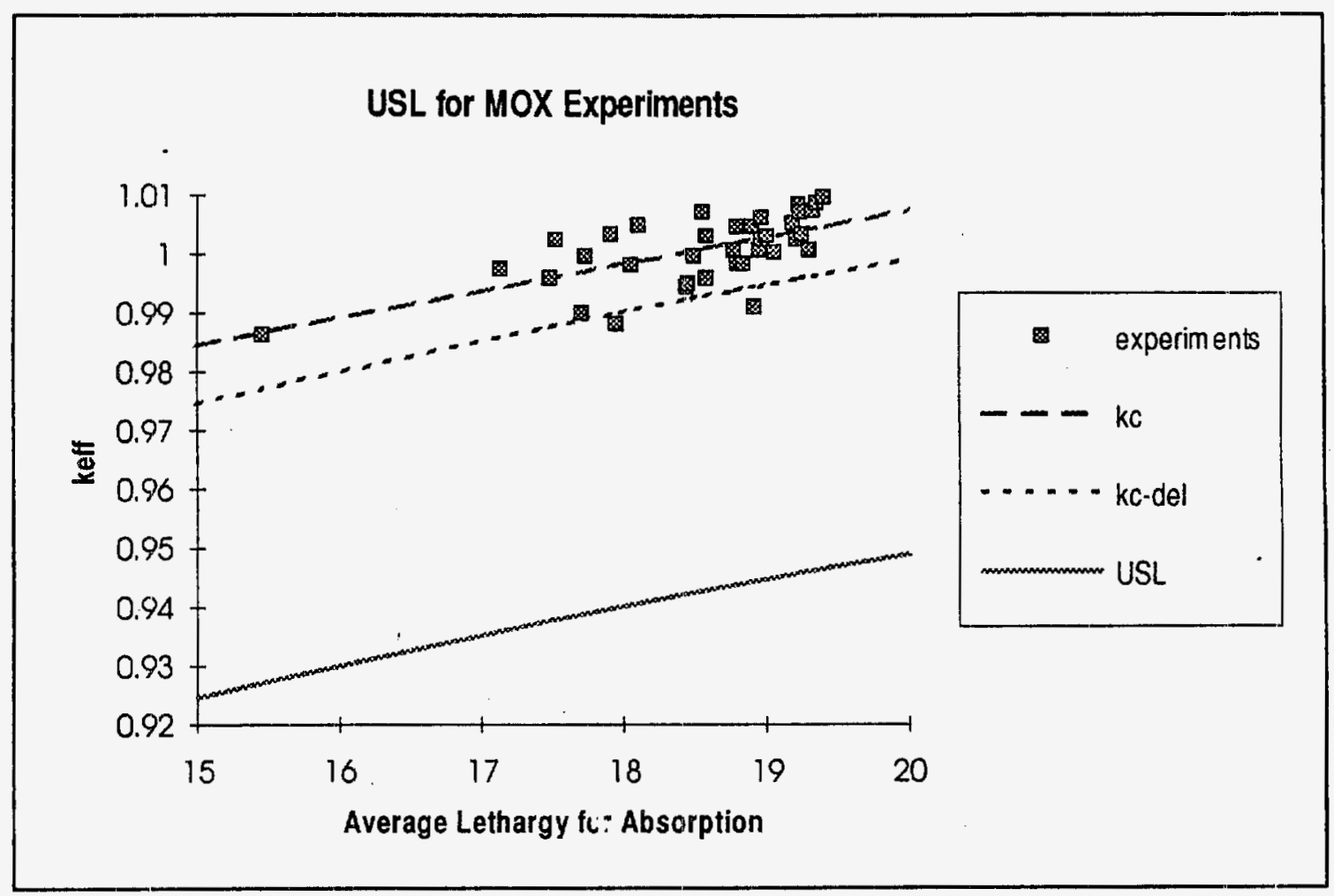

Figure 3-5. Upper Safety Limit (USL) for MOX Experiment Subset

I From the combination of the subsets' USLs, the final USL is I

I ALA $\leq 17.58: \mathrm{USL}=0.8663+0.004550 * \mathrm{ALA}-0.001665 * \mathrm{SQRT}\left[23.402+(\mathrm{ALA}-18.54)^{2}\right]$ I

| $17.58 \leq$ ALA: USL $=0.9381$

1

I The value of 17.58 corresponds to the intersection of the two USLs. Figure 3-6 presents the final, 1 combined USL. 


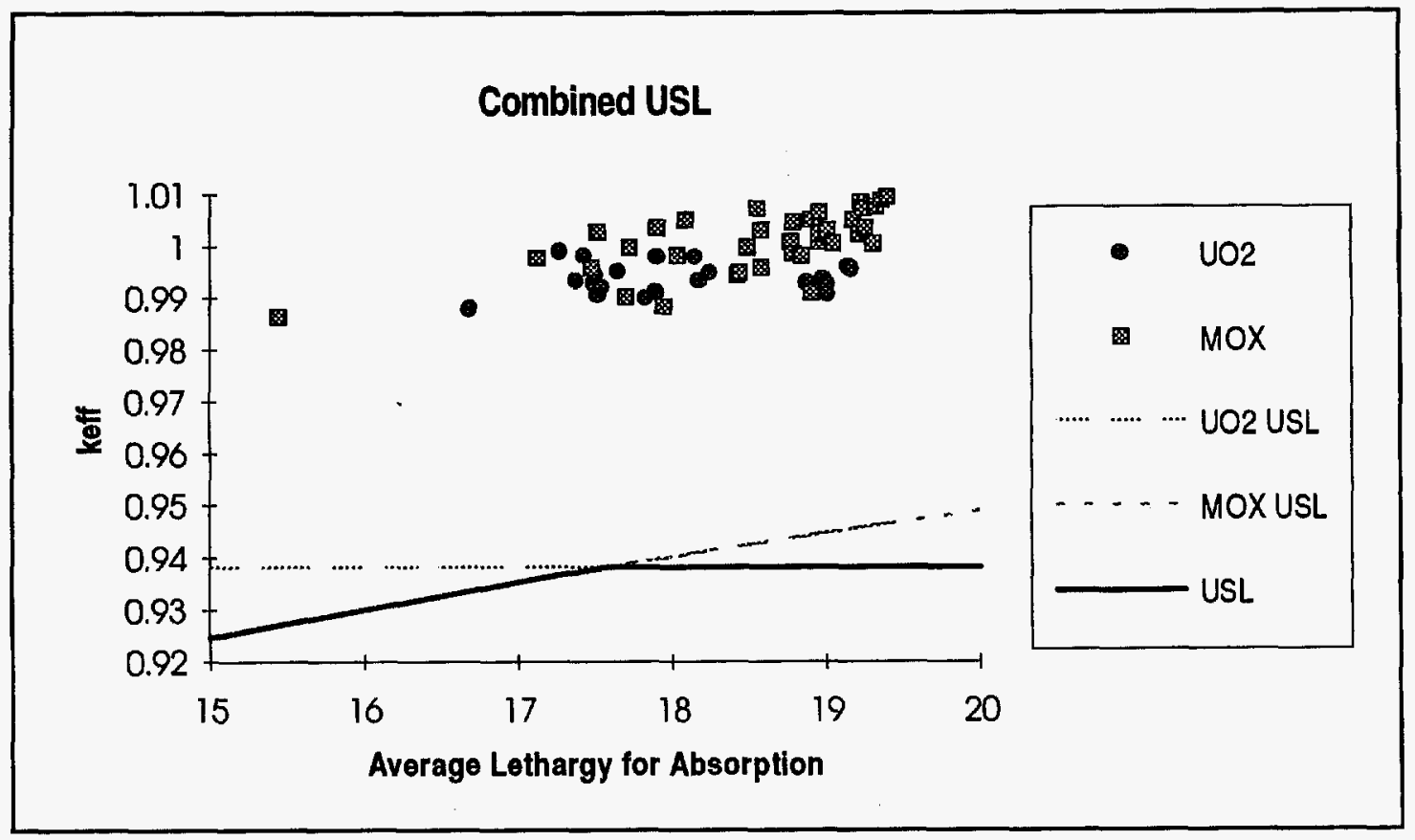

Figure 3-6. Final Upper Safety Limit (USL)

\subsection{SUMMARY AND CONCLUSION}

This chapter presents a set of critical experiments for validation of criticality calculations and a method for using these experiments to determine a USL on $\mathrm{k}_{\mathrm{eff}}$, and it demonstrates the use of the data and method. The 57 experiments selected have been shown to cover the range of expected conditions for the SNF package. Although they do not include actual spent fuel, they include MOX fuel to cover $\mathrm{Pu}$ isotopes. The method uses the data to establish a USL on $\mathrm{k}_{\text {eff. }}$ This is done by calculating a bias and the uncertainty on that bias as a function of trending parameters. Depending on the trending analyses results, the uncertainty is subtracted from either the best fit on $k_{\text {eff }}$ or the calculated mean value for the critical experiments. An additional conservative factor, the 0.05 administrative safety margin, is then subtracted resulting in the USL. The use of the data and method is demonstrated with the CSAS/27BURNUPLIB code system. For that analysis, the average lethargy for absorption was selected as the spectral trending parameter, and a significant trend was found for the MOX subset only.

The specific calculational requirements are discussed within the methodology. The following must be performed: 1) analysis of the fifty-seven critical experiments with code system to be validated, 2) regression analyses for each critical experiment subset independently, against a spectral parameter, initial enrichment, outside clad diameter, and soluble boron concentration, 3) a trend test on the linear regression slope for each trended parameter, to determine if the observed trend against the given parameter is statistically significant, 4) determination of a USL, as a function of the 
I significant trends, for each subset, and 5) combination of the two USLs conservatively by taking the lowest of the two at any value of the trending parameter(s).

1

I This topical report specifically seeks NRC acceptance of: 1) the selection of the 57 critical 1 experiments for actinide-only burnup credit analysis, 2) the selected trend analyses requirements, I 3) the method of determining the upper safety limit, and 4) the use of the CSAS/27BURNUPLIB code system with a $0.05 \Delta \mathrm{k}_{\mathrm{m}}$ administrative safety margin to perform actinide-only burnup credit criticality safety calculations in SNF package design. 


\section{ANALYSIS AND MODELING PARAMETERS}

This chapter provides limiting values of parameters that are used in burnup credit analyses. SNF modeling parameters important to depletion and/or criticality calculations are described. Sensitivity studies and assumptions that were made to obtain the limiting values are presented. Some parameters are generic to all SNF assembly design types, so that a single value of a parameter is used for all PWR fuel types, while others are specific to the fuel assembly design. Parameters that are needed for isotopic calculations are generic to all SNF package system designs while parameters that are needed in criticality calculations are SNF package system design specific.

The parameters considered are discussed below, along with the nuclear phenomena that are affected. The sensitivity studies provide the values that are needed for the burnup credit analysis. The studies cover the range of parameter values appropriate for burnup credit analyses.

\subsection{LIMITING PARAMETERS IN THE CALCULATION OF ISOTOPIC CONCENTRATIONS}

The parameters discussed in this section are independent of the specific design of an SNF package system and only affer . the isotopic concentration of the fuel to be loaded in the package. They are determined by the operating history at the nuclear power plant. The parameters are the specific power level, operating time at that power, the dissolved boron concentration (parts per million boron, ppmb), the water moderator temperature, the water density, and the fuel pellet temperature.

\subsubsection{Specific Power}

The specific power level of the assembly determines the rate of production of heavy elements and fission products of interest to burnup credit. A number of these isotopes undergo significant radioactive decay during the burning of the fuel. In addition, isotopes have a neutron capture cross section so that a quantity of the isotope is transmuted during the burning process. The rate of production compared to the rate of decay and transmutation determines the isotopic concentration in the spent nuclear fuel.

An increase in specific power results in two changes: (1) increase in neutron flux used for fuel depletion and (2) decrease in fuel depletion time (to achieve a same burnup). The decrease in fuel depletion time has a negligible effect on the majority of the actinides because of their long halflives. However, Pu-241 is affected because of its short half-life of 14.4 years. Essentially, Pu-241 has less time to $\beta$-decay to Am-241. Therefore, the concentration of Pu- 241 increases as the specific power increases. Consequently, the concentration of Am-241 decreases as the specific power increases because the main production chain of Am-241 is the $\beta$-decay of Pu-241. Also, the concentration of Pu-238 decreases as the specific power increases. Increase in neutron flux affects the actinide concentration rather indirectly. The equilibrium concentration of Xe-135 increases as the neutron flux increases. This increase in Xe-135 concentration hardens the neutron spectrum ${ }^{4-1}$ to which a fuel assembly is exposed. The spectrum hardening causes increased absorption in U-238 by resonance capture and consequently increases the concentration of fissile plutonium isotopes. Subsequently, U-235 is depleted less as more fissions occur in plutonium isotopes. Ultimately, the net effect of these changes is the increase in spent fuel reactivity with respect to specific power. 
A comparison ${ }^{4-1}$ of the reactivity of PWR fuel versus the specific power level at which the irradiation occurred is shown in Table 4-1. In these comparisons, the burnup is fixed, and the specific power level is varied from 10 to $50 \mathrm{MW} / \mathrm{MTU}$. Reactivity calculations were performed with U-235 initial enrichments of 3.0, 3.6, and $4.5 \mathrm{w} / \mathrm{o}$ U-235 and burnups of 10,30, and 50 GWD/MTU to encompass the typical range of enrichments and burnups for PWR fuel assemblies. Fuel and moderator temperatures were fixed to limit the number of variables being studied. Table 4-1 provides reactivities at a 3.6 w/o U-235 initial enrichment and 30 GWD/MTU burnup. The reactivities for the other enrichments and burnups displayed trends consistent with the $3.6 \mathrm{w} / \mathrm{o}, 30$ GWD/MTU trend and are not shown in Table 4-1 for clarity. Inspection of the table shows that a higher specific power level assumption results in a higher discharge reactivity.

Table 4-1. $\mathrm{k}_{\mathrm{inf}}$ versus Specific Power

\begin{tabular}{|c|c|}
\hline $\begin{array}{c}\text { Specific Power } \\
\text { (MW/MTU) }\end{array}$ & $\begin{array}{c}\mathbf{k}_{\text {inf }} \\
(\mathbf{3 . 6} \mathbf{w} / \mathbf{0}, \mathbf{3 0} \mathbf{G W D} / \mathbf{M T U})\end{array}$ \\
\hline \hline 10 & 1.19194 \\
\hline 15 & 1.19503 \\
\hline 20 & 1.19671 \\
\hline 25 & 1.19781 \\
\hline 30 & 1.19855 \\
\hline 35 & 1.19913 \\
\hline 40 & 1.19950 \\
\hline 45 & 1.19982 \\
\hline 50 & 1.20008 \\
\hline
\end{tabular}

The dependence of reactivity upon fuel cycle variations was also investigated..$^{4-1}$ Eleven variations of a three-cycle burnup were evaluated ranging from constant power to variable specific power levels. The cycle variations are illustrated in Figure 4-1, and the resulting reactivities are tabulated in Table 4-2. The reactivity after a continuous burning (Case 1, No Downtime, which is equivalent to a single cycle) is higher than other cases because the omission of the time between cycles (used to reload fuel in the reactor and perform maintenance) effectively shortens the cooling time and contributes to the increased reactivity. Furthermore, the power in an assembly depends upon its position within the reactor core, which is typically changed each cycle, so cycles with higher and lower power were evaluated (Cases 9 through 11). A higher power (120\% of the average in the 
core) in the third cycle (Case 11) results in a higher reactivity for the discharged fuel, again due to an effective shortening of the cool time for most of the radionuclides produced during the burning. The number of possible variations of cycle power and cycle lengths is large, so a single irradiation cycle (Case 1) combined with higher than average power (Case 11) is required to provide a conservative cycle model. Specific powers for PWR fuel are typically $45 \mathrm{MW} / \mathrm{MTU}$ or less ${ }^{4-2}$, and applying a $120 \%$ factor yields a specific power for the single cycle model of $54 \mathrm{MW} / \mathrm{MTU}$. Thus, to ensure conservative results, fuel depletion analyses shall be performed with a single cycle at 60 MW/MTU.

Table 4-2. $\mathrm{k}_{\mathrm{inf}}$ versus Cycle Operating History

\begin{tabular}{|c|c|}
\hline Case & $\begin{array}{c}\mathbf{k}_{\text {inf }} \\
\mathbf{( 3 . 0} \mathbf{w} / \mathbf{0}, \mathbf{3 0} \text { GWd/MTU) }\end{array}$ \\
\hline 1 & 1.14391 \\
\hline 2 & 1.14370 \\
\hline 3 & $1 . .14333$ \\
\hline 4 & 1.14287 \\
\hline 5 & 1.14355 \\
\hline 6 & 1.14308 \\
\hline 7 & 1.14237 \\
\hline 8 & 1.13890 \\
\hline 9 & 1.14312 \\
\hline 10 & 1.14360 \\
\hline 11 & 1.14448 \\
\hline
\end{tabular}



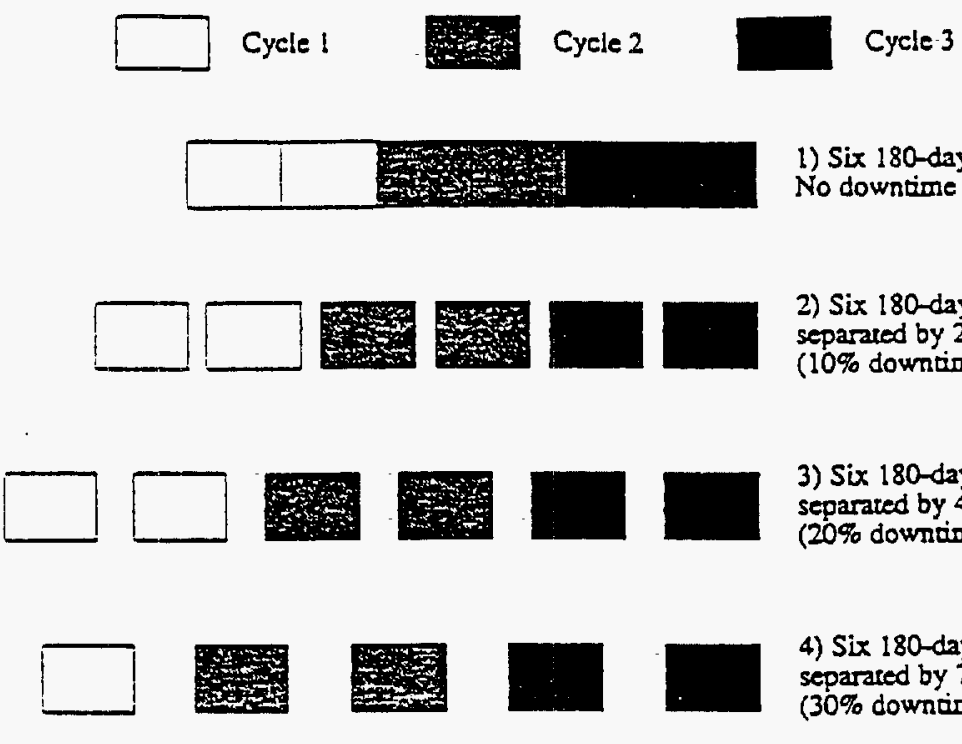

1) Six 180-day full-power periods, No downtime

2) Six 180-day full-power periods. separzied by 20-day down periods (10\% downtime)

3) Six 180-day full-power periods. separated by 45-day down periods (20\% downime)

4) Six 180-day full-power periods, separared by 77 -day down periods (30\% downime)

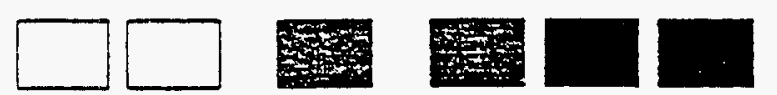

5) Six 180-day full-power periods, $10 \%$ downtime, $30 \%$ downtime in middle cycle
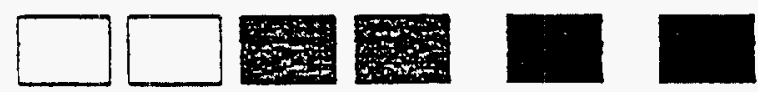

6) Six 180-day full-power periods, $10 \%$ downtime, $30 \%$ downtime in last cycle

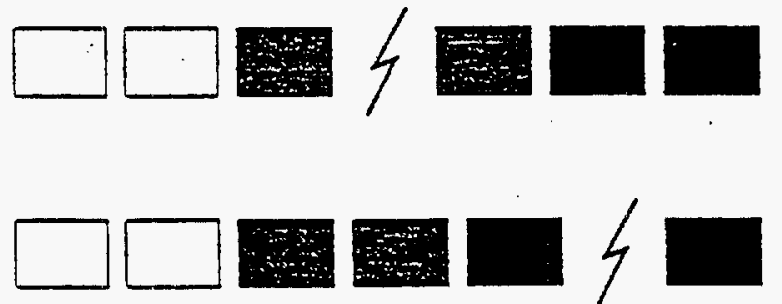

7) Six 180-day full-power periods, 10\% dowatime. 720 -day downtime in middle of middle cycle

8) Six 180-day full-power periods. $10 \%$ downtime. 720-day dowatime in middle of last cycle

9) Six 180-day periods,

$120 \%$ power in first cycle, $90 \%$ power in remaining cycles, $10 \%$ downtime

10) Six 180-day periods.

$120 \%$ power in middle cycle, $90 \%$ power in remaining cycles, $10 \%$ downtime

11) Six 180 -day periods.

$120 \%$ power in last cycle. $90 \%$ power in remaining cycles, $10 \%$ downtime

Figure 4-1. Cycle Operating History Cases 


\subsubsection{Dissolved Boron Effects}

Boron is dissolved in the reactor coolant of PWRs so that the reactivity change due to burnup, and excess initial reactivity, can be adjusted without the use of control rods. This provides significant core design benefits. At the beginning of an irradiation cycle, the boron concentration is at a maximum level. As the fuel is burned and the core becomes less reactive, the boron concentration is reduced. A higher concentration of boron causes a harder spectrum in the reactor core and fuel assembly, and the lower thermal flux component reduces the U-235 use. Therefore, when the fuel assembly is discharged from the reactor, it retains a greater portion of the initial U-235. Enhanced plutonium utilization includes greater production of $\mathrm{Pu}-239$ by U-238 neutron capture because the plutonium value of $v$ (number of neutrons produced per fission) is greater. In addition, the total recoverable energy per fission is approximately $4 \%$ greater for Pu- 239 than for U-235, so that less total fissioning is required to maintain a given specific power level when $\mathrm{Pu}-239$ is burned. Thus a discharged PWR fuel assembly contains a higher effective (U-235 and fissile plutonium) enrichment and is more reactive when placed in the SNF package system. Enhanced plutonium production also includes increased production of Pu-240 and Pu-242, which absorb neutrons, so there is some counteracting decrease in reactivity. However, this effect is smaller than the reactivity increase caused by the U-235 and fissile plutonium. Figure 4-2 indeed shows the increase in spent fucl reactivity with respect to boron concentration. ${ }^{4 \cdot 2}$ Hence the use of the maximum value that the cycle average ppmb can attain for a given fuel type results in a conservative prediction of the reactivity effects of dissolved boron.

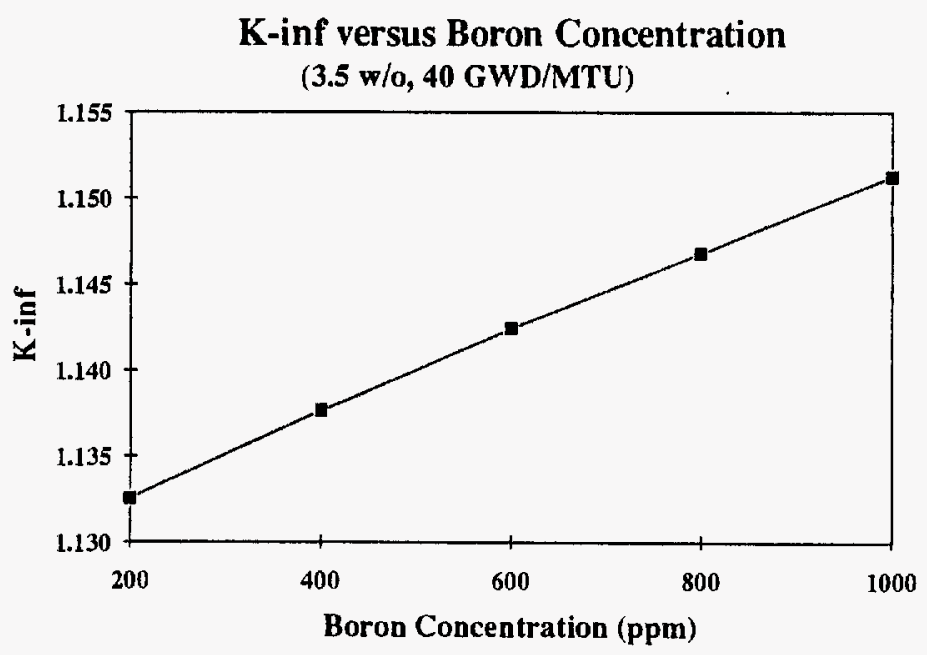

Figure 4-2. $\mathrm{k}_{\mathrm{inf}}$ versus Boron Concentration 
In practice, the boron concentration is adjusted continuously as the fuel is burned, and the critical boron letdown curve is generated as part of normal fuel reload analysis. The average boron concentration is to be found by integrating the boron letdown curve with respect to time and 1 dividing it by the cycle length. The maximum average boron concentration for a particular fuel 1 assembly type is to be identified from all reactor types and cycles which utilize the same assembly 1 type and recorded in the loading curve (see chapter 5). The maximum average boron concentration I shall be used for burnup credit analyses.

\subsubsection{Reactor Coolant Temperature and Density}

The neutron spectrum in a reactor core and the fuel assembly is influenced by the moderator density during reactor operation. As the reactor coolant density decreases there is less hydrogen between I the fuel rods to slow down neutrons, and a spectral shift toward a harder spectrum is the result. The 1 spectrum hardening increases the resonance capture in U-238. The increase of resonance capture 1 in U-238 results in increased fissile plutonium production. This in turn leads to increased fission 1 in plutonium and decreases $\mathrm{U}-235$ depletion. The net effect is an increase in spent fuel reactivity ${ }^{4-2}$ 1 as shown in Figure 4-3.

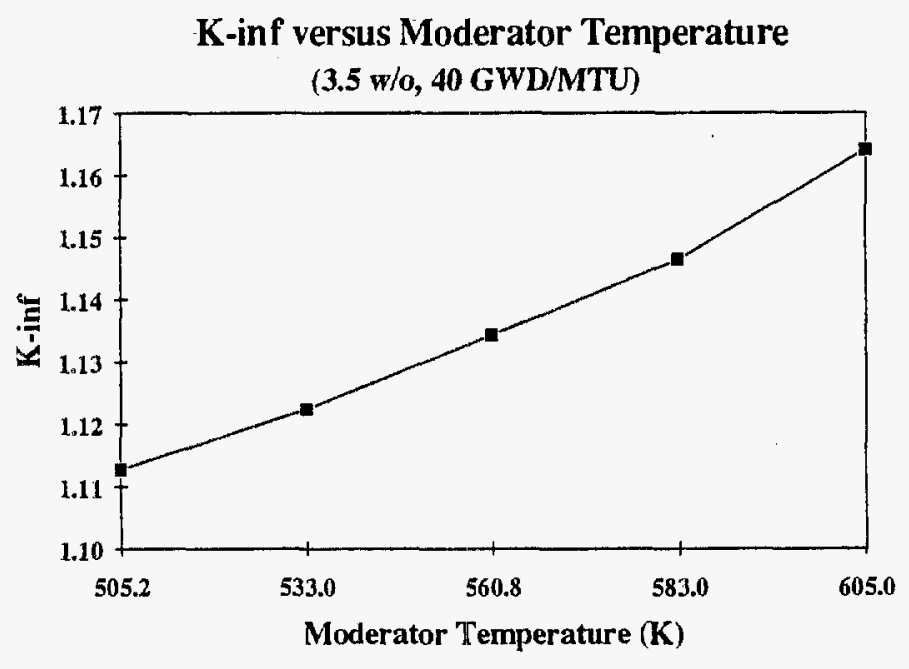

Figure 4-3. $\mathrm{k}_{\mathrm{inf}}$ versus Moderator Temperature

I The moderator temperature increases from the bottom to the top of the core. Thus, the use of average core outlet temperature appears to bound the moderator temperature conservatively. Applying the average core outlet temperature over the entire fuel length and for the entire depletion time provides adequate assurance of bounding treatment. The maximum average core outlet temperature and its equivalent density for a particular assembly type are to be identified from all 
reactor types and cycles which utilize the same assembly type and recorded in the loading curve (see chapter 5). The maximum average core outlet temperature shall be used for burnup credit analyses.

\subsubsection{Fuel Pellet Temperature}

At reactor startup the fuel pellet temperature rises when the fuel begins to generate the heat that will power the steam turbine to produce electricity. The fuel pellet temperature rise causes the U-238 resonance cross sections to become Doppler broadened, which in turn increases the probability of resonance capture within the pellet. As more U-238 resonance captures occur more $\mathrm{Pu}-239$ and $\mathrm{Pu}-$ 241 are produced. This in turn leads to increased fission in plutonium and decreases U-235 depletion. Therefore, as shown in Figure 4-4 spent fuel is more reactive after loading in an SNF package when higher pellet temperatures are used in the depletion calculations ${ }^{4-2}$.

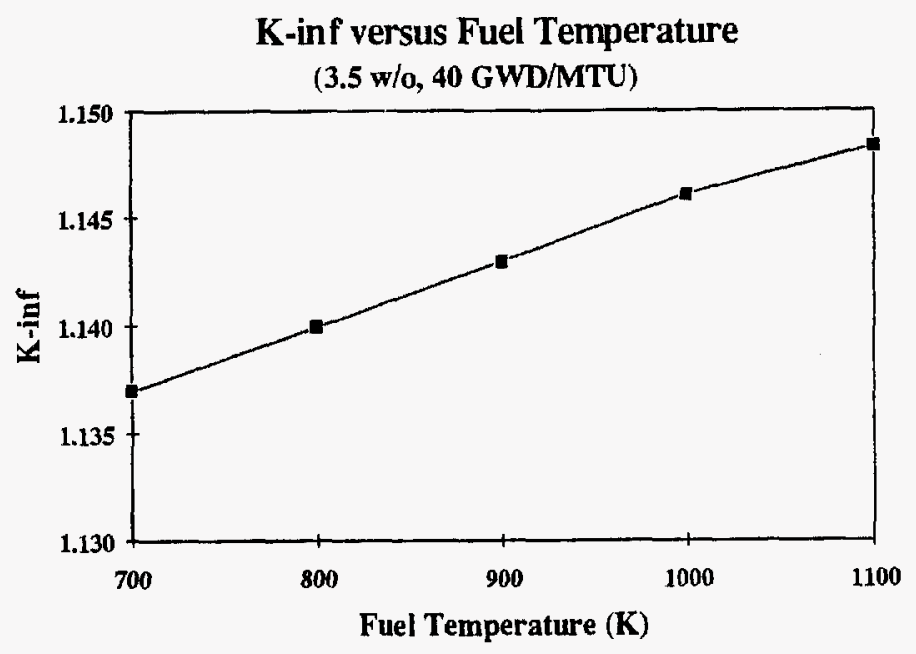

Figure 4-4. $\mathrm{k}_{\mathrm{inf}}$ versus Fuel Temperature

The nominal average pellet temperature should be calculated based on a reactor rated linear power multiplied by the radial peaking factor limit. A sufficiently conservative value can be obtained using a uniform axial power distribution and taking the average pellet temperature from the top of the fuel assembly. For gap conductance and thermal conductivity, the burnup that results in the highest fuel temperature should be used. The maximum average pellet temperature for a particular assembly type is to be identified from all reactor types and cycles which utilize the same assembly type and recorded in the loading curve (see chapter 5). The maximum average pellet temperature shall be used for burnup credit analysis. 


\subsubsection{Summary of Limiting Parameters}

To provide a consistent set of modeling parameters for actinide-only burnup credit analyses, the depletion isotopic calculations performed for burnup credit analyses shall use a specific power of $60 \mathrm{MW} / \mathrm{MTU}$ applied for a single cycle of sufficient length to produce the desired burnup. The boron concentration used shall be the maximum value of the cycle average ppmb appropriate for the assembly type being analyzed, and the moderator temperature shall be the maximum coreaverage outlet temperature. The fuel pellet temperature shall be the maximum average pellet temperature for the given assembly design. These values shall be appropriate for the PWR assembly type being analyzed and represent the maximum, most conservative values. The values shall be recorded on the burnup credit loading curve as presented in Chapter 5 of this topical report.

\subsection{SNF PACKAGE DESIGN SPECIFIC EFFECTS}

The effects discussed in this section are dependent upon the specific design of a cask system. These 1 modeling parameters include the density of the water moderator in the SNF package, the fuel I temperature and the fuel assembly axial and horizontal burnup profile.

\subsubsection{Moderator Density}

Criticality saiety analyses must consider optimum moderator density to ensure that the most reactive configuration is evaluated (i.e., a fully flooded cask must be evaluated per 10 CFR \$71.55). PWR assemblies are designed to be under-moderated, and reductions in water density from the maximum value of $1.0 \mathrm{~g} / \mathrm{cc}$ result in a decrease in the $k_{\infty}$ of the fuel. The maximum reactivity for spent fuel in storage or transport fuel baskets is thus usually achieved at $1.0 \mathrm{~g} / \mathrm{cc}$, the maximum density of water. However, for systems in which the water contains dissolved boron and for new fuel storage racks, a reactivity maximum may occur at lower densities. Typical maximum reactivity densities for new fuel storage racks are $0.1 \mathrm{~g} / \mathrm{cc}$ and spent fuel baskets in borated water achieve a maximum reactivity at 0.7 to $0.8 \mathrm{~g} / \mathrm{cc}$.

In an SNF package design, the most reactive moderator density varies depending upon the detailed design of the spent fuel basket. Significant differences in sensitivity to moderator density occur between baskets with closely-packed fuel arrays and baskets that include flux traps. The addition of a water gap flux trap to the basket structure could cause a reactivity maximum at a density less than $1.0 \mathrm{~g} / \mathrm{cc}$ because even though low water density decreases the moderation of neutrons within the fuel, it also decreases the effectiveness of the flux trap. The flux trap works by slowing down fast neutrons within the water gap, so that they will be absorbed by neutron absorbers such as B-10 within the structure of the fuel basket. The low water density decreases the moderation of fast neutrons within the flux trap so that more neutrons pass between adjacent assemblies, increasing the reactivity of the SNF package.

Burnup credit analyses must consider the effects of moderator density from 0 to $1.0 \mathrm{~g} / \mathrm{cc}$ within the spent fuel package. Given the sensitivity of SNF multiplication factor on the moderator density, the full moderator density range must be considered. Especially in the low moderator density range, a small density increment should be adopted. Also, the potential for uneven and preferential flooding which might decrease the effectiveness of criticality control design features must be 
addressed in the same manner as in the fresh fuel assumption. The moderator density effects must be evaluated with zero burnup at low enrichments (the maximum fresh fuel enrichment limit for the SNF package) and at high enrichments (the highest enrichment evaluated for the package) with the associated burnup from the burnup credit loading curve. If these evaluations indicate that a reactivity maximum exists at any density but $1.0 \mathrm{~g} / \mathrm{cc}$, then an optimum moderator density search is required at all enrichments evaluated for the burnup credit loading curve.

\subsubsection{Fuel Temperature}

When a cask loaded with spent fuel reaches thermal equilibrium, it can be significantly hotter than when first loaded. The increase in fuel temperature increases the resonance capture of neutron in $\mathrm{U}-238$ and decreases the multiplication factor of the SNF ${ }^{4-2}$. Therefore, an ambient temperature of $20{ }^{\circ} \mathrm{C}=293 \mathrm{~K}$ should be used as the fuel temperature in SNF casks regardless of the thermal equilibrium temperatures expected in normal and accident conditions.

\subsubsection{Axial Burnup Profile}

The axial power peaking effect caused by neutron leakage from the ends of the finite-length fuel assembly produces an axial profile in the burnup. This axial variation in burnup can be accurately described by adopting multiple zones of varying burnup within a fuel assembly. I fowever, the fuel assembly modeled with an axially uniform assembly average burnup results in over-prediction of reactivity in the fuel mid-region and under-prediction in fuel end region. The reactivity difference between the axially burnup dependent analysis and the uniform analysis is commonly known as "end effects", and the relative importance of the over-predicted fuel mid-region and the under-predicted fuel end region determines the sign and magnitude of the end effect. The parameters that influences the end effect include axial burnup profile, axial reflector, cask configuration, fuel assembly length and cooling time.

\subsubsection{Limiting Axial Burnup Profile}

An example of the axial profile of spent fuel is illustrated by the measurement of Cs-137 as shown in Figure 4-5..$^{4-3}$ The shape of the burnup profile is a flattened cosine, with a peak from 1.1 to 1.2 times the average value of the burnup, and a burnup at the fuel rod ends that equals from 50 to $60 \%$ of the average value. Details of the calculational modeling approach used for the end effects are discussed below. The axial profile for each individual spent fuel assembly will vary somewhat from this profile depending on the specific power history of the assembly. Restrictions are placed upon the selection of candidate fuel assemblies in Section 6 to ensure that the profiles of assemblies loaded into an SNF package system with burnup credit do not differ significantly from the profile used as a basis for studies in this topical report.

A PWR axial burnup profile database ${ }^{4-4}$ has been compiled to study the effect of different axial burnup profiles on the end effects. The database includes 3169 axial burnup profiles from five different PWR fuel types. The profiles are calculated from fuel management codes and represent 20 different PWR reactors and 105 operating cycles. The profiles are tabulated as 18 normalized, equal-size nodes. These shapes have been analyzed ${ }^{4-5}$ and the results are shown in Figure 4-6. The end effect reactivity shown in Figure $4-6$ is defined as $\left(\mathrm{k}_{18 \text { nodes }}-\mathrm{k}_{\text {uniform }}\right) / \mathrm{k}_{\text {uniform }}$. 


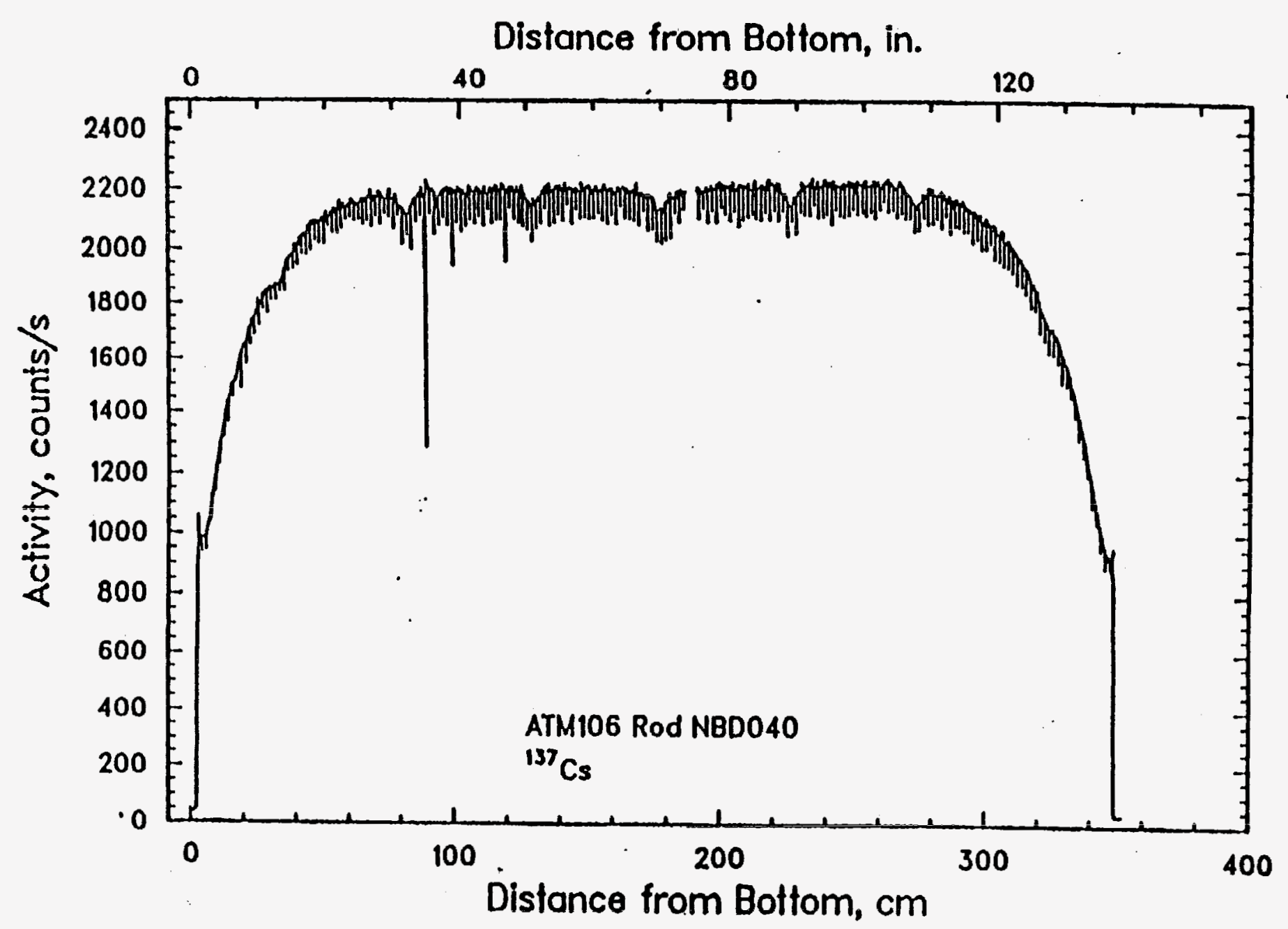

Figure 4-5. Burnup Profile Measurement by Gamma Scan 
The bounding axial profile analysis ${ }^{4-5}$, however, implicitly included fission products in addition to actinides. The end effect profile rankings determined by the bounding profile analysis ${ }^{4-5}$ have been repeated on selected profiles and confirmed in a separate analysis ${ }^{4-2}$ using the actinide-only methodology: Also, the limiting profiles to be used with actinide-only burnup credit methodology have been determined in the same study. ${ }^{4-2}$ Table 4-3 shows the limiting axial profiles. In general, the end effect is negative at a low burnup and increases as the burnup increases. At a low burnup, the fuel mid-region, where reactivity is over-predicted, is emphasized since the flux shape is close to cosine. This results in a negative end effect. At a high burnup, however, the flux shape significantly deviates from the cosine shape and become more pronounced in fuel end region. Thus, the fuel end region, where reactivity is under-predicted, becomes more important and the end effect becomes positive.

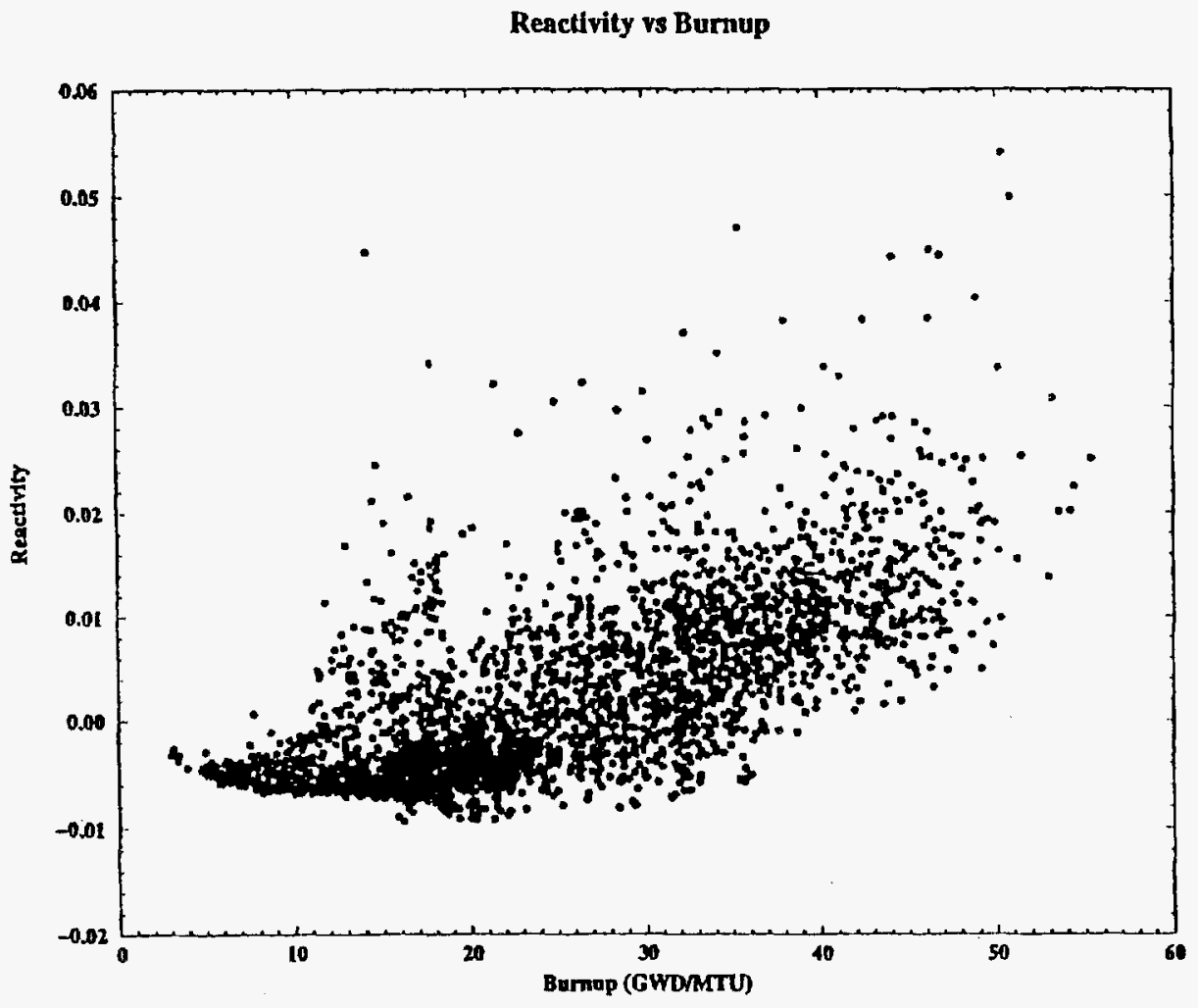

Figure 4-6. End Effect Reactivity versus Burnup

\subsubsection{Axial Modeling Requirements}

Any cask design using actinide-only burnup credit shall model the axial burnup with the 18 normalized, equal-size burnup profile given in Table 4-3. Different profiles are to be applied depending on the assembly average burnup value. For example, an assembly with an average burnup of $25 \mathrm{GWD} / \mathrm{MTU}$ is to be analyzed with profile 2 . Every analysis is to be performed based on the actual cask configuration with a chosen assembly type and cooling time. However, if a cask has an axially varying poison plate design, the minimum poison concentration is to be assumed for the whole length. Also, if a fuel assembly employs multiple enrichment design, the maximum 
enrichment is to be assumed for the entire length. The same depletion code and cross section library used for isotopic validation (chapter 2) must be used for the calculation of actinide concentrations. Also, the isotopic correction factors determined consistent with the methodology presented in chapter 2 must be applied. The same criticality code and cross section library used for criticality validation (chapter 3 ) must be used with both the uniform and 18-node analysis.

Table 4-3. Limiting Axial Burnup Profiles

\begin{tabular}{|c|c|c|c|}
\hline \multirow{2}{*}{$\begin{array}{c}\text { Axial Position } \\
\text { (\% of Core Height) }\end{array}$} & \multicolumn{3}{|c|}{$\begin{array}{c}\text { Normalized Burnup } \\
\text { (Fraction of Assembly Average) }\end{array}$} \\
\hline & $\begin{array}{c}\text { Profile } 1 \\
\text { BU }<18 \text { (GWD/MTU) } \\
\end{array}$ & $\begin{array}{c}\text { Profile } 2 \\
\mathbf{1 8} \leq \mathrm{BU}<\mathbf{3 0}(\mathrm{GWD} / \mathrm{MTU}) \\
\end{array}$ & $\begin{array}{c}\text { Profile } 3 \\
30 \leq \text { BU (GWD/MTU) } \\
\end{array}$ \\
\hline 2.78 & 0.649 & 0.668 & 0.652 \\
\hline 8.33 & 1.044 & 1.034 & 0.967 \\
\hline 13.89 & 1.208 & 1.150 & 1.074 \\
\hline 19.44 & 1.215 & 1.094 & 1.103 \\
\hline 25.00 & 1.214 & 1.053 & 1.108 \\
\hline 30.56 & 1.208 & 1.048 & 1.106 \\
\hline 36.11 & 1.197 & 1.064 & 1.102 \\
\hline 41.67 & 1.189 & 1.095 & 1.097 \\
\hline 47.22 & 1.188 & 1.121 & 1.094 \\
\hline 52.78 & 1.192 & 1.135 & 1.094 \\
\hline 58.33 & 1.195 & 1.140 & 1.095 \\
\hline 63.89 & 1.190 & 1.138 & 1.096 \\
\hline 69.44 & 1.156 & 1.130 & 1.095 \\
\hline 75.00 & 1.022 & 1.106 & 1.086 \\
\hline 80.56 & 0.756 & 1.049 & 1.059 \\
\hline 86.11 & 0.614 & 0.933 & $0.971^{\circ}$ \\
\hline 91.67 & 0.481 & 0.669 & 0.738 \\
\hline 97.22 & 0.284 & 0.373 & 0.462 \\
\hline
\end{tabular}




\subsubsection{Simplified Axial Modeling}

If cask designers feel that their cask design has a large reactivity margin and want to avoid the timeconsuming axially burnup dependent analysis, a simplified axial modeling approach is available. Instead of 18 -node, burnup dependent analysis, a fuel assembly can be analyzed with an axially uniform burnup at the assembly average burnup value. To account for the end effects, $\mathrm{k}_{\text {eff }}$ biases presented later in this section must be added to the axially uniform calculation. Because the $\mathrm{k}_{\text {eff }}$ biases need to encompass every commercial and conceptual cask designs, they are determined based on a significantly conservative cask configuration, namely a single assembly configuration. For this reason, the simplified axial modeling approach is recommended only for cask designs with large reactivity margins. The requirements for simplified axial modeling are the same as those given in section 4.2.3.2 except that an uniform analysis needs to be performed and $\mathrm{k}_{\text {eff }}$ bias is to be added to the resulting multiplication value.

The following four sections describe the end effect trends with respect to axial reflector, cask configuration, fuel assembly length and cooling time. The $k_{\text {eff }}$ bias curves to be used in a simplified axial modeling approach are established based on the observed end effect trends.

\subsection{Axial Reflector}

The cask designers would use the actual axial characteristics of the fuel and cask, but for the $\mathrm{k}_{\text {eff }}$ bias curves a limiting axial reflector must be determined. Two different axial reflector modeling assumptions, pure water reflector and 50/50 (by volume) homogenous mixture of stainless steel and water, are studied for their effect on the magnitude of end effect. ${ }^{4-2}$ The 50/50 stainless steel and water mixture axial reflector approximates the presence of the top and bottom nozzles at assembly end regions. It is shown $\mathrm{n}^{4-2}$ that the pure water reflector assumption is more conservative at a high burnup while there is no significant difference between the two assumptions at a low burnup. At a low burnup, axial modeling assumptions do not affect the magnitude of the end effect significantly because the axial neutron leakage is minimal. At a high burnup, however, the neutron flux becomes peaked in the fuel end regions and different axial reflector assumptions do change the magnitude of the end effect.

\subsection{Cask Configuration}

Again, the cask designers will fully model the actual cask configuration, but for the $\mathrm{k}_{\text {eff }}$ bias curves a limiting cask configuration must be determined. The magnitude of end effect is a function of cask size and poison plates in casks. ${ }^{4-2}$ Three cask configurations considered in a sensitivity study ${ }^{4-2}$ include: (1) infinite array to approximate a large cask, (2) a four-assembly configuration to approximate a small cask and (3) a single assembly configuration to approximate the presence of completely "black" poison plates. It is shown that the magnitude of the end effect increases with the decrease in cask size and with the addition of poison plates. ${ }^{4-2}$ Thus, a single assembly configuration is the most limiting one for the end effect. The end effects for a single assembly configuration is significantly higher than those for an conceptual cask design with poison plates ${ }^{4-3}$. 


\section{4.2.3.3.3 Fuel Assembly Length}

A sensitivity analysis on three different assembly fuel lengths - 10, 12 and 14 feet - shows that the magnitude of the end effect increases with the increase in the active fuel length. ${ }^{4-2}$ The increase in the active fuel length increases the fuel end regions which are the main cause of the end effect. The decrease in axial neutron leakage with respect to the increase in the under-burned fuel end regions I is the physical reason for this observed trend.

\section{| 4.2.3.3.4 Cooling Time}

$\mathrm{Pu}-241$ and $\mathrm{Am}-241$ are the only isotopes that undergo a significant isotopic changes during the first I 100 years after SNF discharge from reactors. Pu-241 has a half-life of 14.4 years and decays to Am1 241. At discharge, the concentration of Pu-241 is higher in the fuel mid region that the fuel end 1 regions. Consequently, the $\mathrm{Pu}-241$ concentration change with time is greater in fuel mid region. In addition, the concentration of Am-241, most of which comes from the decay of Pu-241, increase more in the fuel mid region. This phenomena lead to an increase in relative reactivity of the fuel end regions compared to the fuel mid region and results in increased end effect. A sensitivity analysis shows that the increase in the end effect, from 5 to 15 year cooled assembly, can be as large as $1.0 \%$ in $\mathrm{k}_{\text {eff }}$ at a high burnup for $:$ single assembly configuration. ${ }^{4 \cdot 2}$

\section{4.2.3.3.5 $\mathrm{k}_{\mathrm{err}}$ Bias Curves}

1 The $\mathrm{k}_{\text {eif }}$ bias curves to be applied in the simplified axial modeling approach are determined based I on the single assembly cask configuration, pure water axial reflector and the limiting axial burnup profiles given in Table 4-3. Separate curves are provided for different fuel assembly lengths and conling times. Figure 4-7 through 4-9 show the $k_{\text {eff }}$ bias curves corresponding to 5,10 and 15 year cooling time. ${ }^{4-2}$ The $k_{\text {eff }}$ bias curves are piecewise straight lines in three burnup zones consistent with the limiting axial profiles shown in Table 4-3. The $k_{\text {eff }}$ bias values at different burnups are shown in Table 4-4 through 4-6. ${ }^{4-2}$ The end effect is defined as $\Delta \mathrm{k}_{\text {eff }}(\%)=100 *\left(\mathrm{k}_{18 \text { nodes }}-\mathrm{k}_{\text {unifom }}\right)$ in Figure 4-7 through 4-9 and Table 4-4 through 4-6.

Any cask designed for cooling time greater than 15 years cannot use the $\mathrm{k}_{\text {eff }}$ bias curves and must resort to axially burnup dependent analyses. The $\mathrm{k}_{\mathrm{eff}}$ bias curves can be interpolated between different assembly lengths but not between cooling time. A conservative cooling time must be adopted if an intermediate cooling time not shown in Figure 4-7 through 4-9 is to be used. For example, 7 year-cooled, 12.5-foot assembly must use 10 year $\mathrm{k}_{\text {eff }}$ bias curves for interpolation between 12 and 14-foot values. 


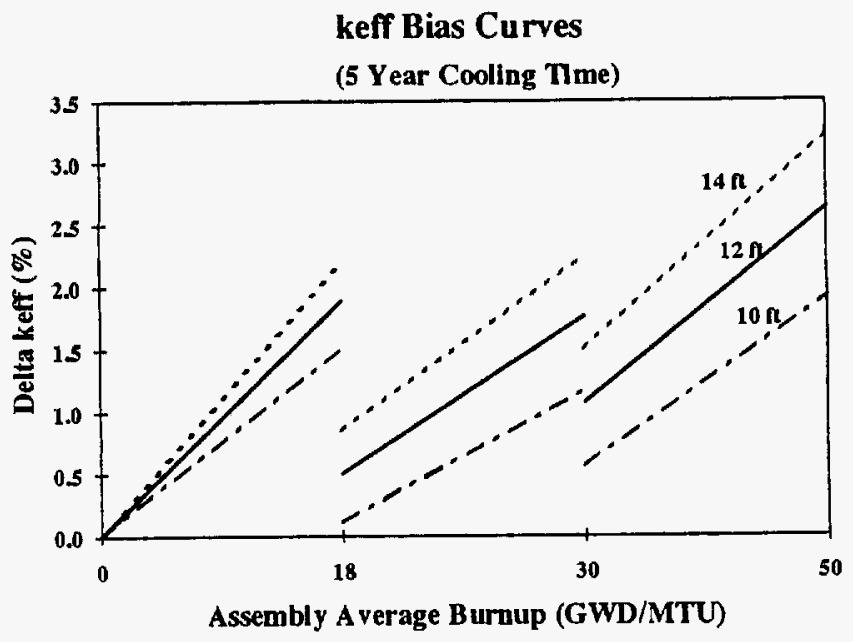

Figure 4-7. $k_{\text {eff }}$ Bias Curves for 5 Year Cooling Time

keff Bias Curves

(10 Year Cooling Time)

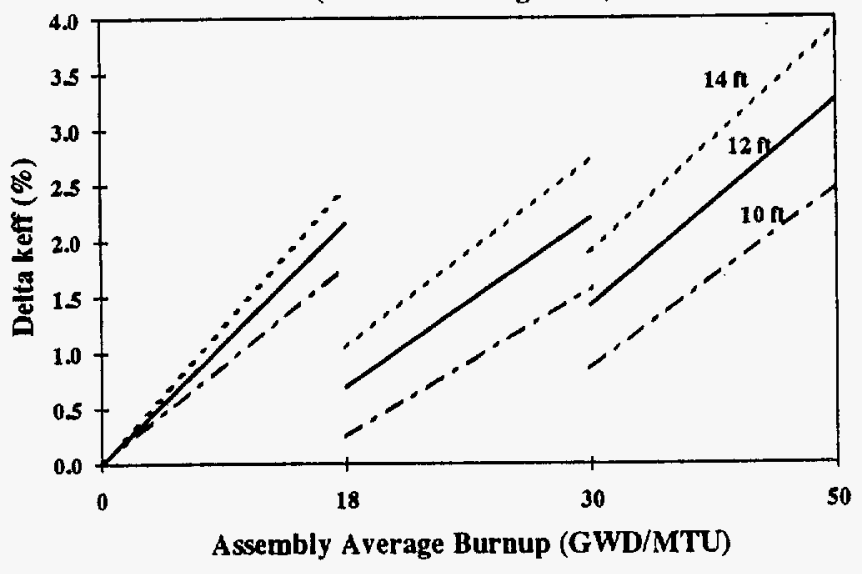

Figure 4-8. $\mathrm{k}_{\text {eff }}$ Bias Curves for 10 Year Cooling Time 


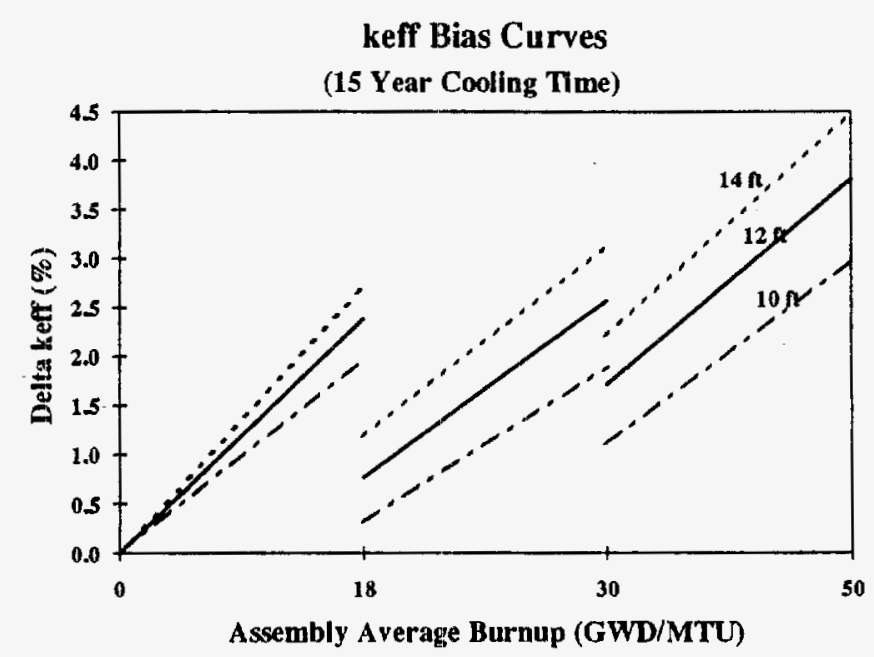

Figure 4-9. $\mathrm{k}_{\mathrm{eff}}$ Bias Curves for 15 Year Cooling Tir :e

Table 4-4. $\mathbf{k}_{\text {eff }}$ Bias Values for 5 Year Cooled Assembly

\begin{tabular}{||c|c|c|c||}
\hline \hline \multirow{2}{*}{$\begin{array}{c}\text { Average Burnup } \\
\text { (GWD/MTU) }\end{array}$} & \multicolumn{3}{|c|}{$\Delta \mathrm{k}_{\text {eff }}(\%)$} \\
\cline { 2 - 4 } & 10 foot Assembly & 12 foot Assembly & 14 foot Assernbly \\
\hline \hline 0 & 0 & 0 & 0 \\
\hline $18-$ & 1.51 & 1.89 & 2.18 \\
\hline $18+$ & 0.11 & 0.50 & 0.85 \\
\hline $30-$ & 1.17 & 1.76 & 2.24 \\
\hline $30+$ & 0.56 & 1.07 & 1.50 \\
\hline 50 & 1.92 & 2.63 & 3.22 \\
\hline
\end{tabular}


Table 4-5. $k_{\text {eff }}$ Bias Values for 10 Year Cooled Assembly

\begin{tabular}{|c|c|c|c|}
\hline \multirow{2}{*}{$\begin{array}{c}\text { Average Burnup } \\
\text { (GWD/MTU) }\end{array}$} & \multicolumn{3}{|c|}{$\Delta \mathrm{k}_{\text {eff }}(\%)$} \\
\cline { 2 - 4 } & 10 foot Assembly & 12 foot Assembly & 14 foot Assembly \\
\hline \hline 0 & 0 & 0 & 0 \\
\hline $18-$ & 1.77 & 2.16 & 2.46 \\
\hline $18+$ & 0.25 & 0.69 & 1.05 \\
\hline $30-$ & 1.57 & 2.20 & 2.73 \\
\hline $30+$ & 0.86 & 1.42 & 1.89 \\
\hline 50 & 2.48 & 3.26 & 3.91 \\
\hline
\end{tabular}

Table 4-6. $k_{\text {eff }}$ Bias Values for 15 Year Cooled Assembly

\begin{tabular}{|c|c|c|c||}
\hline \hline \multirow{2}{*}{$\begin{array}{c}\text { Average Burnup } \\
\text { (GWD/MTU) }\end{array}$} & \multicolumn{3}{|c|}{$\Delta \mathrm{k}_{\text {eff }}(\%)$} \\
\cline { 2 - 4 } & 10 foot Assembly & 12 foot Assembly & 14 foot Assembly \\
\hline \hline 0 & 0 & 0 & 0 \\
\hline $18-$ & 1.97 & 2.38 & 2.69 \\
\hline $18+$ & 0.32 & 0.76 & 1.19 \\
\hline $30-$ & 1.89 & 2.57 & 3.12 \\
\hline $30+$ & 1.11 & 1.71 & 2.21 \\
\hline 50 & 2.97 & 3.81 & 4.49 \\
\hline
\end{tabular}




\section{| 4.2.3.4 Summary of Axial Burnup Profile}

Axially burnup dependent analyses and $\mathrm{k}_{\text {eff }}$ bias curves are applicable only to those casks with an axially uniform poison concentration. If a cask employs axially varying poison plate design, the minimum poison concentration is to be assumed for the whole length. Also, if a fuel assembly employs multiple enrichment design, the maximum enrichment is to be assumed for the entire assembly. Assemblies with part-length burnable absorbers are included from the end effect viewpoint because they are inserted to flatten the flux distribution. The flattened flux distribution eventually results in flattened burnup distribution and ultimately reduces the end effect. The partlength control rods are designed to perform a similar function and included from the end effect viewpoint. The limiting axial profiles shown in Table 4-3 are determined from a database which include a number of assemblies irradiated with axial power shaping rods. Thus, the database and the burnup profile analysis properly reflect the effect of axial power shaping rod. There are no initial enrichment nor burnup limits in using axially burnup dependent analyses from the end effect view point. However, the burnup limit is $50 \mathrm{GWD} / \mathrm{MTU}$ if $\mathrm{k}_{\mathrm{eff}}$ bias curves are used. The $\mathrm{k}_{\mathrm{eff}}$ bias curves are not intended to be extrapolated beyond the ranges shown in Figure 4-7 through 4-9.

\subsubsection{Horizontal Burnup Profile}

A significant horizontal variation in burnup can exist in PWR assemblies particularly if they are irradiated near the periphery of a core and discharged following a single irradiation cycle. Limiting arrangement of two or more assemblies with low burnup zones placed inward and adjacent to one another could potentially result in reactivity increase in a SNF cask. This consideration is of special concern for small SNF cask designs where the radial neutron leakage is significant, and thus, the orientation of fuel assemblies could make a significant change in the multiplication factor.

Figure 4-10 shows the maximum quadrant deviation from the assembly average burnup with respect to the assembly averaged burnup determined from a compiled horizontal burnup database. ${ }^{4-6}$ The horizontal burnup gradient is inversely proportional to the assembly averaged burnup reflecting typical fuel management practices of moving assemblies from cycle to cycle to minimize the local power peaking and maximize the fuel economy. It is clear from Figure 4-10 that the values given in Table 4-7 conservatively estimate the horizontal burnup gradient expected in PWR assemblies. Any cask design utilizing actinide-only burnup credit shall use the values listed in Table 4-7. These values represents horizontal burnup gradient within a single fuel assembly. For example, an assembly with an average assembly burnup of $15 \mathrm{GWD} / \mathrm{MTU}$ is to be analyzed with $10 \mathrm{GWD} / \mathrm{MTU}$ on one half and $20 \mathrm{GWD} / \mathrm{MTU}$ on the other half. The most reactive loading configuration of multiple fuel assemblies must be identified by cask designers for their particular casks. 


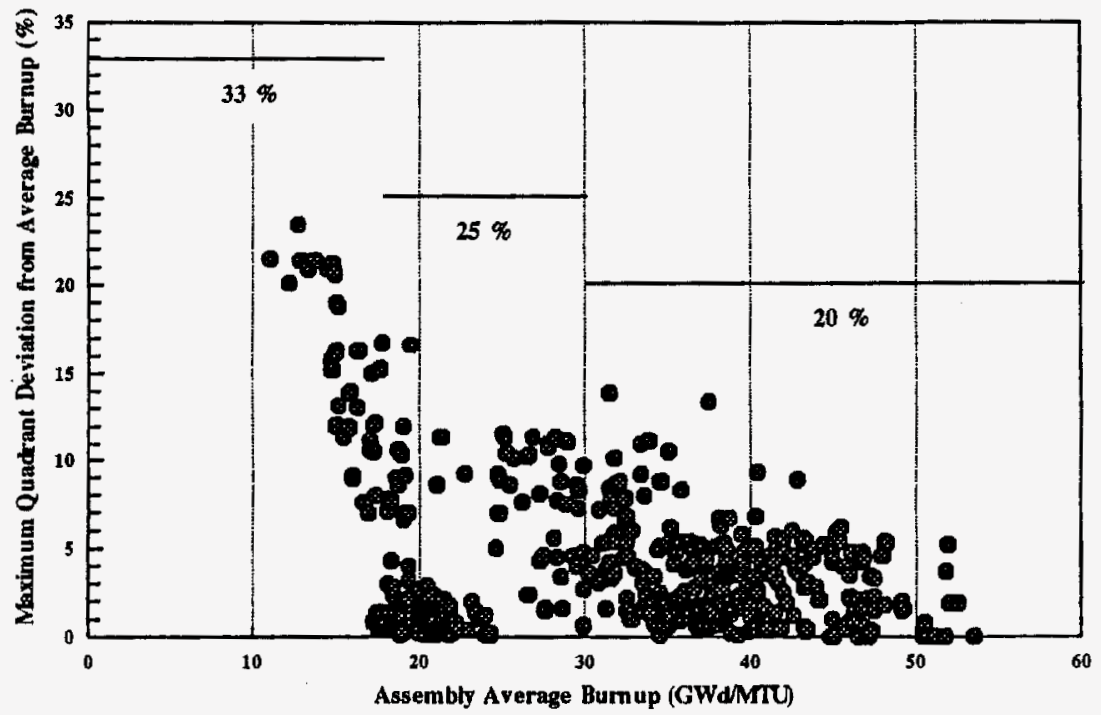

Figure 4-10. Maximum Quadrant Deviation versus Assembly Average Burncp $p^{+6}$

Table 4-7. Conservative Horizontal Burnup Gradients in PWR Assemblies

\begin{tabular}{|c|c|}
\hline Assembly Average Burnup (GWD/MTU) & Horizontal Gradient (\%) \\
\hline \hline$<18$ & 33 \\
\hline $18 \leq$ and $<30$ & 25 \\
\hline $30 \leq$ & 20 \\
\hline
\end{tabular}




\subsection{CONCLUSIONS}

This chapter defined the limiting parameters for the isotopic depletion analyses and the limiting SNF package analyses that must be performed for criticality calculations. This topical report seeks NRC acceptance of the limiting values for these parameters as presented in Table 4-8 below.

Table 4-8. Limiting Values of Modeling Parameters

\begin{tabular}{|c|c|c|}
\hline Parameter & Analysis Affected & Value/Assumption \\
\hline Cycle History & Depletion & $\begin{array}{l}\text { One Irradiation Cycle } \\
\text { (No Downtime) }\end{array}$ \\
\hline Specific Power & Depletion & $60 \mathrm{MW} / \mathrm{MTU}$ \\
\hline $\begin{array}{l}\text { Moderator Density } \\
\text { (In Reactor) }\end{array}$ & Depletion & $\begin{array}{c}\text { Maximum Average Core Outlet } \\
\text { Temperature } \\
\end{array}$ \\
\hline Dissolved Boron & Depletion & Maximum Cycle Average ppmb \\
\hline $\begin{array}{c}\text { Fuel Pellet Temperature } \\
\text { (In Reactor) }\end{array}$ & Depletion & $\begin{array}{c}\text { Maximum Average Pellet } \\
\text { Temperature } \\
\end{array}$ \\
\hline $\begin{array}{c}\text { Moderator Density } \\
\text { (In SNF Package) }\end{array}$ & Criticality & Search for Maximum Reactivity \\
\hline $\begin{array}{l}\text { Fuel Pellet Temperature } \\
\text { (In SNF Package) }\end{array}$ & Criticality & $\begin{array}{c}\text { Ambient Temperature } \\
20^{\circ} \mathrm{C}(293 \mathrm{~K}) \\
\end{array}$ \\
\hline Axial Burnup Profile & Criticality & $\begin{array}{c}\text { Axial Burnup-Dependent, 18- } \\
\text { Node Analysis with Profiles in } \\
\text { Table 4-3 } \\
\text { or } \\
\text { Uniform Analysis with keff Bias } \\
\text { Curves } \\
\end{array}$ \\
\hline $\begin{array}{c}\text { Horizontal Burnup } \\
\text { Gradient }\end{array}$ & Criticality & $\begin{array}{c}\text { Horizontal Burnup Gradients in } \\
\text { Table 4-7 } \\
\end{array}$ \\
\hline
\end{tabular}




\section{LOADING CRITERIA}

Burnup credit loading curves are the criteria used to determine whether it is permissible to load an assembly in an SNF package using burnup credit. This chapter describes the steps required to develop burnup credit loading curves. These curves identify the lowest acceptable burnup as a function of the initial enrichment. To generate a loading curve, the maximum fresh fuel enrichment meeting the upper safety limit on $\mathbf{k}_{\text {eff }}$ is determined. Subsequently, a curve of required minimum burnup versus initial enrichment is developed by applying the burnup credit methodology at various initial enrichments. Loading curves may be developed for each assembly type which will be stored, transported, or disposed in the SNF package. Since additional cooling time makes the loading curves less restrictive, they also can be generated as a function of cooling time. In general, there will be a single loading curve applicable to each specific combination of cask type, assembly type, and assembly minimum cooling time.

\subsection{FRESH FUEL CALCULATIONS}

The maximum fresh fuel U-235 enrichment that may be used in a given SNF package is determined first. The $k_{\text {eff }}$ is calculated with a validated code system (Chapter 3 ) for a range of initial enrichments to determine the enrichment that produces a $k_{\text {eff }}$ (or $k+1.645 \sigma$ for Monte Carlo results) equal to the upper safety limit. This is the maximum fresh fuel enrichment point and is labeled as point "A" on the loading curve (Figure 5-1). The loading curve consists of an abscissa that represents initial (fresh) fuel enrichment and an ordinate that represents the required minimum burnup for a given initial enrichment. Next, a vertical line is drawn at the maximum fresh fuel enrichment limit. All assemblies that have initial U-235 enrichments less than or equal to the maximum fresh fuel enrichment limit (point A) may be stored or transported regardless of burnup.

\subsection{GENERATION OF THE BURNUP CREDIT LOADING CURVE}

\subsubsection{Find the Limiting Burnup for Each Initial Enrichment}

The required minimum burnup for a specific initial enrichment value is the burnup at which the calculated $k_{\text {eff }}$ (or $k+1.645 \sigma$ ), using the burnup credit methodology, is just equal to the upper safety limit. The process for determining a required minimum burnup for a given initial enrichment is illustrated in Figure 5-2. A series of runs of validated computer codes (i.e., SAS2H and CSAS25) is performed to calculate $k_{\text {eff }}$ values for a range of burnups to search for the burnup value that produces the reactivity limit. The reactivity limit is the upper safety limit as determined in Chapter 3. As indicated in Figure 5-2, the calculated $\mathbf{k}_{\text {eff }}$ is plotted against the burnup that produced that value of $k_{\text {eff. }}$ The curve is then fit to estimate the burnup that crosses the upper safety limit. Since the radial and axial burnup modeling have discontinuities at 18 and $30 \mathrm{GWd} / \mathrm{MTU}$, care must be taken to avoid extrapolation or interpolation across these discontinuities. The process is repeated for various initial enrichments as illustrated in Figure 5-2. A calculation is performed near that burnup (for each initial enrichment value) which will be less than or equal to the upper safety limit. This limiting burnup will be used with the corresponding initial enrichment to establish a point on the burnup credit loading curve. 


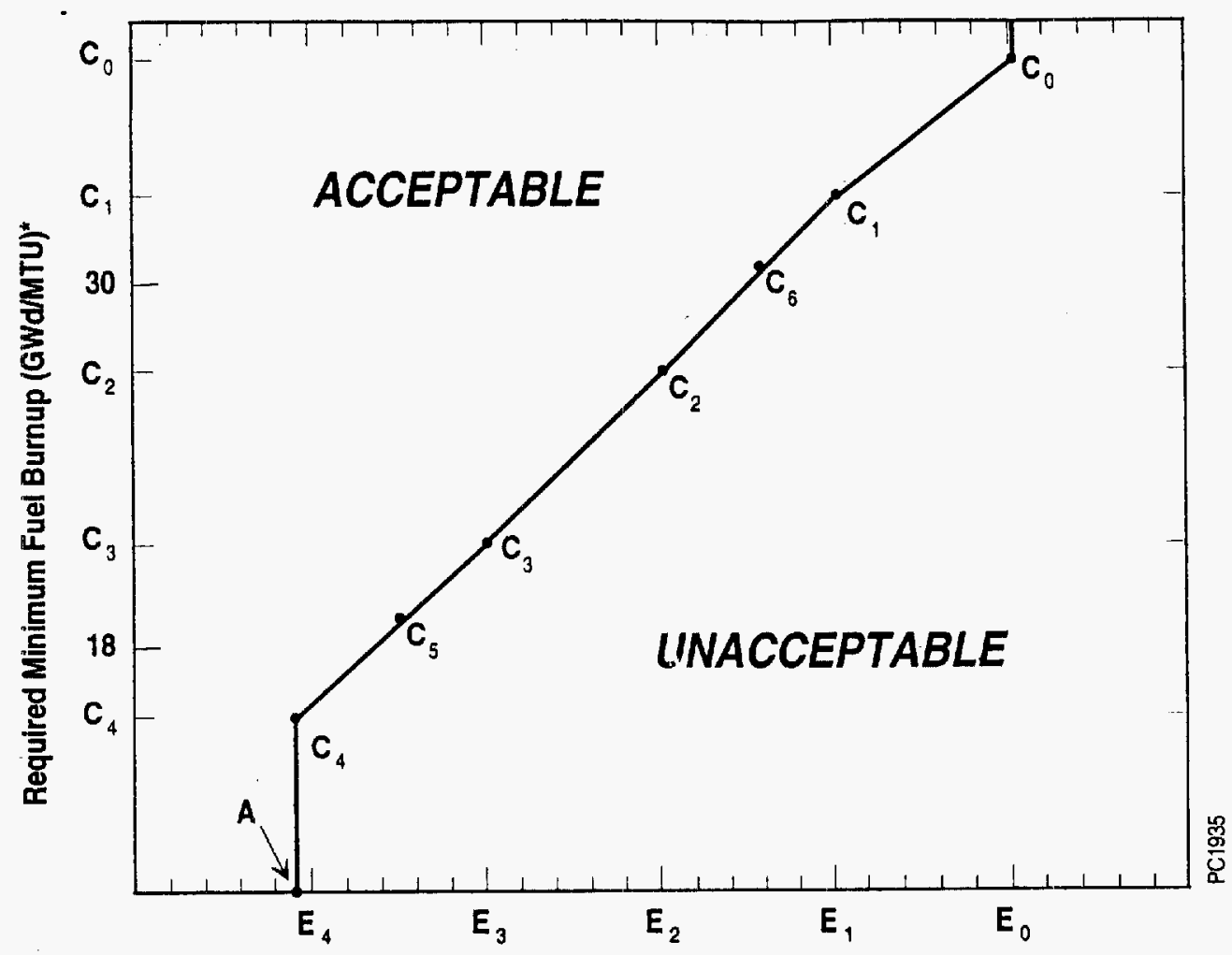

Initial Fuel Enrichment (U-235 wt\%)**

\section{Assembly Design:}

Minimum Cooling Time:

Maximum Number of Removable Burnable Absorber Rods

Note: This loading curve was generated with the following generic assumptions: Maximum Cycle Average ppm Boron of Temperature of Maximum Core Outlet , and the Maximum Pellet Average Temperature

* The nominal burnup must be reduced by the utility so there is a $95 \%$ confidence level of meeting the Required Minimum Fuel Burnup.

$\star \star$ If the assembly has more than one enrichment, the highest enrichment must be used.

Figure 5-1. Development of Burnup Credit Loading Curve For a Specific SNF Package 


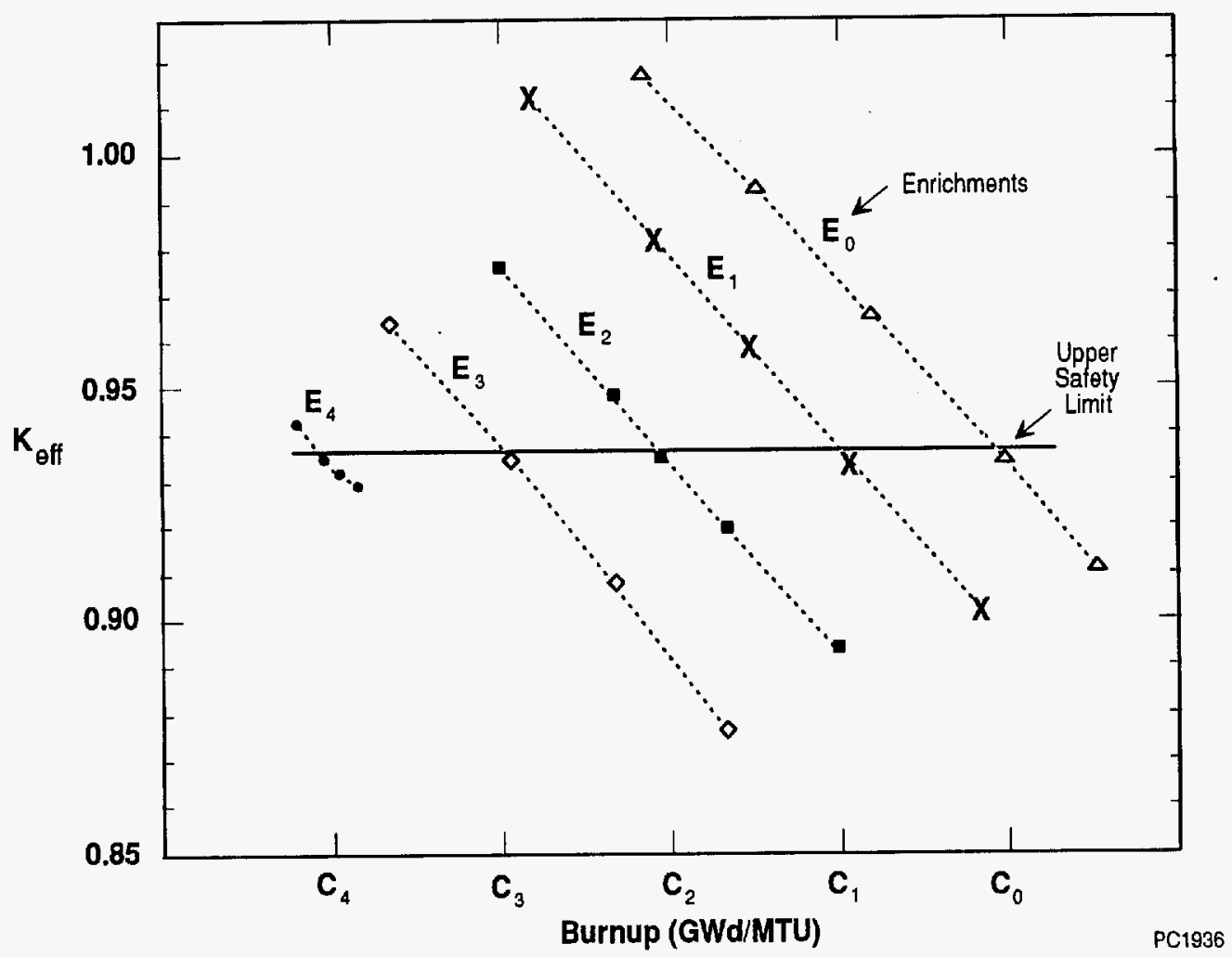

Figure 5-2. Determination of Required Minimum Burnups for a Specific SNF Package 


\subsubsection{Plot the Burnup Credit Loading Curve}

I After the calculations of Section 5.2.1 are performed, a curve of minimum burnup as a function of the initial enrichment is generated (see Figure 5-1). Calculations of the required minimum burnup must be performed at the maximum enrichment for the SNF package $\left(E_{0}\right)$. (This limit is often not set by burnup credit concerns. The limiting enrichment for this burnup credit methodology is 5 weight percent U-235.) Calculations of the required minimum burnup must also be performed at the maximum fresh fuel enrichment for the package $\left(\mathrm{E}_{4}\right)$. Burnup credit calculations will not show a zero minimum burnup for the maximum fresh fuel limit demonstrated using fresh fuel assumptions. This is because in performing the calculations, the isotopic correction factors on $U$ 238 and U-235 are used that only need to be applied for irradiated fuel. The required minimum burnup for the highest enrichment is indicated as point $C_{0}$ on Figure 5-1. Subsequent values $C_{G}$ through $\mathrm{C}_{\mathrm{n}}$ are obtained by decreasing the initial enrichment parameter by a value not to exceed 0.5 weight percent $\mathrm{U}-235$ until an initial enrichment equal to the maximum fresh fuel enrichment limit is reached. The optimum moderation must be checked at point " $\mathrm{A}$ " and the point $\left(\mathrm{C}_{0}, \mathrm{E}_{0}\right)$. The loading curve is created by a segmented straight line through the data points. If there is significant curvature in the loading curve at burnups other than 18 and $30 \mathrm{GWd} / \mathrm{MTU}$, the enrichment points should be spaced so that the loading curve is smooth, with no abrupt direction changes.

The loading curve will contain discontinuities at 18 and $30 \mathrm{GWd} / \mathrm{MTU}$. These are due to changing the axial and radial burnup models at these burnups. The discontinuities will look like short horizontal sections at 18 and $30 \mathrm{GWd} / \mathrm{MTU}$. The size of the flat sections at 18 and $30 \mathrm{GWd} / \mathrm{MTU}$ are expected to be about 0.2 and $0.1 \mathrm{wt} \% \mathrm{U}-235$, respectively. The amount of effort to establish the flat portion is optional. However, it is required that the loading curve be conservatively constructed. In order to assure this, it is required that a point on the loading curve be found at 18 and 30 GWd/MTU using the more limiting burnup shapes at those burnups. This may require some iteration since the loading curve generation procedure is based on enrichment rather than burnup.

I A spent fuel assembly that has a verified burnup greater than the required minimum burnup on the loading curve, at the assembly's initial enrichment, may be loaded into the SNF package. Note that an assembly that has an initial enrichment less than the maximum fresh fuel enrichment limit does not require any burnup. Conversely, an assembly that has an initial enrichment that exceeds the highest enrichment on the loading curve may not be loaded into the package regardless of its burnup. If an assembly is initially loaded with fuel of different enrichments, the maximum enrichment value at any point in the assembly is used for the assembly in comparing the assembly to the loading curve. This conservatively bounds the reactivity of such an assembly.

\subsubsection{Burnup Records Adjustment}

The loading curve is based on the minimum assured burnup. Therefore, the loading curve burnup value should be compared to the utility-maintained reactor records for that assembly, reduced by the appropriate conservatism. Thus, it is important to quantify the uncertainty associated with each assembly's reactor record burnup, and to make the proper adjustment before comparing to the loading curve. It is difficult to establish a single reactor record uncertainty applicable to every assembly, regardless of age, reactor plant type, and calculational method. Therefore, each utility 
determines the appropriate nominal reactor record assembly average burnup for the assemblies they intend to load into burnup credit casks, and determines the associated burnup uncertainties via utility-developed, approved procedures. Note that in deriving reactor record burnup uncertainties, conservative bounding values (e.g., derived from the plant's Final Safety Analysis Report) may be used where appropriate for the standard deviation, effective degrees of freedom, or any of the parameters discussed in the guidelines below. Guidelines for development of utility-specific procedures to determine reactor record burnup uncertainties are as follows:

1. Use the in-core detector system to establish relative assembly-average power (RelAssm), with an uncertainty consistent with power distribution uncertainty.

2. Establish core power $(\mathrm{P})$ using calibrated instrumentation with known uncertainties (e.g., flowmeters, thermocouples, etc.).

3. Determine the nominal reactor record assembly-average burnup $\left(\mathrm{RRAA}_{\mathrm{Burup}}\right)$ from:

$$
\operatorname{RRAA}_{\text {Burnup }}(M W D / A s s y-M T U)=\left[\int_{\text {assem. lifetime }}[\operatorname{RelAssm}(t) * P(t)] d t\right] / M^{\prime} U_{\text {assem }}, \text { Eq. 5-1 }
$$

or

$$
\operatorname{RRAA}_{\text {Burnup }}(M W D / A s s y-M T U)=\operatorname{sum}_{\mathrm{i}}\left[\operatorname{RelAssm}_{\mathrm{i}}(\mathrm{t}) * \mathrm{P}_{\mathrm{i}}(\mathrm{t}) * \Delta \mathrm{t}_{\mathrm{i}}\right] / \mathrm{MTU}_{\text {assem }}
$$

4. Document the nominal reactor record assembly-average burnup (RRAA $A_{\text {Burnup }}$ ) for each assembly to be loaded into a burnup credit cask/canister, and the specific method by which periodic observations of RelAssm and $P$ are used to establish RelAssm(t) and $P(t)$. Also document the uncertainties associated with the input data $\left(\operatorname{RelAssm}(t), P(t)\right.$, and $\left.M T U_{\text {assem }}\right)$ and the calculated nominal reactor record assembly-average burnup (RRAA Bunup $)$ from step 3. The uncertainty of the calculated nominal reactor record assembly-average burnup $\left(\right.$ RRAA $\left._{\text {Burnup }}\right)$ should be based on a two-sided $95 \%$ confidence tolerance interval.

5. The minimum assembly-average burnup (MinAA $A_{\text {Burnup }}$ ) shall be used for loading a cask for burnup credit. Hence, for cask loading, the minimum assembly average burnup, defined as:

$$
\operatorname{MinAA}_{\text {Burnup }}<\text { RRAA }_{\text {Burnup }} \text { - uncertainties, }
$$

must be greater than the loading curve value at the assembly's initial enrichment.

Since each utility may have assemblies for which burnup has been calculated using different methods, codes, etc., different assemblies may have different reactor record burnup uncertainties. The reactor record uncertainty value associated with each assembly needs to be appropriate, or conservative, for the particular reactor record calculational method used.

Note that there are compelling reasons to believe that most reactor records have uncertainties less than approximately $5 \%$. Among them are the following: 
(1) Westinghouse Standard Technical Specifications $\mathrm{s}^{5-1}$ require that the measured radial peaking factor, $\mathrm{F}_{\Delta \mathrm{H}}$, be increased by $4 \%$ to account for measurement uncertainties, and that measured heat flux hot channel factors be increased by $5 \%$. Both of these uncertainties are for localized, pin-wise power measurements within an assembly. Therefore, the measurement uncertainties associated with the entire assembly (from which assemblyaverage burnup values are derived), would be expected to be smaller than $4-5 \%$, due to the effects of averaging.

(2) The improved Standard Technical Specifications require daily adjustment of excore neutron detectors to ensure the core power level determined by the excore detectors is within $\sim 2 \%$ of the value calculated via calorimetry. A monthly calibration of incore detectors using the excore detectors (generally to within 3\%) is also required. Since the above limits are technical specification limits, actual variations are likely to be significantly less. Combining these two uncertainties yields the conclusion that incore detector systems are routinely demonstrated to measure core power level to well within $\sim 5 \%$. Since incore detector measurements are generally used in assembly burnup calculations, a value of $\sim 5 \%$ for burnup uncertainty is consistent with the above discussion.

\subsection{LIMITATIONS ON THE BURNUP CREDIT LOADING CURVES}

A burnup credit loading curve will be valid for a class of assemblies. The class is characterized by 1 the assembly design type, the number of removable burnable absorbers (if any) used in the assembly, and cooling time. The limitations on the acceptable parameters for a class of assemblies for each loading curve shall be notated on the curve. There are also parameters that are not intended to identify a class, but to be generically acceptable (maximum cycle average ppm boron, maximum core outlet temperature, and maximum pellet average temperature), which are notated on the loading curve in case unanticipated design changes invalidate the generic assumptions. For any SNF package 1 design, several loading curves may be generated. Separate loading curves may be generated for each 1 assembly design type, cooling time, and number of removable burnable absorbers.

The following subsections describe the parameters that can be varied for which a separate loading I curve is able to be generated in lieu of establishing a bounding curve. (Note that if an assembly is 1 initially loaded with fuel of different enrichments, the maximum enrichment value at any point in the I assembly is used for the assembly in comparing the assembly to the loading curve.)

\subsubsection{Assembly Design Type}

PWR fuel assembly designs vary in their rate of change in reactivity with burnup. Typically, a design that has a higher hydrogen to uranium ratio ( $\mathrm{H} / \mathrm{U}$ ratio) will initially have a higher reactivity for a given enrichment. This high $\mathrm{H} / \mathrm{U}$ design, however, will typically lose more reactivity for a given burnup than a low $\mathrm{H} / \mathrm{U}$ design. With this observation, it is clear that there is no one assembly design that would be the most limiting at all burnups on a burnup loading curve. In addition, the assembly 
type that has the highest reactivity in the cask may be dependent upon the specific design of the spent fuel basket.

The consequence of this variability in assembly design is that separate burnup credit loading curves should be generated for each fuel assembly design type. Assemblies with fixed burnable absorbers represent an assembly design type. Assemblies with more than one fuel enrichment must be analyzed as though they have a uniform enrichment with that enrichment being the highest in the assembly. Multiple enrichments cannot be represented as a separate assembly design type.

\subsubsection{Assemblies Loaded With Removable Burnable Absorber Rods}

The insertion of burnable absorber rods into a fuel assembly for a cycle affects the irradiated fuel isotopic composition by hardening the neutron spectrum. This hardened spectrum results in more U-238 fast fission and a higher conversion ratio. The net effect is that the fuel assembly isotopic composition and reactivity characteristics as a function of burnup deviate from those for assemblies without burnable absorbers. The assemblies that contained burnable absorbers will have a higher reactivity for a given burnup and enrichment than those that did not. The effect increases with larger amounts of burnable absorbers in the assembly. This effect is generally small but may be as large as a few percent in reactivity. ${ }^{5-2}$

Separate burnup credit loading curves or a bounding treatment of burnable absorber rod effects must be included for each reactor fuel design covered by an SNF package design Safety Analysis Report. A burnup credit loading curve should state whether it applies to fuel with burnable absorbers. Typically, burnable absorber assemblies are removed after one cycle. However, the SNF depletion analysis should be performed with the burnable absorbers in the assembly throughout the life of the assembly to bound the possible time actually in the assembly. Note that part length removable absorbers must be analyzed as though the maximum concentration absorber is uniform over the entire length of the fuel. In the criticality analysis for the package, the depleted burnable absorbers should not be modeled. This is a conservative assumption for all fuel designs. The more burnable absorber rods assumed in the isotope depletion/generation calculations, the larger the positive reactivity effect. Due to this, it is conservative to perform the analysis with the maximum burnable absorber loading during operation in the reactor. Loading curves developed with burnable absorbers could be conservatively applied for fuel without burnable absorbers. Reactor records provide the necessary documentation to determine whether an assembly had a burnable absorber loaded any time during exposure in the core. Verification of assembly records is addressed in the next chapter.

\subsubsection{Cooling Time}

The cooling time after discharge of an SNF assembly from the reactor affects the isotopic inventory within the fuel material since many isotopes are unstable and decay with time. A study of the $\mathrm{k}_{\infty}$ of spent fuel versus cooling time with several operating history options was performed..$^{5-3}$ Figure $5-3$ shows that shortly after discharge from the reactor the reactivity decreases monotonically for the first 100 years. (The change in reactivity after 50 years is too small to be evident in Figure 5-3.) Decrease 
in $\mathrm{k}_{\infty}$ for the actinide case is mainly due to decay of fissile Pu-241, which has a half life of 14.4 years. The negative reactivity worth of fission products increases with cooling time; therefore, neglecting fission products adds more conservatism with cooling time.

Since additional cooling time decreases reactivity during the first 100 years, a loading curve would be valid for any cooling time greater than that used in the analysis. After 100 years of cooling, the reactivity starts to increase due to $\mathrm{Pu}-240$ decay. This topical report does not analyze or provide parameter limits to cover this increase in reactivity, therefore, the scope of this topical report is limited to 100 years of cooling time. The cooling time used in the analysis must be placed on the loading curve. The records verification presented in the next chapter is used to verify that the cooling time is greater than the value shown on the loading curve.

\subsection{SUMMARY}

Burnup credit loading curves are generated that establish the minimum burnup that can be loaded into an SNF package as a function of initial enrichment. These curves are generated using the conservative isotopic correction factors presented in Chapter 2, the upper safety limit developed in Chapter 3, and the conservative burnup analysis presented in Chapter 4 . The package criticality analysis is also described in Chapter 4. The reactor record burnup uncertainty is accounted for by utilities following established guidelines.

Burnup credit loading curves are generated for each assembly and SNF package design. The use of burnable absorbers may be considered as a separate design. The more burnable absorbers, the more reactive the assemblies. Therefore, a loading curve can be valid for any assembly with fewer burnable absorbers installed during plant operation than that used for the analysis. The burnup credit loading curve will be calculated with an assumed minimum cooling time. An assembly with a cooling time greater than the burnup credit loading curve design basis cooling time, but less than 100 years, may be loaded. The limits of the burnup loading curve will be indicated on the loading curve, and the assemblies to be loaded will be verified to meet these limits by the method described in the next chapter. 


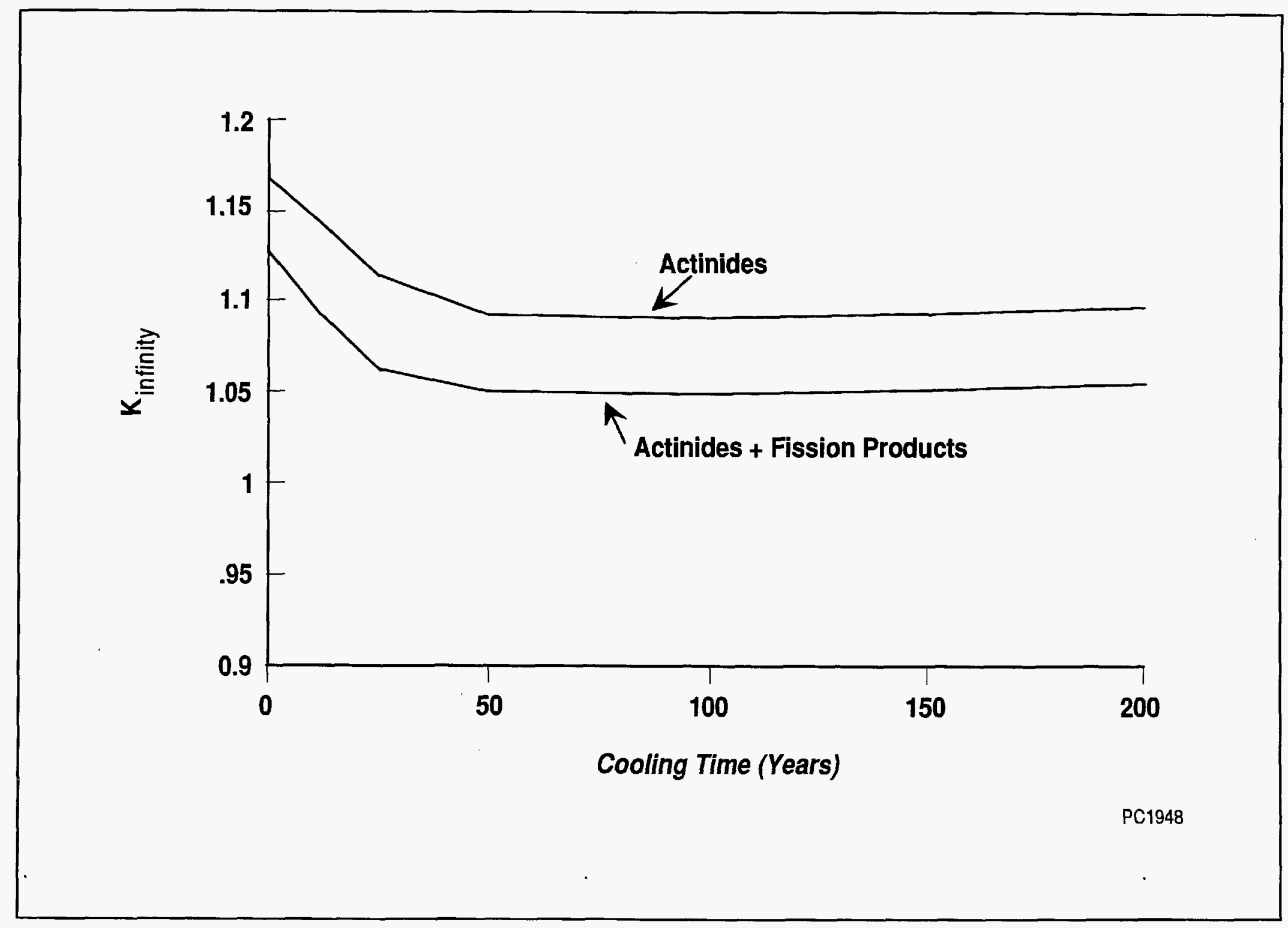

Figure 5-3. $\mathrm{k}_{\text {infinity }}$ versus Cooling Time $(3.0 \mathrm{wt} \% \mathrm{U}-235,30 \mathrm{GWd} / \mathrm{MTU}$ Burnup) 
INTENTIONALLY LEFT BLANK

WP.428.R1 


\section{PHYSICAL IMPLEMENTATION AND CONTROLS}

This chapter addresses the physical implementation and administrative controls that should be imposed in loading a burnup credit package. As discussed previously, burnup credit loading curves specify the criticality control fuel acceptance criteria and serve as operational limits for selecting fuel assemblies for loading into a burnup credit package. The applicable burnup credit loading curve is used along with reactor records, fuel assembly classification and package loading procedures, and an independent burnup verification measurement to ensure that spent fuel assemblies have experienced sufficient burnup to satisfy minimum criticality safety design requirements prior to loading in a burnup credit package. Although specific interfaces with $10 \mathrm{CFR}$ $50^{6-1}$ site operations regulations are not addressed within the scope of this topical report, administrative controls and procedures proposed to ensure proper loading of burnup credit packages are consistent with Regulatory Guide $1.13^{6-2}$ guidance.

A competitive commercial market is developing for burnup measurement systems. This chapter describes the requirements for burnup measurement systems used to verify fuel assembly burnup as a pre requisite for loading into a burnup credit package. Two examples of the technology are found in Appendix B. Both of these systems have been recently tested in the U.S. on PWR fuel assemblies in commercial reactor spent fuel pools, and both have the potential to meet the requirements of this chapter.

\subsection{BURNUP CREDIT PACKAGE LOADING PROCESS}

Before burnup credit package loading operations, specific burnup credit package loading licensing limits are established. These limits are established in the Certificate of Compliance or Safety Evaluation Report and are discussed in the Safety Analysis Report for the specific package design. As discussed in previous chapters, the parameters to be used in establishing the loading limits for a burnup credit package include the fuel assembly type, initial enrichment, assembly average burnup, burnable absorber irradiation history, and cooling time. Confirmation of fuel assembly acceptance status is also required for a number of other fuel design and operating history characteristics.

Burnup credit loading curves specify the criticality control fuel acceptance criteria and serve as the operational limits for selecting fuel assemblies for loading into a burnup credit package. Physical implementation of burnup credit involves facility preparations, including development and implementation of fuel classification procedures and procedures for actual fuel loading operations. A block diagram illustrating the process and procedures involved in the burnup credit package loading process is provided in Figure 6-1. The shaded blocks highlight the items that are unique to the loading of burnup credit packages. The unshaded items are activities that are also associated with standard fresh fuel assumption package loading activities. The following sections discuss the key elements of the loading process illustrated in Figure 6-1. 


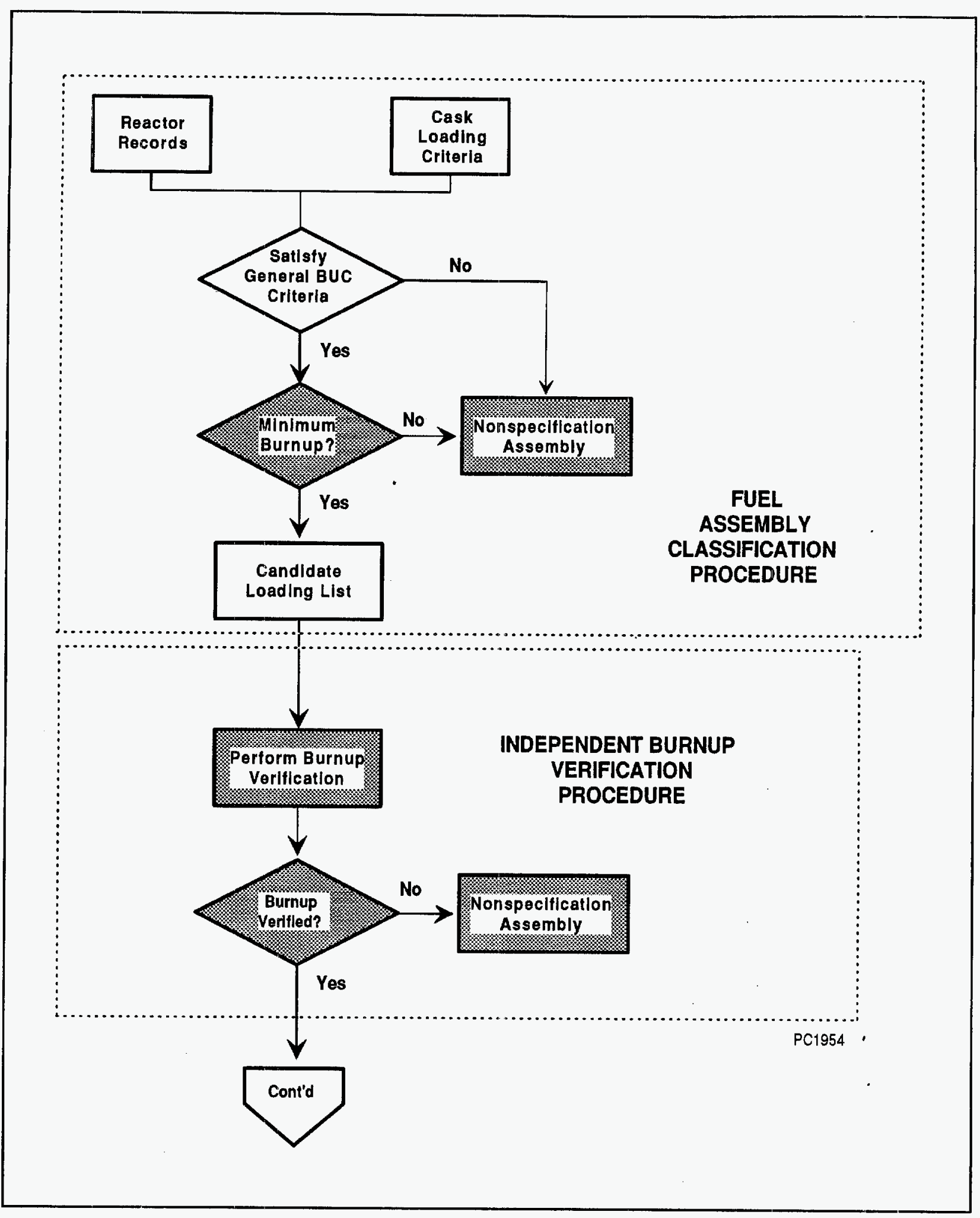

Figure 6-1. Burnup Credit Package Loading Process 


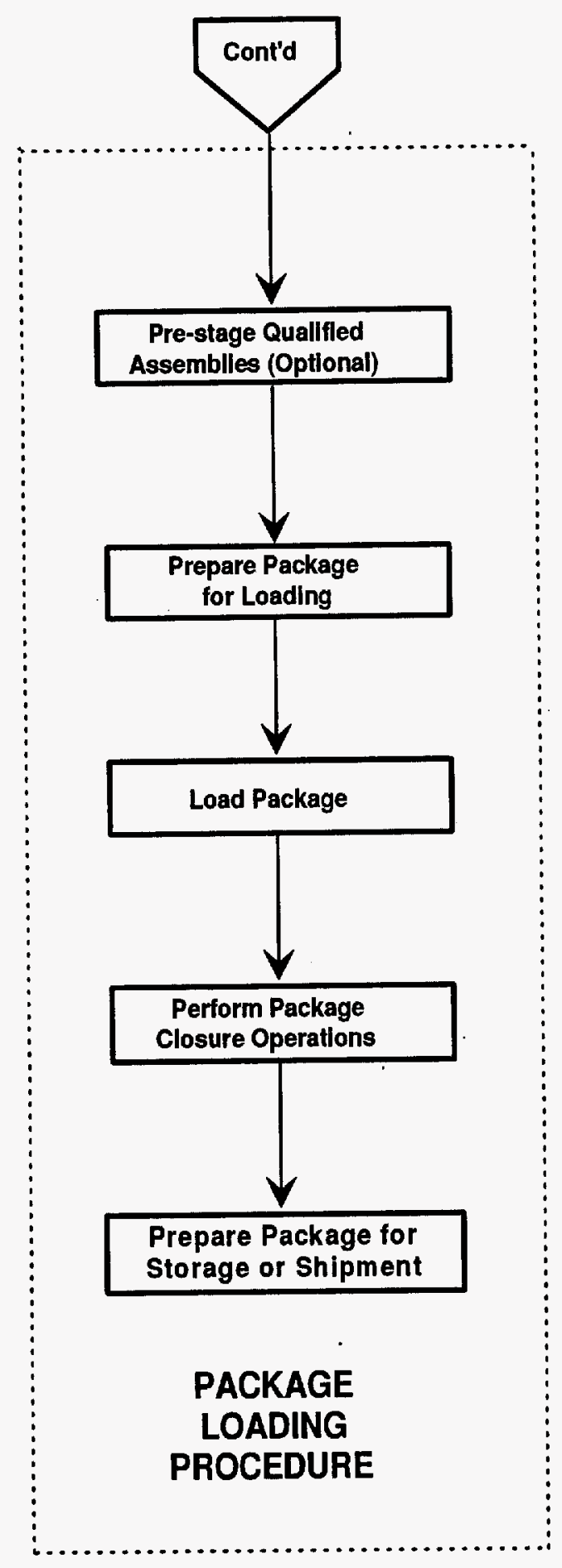

PC1627

Figure 6-1. Burnup Credit Package Loading Process (Continued) 


\subsubsection{Fuel Assembly Classification Procedure}

Reactor records and the burnup credit package loading criteria are used to classify spent fuel assemblies as acceptable or not acceptable for loading into a burnup credit package. Reactor records are maintained for each assembly received at a reactor site. Records are tracked by a unique alphanumeric assembly identifier physically stamped on each assembly. Reactor record sources include facility-specific Special Nuclear Material accountability records, reactor core design reports, reactor core operating reports, and spent fuel pool inventory records. Records maintained include as-received fuel characteristics such as initial enrichment and physical configuration, current and historical assembly location(s) onsite, and the complete operating history of each assembly while in the reactor core. Operating history parameters recorded include assembly average burnup (calculated based on guidance in section 5.2.2), average power level, axial power distribution, and non-fuel core power shaping component histories. Physical modifications performed on fuel assemblies are also documented for Special Nuclear Material accountability purposes. The package loading criteria are specified in the package Certificate of Compliance or Safety Evaluation Report, and the supporting Safety Analysis Report. These criteria ensure that criticality, thermal, and radiation design and licensing limits of the package are not exceeded.

Fuel assembly classification procedures will be prepared before planned loading operations and will be unique to specific package designs. Prior to commencement of burnup credit package loading operations, a Fuel Assembly Classification Procedure is implemented to identify any spent fuel assemblies that do not meet the applicable criticality design requirements specified for the burnup credit package. These assemblies are classified as "nonspecification" spent fuel assemblies and are prohibited from further consideration for loading into the package. Fuel assemblies are classified as nonspecification based on: 1) failure to satisfy general burnup credit criteria or 2) noncompliance with the minimum burnup criterion.

General burnup credit criteria identify fuel assembly attributes that must be considered outside the scope, or outside the range of applicability, of this topical report. These criteria are identified in section 1.3.

After confirming compliance with the general burnup credit criteria identified in section 1.3, each fuel assembly is screened for compliance with the minimum burnup criterion. Fuel assemblies that meet the minimum burnup criterion for their respective fuel assembly type, initial enrichment, cooling time and burnable absorber configuration history are then evaluated with respect to the remaining package loading criteria not related to criticality safety. The Fuel Assembly Classification Procedure is performed and documented in a site-specific QA calculation format satisfying 10 CFR 50, Appendix B, requirements. The determination that a fuel assembly satisfies the package loading criterion is based upon comparing the information in reactor records or information derived through calculation, such as decay heat, to loading criteria obtained from the package Certificate of Compliance or Safety Evaluation Report, and the Safety Analysis Report. A fuel assembly that meets all applicable loading criteria is considered to be a "candidate" fuel assembly for loading into the specified package design. The Fuel Assembly Classification I Procedure maintains up-to-date lists of fuel assemblies classified as candidate or nonspecification. The lists will include fuel assembly identification and fuel rack location identifiers, and other 
pertinent information obtained from reactor records such as assembly initial enrichment, average burnup, burnable absorber status, and discharge date.

\subsubsection{Independent Burnup Verification Procedure}

Prior to burnup credit package loading, candidate fuel assemblies undergo burnup verification. Burnup verification consists of double verification of the fuel assembly identifier and corresponding cell location, and physical measurement. The verification measurement consists of physically measuring the gamma-ray and/or neutron emissions from the spent fuel assembly and determining if the emissions correspond to those expected from an assembly with the burnup, initial enrichment, and cooling time since discharge specified in the reactor records. The burnup verification is performed with a measurement system which meets the guidelines of section 6.4 . In addition to confirming proper assembly selection, the measurement system verifies the consistency of the data recorded in the reactor records for each assembly prior to loading. Examples of two candidate measurement systems are briefly described in Appendix B.

The need for an Independent Burnup Verification Procedure is unique to the use of burnup credit packages. Criticality control loading restrictions for packages designed using the fresh fuel assumption only require confirmation that fuel assemblies satisfy initial enrichment limitations prior to loading. Enrichment confirmation is done purely via administrative controls (e.g., independent checks of assembly numbers prior to loading), whereas for burnup, an actual measurement is performed to augment the administrative controls. If the verification confirms the consistency of the burnup, and cooling time values assigned by the Fuel Assembly Classification Procedure, the candidate fuel assembly is classified as qualified for loading into the burnup credit package. Qualified spent fuel assemblies may be moved to a segregated region of the spent fuel pool for eventual package loading. A list of qualified fuel assembly identifiers and corresponding fuel pool location identifiers is maintained, and the reactor records are updated accordingly.

If an inconsistency between the assigned assembly burnup or cooling time and the measurement system value for that assembly is identified, the fuel assembly is classified as nonspecification. Section 6.3.1 discusses the criteria for determining such inconsistencies. Although the general disposition of nonspecification fuel assemblies is beyond the scope of this topical report, burnup credit package loading procedures will require investigation of inconsistencies detected between reactor records and the measurement system values. The focus of the investigation procedure will be to identify and correct any possible errors in reactor records which could contribute to future verification inconsistencies or loading errors.

\subsubsection{Package Loading Procedure}

The Package Loading Procedure governs activities related to facility-specific pre-staging of qualified assemblies, double verification of the fuel assembly identification numbers prior to and following package loading, loading the qualified assemblies into the package, and package closure operations. 
The need for a Package Loading Procedure is not unique to the use of burnup credit packages. Control of package loading operations is required to ensure that only qualified assemblies are loaded. Prior to fuel movement out of an existing pool storage location, the Package Loading Procedure requires independent double verification of the assembly identifier and corresponding fuel pool location by two fuel handling operators. Following confirmation that the proper assembly is engaged by the fuel handling device, individual fuel assemblies are removed from the fuel rack, moved to the package loading area, and placed into the predesignated fuel cell location in the package. Following placement in the package, the fuel assembly identifier and corresponding package fuel cell location is again independently double verified. Upon completion of the package loading, each fuel assembly identifier and package location is again double verified.

\subsection{FUEL ASSEMBLY MISLOAD}

The burnup credit package loading process described in the previous section provides sufficient control over nuclear criticality safety practices to satisfy the Double Contingency Principle of ANSI/ANS-8.1..$^{6-3}$ Assembly identifiers are independently verified by two fuel handling operators at each stage of the burnup verification and package loading procedures and the reactor records

1 assigned burnup levels are independently verified using a measurement system prior to spent fuel package loading. These procedural measures ensure proper assembly selection and records assignment. Therefore, the loading procedures incorporate sufficient factors of safety to require at least two unlikely, independent, and concurrent errors in the loading process to occur before a criticality accident is possible. This conclusion does not rely on PWR storage pool soluble boron credit and is valid assuming pure water moderation as a normal preexisting condition.

\section{6.3 BURNUP VERIFICATION REQUIREMENTS}

The Independent Burnup Verification Procedure requires a physical measurement to confirm proper reactor records assignment of burnup and enrichment prior to loading specific fuel assemblies into a burnup credit package. A negative result of this measurement is a rejection of the acceptance of the assembly for loading in a burnup credit package. Hence, a rejection criteria must be established. This requirement should be consistent with the need for confirmation as well as the technology available to do the verification. The rejection criterion is that the measured burnup must be within $10 \%$ of the reactor record burnup. This is a two-sided requirement since it is desirable to reject any assembly with an unexpected result. Although, measuring a burnup greater than the reactor record by more than $10 \%$ may be safe with regard to burnup, it implies a bad record which includes the enrichment. No direct measurement of enrichment is required so any indication of an erroneous record must cause a rejection until it is resolved.

I

1 The measurement is to confirm the reactor record value of burnup and the uncertainty in this reactor I record is accounted for by a reduction in the burnup before comparing to the loading curve. 1 Disagreement between the measurement and the reactor record is not an uncertainty that needs to I be used to reduce burnup credit but rather an indication that something is wrong. The question arises whether an unnoticed error of $10 \%$ would lead to an unsafe condition. First, it is projected I that about half of this difference is accounted for in the reduction of the assembly burnup due to 
uncertainty in the reactor records. However, if the assembly was at the low end of the reactor record uncertainty, the maximum error in burnup would be $10 \%$. Since about $30 \%$ of the change in reactivity due to burnup is from fission products, this unexpected event is well within the available safety margin.

As stated in the first paragraph of the section, the measurement rejection requirement should be achievable with the current state of the art. Five percent is an engineering approximation of the uncertainty in both of the reactor records and measurement systems. Using this estimate, it would appear that deviations of greater than $10 \%$ between the measurement and reactor records would be unlikely and a basis for rejection.

\subsection{MEASUREMENT SYSTEM DESIGN REQUIREMENTS}

This section describes design requirements for burnup measurement systems. Any measurement system which meets these design requirements can be used to verify the burnup of fuel assemblies prior to loading in a burnup credit package. Burnup measurement systems fall into two broad classes, herein termed "dependent," and "independent." Dependent systems (e.g., gross neutron detection systems) rely on knowledge of the reactor record burnup values for a set of assemblies for a calibration. Hence, these systems cannot truly "measure" burnup independently. The primary use for such systems is detection of "outlier" assemblies which for some reason have a radiation signature at odds with their reactor record burnup value. Independent measurement systems (e.g., gamma spectrum detection systems) are capable of performing a true independent measurement of assembly burnup, without reliance on reactor records, using the gamma emission signatures fission products (principally cesium isotopes).

These design requirements are performance-based; the operating principle and design details for the measurement system are not prescribed, and hence are left to the measurement system designer. However, because of the fundamental differences between dependent and independent measurement systems, specific requirements are developed for each system type. Where appropriate, a justification is provided after the requirement which describes the rationale for the requirement. The requirements are as follows:

\subsubsection{Accuracy Requirement}

\subsubsection{Dependent Measurement Systems}

Dependent measurement systems measure a neutron or gamma count rate, and plot count rate as a function of reactor record burnup for each assembly to generate a calibration curve. For dependent systems, a calibration curve of the following form is used to correlate the neutron counts to the reactor record burnup:

$$
\mathrm{y}_{\text {counts }}=\mathrm{a}+\mathrm{bx}_{\text {reac }} \text { where }
$$

$a$ and $b$ are constants, $y_{\text {counts }}$ is the count rate (or, for neutron detection systems, typically the logarithm of the neutron count rate), and $x_{\text {reac }}$ is the reactor record burnup value (or, for neutron 
detection systems, typically the logarithm of the reactor record value). Constants a. and b are determined using standard linear regression techniques, following measurement of a group of assemblies.

The burnup uncertainty of dependent measurement systems is most conveniently stated in terms of a count rate predication band. (Note that for dependent measurement systems, the count rate prediction band incorporates both reactor records errors and intrinsic measurement system errors.) For dependent measurement systems, the count rate for a particular assembly should not differ from the calibration line by more than the following amount:

Prediction Band Width (count rate) $=t_{0.025,1-2}\left\{\left[(n+1) / n+\left(x_{i}-x_{\text {avg }}\right)^{2} / S_{x x}\right] S S_{R} /(n-2)\right\}^{0.5} \quad$ Eq. $6-2$ where,

$\mathrm{t}_{0.025, \mathrm{n}-2}$ is the $\mathrm{t}$-distribution statistic bounding $95 \%$ of distribution for $\mathrm{n}$ degrees of freedom (two-sided distribution), $\mathrm{n}$ is the number of assemblies in a calibration run, $x_{i}$ is the $x_{\text {reac }}$ (burnup or log of burnup) for assembly $i$, $\mathrm{x}_{\mathrm{avg}}$ is the average of the $\mathrm{x}_{\text {reac }}$ 's for all assemblies in a calibration run, $\mathrm{S}_{\mathrm{xx}}=\sum\left(\mathrm{x}_{\mathrm{i}}-\mathrm{x}_{\mathrm{avg}}\right)^{2}$, $\mathrm{SS}_{\mathrm{R}}=\sum\left(\mathrm{y}_{\mathrm{i}}-\mathrm{y}_{\mathrm{fit}}\right)^{2}$ $y_{i}$ is the count rate (or log of the neutron count rate) measured for assembly $i$. $y_{\text {fit }}$ is the value from equation 6-1 for assembly $i$.

Since, for dependent measurement systems, prediction band width on uncertainty depends on the number of assemblies measured, an appropriate bound on the band width is required to ensure an adequate sample size for the calibration curve. Thus, dependent measurement systems must demonstrate, via analysis and confirmatory testing, that the following criterion can be met:

\section{Prediction Band Width / Assembly Burnup $<0.1$}

Where the Prediction Band Width is given in Equation 6-2.

The $10 \%$ requirement on the prediction band width is consistent with the $10 \%$ value used as a I rejection criterion.

If reactor record values are such that they overestimate low burnup assemblies and underestimate high burnup assemblies, the neutron count rate vs. reactor record burnup calibration line could be unconservatively tilted, giving potentially erroneous results. To mitigate this effect, either of the following may be done:

a. Limit the set of assemblies used to develop a particular calibration line as follows: Ensure that the maximum and minimum reactor record burnup values for the set differ by at most 10 GWD/MTU. This minimizes the range of the calibration line, hence minimizing the effect of any unconservative tilt in the line. 
or,

b. Establish via analysis the expected range for the calibration line's slope, and limit the slope to values within that range.

Ten GWD/MTU represents roughly one cycle of burnup. It is expected that assemblies within this burnup range have similar reactor power histories, and hence any reactor record calculational biases would be expected to be similar for such assemblies, and hence would not cause a significant tilt in the calibration line. $10 \mathrm{GWD} / \mathrm{MTU}$ is also a large enough range to allow for an appropriately large calibration set. Establishing the expected slope range by analysis would appropriately bound the tilt which could be caused by reactor records biases.

\subsubsection{Independent Measurement Systems}

Independent measurement systems should demonstrate, via analysis and confirmatory testing, the uncertainty associated with a single assembly-average burnup measurement. That uncertainty should be $10 \%$ or less. This is consistent with the rejection criteria.

\subsubsection{Correct Horizontal Average}

The measurement system should account for the potential variation in burnup across the cross-section of the assembly, and the effect of such a variation on the measurement value should be quantified. Such an effect should not be large enough to cause the accuracy requirements to be exceeded. Such radial effects shall be mitigated by measuring at least two opposing sides of the assembly, at the same assembly height (e.g., the assembly midplane).

\subsubsection{Operational Considerations}

The measurement system operating/calibration procedures shall detect and adjust for variations in the system and/or the environment which could affect the measurements, and/or the detector accuracy. Parameters which could affect measurements include, but are not limited to:
A. Detector electronic drift
B. Detector positioning
C. Pool boron concentration, temperature, and water purity
D. Fuel characteristics differences listed in section 2.0
E. Counting time

\subsubsection{Characteristics of Assemblies To Be Measured}

Prior to measurement of assemblies with a particular set of characteristics, the measurement system shall be qualified, via analysis and/or qualification testing, to measure assemblies with those characteristics to the accuracies specified in section 6.4.1. Characteristics for which a measurement system should be qualified include: 
A. Burnup Range

B. Initial Enrichment Range (Prior to measurement of assemblies with variable initial enrichments, the measurement system should be specifically qualified for such assemblies.)

C. Cooldown Range

D. Nominal Dimensions

E. Assembly Design Type

Note that a particular measurement system need not be qualified to measure the entire set of assemblies within the scope of this burnup credit methodology.

\section{6.4.5 Analysis Tools}

Analysis tools (e.g., computer codes) used to calculate assembly burnup values based on detector responses should be appropriately benchmarked, qualified and up-to-date. Justification should be provided for why each analysis tool was used, including information on benchmarking and qualification which was performed for the tool. In particular, neutron detection systems should use an appropriately benchmarked and validated code to calculate $\mathrm{Cm}-244$ production as a function of burnup. Neutron measurement systems should also account for neutron sources other than Cm-244, or should justify neglecting them.

\subsubsection{Pool Compatibility}

The process and equipment used for the verification measurement should be compatible with normal operations in spent fuel pools.

\subsection{SUMMARY}

Generic physical implementation and administrative control issues related to loading burnup credit packages are addressed by a generic burnup credit package loading process. The generic process provides the necessary control over nuclear criticality safety practices associated with loading burnup credit packages. The loading process relies on reactor records to establish fuel assembly loading qualification status and an independent burnup verification procedure to detect errors in the burnup records and ensure proper assembly selection. The proposed administrative controls and independent burnup verification procedure provide a high level of assurance that misloading of unqualified fuel assemblies will not occur.

I This topical report is specifically seeking NRC acceptance of the use of reactor records (with reactor record burnup uncertainties accounted for by the utilities) to confirm fuel assembly compliance with burnup credit analysis assumptions and parameters, and for the use of a measurement system which meets the requirements of sections 6.3 and 6.4 to verify proper assembly selection prior to loading burnup credit packages. Reactor records, with burnup uncertainties accounted for, will be used in burnup credit SNF package loading procedures as the basis for assigning fuel assembly characteristics important to criticality safety. The specific fuel assembly 
parameters that must be assigned include: a) fuel assembly design type, b) initial enrichment, c) average burnup, d) cooling time following final reactor discharge, e) axial power shaping status, $f$ ) burnable absorber status, and $\mathrm{g}$ ) intact configuration status. The measurement system is applied in the loading procedure to verify that the correct reactor records have been assigned to the proper assembly, as identified by a unique assembly identifier stamped on fuel assembly hardware. 
INTENTIONALLY LEFT BLANK 


\section{SUMMARY OF THE BURNUP CREDIT PROCESS}

This chapter summarizes the burnup credit methodology presented in the previous chapters. It provides a review of the burnup credit process, a discussion of the range of applicability, conservatism in the methodology, and a summary of the NRC approvals sought.

\subsection{OVERVIEW}

The burnup credit process was introduced in Chapter 1, Figure 1-2. The process builds upon those currently used for cask analysis and operations (i.e., the fresh fuel assumption and reliance on utility records for assembly initial enrichment). These steps are supplemented by analytical steps and operational procedures that are unique to burnup credit.

The fresh fuel assumption considers a cask loaded only with unirradiated (fresh) fuel assemblies. With this assumption, the initial enrichment of the fuel assembly is the single parameter upon which cask criticality safety is based. The cask design is analytically shown to satisfy the criticality safety criterion, i.e., $\mathrm{k}_{\text {eff }} \leq 0.95$ including all bias and uncertainties, for specified fuel designs with initial enrichments less than the design basis enrichment. Operationally, reactor records for assembly initial enrichment are used to qualify assemblies to be loaded into the cask.

Burnup credit adds fuel assembly burnup as a second key qualification parameter for criticality safety. This requires determining the reactivity relationship between the required fuel assembly burnup and initial enrichment over the range of allowable enrichments to establish loading criteria for the cask. The criteria are curves of burnup versus enrichment called the burnup credit loading curves. An example of a loading curve is shown in Figure 7-1. Over the range of enrichment, assemblies with burnups above and to the left of the curve (the acceptable region) may be loaded into the SNF package; those with burnups below and to the right of the curve (unacceptable region) may not. Reactor records for assembly enrichment and burnup are used to demonstrate that the loading criteria are satisfied. This assembly qualification process is augmented by a physical measurement that confirms proper assembly selection and reactor record assignment prior to declaring an assembly qualified for loading into a specific burnup credit package.

\subsection{REVIEW OF THE BURNUP CREDIT STEPS}

There are five major steps to implementing burnup credit:

1. Validate a computer code system to calculate isotopic concentrations in SNF created during burnup in the reactor core and subsequent decay

2. Validate a computer code system to predict the subcritical multiplication factor, $\mathrm{k}_{\mathrm{eff}}$, of a spent nuclear fuel package

3. Establish bounding conditions for the isotopic concentration and criticality calculations 


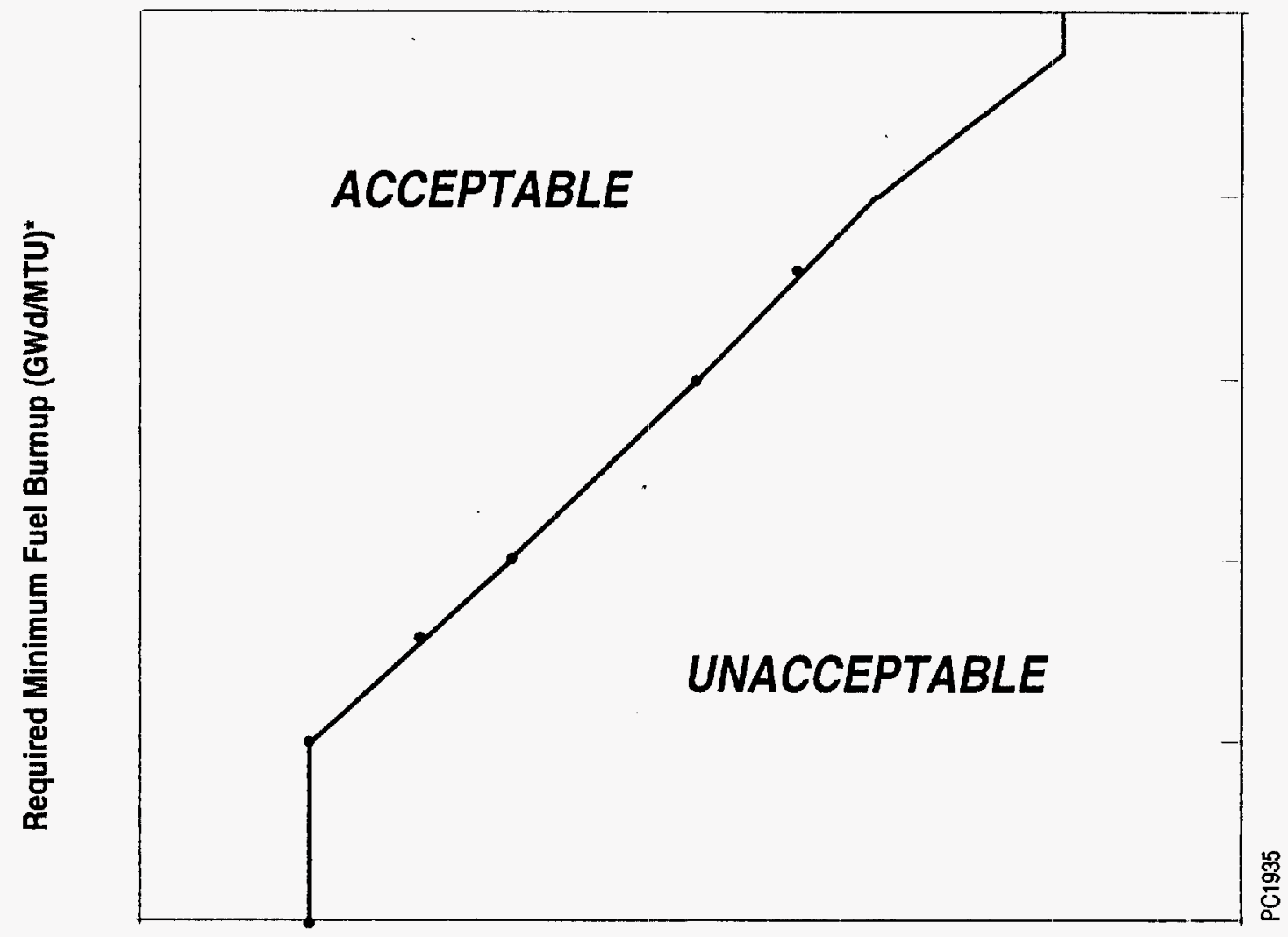

Initial Fuel Enrichment (U-235 wt\%)

\section{Assembly Design:}

\section{Minimum Cooling Time:}

Maximum Number of Removable Burnable Absorber Rods

Note: This loading curve was generated with the following generic assumptions: Maximum Cycle Average ppm Boron of Temperature of . Maximum Core Outlet , and the Maximum Pellet Average Temperature

* The nominal burnup must be reduced by the utility so there is a $95 \%$ confidence level of meeting the Required Minimum Fuel Burnup.

**If the assembly has more than one enrichment, the highest enrichment must be used.

Figure 7-1. Burnup Credit Loading Curve 
4. Use the validated codes and bounding assumptions to generate package loading criteria (burnup credit loading curves)

5. Verify that SNF assemblies meet the package loading criteria and confirm proper assembly selection prior to loading.

Table 7-1 summarizes the key steps in the burnup credit process. The following sections provide a brief description of each of these steps.

\subsubsection{Validation of a Code System for Calculation of Isotopic Concentrations}

This topical report addresses three separate steps in the validation of isotopic concentration predictions. First, a data set suitable for the validation is presented. Second, a method for the isotopic validation is developed, consisting of best estimate analyses of the data and then conservative biasing of the isotopic results. Finally, the data and method are demonstrated in validating a code system.

A set of chemical assays of spent nuclear fuel is presented in this topical report. The chemical assay data come from measurements of PWR fuel assemblies. The range of applicability for the measured data is discussed in Section 2.2.2. The set of experiments is sufficient for burnup credit analysis using actinides-only. This set of experiments could be used with any computer code system to validate burnup credit.

The method of analysis consists of conservatively selecting isotopes, followed by a method to determine biases, uncertainties, and then conservative correction factors. The isotopes selected are U-234, U-235, U-236, U-238, Pu-238, Pu-239, Pu-240, Pu-241, Pu-242, and Am-241. The biases are multiplicative and are the expected mean of the ratio of the experimental observation over the best estimate calculation of the isotopic concentration determined for each isotope. The uncertainty is determined by standard statistical procedures. The conservative correction factors are determined by combining the bias and uncertainties in a conservative direction for each isotope. (For example, if an isotope has a bias of 0.98 and an uncertainty of $5 \%$, the isotopic concentration correction factor would be calculated as $0.98+0.05=1.03$ for a fissile material but $0.98-0.05=0.93$ for an absorber.) If an isotope shows a trend with burnup, spectrum, enrichment, or specific power, the mean bias and the uncertainty are a function of that trending parameter.

Using the method and data presented in this topical report, the SAS2H module of SCALE 4.2 code system with the 27BURNUPLIB cross section set has been validated for use in calculating the isotopic concentrations. The biases, uncertainties, and correction factors used are presented in Chapter 2. The validation of this system allows for quick use of an available code package, as well as an example of how to properly use the data and method presented.

\subsubsection{Validation of a Code System for Calculation of Criticality in an SNF Package}

Fifty-seven critical experiments were selected to establish the bias over the anticipated range of PWR burnup credit package conditions. They span the range of applicability of the various parameters associated with a spent fuel shipping package. Table 3-2 in Chapter 3 provides the 
Table 7-1. Burnup Credit Analysis Process

\begin{tabular}{|c|c|c|}
\hline $\begin{array}{l}\text { Summary } \\
\text { Section } \\
\text { (Steps) }\end{array}$ & Step in Burnup Credit Process & $\begin{array}{l}\text { Detailed } \\
\text { Technical } \\
\text { Basis } \\
\text { Section } \\
\end{array}$ \\
\hline 7.2 .1 & \multicolumn{2}{|l|}{ ISOTOPIC VALIDATION } \\
\hline & $\begin{array}{l}\text { Determine which isotopes to use in the analysis (currently } \\
\text { restricted to selected actinides only) }\end{array}$ & 2.1 \\
\hline & $\begin{array}{l}\text { Perform best estimate analysis of isotopic concentrations of } \\
\text { chemical assay measurements of spent nuclear fuel (validated for } \\
\text { SCALE } 4.2 \text { in this report) }\end{array}$ & 2.2 \\
\hline & $\begin{array}{l}\text { Determine biases and uncertainties for each isotope and calculate } \\
\text { conservative correction factors (validated for SCALE } 4.2 \text { in this } \\
\text { report) }\end{array}$ & 2.3 \\
\hline 7.2 .2 & \multicolumn{2}{|l|}{ CRITICALITY VALIDATION } \\
\hline & $\begin{array}{l}\text { Perform best estimate analysis of the selected critical } \\
\text { experiments. }\end{array}$ & 3.1 \\
\hline & $\begin{array}{l}\text { Check for trending on a spectral parameter, fuel initial } \\
\text { enrichment, fuel outside diameter, and boron concentration. } \\
\text { Calculate the bias and uncertainty utilizing all significant trends } \\
\text { observed. }\end{array}$ & 3.2 \\
\hline & $\begin{array}{l}\text { Calculate the Upper Safety Limit (USL) from the } \mathrm{UO}_{2} \text { and MOX } \\
\text { and take the most limiting. (Validated USL for SCALE } 4.2 \text { can } \\
\text { be found in Section 3.3) }\end{array}$ & 3.2 \\
\hline 7.2 .3 & \multicolumn{2}{|l|}{ LIMITING PARAMETERS } \\
\hline & $\begin{array}{l}\text { Determine highest moderator temperature, and fuel temperature } \\
\text { for all fuel assemblies to be put in the SNF package. }\end{array}$ & 4.1 \\
\hline & $\begin{array}{l}\text { Determine highest cycle average soluble boron concentration } \\
\text { during burnup for any assembly to be put in the SNF package. }\end{array}$ & 4.1 \\
\hline & $\begin{array}{l}\text { Determine the moderator density that yields the highest } \mathrm{k}_{\text {eff }} \text { for } \\
\text { the SNF package criticality analysis. }\end{array}$ & 4.2 \\
\hline
\end{tabular}


Table 7-1. Burnup Credit Analysis Process (Continued)

\begin{tabular}{|c|c|c|}
\hline $\begin{array}{l}\text { Summary } \\
\text { Section } \\
\text { (Steps) }\end{array}$ & Step in Burnup Credit Process & $\begin{array}{c}\text { Detailed } \\
\text { Technical } \\
\text { Basis } \\
\text { Section } \\
\end{array}$ \\
\hline 7.2 .4 & \multicolumn{2}{|l|}{ CONSTRUCTION OF LOADING CURVE } \\
\hline & $\begin{array}{l}\text { Use validated code to calculate the maximum fresh fuel } \\
\text { enrichment that can be loaded in the SNF package. }\end{array}$ & 5.1 \\
\hline & $\begin{array}{l}\text { Use validated code and limiting values to compute spent fuel } \\
\text { isotopic composition and correct with the isotopic correction } \\
\text { factors. }\end{array}$ & 5.2 \\
\hline & $\begin{array}{l}\text { Use validated code, limiting axial and horizontal burnup profiles, } \\
\text { and the limiting moderator density to compute } \mathrm{k}_{\text {eff }} \text { for the } \\
\text { package for an enrichment and burnup }\end{array}$ & 5.2 \\
\hline & $\begin{array}{l}\text { Repeat the above two steps for a series of enrichments and } \\
\text { burnups establishing limiting burnup for each enrichment where } \\
k_{\text {eff }} \text { is less than or equal to the USL }\end{array}$ & 5.2 \\
\hline & $\begin{array}{l}\text { Repeat this section's steps for each assembly design for a selected } \\
\text { cooling time and burnable absorber loading }\end{array}$ & 5.3 \\
\hline \multirow[t]{3}{*}{7.2 .5} & \multicolumn{2}{|l|}{ LOADING VERIFICATION } \\
\hline & $\begin{array}{l}\text { Identify candidate assemblies satisfying the loading criteria and } \\
\text { verify assembly IDs }\end{array}$ & 6.1 \\
\hline & $\begin{array}{l}\text { Verify reactor records are consistent with the selected assembly } \\
\text { characteristics for each assembly by measurement. Measurement } \\
\text { and reactor record burnup must be with } 10 \% \text {. When comparing } \\
\text { the selected assembly burnup to the package loading curve the } \\
\text { reactor record burnup must be decreased by the utility declared } \\
\text { uncertainty in those records. }\end{array}$ & 6.1 \\
\hline
\end{tabular}

range of applicability matrix for the benchmark cases. The experiments consist of $21 \mathrm{UO}_{2}$ criticals (including 2 gadolinium criticals) and 36 mixed oxide configurations. The $19 \mathrm{UO}_{2}$ criticals without gadolinium (see Table 3-1) were used to assess the computational bias associated with the various parameters affecting SNF package criticality (e.g., spacing, supplemental neutron absorbers, and reflector materials). Table 3-1 lists the parameters examined in these critical configurations for the benchmarking process. Two $\mathrm{UO}_{2}$-gadolinium experiments were evaluated to assess the bias associated with criticals with a harder neutron spectrum caused by fission products. The two experiments listed in Table 3-1 provide a well characterized experimental configuration with a known amount of gadolinium. The bias associated with fuel containing higher-order actinides may be obtained from mixed-oxide (MOX) critical experiments. Thirty-six mixed-oxide criticals are 
listed in Table 3-1. Chapter 3 provides references for the data required to analyze all the experiments listed in Table $3-1$.

The criticality validation method developed combines biases, uncertainties, and an administrative safety margin to arrive at an upper safety limit (USL) for $\mathrm{k}_{\text {eff. }}$ This method of treating the criticality calculation bias has two primary components. A lower prediction band (LPB) is defined by the $95 \%$ confidence level for a single future calculation. The prediction band width accounts for the statistical uncertainty in the bias. An administrative safety margin of $5 \% \Delta \mathrm{k}$ is added to establish the USL, which becomes the bounding value for the criticality safety criterion. Although the use of a USL differs from the current practice of an explicit bias and criticality criterion, it provides a statistically sound method of establishing the bias as a function of any parameter while incorporating an additional safety margin that is consistent with the current practice.

With the experimental data established and the method developed, the CSAS criticality sequences of SCALE 4.2 using the 27BURNUPLIB cross section set were demonstrated to be valid for burnup credit SNF package criticality analyses. The USL as a function of Average Lethargy causing Absorption (ALA) is presented. This USL may be used for any package analysis using the validated code system (SCALE 4.2 with 27BURNUPLIB).

\subsubsection{Limiting Conditions for Analysis}

The actual analysis for burnup credit must be performed with validated codes at limiting conditions for the SNF package. These limiting conditions apply to the generation of SNF isotopic compositions as well as the package criticality analysis. The actual values of the limiting conditions depend on the set of assemblies that they are intended to address. Hence, for most of the parameters, only the direction of the most limiting condition is addressed in this topical.

The isotopic analysis depends on the reactor conditions during the burnup. These conditions are specific power, moderator temperature, fuel temperature, soluble boron concentration, and power versus time for the life of the fuel. The higher the specific power (MW/MTU), moderator temperature, and fuel temperature, the more reactive the fuel assembly is after a given burnup. A specific power of $60 \mathrm{MW} / \mathrm{MTU}$ bounds PWR fuel designs and does not overly burden the analysis with conservatism. The maximum core outlet moderator temperature and the maximum pellet averaged temperature should be used. The higher the average soluble boron concentration during burnup, the more reactive the fuel assembly would be following the discharge. The highest average boron concentration for any cycle for each fuel design should be used. The less time the reactor is shut down during the burnup, the more reactive the fuel assembly. Therefore, the burnup analysis should be performed as one continuous burn with no down time because this maximizes reactivity and is therefore conservative.

The criticality analysis of the SNF package must also be done at the most limiting conditions. There are three effects that are treated slightly differently for burnup credit. First, the optimum moderator density must be established for each specific package design for at least two burnup-enrichment conditions. The second consideration is the axial burnup modeling. A large database of axial burnup profiles has been developed and the most limiting shapes (as a function of burnup) have been selected. Package criticality analysis is to be performed with 18 axial nodes and the limiting shapes presented in Chapter 4. If the package has large margins, $\mathrm{k}$ bias curves are provided that allow 
axially uniform analysis. The final effect is the horizontal burnup gradient modeling. Again, a database of assembly quadrant horizontal burnup gradients has been created. Conservatively assumed gradients as a function of burnup are provided in Chapter 4. All package analysis must use these assumed burnup gradients.

\subsubsection{Generation of Burnup Credit Loading Curves}

Once the codes are validated and the bounding values for input to the analysis are known, burnup credit loading curves can be generated. The procedure requires determining the maximum fresh fuel enrichment and then burnup analysis of enrichments up to a limiting maximum enrichment. For each enrichment, the burnup where the SNF package design $\mathbf{k}_{\text {eff }}$ approximately equals, but does not exceed the USL, is determined. These values are then plotted to develop the burnup credit loading curve. The burnup plotted on the loading curve is the minimum allowable burnup and the utility is required to reduce the burnup by the uncertainty in the burnup records.

Burnup credit loading curves should be generated for each assembly design. Separate loading curves may be generated for assemblies with removable burnable absorbers. The burnup credit loading curve will specify the minimum cooling time used in the analysis. Cooling times longer than the minimum specified are conservative for the first 100 years of cooling.

\subsubsection{Verification of Loading}

The analysis of an SNF package using burnup credit results in loading criteria to identify assemblies that may be placed in a burnup credit package. These criteria provide the relationship between the minimum allowable average burnup and the initial enrichment of an assembly for a given assembly design, burnable absorber loading, and cooling time. Therefore, the package loading procedure requires knowledge of this information for a candidate assembly. This information resides in the reactor operating records. These records associate this information with a storage rack location and the ID of the assembly. Part of this record, the initial enrichment and storage rack location, is used to satisfy the criterion for current spent fuel shipments. Thus, the operational aspects of burnup credit require only an extension of the reliance of reactor records currently used for package loading. However, such an extension increases the reliance on administrative controls to ensure criticality safety. To mitigate this reliance, the burnup credit process includes a measurement technique to verify that the reactor records specified for a specific assembly correlate with the measured neutron or gamma emissions for the assembly. Chapter 6 describes the impact of burnup credit on the loading process. It discusses the enhanced procedures necessary to incorporate the verification measurement before package loading. The verification measurement reduces reliance on administrative controls and provides sufficient additional protection against misloading to satisfy ANSI/ANS 8.1. A maximum disagreement between the measurement of burnup and burnup records is set at $10 \%$. A set of minimum specifications for the measurement device is presented in Chapter 6. 


\subsection{RANGE OF APPLICABILITY}

I This topical report has a wide range of applicability for commercial power plant PWR fuel. Fifty-

I four chemical assays were performed which cover all commercial fuel except that with integral fuel

I burnable absorbers. The critical experiments contained configurations with a wide variety of supplemental absorbers (integral and external to the fuel assemblies), reflectors, and pin spacings. The limiting conditions (i.e., specific power, moderator and fuel temperature, ppmb, and axial burnup model) for the analysis bound the assemblies and package criticality analyses. The items that limit the range of applicability for this topical report are:

I 1. Burnup credit benefits can be gained from fuel burned from 1 to $50 \mathrm{GWd} / \mathrm{MTU}$. SNF with an assembly average burnup greater than $50 \mathrm{GWd} / \mathrm{MTU}$ shall be treated as having a burnup of $50 \mathrm{GWd} / \mathrm{MTU}$ for the purposes of this methodology.

The highest burnup in the chemical assays was $46 \mathrm{GWd} / \mathrm{MTU}$. There is sufficent data to allow burnups much greater than $50 \mathrm{GWd} / \mathrm{MTU}$ by extrapolation of trends but, it is expected that burnup credit for burnups beyond $50 \mathrm{GWd} / \mathrm{MTU}$ will not be needed.

2. Enrichments above 5 weight percent U-235 are excluded.

Enrichment has a direct impact on criticality and an indirect impact on isotopic depletion. The criticality experiments contain enrichments up to 5.7 weight percent U-235. The chemical assays also contain a range of enrichments that can be used to establish the existence of any trend. Trends on enrichment in the isotopic concentration prediction are not expected since it would have to be due to and error in the fission cross section and any error that would be sufficient to cause a significant error in isotopic concentration would generally provide unacceptable errors in the criticality analysis.

3. Assemblies with integral fuel burnable absorbers (IFBAs) are excluded.

No chemical assays were analyzed for fuel with IFBAs. The boron-coated IFBAs may be closely represented by the assayed pin that was next to a removable burnable absorber, but at this time it is viewed prudent to exclude such assemblies.

4. The methodology applies to SNF with cooling times ranging from 1 to 100 years.

Cooling times under one are not of interest to current burnup credit concepts and hence no effort was made to find the limits of applicability below one year. The 100 year limit is due to the reactivity increasing beginning sometime after 100 years.

5. MOX initial enrichment fuel is excluded.

No chemical assays are available from this type of fuel. 
6. Reconstituted or disassembled fuel is excluded. Also excluded is fuel which has had any of I its original rods removed or replaced.

Modified or non-intact fuel assemblies may not be bounded by design basis criticality analyses.

\subsection{CONSERVATISM IN THE BURNUP CREDIT METHOD}

The methodology for utilizing actinide-only burnup credit described in this topical report includes substantial conservatism. This conservatism is the result of the methodology compensating for the incomplete knowledge of the fuel isotopic composition (including the spatial distribution) and limited knowledge of some cross sections. This section will explore some of the issues associated with the conservatism.

A great deal of the conservatism in the method is imbedded in the isotopic concentrations that are allowed by the method. In order to explore this some analysis has been performed. ${ }^{7-1} \mathrm{k}_{\text {inf }}$ calculations have been done using best estimate values of the isotopic concentrations after burnup. These best estimate values use the isotopic biases from chapter 2 but the concentrations are not corrected for the uncertainties. Further the analysis was performed with best estimate values of $t_{\text {ave }}$ for the moderator temperature, the average fuel temperature, an average specific power, and finally an average ppm boron concentration in the core. This analysis is then compared to a case without fission products. Finally, the analysis is repeated with the correction factors and modeling parameters recommended in this topical report. Table 7-2 shows the results of this analysis. Table 7-3 uses the same data and shows the best estimate of the change in $\mathrm{k}$ with burnup and compares that to the change in $\mathrm{k}$ observed with the method presented in this topical report.

The fission product conservatism shown on Table 7-2 is large. This conservatism is not taken at this time since there is not strong documentation of individual fission worths. The fission product yields can be measured relatively easily but the transmutation in the reactor again has little experimental verification. The reactor vendors and utilities in their core analysis use lumped fission products whose worth must be close to true in order to obtain the standard accuracy in reactor physics calculations. The calculations performed for this report were not done with standard fuel management tools and thus no credit will be taken for power reactor data analyzed with other codes.

The other conservatism shown on Table 7-2 is due to the correction factors and modeling parameters. This conservatism is dominated by the correction factors. To some this may not be seen as a conservatism since it is merely accounting for the uncertainty in the data. This would be logical if it was done for one isotope but since it is done for each isotope, it implies that each isotope deviates from its expected value in the same direction (in the direction that creates more reactivity). Unfortunately, since the isotopes are all of different worths it is not clear how to statistically combine the uncertainties. It is anticipated that future work may allow the combination of these errors. 
Table 7-2: Conservatisms in the Actinide-Only Burnup Credit Methodology

\begin{tabular}{|c|c|c|c|c|}
\hline $\begin{array}{c}\text { Enrichment } \\
(\mathrm{wt} \% \text { U-235) }\end{array}$ & $\begin{array}{c}\text { Burnup } \\
(\mathrm{GWd} / \mathrm{MTU})\end{array}$ & $\begin{array}{c}\text { Isotopic Correction } \\
\text { Factors/Modeling } \\
\text { Parameters } \\
\text { Conservatism }(\% \Delta \mathrm{k})\end{array}$ & $\begin{array}{c}\text { Fission Product } \\
\text { Conservatism } \\
(\% \Delta \mathrm{k})\end{array}$ & $\begin{array}{c}\text { Addled } \\
\text { Conservatism } \\
(\% \Delta \mathrm{k})\end{array}$ \\
\hline \multirow{3}{*}{3.0} & 15 & 2.8 & 7.8 & 10.6 \\
\cline { 2 - 5 } & 30 & 4.1 & 12.1 & 16.2 \\
\cline { 2 - 6 } & 45 & 5.3 & 15.3 & 20.6 \\
\hline \multirow{3}{*}{3.6} & 15 & 2.4 & 7.5 & 9.9 \\
\cline { 2 - 6 } & 30 & 3.6 & 11.8 & 15.3 \\
\cline { 2 - 6 } & 45 & 4.9 & 15.2 & 20.1 \\
\hline \multirow{3}{*}{4.5} & 15 & 2.1 & 7.2 & 9.3 \\
\cline { 2 - 6 } & 30 & 3.0 & 11.4 & 14.4 \\
\hline
\end{tabular}

Table 7-3: Conservatisms in the Change in Reactivity as a Function of Burnup

\begin{tabular}{|c|c|c|c|c|}
\hline $\begin{array}{c}\text { Enrichment } \\
\text { (wt\% U-235) }\end{array}$ & $\begin{array}{c}\text { Burnup } \\
(\mathrm{GWd} / \mathrm{MTU})\end{array}$ & $\begin{array}{c}\text { Best Estimate Change in } \\
\text { Reactivity with Burnup } \\
(\% \Delta \mathrm{k})\end{array}$ & $\begin{array}{c}\text { Actinide-Only } \\
\text { Change in Reactivity } \\
\text { with Burnup } \\
(\% \Delta \mathrm{k})\end{array}$ & $\begin{array}{c}\text { Percent } \\
\text { of Best } \\
\text { Estimate }\end{array}$ \\
\hline \multirow{3}{*}{3.0} & 15 & 18.6 & 8.0 & $43 \%$ \\
\cline { 2 - 5 } & 30 & 32.2 & 16.0 & $50 \%$ \\
\cline { 2 - 5 } & 45 & 42.6 & 22.1 & $52 \%$ \\
\hline \multirow{3}{*}{3.6} & 15 & 17.6 & 7.7 & $44 \%$ \\
\cline { 2 - 6 } & 30 & 31.0 & 15.6 & $50 \%$ \\
\hline \multirow{3}{*}{4.5} & 45 & 42.2 & 22.1 & $52 \%$ \\
\cline { 2 - 6 } & 15 & 16.4 & 7.1 & $43 \%$ \\
\cline { 2 - 6 } & 30 & 28.8 & 14.5 & $50 \%$ \\
\hline
\end{tabular}


Table 7-3 shows that only half the change in reactivity with burnup is accounted for with actinideonly burnup credit. If utilities were to miss the change in burnup by this much they would be forced to shutdown their reactors after a few months of operation due to a reactivity anomaly. (Utilities are generally not allowed a $1 \%$ deviation from their reactivity prediction. The change in reactivity in a standard PWR is about $1 \%$ per month.) Once again, the code package used to demonstrate the actinide-only burnup credit is not a standard fuel management tool so direct credit for power reactor data is not being used.

Tables 7-2 and 7-3 only review the conservatism in the isotopic concentrations. In addition to this conservatism is that due to using the most limiting axial burnup profiles. Again, since the profiles are possible profiles some would not consider this a conservatism. Most fuel assemblies have burnup profiles that do not produce positive end effects with the actinide-only assumption. Figure 4-6 shows the population of fuel assemblies and it can be clearly seen that the limiting profiles represent a small fraction of the assemblies. It is assumed that the package is full of only the limiting profile assemblies. Clearly, most packages will contain assemblies with a mix of axial profiles and hence a mean profile would be expected. The magnitude of this conservatism can be estimated as the same as the $\mathbf{k}_{\text {eff }}$ bias curves (Figures 4-7 to 4-9) in chapter 4. This results in a few more percent $\mathrm{k}$ conservatism. There is also the conservatism due to horizontal burnup tilt. For large packages this is small, but for four assembly packages this also can be large. Here it is not only assumed that strong horizontal gradients exist in every assembly but that they are loaded in the most limiting way.

The methodology presented in this topical has been developed to meet the regulatory assumption of limiting $\mathrm{k}_{\mathrm{eff}}=0.95$, which has been determined to provide an adequate safety margin. The conservatisms that have been qualitatively discussed here are in excess of that margin. Future efforts will quantitatively address these conservatisms and work to reduce them.

\subsection{SUMMARY OF NRC APPROVALS SOUGHT}

This topical report seeks NRC concurrence that: 1) the data presented are sufficient to validate actinide-only burnup credit, 2) the method presented to provide a basis for using burnup credit is valid, and 3 ) the computer analysis methods used to demonstrate this method are validated for burnup credit analysis as set forth in this topical report. This topical report is specifically seeking NRC acceptance of the following:

1. That the PWR fuel post irradiation examination assay data selected for isotopic inventory bias and uncertainty determination are sufficient for validating the selected actinide composition in spent fuel.

2. That the statistical procedure proposed for establishing isotope-specific biases and correction factors is a conservative method to account for isotopic concentration changes during burnup.

3. That the SAS2H sequence of the SCALE 4.2 code system using 27BURNUPLIB cross sections has been validated and appropriate isotopic correction factors have been determined. 
4. That the 57 criticality experiments selected are sufficient for validating computer codes for actinide-only burnup credit analysis.

5. That the selected trend analyses requirements on the criticality experiment analysis are adequate.

6. That the method of determining the upper safety limit assures criticality safety.

7. That the use of the developed USL with CSAS/27BURNUPLIB code system and with a $0.05 \Delta \mathrm{k}_{\mathrm{m}}$ administrative safety margin is acceptable to perform actinide-only burnup credit criticality safety calculations in SNF package design.

8. That a single cycle burnup at a specific power of $60 \mathrm{MW} / \mathrm{MTU}$ conservatively bounds the effects of specific power and operating history on isotopic concentrations.

9. That the use of the maximum cycle average dissolved boron concentration conservatively accounts for soluble boron effects on isotopic concentrations.

10. That the reactivity of the spent fuel is maximized by setting the fuel temperature to the maximum pellet averaged temperature.

11. That the use of the maximum core outlet temperature in determining the moderator density for depletion produces conservative isotopic concentrations.

12. That the method presented for determining optimum moderation in the SNF package is acceptable.

13. That the use of the selected limiting axial burnup profiles for burnup credit adequately capture the end effects

14. That the selected horizontal gradients and use of the most limiting arrangement in the package sufficiently model horizontal burnup effects.

15. That the method for developing the burnup loading criteria is adequate.

16. That the use of reactor records and the method of verifying proper assembly selection is acceptable. 


\section{REFERENCES}

\section{Chapter 1}

1-1. The Nuclear Waste Policy Act of 1982, as amended, 42 U.S.C. 10101 et seq.

1-2. 10 CFR Part 71 sets forth NRC regulations on "Packaging and Transportation of Radioactive Material," (1994).

1-3. T. L. Sanders, R. M. Westfall, and R. H. Jones, August 1987. Feasibility and Incentives for the Consideration of Spent Fuel Operation Histories in the Criticality Analysis of Spent Fuel Shipping Casks, Sandia National Laboratories, SAND87-0151.UC-71.

1-4. Computer Code Collection, Draft November 1993, Revision 4. SCALE 4.2, A Modular Code System for Performing Standardized Computer Analyses for Licensing Evaluation, Vol. 1-3, CCC-545, Oak Ridge National Laboratory.

1-5. U.S. Nuclear Regulatory Commission, Regulatory Guide 3.4. Nuclear Criticality Safety in Operations with Fissionable Materials at Fuels and Materials Facilities, March 1986, Revision 2, Washington: Office of Nuclear Regulatory Research, Washington, D.C.

1-6. American Nuclear Society, October 1983. Nuclear Criticality Safety in Operations with Fissionable Materials Outside Reactors, ANSI/ANS-8.1-1983, La Grange Park, IL.

1-7. U.S. Nuclear Regulatory Commission, Regulatory Guide 3.58. Criticality Safety for Handling, Storing, and Transporting LWR Fuel at Fuels and Materials Facilities, October 1986, Washington: Office of Nuclear Regulatory Research, Washington, D.C.

1-8. American Nuclear Society, January 1984. Criticality Safety Criteria for the Handling, Storage, and Transportation of LWR Fuel Outside Reactors, ANSI/ANS-8.17-1984, La Grange, IL.

1-9. U.S. Nuclear Regulatory Commission, Regulatory Guide 3.60. Design of an Independent Spent Fuel Storage Installation (Dry Storage), March 1987, Washington: Office of Nuclear Regulatory Research, Washington, D.C.

1-10. American Nuclear Society, May 1992. Design Criteria for an Independent Spent Fuel Storage Installation, ANSI/ANS-57.9-1992, La Grange, IL.

1-11. U.S. Nuclear Regulatory Commission, December 1981. Proposed Revision 2. Spent Fuel Storage Facility Design Basis, Regulatory Guide 1.13, Washington: Office of Nuclear Regulatory Research, Washington, D.C.

1-12. American Nuclear Society, October 1983. Design Requirements for Light Water Reactor Spent Fuel Storage Facilities at Nuclear Power Plants, ANSI/ANS-57.2-1983. La Grange, IL. 
1-13. Quality Assurance Requirements and Description (QARD) document, DOE/RW-0333P, Revision 2. March 1995.

\section{Chapter 2}

2-1. M. D. DeHart, 1995. Sensitivity and Parametric Evaluations of Significant Aspects of Burnup Credit for PWR Spent Nuclear Fuel Packages, ORNL/TM-12973, Oak Ridge National Laboratory, Martin Marietta Energy Systems, Inc. (to be published).

2-2. R. J. Guenther, 1988. Characterization of Spent Fuel Approved Testing Material - ATM103, PNL-5109-103, Pacific Northwest Laboratory.

2-3. R. J. Guenther, 1988. Characterization of Spent Fuel Approved Testing Material - ATM104, PNL-5109-104, Pacific Northwest Laboratory.

2-4. R. J. Guenther, 1988. Characterization of Spent Fuel Approved Testing Material - ATM106, PNL-5109-106, Pacific Northwest Laboratory.

2-5. J. O. Banner, 1985. Characterization of LWR Spent Fuel MCC-Approved Testing Material ATM-101, PNL-5109, Rev. 1, Pacific Northwest Laboratory.

2-6. U. Fisher and H. W. Wiese, January 1983. Improved and Consistent Determination of the Nuclear Inventory of Spent PWR Fuel on the Basis of Cell Burnup Methods Using KORIGEN, (ORNL-TR-5043), KFK 3014, Karlsruhe Nuclear Research Center; available from Radiation Shielding Information Center, Oak Ridge National Laboratory, as CCC-457.

2-7. U. Hesse, Verification of the OREST (HAMMER-ORIGEN) Depletion Program System Using Post-Irradiation Analyses of Fuel Assemblies 168, 170, 171, and 176 from the Obrigheim Reactor (ORNL-TR-8820). GRS-A-962 Gesellschaft fur Reaktorscherheit (GRS) $\mathrm{mbH}, 1984$.

2-8. Y. Naito, M. Kurosawa, and T. Kaineko, March 1994. Data Book of the Isotopic Composition of Spent Fuel in Light Water Reactors, JAERI-M, 94-034, Japan Atomic Research Institute.

2-9. M. Rahimi, E. Fuentes, and D. B. Lancaster, April 1997. Isotopic and Criticality Validation for PWR Actinide-Only Burnup Credit, DOE/RW-0XXX Rev 0, Office of Civilian Radioactive Waste Management, U.S. Department of Energy.

2-10. M. D. DeHart and O.W. Herman, September 1996. An Extension of the Validation of SCALE(SAS2H) Isotopic Predictions for PWR Spent Fuel, ORNL/TM-13317, Oak Ridge National Laboratory.

2-11. O. W. Herman, et al., March 1995. Validation of the Scale System for PWR Spent Fuel Isotopic Composition Analyses, ORNL/TM-12667, Oak Ridge National Laboratory. 
2.12. American Nuclear Society, October 1983. Nuclear Criticality Safety in Operations with Fissionable Materials Outside Reactors, ANSI/ANS-8.1-1983, La Grange Park, IL.

2-13. Computer Code Collection, Draft November 1993, Revision 4. SCALE 4.2, A Modular Code System for Performing Standardized Computer Analyses for Licensing Evaluation, Vol. 1-3, CCC-545, Oak Ridge National Laboratory.

2-14. Sheldon M. Ross. Introduction to Probability and Statistics for Engineers and Scientists. New York: John Wiley \& Sons, Inc., 1987.

2-15. Ronald L. Iman and W. J. Conover. A Modern Approach to Statistics. New York: John Wiley \& Sons, Inc., 1983.

2-16 William J. Beggs, 1981. Statistics for Nuclear Engineers and Scientists; Part 1: Basic Statistical Inference, Bettis Atomic Power Laboratory, Page 79.

\section{Chapter 3}

3-1. American Nuclear Society, October 1983. Nuclear Criticality Safety in Operations with Fissionable Materials Outside Reactors, ANSI/ANS-8.1-1983, La Grange Park, IL.

3-2. American Nuclear Society, January 1984. Criticality Safety Criteria for the Handling, Storage, and Transportation of LWR Fuel Outside Reactors, ANSI/ANS-8.17-1984, LA Grange, IL.

3-3. Computer Code Collection, April 1995, Revision 4. SCALE 4.2, A Modular Code System for Performing Standardized Computer Analyses for Licensing Evaluation, Vol. 1-3, CCC545, Oak Ridge National Laboratory.

3-4. S. R. Bierman, October 1977. Critical Separation Between Subcritical Clusters of 2.35 Wt\% U-235 Enriched $\mathrm{UO}_{2}$ Rods in Water with Fixed Neutron Poisons, PNL-2438, Battelle Pacific Northwest Laboratory.

3-5. S. R. Bierman, December 1981. Criticality Experiments with Subcritical Clusters of 2.35 Wt\% and $4.31 \mathrm{Wt} \% \mathrm{U}-235$ Enriched $\mathrm{UO}_{2}$ Rods in Water with Uranium or Lead Reflecting Walls, PNL-3926, Battelle Pacific Northwest Laboratory.

3-6. S. R. Bierman and E. D. Clayton, April 1981. Criticality Experiments with Subcritical Clusters of $2.35 \mathrm{Wt} \%$ and $4.31 \mathrm{Wt} \%$ U-235 Enriched $\mathrm{UO}_{2}$ Rods in Water with Steel Reflecting Walls, PNL-3602, Battelle Pacific Northwest Laboratory.

3-7. B. M Durst, August 1982. Critical Experiments with 4.31 Wt\% U-235 Enriched UO Rods $_{2}$ in Highly Borated Water Lattices, PNL-4267, Battelle Pacific Northwest Laboratory.

3-8. S. R. Bierman, April 1990. Criticality Experiments with Neutron Flux Traps Containing Voids, PNL-7167, Battelle Pacific Northwest Laboratory. 
3-9. M. N. Baldwin, July 1979. Critical Experiments Supporting Close Proximity Water Storage of Power Reactor Fuel, BAW-1484, Babcock and Wilcox Company.

3-10. L. W. Newman, April 1984. Urania Gadolinia: Nuclear Model Development and Critical Experiment Benchmark, BAW-1810, Babcock and Wilcox Company.

3-11. R. I. Smith and G. J. Konzek, April 1976 and September 1978. Clean Critical Experiment Benchmarks for Plutonium Recycle in LWRs, EPRI NP-196, Volumes I and II, Electric Power Research Institute.

3-12. E. G. Taylor et al., December 1965. Saxton Plutonium Critical Experiments for the Saxton Partial Plutonium Core, WCAP-3385-54, Westinghouse Electric Corporation.

3-13. S. R. Bierman, February 1984. Criticality Experiments with Low Enriched $\mathrm{UO}_{2}$ Fuel Rods in Water Containing Dissolved Gadolinium, PNL-4976, Battelle Pacific Northwest Laboratory.

3-14. V. O. Uotinen, et al., August 1972. "Lattices of Plutonium-Enriched Rods in Light WaterPart I: Experimental Results," Nuclear Technology, 15, 257.

3-15. M. D. DeHart and S. M. Bowman, October 1995. Analysis of Fresh Fuel Critical Experiments Appropriate for Burnup Credit Validation, ORNL/TM-12959, Oak Ridge National Laboratory.

3-16. M. Rahimi, E. Fuentes, and D. B. Lancaster, April 1997. Isotopic and Criticality Validation for PWR Actinide-Only Burnup Credit, DOE/RW-0XXX Rev 0, Office of Civilian Radioactive Waste Management, U.S. Department of Energy.

3-17. R. L. Iman and W. J. Conover, 1983. A Modern Approach to Statistics, John Wiley \& Sons.

3-18. H. R. Dyer, W. C. Jordan, and V. R. Cain, June 1991. "A Technique for Code Validation for Criticality Safety Calculations," Trans. Am. Nucl. Soc., 63, 238.

3-19. M. E. Easter, July 1985. Validation of KENO V.a and two Cross-Section Libraries for Criticality Calculations of Low-Enriched Uranium Systems, ORNL/CSD/TM-223, Oak Ridge National Laboratory.

3-20. S. M. Ross, 1987. Introduction to Probability and Statistics for Engineers and Scientists, John Wiley \& Sons.

3-21. M. D. DeHart and S. M. Bowman, September 1994. Validation of the SCALE Broad Structure 44-Group ENDF/B-V Cross Section Library for Use in Criticality Safety Analyses, NUREG/CR-6102 (ORNL/TM-12460).

3-22. R. J. Brissenden, September 19-23, 1993. "Increasing the Physical Realism of the MONK Criticality Code," Proc. of the Topical Meeting on Physics and Methods in Criticality Safety, Nashville, TN, 51-57. 


\section{Chapter 4}

4-1 M. D. DeHart, "Sensitivity and Parametric Evaluations of Significant Aspects of Burnup Credit for PWR Spent Fuel Packages," ORNL/TM-12973, Oak Ridge National Laboratory (May 1996).

4-2 C. H. Kang, et al., "Depletion and Package Modeling Assumptions for Actinide-Only Burnup Credit," DOE/RW-XXXX, U.S. Department of Energy (May 1996).

4.3 R. J. Guenther, "Characteristics of Spent Fuel Approved Testing Material -ATM-106," PNL5109-106, Pacific Northwest Laboratory (Oct. 1988).

4-4 R. J. Cacciapouti, et al., "Axial Burnup Profile Database for Pressurized Water Reactors," Yankee Atomic Electric Company (August 1996).

4-5 T. A. Parish, et al., "Bounding Axial Profile Analysis for the Topical Report Database," Texas A\&M University (April 1996).

4-6 C. H. Kang, et al., "Radial Burnup Gradient Datafile for PWR Assemblies," DOE/RWXXXX, U.S. Department of Energy (May 1996).

\section{Chapter 5}

5-1. U. S. Nuclear Regulatory Commission, October 1981. Standard Technical Specifications for Westinghouse PWRs, NUREG-0452.

5-2. Dariush G. Adli and Dominic C. Napolitano, March 1992. Burnup Credit Analysis using Advanced Nodel Techniques, Yankee Atomic Electric Company.

5-3. M. D. DeHart, May 1995. Sensitivity and Parametric Evaluations of Significant Aspects of Burnup Credit for PWR Spent Nuclear Fuel Packages, ORNL/TM-12973, Oak Ridge National Laboratory, Martin Marietta Energy Systems, Inc.

\section{Chapter 6}

6-1. 10 CFR Part 50 sets for NRC regulations on Domestic Licensing of Production and Utilization Facilities (1994).

6-2. U.S. Nuclear Regulatory Commission, December 1981. Proposed Revision 2. Spent Fuel Storage Facility Design Basis, Regulatory Guide 1.13.

6-3. American Nuclear Society, October 1983. Nuclear Criticality Safety in Operations with Fissionable Materials Outside Reactors, ANSI/ANS-8.1-1983, La Grange Park, IL. 


\section{Chapter 7}

7-1. M. Rahimi, E. Fuentes, and D. B. Lancaster, April 1997. Isotopic and Criticality Validations for PWR Actinide-Only Burnup Credit, DOE/RW-0XXX Rev 0, Office of Civilian Radioactive Waste Management, U.S. Department of Energy. 
APPENDIX A

EXAMPLE OF BURNUP CREDIT ANALYSIS 


\section{A. AN EXAMPLE OF BURNUP CREDIT ANALYSIS}

This Appendix demonstrates the application of the methodology described in Chapters 2 through 7. The demonstration is accomplished through contributions from cask vendors. All cask vendors with a license or license application for an SNF cask were invited to provide a sample calculation of their cask using actinide-only burnup credit. The methodology presented in the body of this report was still undergoing modification when it was provided to the cask vendors, so their sample calculations deviate in some degree from the method as now documented in this Topical Report. DOE supplied to the vendors isotopic data, a $\mathrm{k}_{\text {bias }}$ curve, and values for the horizontal burnup gradient. All of these have subsequently been modified. Upon review, the changes result in slightly less burnup credit than that showed by the contributed sample calculations. The loading curves however are close approximations and provide a good estimate of the impact of burnup credit on these products.

The cask vendors provided the following appendices at their own expense and DOE is grateful for their participation. Appendix A.1 is on the GA-4 cask. Appendix A.2 is on the Holtec HiStar-32. Appendix A.3 is on the TN-40. Finally, Appendix A.4 is on the Vectra MP-187. The appendices are in alphabetical order. The appendices are printed here exactly as provided by the vendors. 
APPENDIX A.1

GA-4 LEGAL WEIGHT TRUCK CASK 


\section{A.1 GA-4 LEGAL WEIGHT TRUCK CASK}

\section{A.1.1 Cask And Criticality Model Description}

General Atomics (GA) has submitted a licensing application for the GA-4 cask that is currently being reviewed by the NRC Spent Fuel Project Office. The application has a fresh fuel assumption for the criticality analysis. The maximum enrichment permitted for shipping in the cask is $3.1 \mathrm{wt} \%$ with a maximum of $35 \mathrm{GWd} / \mathrm{MTU}$ burnup and 10-year cooling time or $45 \mathrm{GWd} / \mathrm{MTU}$ burnup and 15-year cooling time. Carrying the higher enrichment fuels at full capacity requires burnup credit for the criticality analysis.

Figure A.1-1 shows the GA-4 legal weight truck cask that has a capacity of up to four PWR fuel assemblies. GA designed the cask to maximize the authorized contents by means of a non-circular cask cross section. The shaped containment boundary and depleted uranium gamma shield fit closely around the array of spent fuel assemblies. A cylindrical shell surrounding the cask contains a neutron shield. A fixed stainless steel fuel support structure (FSS) separates the fuel assemblies and contains solid pellets of enriched boron carbide $\left(\mathrm{B}_{4} \mathrm{C}\right)$ in radially drilled holes for criticality control. The $\mathrm{B}_{4} \mathrm{C}$ pellets have a B-10 loading of 1.62 $\mathrm{g} / \mathrm{cm}^{3}$, allowing a compact array of fuel elements. The design uses two diameters of $\mathrm{B}_{4} \mathrm{C}$ pellets. There are $141 \mathrm{in}$. of large diameter $\mathrm{B}_{4} \mathrm{C}$ pellets in the middle region of the FSS and 9.5 to 10 in. of smaller diameter $\mathrm{B}_{4} \mathrm{C}$ pellets at each end. The impact limiters utilize weight efficient aluminum honeycomb. The cask external dimensions are 39.75 in. diameter, 187.76 in. long without impact limiters and 233.95 in. long with impact limiters. The four 8.78 -in. square by 167.26-in. long fuel cells provide sufficient space for all but the extra long PWR fuel assemblies. The Safety Analysis Report for Packaging (SARP), GA Document 910469, Revision D, submitted to the NRC has a more detailed description of the cask along with detailed drawings.

GA models the cask with a square cross section because geometry limitations in KENO V.a of the CSAS25 module in SCALE-4.3 prevent modeling the exact cross section. The slight increase of DU in the corners introduces additional fission reactions in the DU and also reflects more neutrons back into the system, making this assumption conservative.

The cask analytical model represents a full-height and 1/4-radial cross section of the cask. Figure A.1-2 illustrates the cask model used for criticality analysis. For this sample problem, GA uses the W $17 \times 17$ Std fuel assembly. We model the W $17 \times 17$ Std fuel assembly as a $17 \times 17$ array comprising (1) 264 fuel rods, including fuel, gap and cladding, and (2) 25 water holes. Table A.1-1 shows the fuel assembly model parameters. Figure A.1-3 is a cross sectional map of the fuel assembly as modeled. We minimize the assembly-to-assembly pitch (i.e., the assemblies are pushed to the center of the cask), to represent the most reactive configuration in the cask. To be conservative, we include the water holes as compared to modeling the entire $17 \times 17$ array filled with fuel. We model the $\mathrm{B}_{4} \mathrm{C}$ with minimum pellet stack length and diameter in the center of the maximum diameter holes. 


\section{GENERAL ATOMICS}

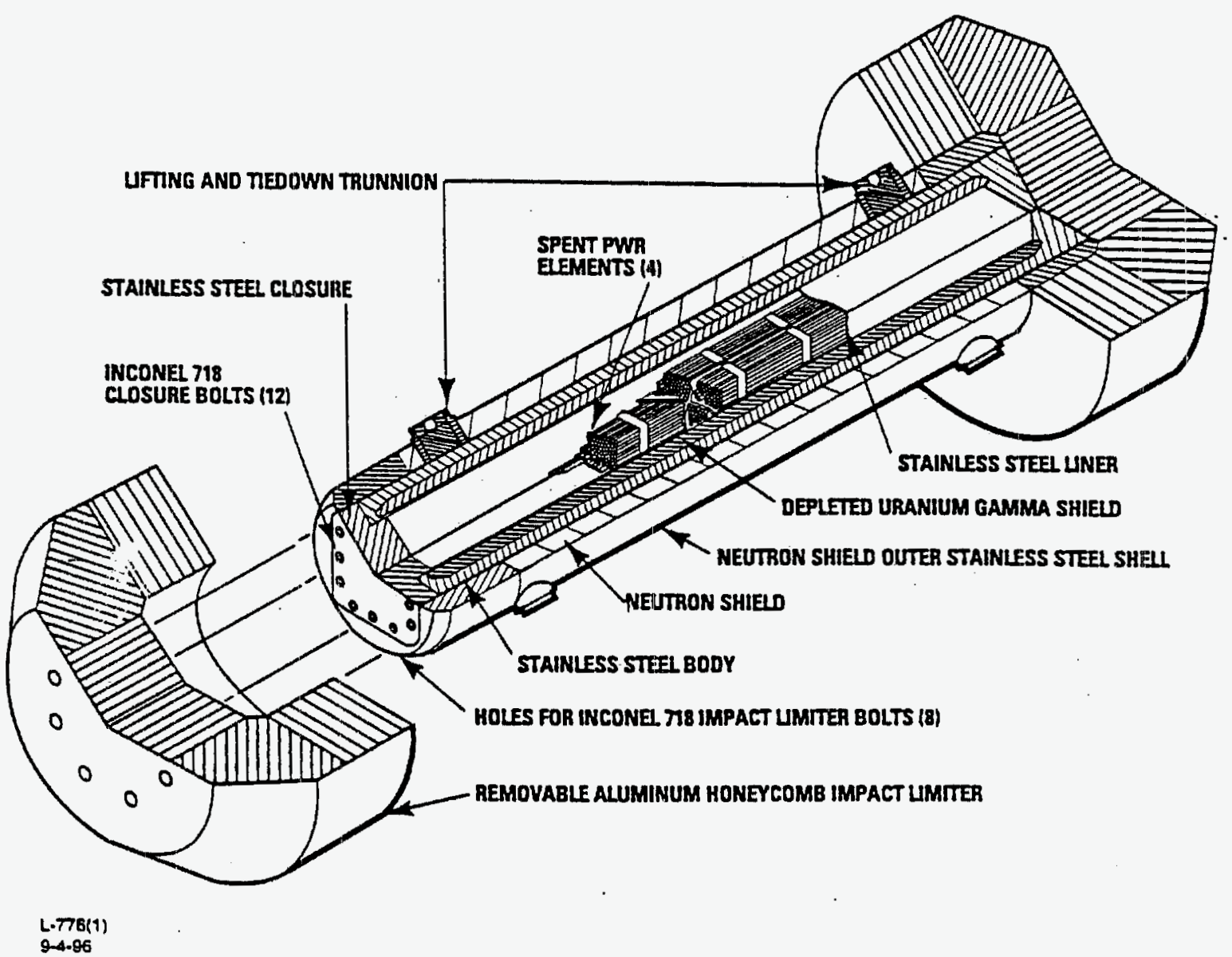

Figure A.1-1 GA-4 Legal Weight Truck Cask 


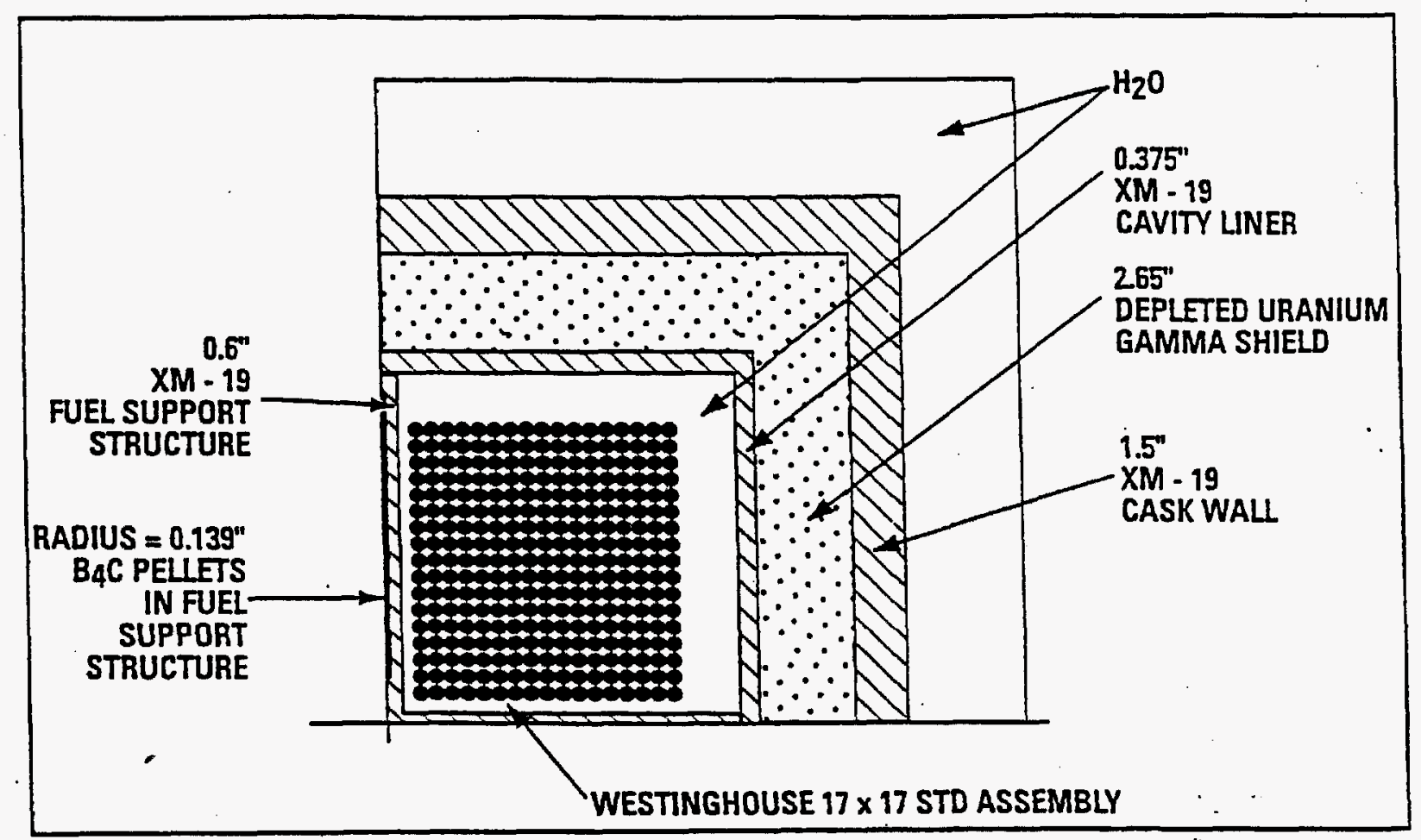

Figure A.1-2 Cross Section View of the KNEO calculational model

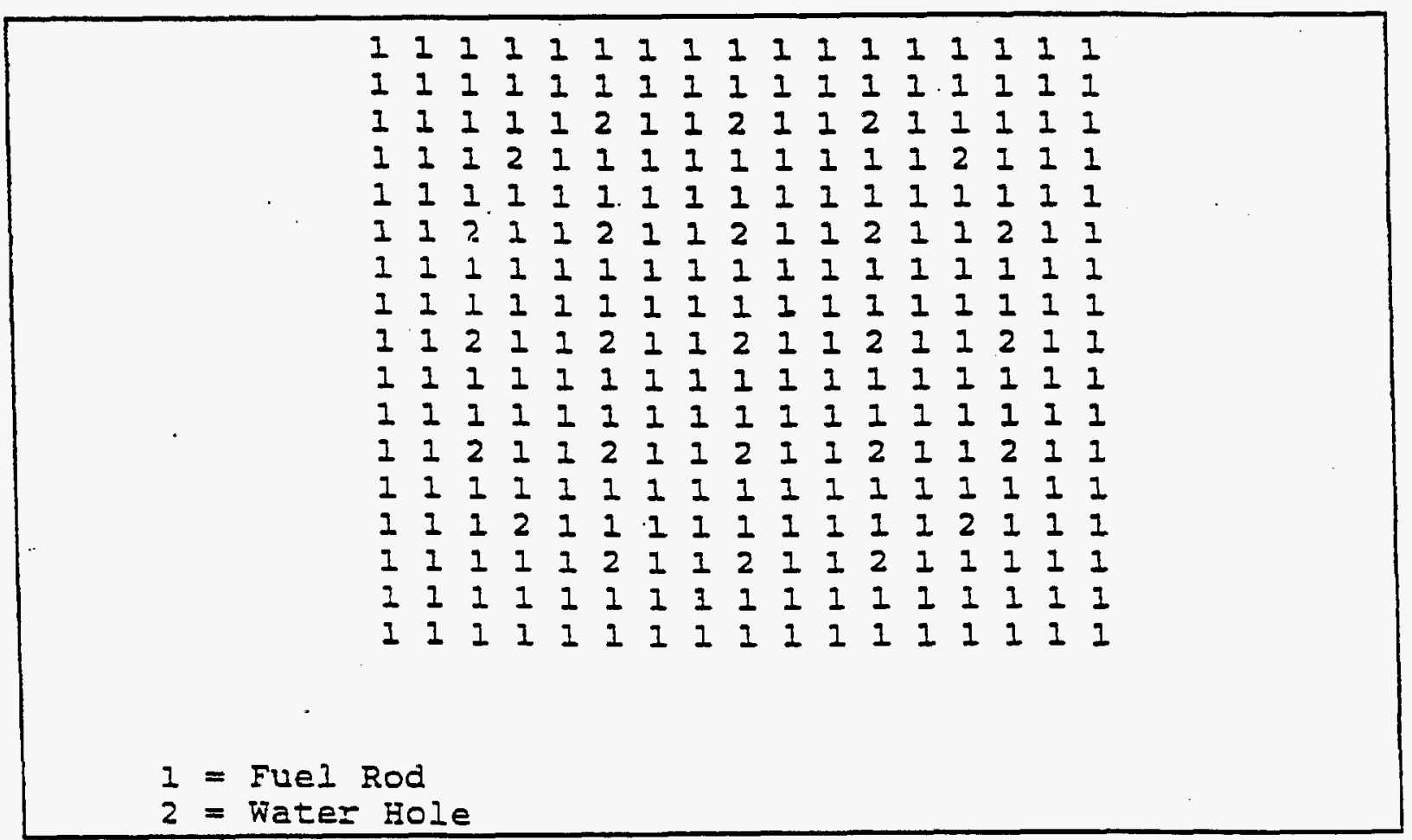

Figure A.1-3 Cross Section View of the W $17 \times 17$ KENO calculational model 
The Oak Ridge National Laboratory (ORNL) SCALE code package contains a standard material data library for common elements, compounds, and mixtures. This data library contains the materials used for the cask analysis. Water represents the neutron shield in the analytical model. The model does not include the neutron shield outer shell. The DOE computerized database contains material data for the fuel assemblies.

Table A.1-1 W 17x17 Fuel Assembly Model Parameters

\begin{tabular}{|l|l|}
\hline \multicolumn{1}{|c|}{ Description } & \\
\hline Number of fuel rods & 264 \\
\hline Number of water holes & 25 \\
\hline Pitch, in. & 0.496 \\
\hline Cladding o.d., in. & 0.374 \\
\hline Cladding thickness, in. & 0.0225 \\
\hline Pellet o.d., in. & 0.3225 \\
\hline Active height, in. & 144 \\
\hline Assembly width, in. & 8.432 \\
\hline Pitch to rod diameter ratio & 1.33 \\
\hline UO2 density, \% TD & 95 \\
\hline Linear U density of assembly, kg/cm & 1.27 \\
\hline Moderator volume fraction & 0.554 \\
\hline Cladding material & Zircaloy \\
\hline
\end{tabular}


Table A.1-2 provides a complete list of all the relevant materials used for the criticality evaluation. The material densities for the $\mathrm{B} 4 \mathrm{C}$ represents $90 \%$ of the minimum B4C (96\% enriched, 96\% theoretical density pellets) poison content in the basket.

Table A.1-2 Model Material Data

\begin{tabular}{|l|c|l|c|c|}
\hline \multicolumn{1}{|c|}{ Material } & $\begin{array}{l}\text { Density } \\
\mathrm{g}^{3} \mathrm{~cm}^{(\mathrm{lb} / \mathrm{in} .}{ }^{3} \text { ) }\end{array}$ & Element & $\begin{array}{c}\text { Modeled } \\
\text { Physical } \\
\text { wt }\end{array}$ & $\begin{array}{c}\text { Atom Density } \\
\text { (atoms/b-cm) }\end{array}$ \\
\hline B4C & 2.19 & $\mathrm{~B}-10$ & 73.91 & $9.760 \mathrm{E}-2$ \\
& $(0.0791)$ & $\mathrm{B}-11$ & 3.08 & $3.698 \mathrm{E}-2$ \\
& & $\mathrm{C}$ & 23.01 & $2.532 \mathrm{E}-2$ \\
\hline XM-19 (SS-304) & 7.92 & $\mathrm{Cr}$ & 19.0 & $1.743 \mathrm{E}-2$ \\
& $(0.286)$ & $\mathrm{Mn}$ & 2.0 & $1.736 \mathrm{E}-3$ \\
& & $\mathrm{Fe}$ & 69.5 & $5.936 \mathrm{E}-2$ \\
& & $\mathrm{Ni}$ & 9.5 & $7.721 \mathrm{E}-3$ \\
\hline Water & $\mathrm{H}$ & 11.1 & $6.677 \mathrm{E}-2$ \\
& $(0.0361)$ & $\mathrm{O}$ & 88.9 & $3.338 \mathrm{E}-2$ \\
\hline Depleted uranium & 19.05 & $\mathrm{U}-235$ & 0.3 & $1.464 \mathrm{E}-4$ \\
& $(0.688)$ & $\mathrm{U}-238$ & 99.7 & $4.805 \mathrm{E}-2$ \\
\hline Fuel W 17x17 & 10.41 & $\mathrm{U}-234$ & 0.035 & $9.84828 \mathrm{E}-6$ \\
UO2 & $(0.3760)$ & $\mathrm{U}-235$ & 3.966 & $1.04557 \mathrm{E}-3$ \\
4.5\% enriched & & $\mathrm{U}-236$ & 0.019 & $4.64700 \mathrm{E}-6$ \\
& & $\mathrm{U}-238$ & 84.122 & $2.21749 \mathrm{E}-2$ \\
& & $\mathrm{O}$ & 11.858 & $4.64700 \mathrm{E}-2$ \\
\hline Zircaloy & 6.44 & $\mathrm{Zr}$ & 100.0 & $4.25156 \mathrm{E}-2$ \\
& $(0.2326)$ & & & \\
\hline
\end{tabular}

\section{A.1.2 Isotopic Validation}

Since GA uses the SCALE program and the 27BURNUPLIB, Chapter 2 of this document provides the necessary isotopic validation. Chapter 2 contains the methodology that was used to calculate the isotopics and the correction factors that were used in this sample calculation. 


\section{A.1.3 Criticality Validation}

Since GA uses the SCALE program and the 27BURNUPLIB, Chapter 3 of this document provides the necessary criticality validation. Chapter 3 contains the methodology used to develop the upper safety limit (USL). USL is defined as

for $\quad \mathrm{ALA} \leq 17.58$,

$\left.\mathrm{USL}=.8663+4.45 \times 10^{-3}(\mathrm{ALA})-1.665 \times 10^{-3} \sqrt{23.402+(\mathrm{ALA}-18.54}\right)^{2}$,

and

for $\quad A L A \geq 17.58$ $\mathrm{USL}=0.9381$,

where ALA = Average Lethargy for Absorption (calculated using program listed in Table A.1-3).

\section{A.1.4 Limiting Parameters}

Chapter 4 discusses many of the limiting parameters required for input to the SAS2H isotopic concentration generation process. The analysis to generate the isotopic concentrations uses the bounding parameter approach found in Chapter 4.

The physical data for the W $17 \times 17$ std fuel assembly are available in Report DOE/RW-0184. Table A.1-4 contains the parameters used in the criticality analysis. 
Table A.1-3 Listing of Program to Calculate the Average Lethargy for Absorption (ALA)

program ALAF

dimension af (27), energy (28), xleth (27)

character*30 filex

character*14 line

C**ENERGY GROUPS

energy $(1)=2.00 E 7$

energy $(2)=6.43 E 6$

energy $(3)=3.00 \mathrm{E} 6$

energy $(4)=1.85 \mathrm{E} 6$

energy $(5)=1.40 \mathrm{E} 6$

energy $(6)=9.00 E 5$

energy $(7)=4.00 \mathrm{E5}$

energy $(8)=1$. 00E5

energy $(9)=1.70 \mathrm{E} 4$

energy $(10)=3.00 \mathrm{E} 3$

energy $(11)=5.50 \mathrm{E2}$

energy $(12)=1$. OOE2

energy $(13)=3.00 E 1$

energy $(14)=1.00 \mathrm{El}$

energy $(15)=3.05$

energy $(16)=1.77$

energy $(17)=1.30$

energy $(18)=1.13$

energy $(19)=1.00$

energy $(20)=8.00 \mathrm{E}-1$

energy $(21)=4.00 \mathrm{E}-1$

energy $(22)=3.25 E-1$

energy $(23)=2.25 E-1$

energy $(24)=1.00 E-1$

energy $(25)=5$. 00E-2

energy $(26)=3.00 \mathrm{E}-2$

energy $(27)=1.00 E-2$

energy $(28)=1$. OOE -5

C**ENIER FIIE

10 WRITE(*, *) 'ENTIR FIIE NAME'

$\operatorname{READ}(*, *)$ fIlEX

OPEN (UNIT=1, FILE=filex, status= ' old' )

$C^{* * C O M P U T E}$ AVG IETHARGY FOR EACF ENTRRGY GROUP

DO $20 \quad j=1,27$

$x \operatorname{leth}(j)=(\operatorname{energy}(j) *(a \log (2 E 7 / \operatorname{energy}(j))+1)$-energy $(j+1)$ *

$+(\operatorname{alog}(2 E 7 / \operatorname{energy}(j+1))+1) /(\operatorname{energy}(j)$-energy $(j+1))$

20 CONTINUE

C**READ ABSORPTION RATES FROM SCAIE OUTPUT FIIE

DO $110 \quad 1=1,100000$

read (1.1001) line

110 CONIINUE

if (Iine.eq. 'GROUP FISSION') GOTO 120

$120 \operatorname{read}(1, *)$

DO $130 \quad j=1,27$

$\operatorname{READ}(1, *)$

$\operatorname{read}(1, *) \times 1, \times 2, \times 3, \times 4$, af $(j)$

130 CONTINUE

CLOSE (UNIT=1) 
Table A.1-3 Listing of Program to Calculate the Average Lethargy for. Absorption (ALA) (Continued)

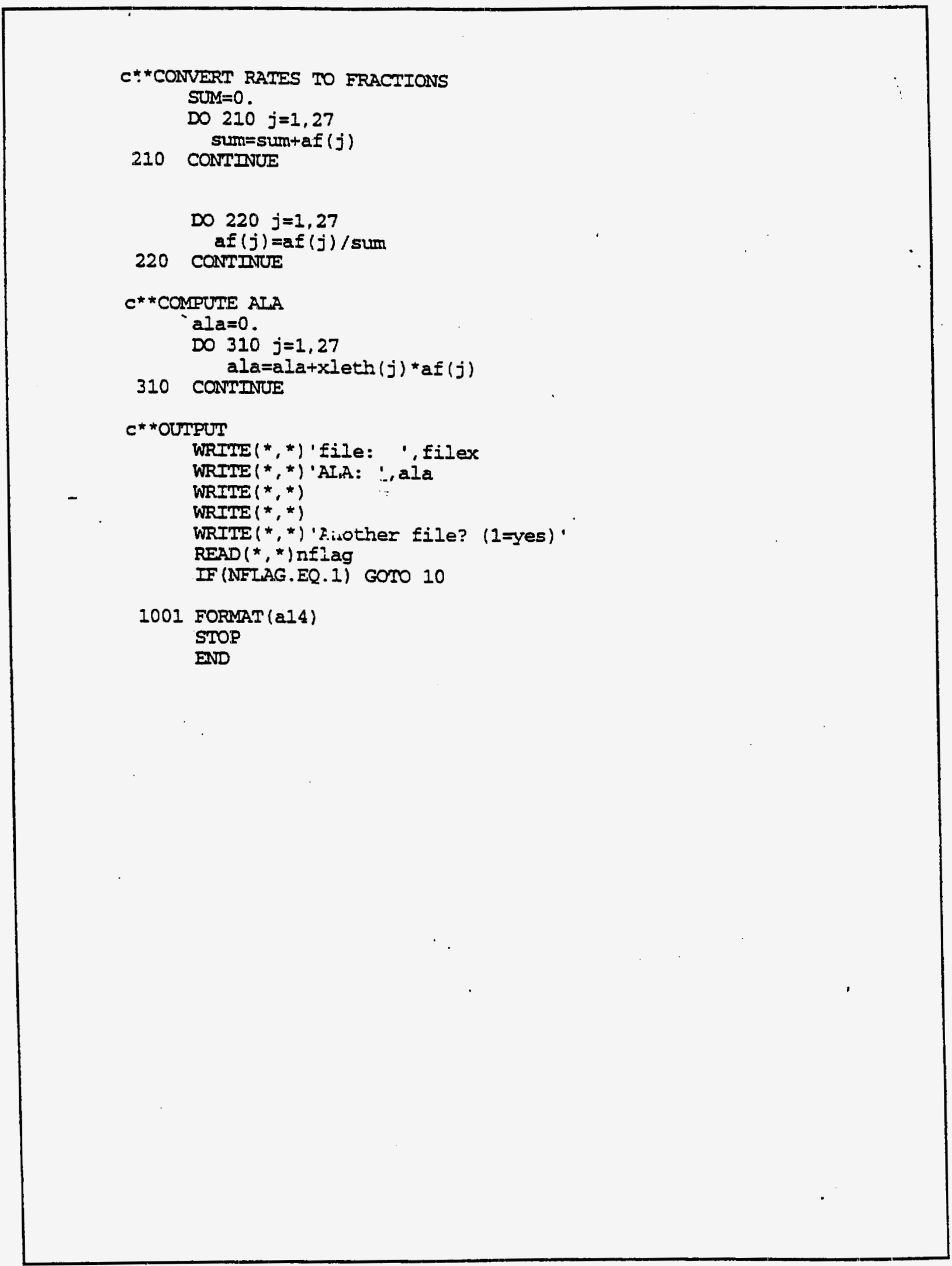


Table A.1-4. Key Parameters for Criticality Analysis

\begin{tabular}{|l|l|}
\hline \multicolumn{1}{|c|}{ Description } & \multicolumn{1}{|c|}{ Parameter } \\
\hline Fuel Support Structure (FSS) Poison & $\mathrm{B}_{4} \mathrm{C}$ \\
Material & \\
\hline Minimum B C Rod Diameter (in.) & \\
Small Pellets (at top and bottom of FSS) & 0.278 \\
Large Pellets (small pellets assumed in & 0.426 \\
model giving a uniform axial poison & \\
distribution to be consistent with the & \\
end effects bias calculation in Ch. 4) & \\
\hline $\mathrm{B}_{4}$ C Rod Pitch (in.) & 0.5 \\
\hline Maximum Fuel Cavity Width (in.) & 8.796 \\
\hline Fuel Type & $\mathrm{W} 17 \times 17$ \\
\hline Fuel Assembly Pitch & Minimum \\
\hline Number of Fuel Rods & 264 \\
Number of Water Holes & 25 \\
\hline Fuel rod pitch (in.) & 0.496 \\
\hline Fuel o.d. (in.) & 0.329 \\
\hline Cladding Thickness (in.) & 0.0225 \\
\hline UO ${ }_{2}$ smear density (\% TD) & 95.0 \\
\hline Fuel Enrichment/Burnup & $3.1 / 7.5$ \\
(wt\% U-235/GWd/MTU) & $3.1 / 9.5$ \\
& $3.1 / 10$ \\
& $3.1 / 15$ \\
& $3.5 / 10$ \\
& $3.5 / 15$ \\
& $3.5 / 16$ \\
& $3.5 / 20$ \\
\hline Cooling Time (Years) & $4.0 / 20$ \\
& $4.0 / 25$ \\
& $4.0 / 30$ \\
& $4.5 / 30$ \\
& $4.5 / 33$ \\
& $4.5 / 35$ \\
\hline
\end{tabular}


In addition to the key parameters shown in Table A.1-4, the following conservative assumptions are also incorporated into the criticality calculations:

1. Omission of grid plates, spacers, and hardware in the fuel assembly.

2. No credit taken for residual burnable poisons in the fuel.

3. Water density at $1.0 \mathrm{~g} / \mathrm{cm}^{3}$.

4. Temperature at $20^{\circ} \mathrm{C}\left(293^{\circ} \mathrm{K}\right)$.

5. $\quad \mathrm{B}_{4} \mathrm{C}$ density assumed to be $86.4 \%$ of theoretical density which accounts for $4 \%$ manufacturing uncertainty and $10 \%$ margin.

6. No boron modeled in the neutron shield.

7. Only the actinide isotopes are used in the analysis.

8. Uniform axial poison used in model. The small pellets of $\mathrm{B}_{4} \mathrm{C}$ were assumed for the entire height of the FSS instead of a combination of small and larger diameter pellets as described in Section A.1.1. This conservatism was added to be consistent with the calculation of the end effects bias shown in Chapter 4 , which was calculated based on a uniform axial poison.

9. Uniform axial burnup profile used in analysis.

\section{A.1.5 Construction Of Loading Curve}

\section{A.1.5.1 Fresh Fuel Intercept}

Fresh fuel calculations are a series of CSAS25 (KENO) calculations using the cask model to determine the maximum fresh fuel enrichment that can be safely loaded into the cask. Issue D of the GA-4 Safety Analysis Report for Packaging, submitted to the NRC for review, contains this calculation for all $14 \times 14$ and $15 \times 15$ PWR fuel assemblies and shows that the intercept is at $3.1 \mathrm{wt} \%$ enrichment which means that all of these assemblies with an initial enrichment $\leq 3.1 \mathrm{wt} \%$ can be shipped without burnup credit. In Issue N/C of the GA-4 SARP, we showed that the most reactive assembly is the W $15 \times 15$ OFA and that it is more reactive than the W $17 \times 17$ Std assembly. Therefore, a fresh fuel intercept calculation was not repeated for this sample calculation of the W $17 \times 17$ Std assembly. Instead, we use the conservative value of $3.1 \mathrm{wt} \%$ determined for the most reactive assembly.

\section{A.1.5.2 Spent Fuel Composition}

GA performed a linear interpolation of the isotopic concentrations provided by DOE to determine the isotopic input to the CSAS25 calculation described in Section A.1.5.3. As stated in Chapter 4, a flat one-zone profile with the addition of the end effects bias is a conservative model. 


\section{A.1.5.3 Spent Fuel Criticality Calculations}

The adjusted isotopics described in Section A.1.2 for a specific initial enrichment and burnup are used as input to CSAS25 to determine the reactivity of the total fuel cask model. To account for radial burnup variation (tilt) in each assembly, each assembly in the model has two burnup levels. For the four element array in the GA-4 Cask, it is obvious that the most reactive configuration is when the lowest burnup for each element is towards the center of the array. DOE has calculated the appropriate amount of radial tilt and is shown in Figure A.1-4. The tilt is 33\% for burnup $<20 \mathrm{GWd} / \mathrm{MTU}, 20 \%$ for burnup $\geq 20 \mathrm{GWd} / \mathrm{MTU}$ and $<40 \mathrm{GWd} / \mathrm{MTU}$ and $15 \%$ for burnup $\geq 40 \mathrm{GWd} / \mathrm{MTU}$.

Using the CSAS25 results, the Average Lethargy of Absorption (ALA) is calculated using the computer code shown in Table A.1-3. The USL was determined using the formulas described in Section A.1.3. Table A.1-5 shows the input for one such calculation at $4.0 \mathrm{wt} \%$ initial enrichment and $25 \mathrm{GWd} / \mathrm{MTU}$ burnup. Table A.1-6 shows the results for the calculated enrichment and burnup pairs that went into the loading curve determination.

Figure A.1-4 plots the calculated $k_{\text {eff }}+1.645 \sigma$ results from the CSAS25 calculations plus the end effects bias from Chapter 4, and the evaluated USL for the example case. The intercept of the USL and $k_{\text {eff }}+1.645 \sigma+$ end effects bias determines the minimum burnup required to safely load the given initial fuel enrichment. Table A.1-7 shows the final required burnup along with the confirmatory calculated $\mathrm{k}_{\text {eff }}$ values at or below the intercepts. The confirmatory calculated $\mathrm{k}_{\text {eff }}$ for these results is close to and below the USL. Figure A.1-5 plots the final required burnup versus initial enrichment for W 17x17 assemblies. As explained in Chapter 5, only spent fuel assemblies with minimum burnup and initial enrichment above the loading curve are qualified for loading into the GA-4 cask. Assemblies that fall below the curve cannot be shipped in this cask. For information, we also show the distribution of all PWR fuel assemblies that fall within each burnup and enrichment range (1993 data, Ref. EIA Service Report, February 1995).

\section{A.1.5.4 Low-Density Moderation Effects}

As described in Chapter 4, criticality analyses must consider optimum moderator density to ensure that the most reactive configuration is evaluated (i.e., a fully flooded cask must be evaluated per $10 \mathrm{CFR}$ Part 71.55). The procedure calls for evaluating the reactivity at reduced moderator density. For this sample calculation, this analysis is not performed since a water density of 1.0 is known to be limiting. 
Table A.1-5 Input File for CSAS25 Calculation of $4.0 \mathrm{wt} \%$ Initial Enrichment and $25 \mathrm{GWd} / \mathrm{MTU}$ Burnup

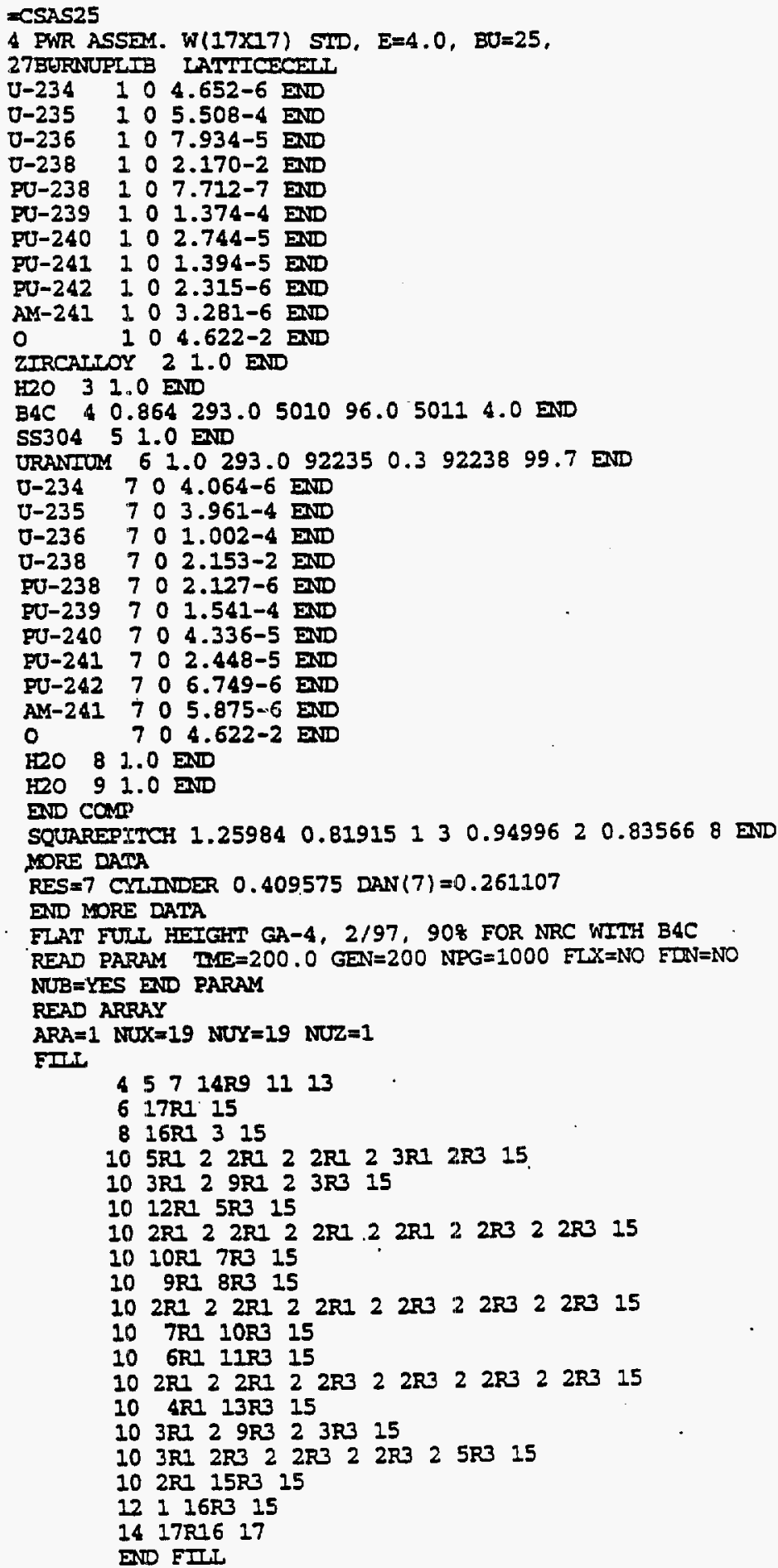


Table A.1-5 Input File for CSAS25 Calculation of $4.0 \mathrm{wt} \%$ Initial Enrichment and $25 \mathrm{GWd} / \mathrm{MTU}$ Burnup (Continued)

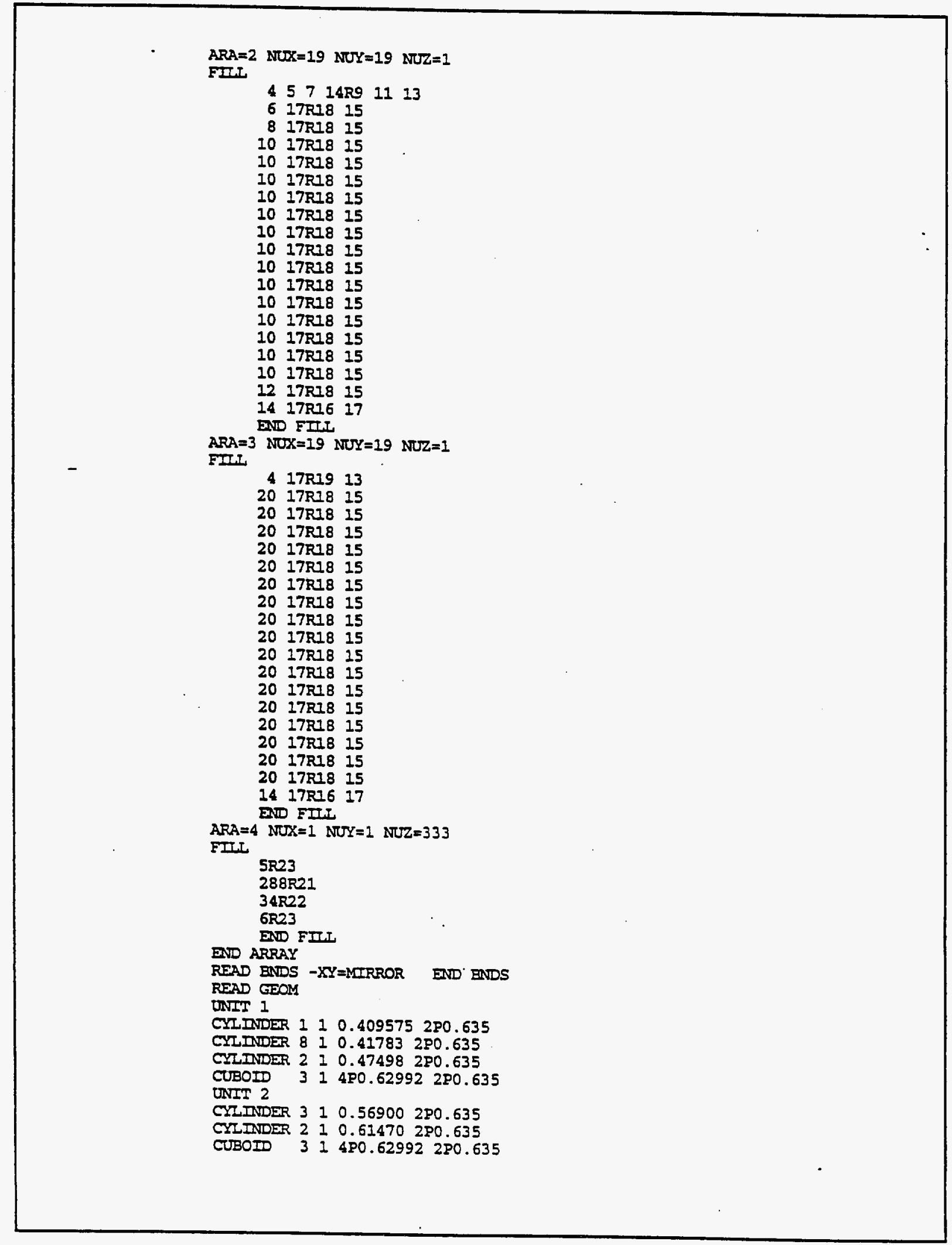


Table A.1-5 Input File for CSAS25 Calculation of $4.0 \mathrm{wt} \%$ Initial Enrichment and $25 \mathrm{GWd} / \mathrm{MTU}$ Burnup (Continued)

ONIT 3

CYLINDER 710.409575 2P0.635

CYZINDER B $110.41783 \quad 2 P 0.635$

CYLINDER 2 I $0.47498 \quad 2 P 0.635$

CUBOID 314 PO.62992 2P0.635

UNIT 4

CUBOID 514 PO.3812P0.635

UNIT 5

XHEMICYL+Y $410.35306 \quad 1.259840 .4572$

XIEMICYI+Y $0110.37084 \quad 1.25984 \quad 0.23622$

$\begin{array}{lllllllll}\text { CUBOID } \quad 5 \quad 1 & 1.25984 & 0.0 & 0.762 & 0.02 P 0.635\end{array}$

TNIT 6

YHEMICIL+X $4110.35306 \quad 1.25984 \quad 0.4572$

$\begin{array}{lllllll}\text { YHENICYL+X } & 0 & 1 & 0.37084 & 1.25984 & 0.23622\end{array}$

$\begin{array}{lllllllll}\text { CUBOID } & 5 & 1 & 0.762 & 0.0 & 1.25984 & 0.0 & 2 \mathrm{PO} & 0.635\end{array}$

UNIT 7

XXIDICIL+Y 410.353061 .259840 .0

XIIEMICYL+Y $0110.370841 .25984 \quad 0.0$

$\begin{array}{llllllllll}\text { CUBOID } \quad 5 & 1 & 1.25984 & 0.0 & 0.762 & 0.0 & 280.635\end{array}$

UNIT 8

YHEMICYL+X $4 \quad I \quad 0.35306 \quad 1.259840 .0$

YHEMICIL+X 0110.370841 .259840 .0

$\begin{array}{lllllllllllll} & \text { CUBOID } & 5 & 1 & 0.762 & 0.0 & 1.25984 & 0.0 & 270.635\end{array}$

UNIT 9

XVENICYL + 410.35306290 .62992

XEIEMICYL+Y $0110.37084 \quad 2 P 0.62992$

$\begin{array}{llllllll}\text { CUBOID } & 5 & 1 & 2 P 0 & 0.62992 & 0.762 & 0.0 & 2 P 0.635\end{array}$

UNIT 10

YHFIICYL+X 410.35306 2P0.62992

YHIMICXL+X $0110.37084 \quad 2 P 0.62992$

$\begin{array}{llllllll}\text { CUBOD } & 5 & 1 & 0.762 & 0.0 & 2 P 0.62992 & 2 P 0.635\end{array}$

UNIS 11

XFIDIICYL+Y $410.35306 \quad 0.7874 \quad 0.0$

XIEMICYI+Y $0110.37084 \quad 0.78740 .0$

$\begin{array}{lllllllll} & 5 & 1 & 1.25984 & 0.0 & 0.762 & 0.02 P 0.635\end{array}$

UNIST 12

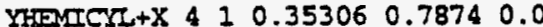

YHEMICYL+X 0 I $0.37084 \quad 0.7874 \quad 0.0$

$\begin{array}{llllllllll}\text { CUBOID } & 5 & 1 & 0.762 & 0.0 & 1.25984 & 0.0 & 2 P 0.635\end{array}$

UNIT 13

CUBOID 512 2P0.46228 2P0.381 2PO.635

UNIT 14

CUBOID $512 \mathrm{2PO} .3812 \mathrm{PO} .46228280 .635$

UNIT 15

CUBOID $312 \mathrm{PO} .46228$ 2P0.62992 2P0.635

UNIT 16

CUBOID 3 I 2PO.62992 2PO.462.28 2P0.635

UNIT 17

CUBOTD 314 4PO.46228 2PO.635

UNIT 18

CUBOID 3 I 4P0.62992 2P0.635

torit 19

$\begin{array}{llllllll}\text { CUBOII } & 5 & 1 & 2 P 0 & 62992 & 0.762 & 0.0 & 2 P 0.635\end{array}$

TNIT 20

CUBOID

UNIT 21

ARRAY 10.00 .00 .635

TNIT 22

$\begin{array}{lllll}\text { ARRAY } 2 & 0.0 & 0.0 & -0.535\end{array}$

UNIT 23

ARRAY $30.0 \quad 0.0 \quad-0.635$

CORE $410.0 \quad 0.0 \quad 0.9652$

$\begin{array}{lllllllll}\text { CUBOID } 3 & 1 & 23.2029 & 0.0 & 23.2029 & 0.0 & 424.815 & 0.0\end{array}$ 
Table A.1-5 Input File for CSAS25 Calculation of $4.0 \mathrm{wt} \%$ Initial Enrichment and $25 \mathrm{GWd} / \mathrm{MTU}$ Burnup (Continued)

CJBOID $5124.1554 \quad 0.0 \quad 24.1554 \quad 0.0424 .815 \quad 0.0$

CTBOID 6 I $30.8864 \quad 0.0 \quad 30.8864 \quad 0.0 \quad 424.815 \quad 0.0$

CIBOID 5 I $34.6964 \quad 0.0 \quad 34.6964 \quad 0.0 \quad 452.755 \quad-24.13$

CUBOID $91100.0 \quad 0.0100 .0 \quad 0.0 \quad 510.0 \quad-75.0$

END GDOS

END DATA

Nㅐ 
Table A.1-6 Spent Fuel Calculational Results - Actinides Only

\begin{tabular}{|l|l|l|l|l|l|l|l|}
\hline $\begin{array}{c}\text { Enrich- } \\
\text { ment }\end{array}$ & Burnup & $\mathbf{K}_{\text {eff }}$ & $\sigma$ & $\begin{array}{c}\text { End } \\
\text { Effects } \\
\text { Bias }\end{array}$ & ALA & $\begin{array}{c}\mathbf{K}_{\text {eff }}+ \\
\mathbf{1 . 6 4 5} \sigma . \\
\text { End } \\
\text { Effects } \\
\text { Bias }\end{array}$ & USL \\
\hline 3.1 & 7.5 & 0.9340 & 0.0014 & 0.0000 & 16.07 & 0.9363 & 0.9288 \\
\hline 3.1 & 9.5 & 0.9263 & 0.0015 & 0.0000 & 16.08 & 0.9288 & 0.9288 \\
\hline 3.1 & 10 & 0.9231 & 0.0015 & 0.0000 & 16.08 & 0.9256 & 0.9288 \\
\hline 3.1 & 15 & 0.8966 & 0.0015 & 0.0000 & 16.06 & 0.8991 & 0.9287 \\
\hline 3.5 & 10 & 0.9478 & 0.0014 & 0.0000 & 16.02 & 0.9501 & 0.9285 \\
\hline 3.5 & 15 & 0.9248 & 0.0015 & 0.0000 & 16.02 & 0.9273 & 0.9285 \\
\hline 3.5 & 16 & 0.9216 & 0.0014 & 0.0000 & 16.02 & 0.9239 & 0.9285 \\
\hline 3.5 & 20 & 0.9061 & 0.0013 & 0.0000 & 16.01 & 0.9082 & 0.9285 \\
\hline 4.0 & 20 & 0.9417 & 0.0015 & 0.0000 & 15.98 & 0.9442 & 0.9283 \\
\hline 4.0 & 25 & 0.9200 & 0.0016 & 0.0028 & 15.97 & 0.9254 & 0.9282 \\
\hline 4.0 & 30 & 0.8974 & 0.0015 & 0.0055 & 15.97 & 0.9054 & 0.9283 \\
\hline 4.5 & 30 & 0.9274 & 0.0015 & 0.0055 & 15.93 & 0.9354 & 0.9280 \\
\hline 4.5 & 33 & 0.9179 & 0.0014 & 0.0072 & 15.95 & 0.9274 & 0.9281 \\
\hline 4.5 & 35 & 0.9086 & 0.0015 & 0.0083 & 15.94 & 0.9193 & 0.9281 \\
\hline
\end{tabular}

Table A.1-7 GA-4 Cask Loading Curve Data for W 17x17 Fuel (Actinides Only)

\begin{tabular}{|c|c|c|c|c|}
\hline $\begin{array}{c}\text { Initial } \\
\text { Enrichment } \\
\text { (wt\%) }\end{array}$ & $\begin{array}{c}\text { Burnup } \\
\text { (GWd/MTU) }\end{array}$ & $\begin{array}{c}\text { Confirmatory } \\
\text { Calculated } \mathbf{k}_{\text {eff }} \\
\mathbf{+ 1 . 6 4 5 \sigma}+ \\
\text { End Effect } \\
\text { Bias }\end{array}$ & ALA & USL \\
\hline 3.1 & 9.5 & .9288 & 16.08 & .9288 \\
\hline 3.5 & 15 & .9273 & 16.02 & .9285 \\
\hline 4.0 & 25 & .9254 & 15.97 & .9282 \\
\hline 4.5 & 33 & .9274 & 15.95 & .9281 \\
\hline
\end{tabular}




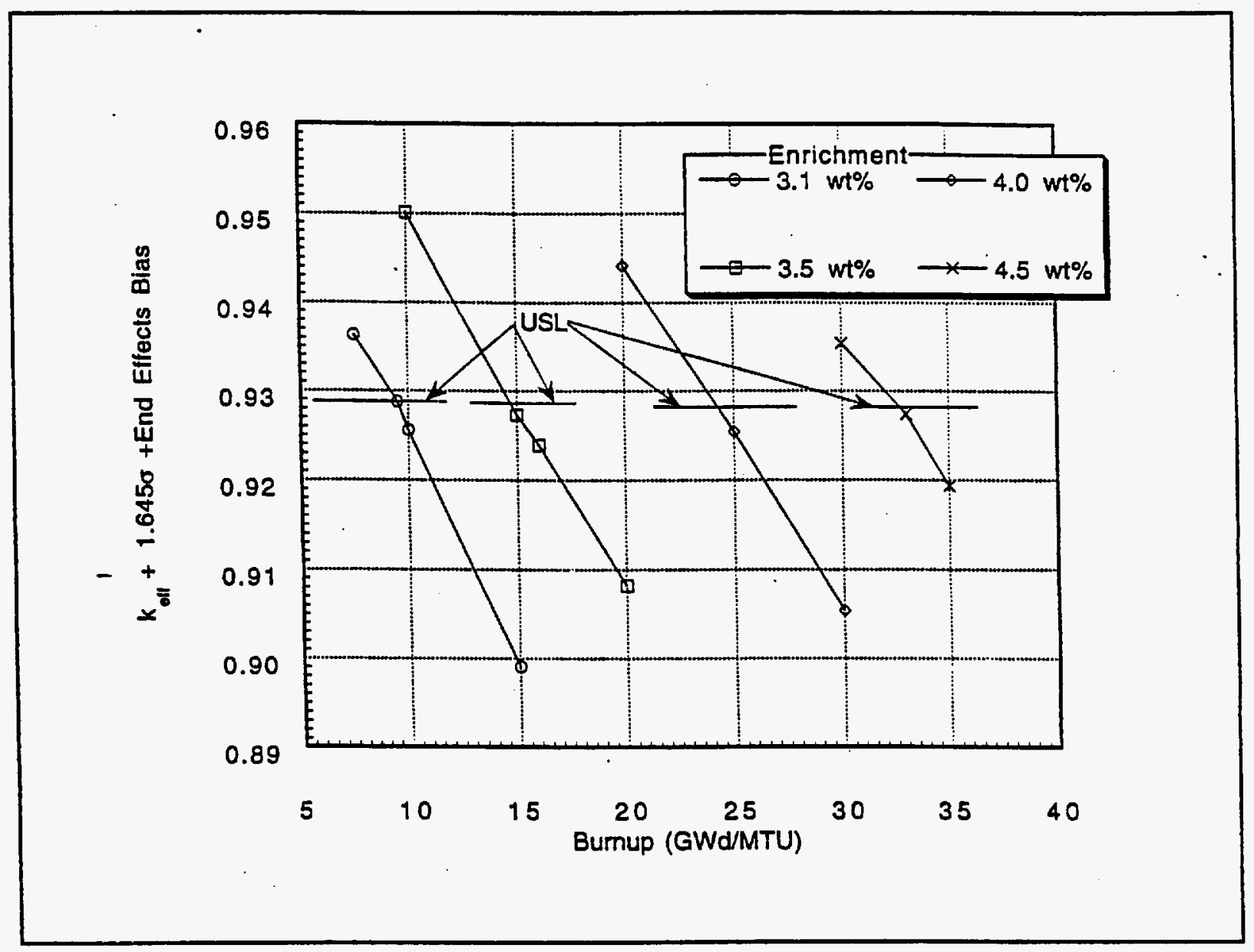

Figure A.1-4 Calculational Results Leading to the Generation of a Loading Curve 


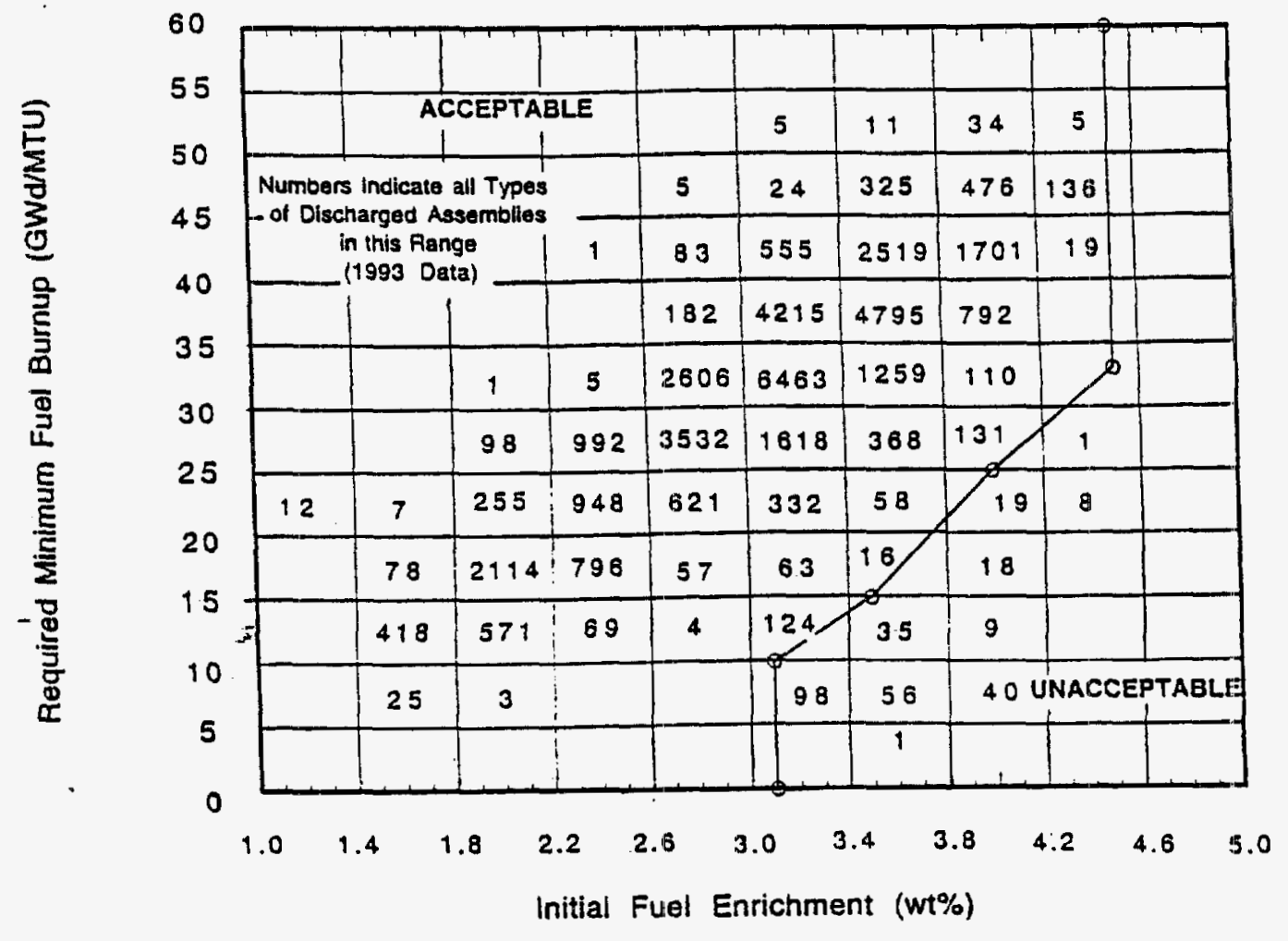

Assembly Design:___ $\quad W 17 \times 17$

Minimum Cooling Time: 5 Years.

Maximum Number of Bumable Absorber Rods: _

Note: This loading curve was gerierated with the following generic assumptons:

Maximum Cycle Average ppm Boron of $650 \mathrm{pom}$. Maximum Core Outtet

Temperature of $570 \mathrm{~K}$, and the Maximum Pellet Average Temperature of $900 \mathrm{~K}$

Figure A.1-5 Loading Curve for W 17x17 Fuel Assemblies in the GA-4 Cask 
APPENDIX A.2

HOLTEC HI-STAR 32 
APPENDIX A.3

TRANSNUCLEAR TN-40 


\section{A.3.1 TN-40 PACKAGE MODEL AND FUEL TYPE}

The containment vessel for the TN-40 cask consists of: an inner shell which is a welded, carbon steel cylinder. with an integrally-welded, carbon steel bottom closure; a welded flange forging; a flanged and bolted carbon steel lid with bolts; and penetration assemblies with bolts. The overall containment vessel length is $175.0 \mathrm{in}$. with a wall thickness of 1.5 in. The cylindrical cask cavity has a diameter of $72.0 \mathrm{in}$. and a length of $163.0 \mathrm{in.}$.

There are two penetrations through the containment vessel, both in the lid: one is for a drain opening and the other is for venting. A double-seal mechanical closure is provided for each penetration. The containment lid is 4.50 in. thick and is fastened to the body by 48 bolts.

A gamma shield is provided around the walls of the containment vessel by an independent shell of carbon steel which is welded to a bottom shield plate and to the closure flange. The gamma shield completely encloses the containment vessel inner shell and bottom closure.

Neutron shielding is provided by a resin compound surrounding the body. The resin compound is enclosed in long, slender aluminum containers. The array of resin-filled containers is enclosed within a smooth outer steel shell constructed of two half cylinders.

The basket structure consists of an assembly of stainless steel cells joined by a r oprietary fusion welding process and separated by aluminum and poison plates which form a sa dxizh panel. The panel consists of two 0.25 in. thick aluminum plates which sandwich a poi son plate 0.075 in. thick. The boron loading of the poison plate is $10 \mathrm{mg} / \mathrm{cm}^{2}$. The aluminum provides the heat conduction paths from the fuel assemblies to the cask cavity wall. The poison material provides the necessary criticality control. This method of construction forms a very strong honeycomblike structure of cell liners which provide compartments for 40 fuel assemblies. The open dimension of each cell is 8.05 in. $\times 8.05$ in. which provides a minimum of $1 / 8$ in. clearance around the fuel assemblies. The overall basket lerigth (160 in.) is less than the cask cavity length to allow for thermal expansion and fuel assembly handling.

Burnup credit is being evaluated for the TN-40 in order to evaluate the possibility of transporting a loaded TN-40 cask from the ISFSI at some future date. The current storage license allows boron credit to be utilized for criticality control. The KENO calculation model assumes a completely flooded cask cavity with the cask body water reflected all around. The fuel rod plenum and assembly end fittings are modeled as water. Figure A.3.-1 shows a radial portion of the model and indicates locations of the 40 fuel assemblies. The lighter and darker diagonals of the fuel assemblies represents the variation in burnup/reactivity due to assembly "tilt" considerations, with the light color representing the lower burnup fuel pins within the assembly. Table A.3-1 gives the radial dimensions of the cask body. The Westinghouse 14x14 OFA fuel assembly is modeled discretely. Figure A.3-2 shows the center of the basket with the fuel assemblies consisting of the fuel rods and guide tubes filled with water. Table A.3-2 provides the fuel assembly parameters. Table A.3-3 gives the material compositions used in the calculations. Although the Westinghouse $14 \times 14$ assembly is physically modeled, the isotopics used for a $17 \times 17$ assembly are still valid because the atom density would be essentially the same for both. The ORNL SCALE 4.3 code package was utilized to perform the criticality calculations presented in this appendix. The SCALE package is available from the Radiation and Shielding Information Center (RSIC) at Oak Ridge. 


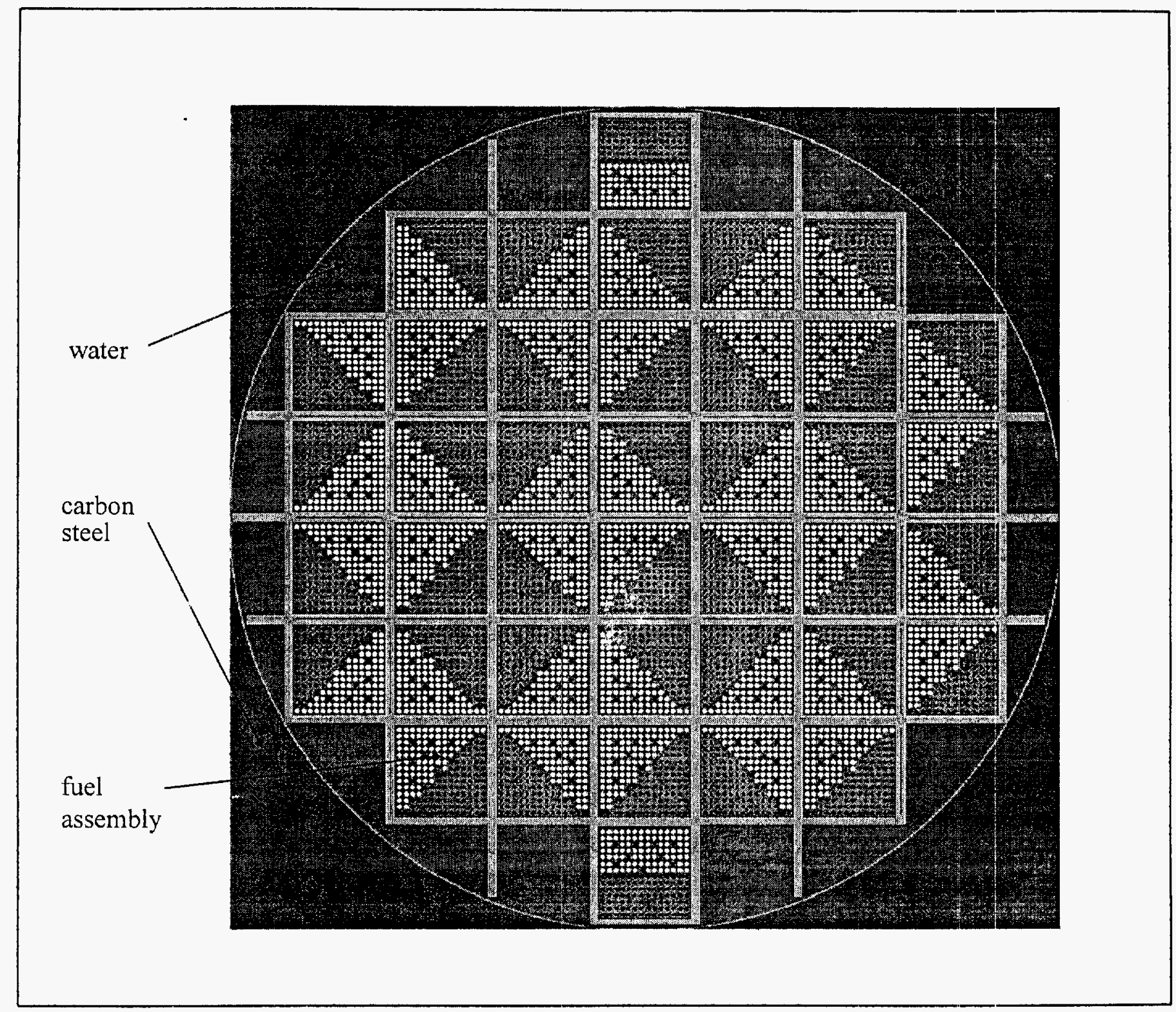

Figure A.3-1 Cross Section of the Keno Model

Table 3A-1 TN-40 Cask Body Radial Dimensions

\begin{tabular}{|l|c|}
\hline \multicolumn{1}{|c|}{ Material } & Outer Radius (cm) \\
\hline SS304, Al \& Boral (basket) & 90.8 \\
\hline Water Gap & 91.4 \\
\hline Carbon Steel & 115.6 \\
\hline Polyester Resin/A1* & 127.0 \\
\hline Carbon Steel* & 128.3 \\
\hline
\end{tabular}

*- Replaced by water in KENO model. 


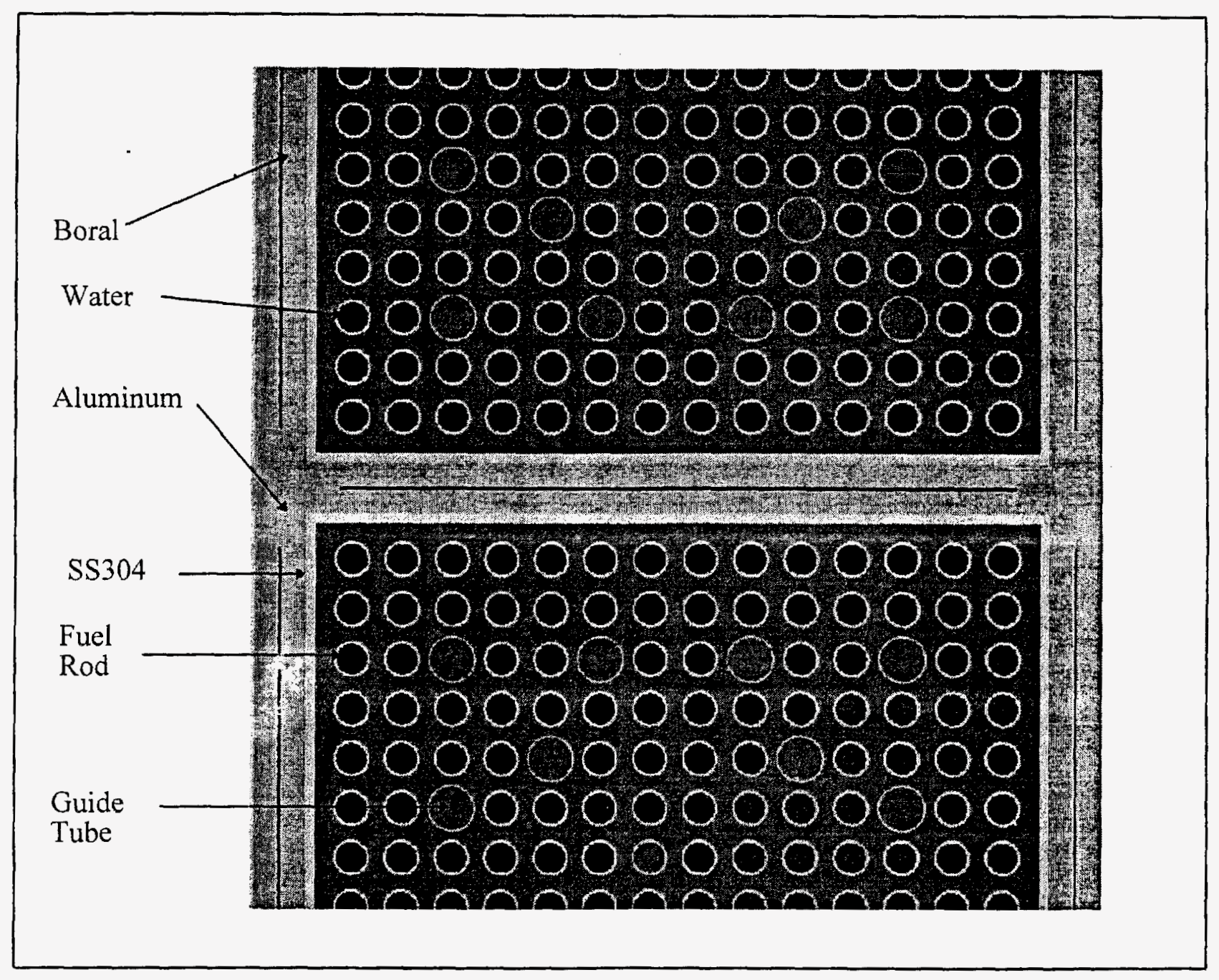

Figure A.3-2 Interior Fuel Assembly Basket with 14x14 Assembly

Table 3.A-2 Westinghouse 14x14 Fuel Assembly Model Parameters

\begin{tabular}{|l|c|}
\hline \multicolumn{1}{|c|}{ Description } & Value \\
\hline Number of Fuel Rods & 179 \\
\hline Number of Water-Filled Guide/Instrument Tubes & 17 \\
\hline Active Fuel Length & $365.8 \mathrm{~cm}$ \\
\hline Effective Fuel Packing Density & $10.39 \mathrm{~g} / \mathrm{cc}$ \\
\hline Fuel Rod Pitch & $1.412 \mathrm{~cm}$ \\
\hline Clad Material & Zircaloy \\
\hline Fuel Outside Radius & $0.4374 \mathrm{~cm}$ \\
\hline Clad Inside Radius & $0.4463 \mathrm{~cm}$ \\
\hline Clad Outside Radius & 0.508 \\
\hline Guide Tube Material & Zircaloy \\
\hline Guide Tube Inside Radius & $0.6223 \mathrm{~cm}$ \\
\hline Guide Tube Outside Radius & $0.6706 \mathrm{~cm}$ \\
\hline
\end{tabular}

A.3-3 
Table 3.A-3 Material Compositions

\begin{tabular}{|c|c|c|c|}
\hline Material & Density & Element & Atom Density \\
\hline Zircaloy & 6.44 & $*$ & $4.251 \mathrm{E}-2$ \\
\hline Water & 0.988 & $\mathrm{H}$ & $6.6759 \mathrm{E}-2$ \\
& & $\mathrm{O}$ & $3.3380 \mathrm{E}-2$ \\
\hline \multirow{2}{*}{ Stainless Steel } & \multirow{2}{*}{7.92} & $\mathrm{Cr}$ & $1.7430 \mathrm{E}-2$ \\
& & $\mathrm{Mn}$ & $1.7364 \mathrm{E}-3$ \\
& & $\mathrm{Fe}$ & $5.9359 \mathrm{E}-2$ \\
& & $\mathrm{Ni}$ & $7.7182 \mathrm{E}-3$ \\
\hline Carbon Steel & 7.82 & $\mathrm{C}$ & $3.9217 \mathrm{E}-3$ \\
& & $\mathrm{Fe}$ & $8.3500 \mathrm{E}-2$ \\
\hline Aluminum & 2.699 & $\mathrm{Al}$ & $6.0242 \mathrm{E}-2$ \\
\hline \multirow{2}{*}{ Boral Core } & & $\mathrm{Bl}$ & $9.4855 \mathrm{E}-3$ \\
& \multirow{2}{*}{2.63} & $\mathrm{B1} 1$ & $3.8518 \mathrm{E}-2$ \\
& & $\mathrm{C}$ & $1.2001 \mathrm{E}-2$ \\
& & $\mathrm{Al}$ & $3.4804 \mathrm{E}-2$ \\
\hline
\end{tabular}

* - Zircaloy is a composite cross section for $97.91 \% \mathrm{Zr}, 1.59 \% \mathrm{Sn}, 0.5 \% \mathrm{Fe}$.

\section{A.3.2 ISOTOPIC VALIDATION}

The SCALE computer code with the 27BURNULIB was utilized for the sample calculations; therefore, isotopic validation was not performed nor necessary.

\section{A.3.3 CRITICALITY VALIDATION}

The SCALE computer code with the 27BURNULIB was utilized for the sample calculations; therefore, criticality validation was not performed nor necessary.

\section{A.3.4 LIMITING PARAMETERS}

Chapter 4 discusses many of the limiting parameters required for input to the SAS2H isotopic concentration generation process.

\section{A.3.5 CONSTRUCTION OF LOADING CURVE}

\section{A.3.5.1 Fresh Fuel Intercept}

The fresh fuel calculations are a series of CSAS25 (KENO) calculations using the cask model to determine the maximum fresh fuel enrichment that can be safely loaded into the cask. The fresh fuel enrichments that were evaluated ranged from $1.6 \mathrm{wt} \% \mathrm{U}-235$ to $2.2 \mathrm{wt} \%$. Fresh fuel isotopics are shown in Table A.3-4. Table A.3-5 shows the results of the calculations and the Upper Safety Limit (USL) value. The $\mathrm{k}_{\text {eff }}$ results plus $1.645 \sigma$ are plotted against the enrichment in Figure A.3-3. The intercept of $k_{\text {eff }}+1.645 \sigma$ and the USL is at an enrichment of $1.95 \mathrm{wt} \%$ U-235. As a result, $1.95 \mathrm{wt} \%$ is the maximum allowable enrichment for fresh Westinghouse $14 \times 14$ fuel for loading in the TN-40 cask. 


\section{A.3.5.2 Spent Fuel Composition}

The spent fuel isotopic composition is determined by executing the code sequence, SAS2H. The isotopics used for these sample calculations are linear interpolations between enrichment and burnup set provided by DOE. The interpolations produced isotopics for $5 \mathrm{yr}$ and for $15 \mathrm{yr}$ cooled fuel. These isotopics are for a standard Westinghouse $17 \times 17$ fuel assembly. However, the atom densities calculated here are very similar to those that would be calculated for a $14 \times 14$ assembly and are appropriate for the sample calculations included herein.

Table A.3-4 Fresh Fuel Isotopics in Weight Percent

\begin{tabular}{|c|c|c|c|}
\hline $\mathbf{U}-235$ & $\mathbf{U}-234$ & $\mathbf{U}-236$ & $\mathbf{U}-238$ \\
\hline 1.6 & 0.01290 & 0.00730 & 98.3798 \\
\hline 1.8 & 0.01462 & 0.00828 & 98.1771 \\
\hline 2.0 & 0.01639 & 0.00920 & 97.9744 \\
\hline 2.1 & 0.01728 & 0.00966 & 97.8731 \\
\hline 2.2 & 0.01817 & 0.01012 & 97.7717 \\
\hline
\end{tabular}

Table A.3-5 Fresh Fuel Calculational Results

\begin{tabular}{|c|c|c|c|c|}
\hline Enrichment \% & $\mathbf{k}$ & $\boldsymbol{\sigma}$ & $\mathbf{k}_{\text {eff }}+\mathbf{1 . 6} \boldsymbol{\sigma}$ & $\mathbf{U S L}$ \\
\hline 1.6 & 0.8714 & 0.0015 & 0.8739 & 0.9388 \\
\hline 1.8 & 0.9098 & 0.0015 & 0.9123 & 0.9388 \\
\hline 2.0 & 0.9438 & 0.0016 & 0.9464 & 0.9388 \\
\hline 2.1 & 0.9618 & 0.0017 & 0.9646 & 0.9388 \\
\hline 2.2 & 0.9721 & 0.0016 & 0.9747 & 0.9388 \\
\hline
\end{tabular}




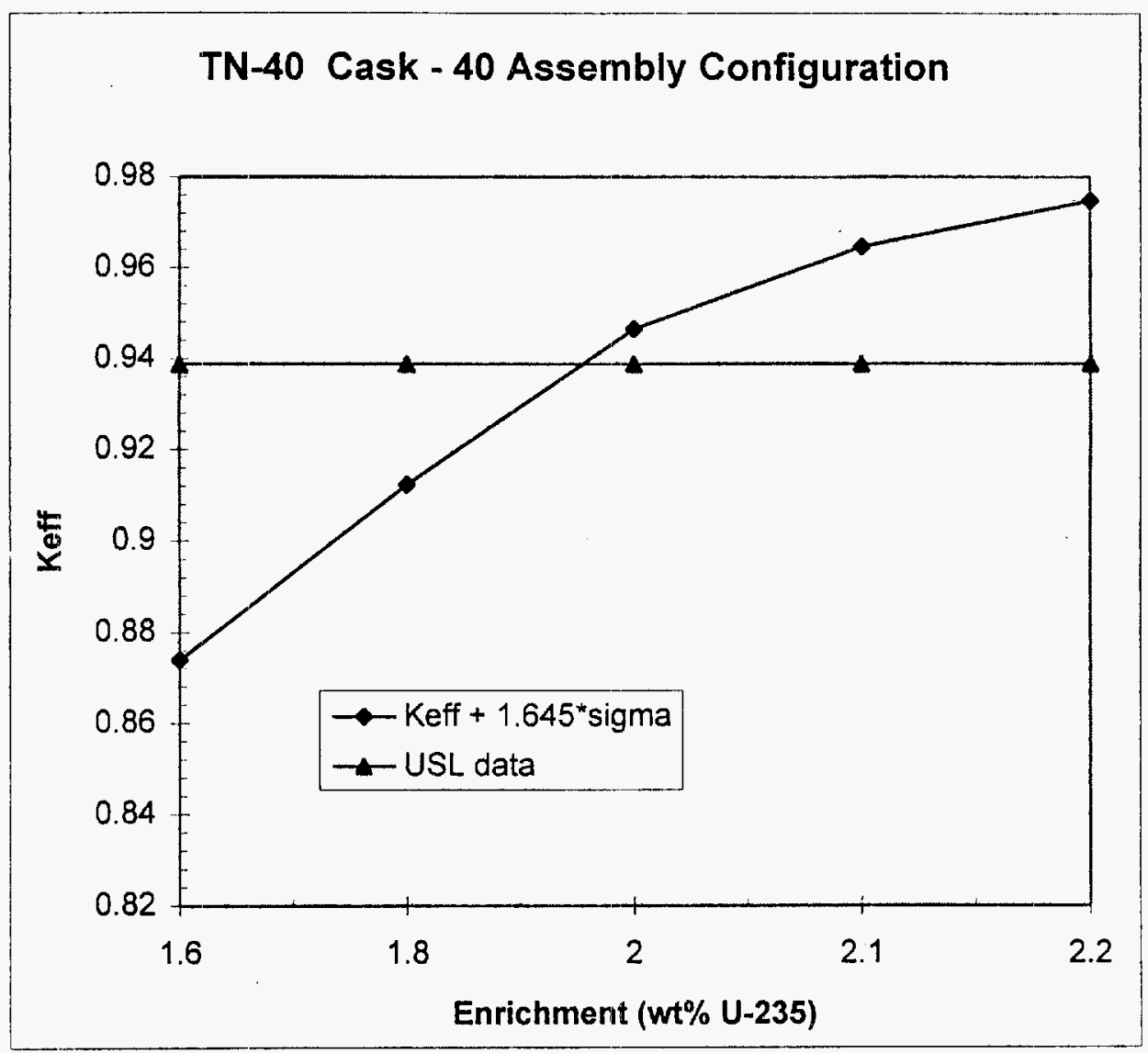

Figure 3A-3 Fresh Fuel Loading Results Considering Biases and Uncertainties 


\section{A.3.5.3 Spent Fuel Criticality Calculations}

For a specific initial enrichment and burnup, the $15 \mathrm{yr}$ isotopics provided by DOE were used to perform a series of CSAS25 calculations to determine the reactivity of the TN-40 cask loaded with 40 fuel assemblies. Horizontal tilt (variation in burnup) was accounted for in the analyses. The burnups for the assemblies were increased and decreased by predetermined percentages based on the range of the nominal burnup. The burnup ranges were 0-20 GWD/MTU, 20-40 GWD/MTU, and 40-60 GWD/MTU, with the corresponding percentages of $\pm 33 \%$, $\pm 20 \%$, and $\pm 15 \%$ respectively. The assemblies were modeled with the orientation as shown in Figure A.3-1.

Using the average lethargy for absorption (ALA) from each calculation, the USL is determined. Table A.3-6 shows the results for the calculated enrichment and burnup pairs that went into the loading curve determination. Figure A.3-4 plots the calculated $\mathrm{k}_{\text {eff }}+1.60$ from the CSAS25 calculations and the evaluated USL for each case. End effects ranging from $0.276 \%$ for $25 \mathrm{GWD} / \mathrm{MTU}$ burnup to $1.656 \%$ for $50 \mathrm{GWD} / \mathrm{MTU}$ burnup are also included in the $\mathrm{k}_{\text {eff }}$ values listed and plotted. Table A.3-7 shows the final interpolated burnup values at the USL intercepts. Figure A.3-5 plots the final required burnup versus initial enrichment. Spent fuel assemblies with minimum burnup and initial enrichment in the region above the loading curve can be loaded safely into the TN-40 cask.

Table A.3-6 Spent Fuel Calculational Results - Actinides Only

\begin{tabular}{|c|c|c|c|c|c|c|c|}
\hline Enrichment & Burnup & $\mathrm{K}_{\text {eff }}$ & $\sigma$ & ALA & end effct $\%$ & $K_{\text {eft }}{ }^{*}$ & USL \\
\hline $1.95 \%$ & 3 & 0.9529 & 0.0013 & 17.85 & & 0.9550 & 0.9388 \\
\hline & 5 & 0.9468 & 0.0013 & 17.81 & & 0.9489 & 0.9388 \\
\hline & 10 & 0.9201 & 0.0013 & 17.78 & & 0.9222 & 0.9388 \\
\hline & 15 & 0.8877 & 0.0012 & 17.75 & & 0.8897 & 0.9388 \\
\hline $2.30 \%$ & 10 & 0.9615 & 0.0012 & 17.75 & & 0.9635 & 0.9388 \\
\hline & 15 & 0.9301 & 0.0012 & 17.72 & & 0.9321 & 0.9388 \\
\hline & 20 & 0.8960 & 0.0012 & 17.72 & & 0.8980 & 0.9388 \\
\hline & 25 & 0.8640 & 0.0012 & 17.71 & 0.276 & 0.8684 & 0.9369 \\
\hline $2.80 \%$ & 20 & 0.9485 & 0.0013 & 17.67 & & 0.9506 & 0.9367 \\
\hline & 25 & 0.9165 & 0.0012 & 17.67 & 0.276 & 0.9210 & 0.9367 \\
\hline & 30 & 0.8847 & 0.0012 & 17.66 & 0.552 & 0.8916 & 0.9367 \\
\hline & 35 & 0.8705 & 0.0012 & 17.7 & 0.828 & 0.8797 & 0.9369 \\
\hline $3.30 \%$ & 25 & 0.9648 & 0.0012 & 17.62 & 0.276 & 0.9694 & 0.9365 \\
\hline & 30 & 0.9320 & 0.0013 & 17.63 & 0.552 & 0.9393 & 0.9366 \\
\hline & 35 & 0.9187 & 0.0012 & 17.65 & 0.828 & 0.9283 & 0.9367 \\
\hline & 40 & 0.8884 & 0.0011 & 17.67 & 1.104 & 0.9000 & 0.9367 \\
\hline & 45 & 0.8669 & 0.0012 & 17.67 & 1.380 & 0.8808 & 0.9367 \\
\hline & 40 & 0.9363 & 0.0012 & 17.63 & 1.104 & 0.9486 & 0.9366 \\
\hline $3.85 \%$ & 45 & 0.9093 & 0.0012 & 17.64 & 1.380 & 0.9238 & 0.9366 \\
\hline & 50 & 0.8957 & 0.0012 & 17.67 & 1.656 & 0.9125 & 0.9368 \\
\hline & & & & & & \\
\hline
\end{tabular}

* - Includes $1.645 \sigma$ and end effects 
Figure A.3-4 Calculational Results Leading to Loading Curve Generation

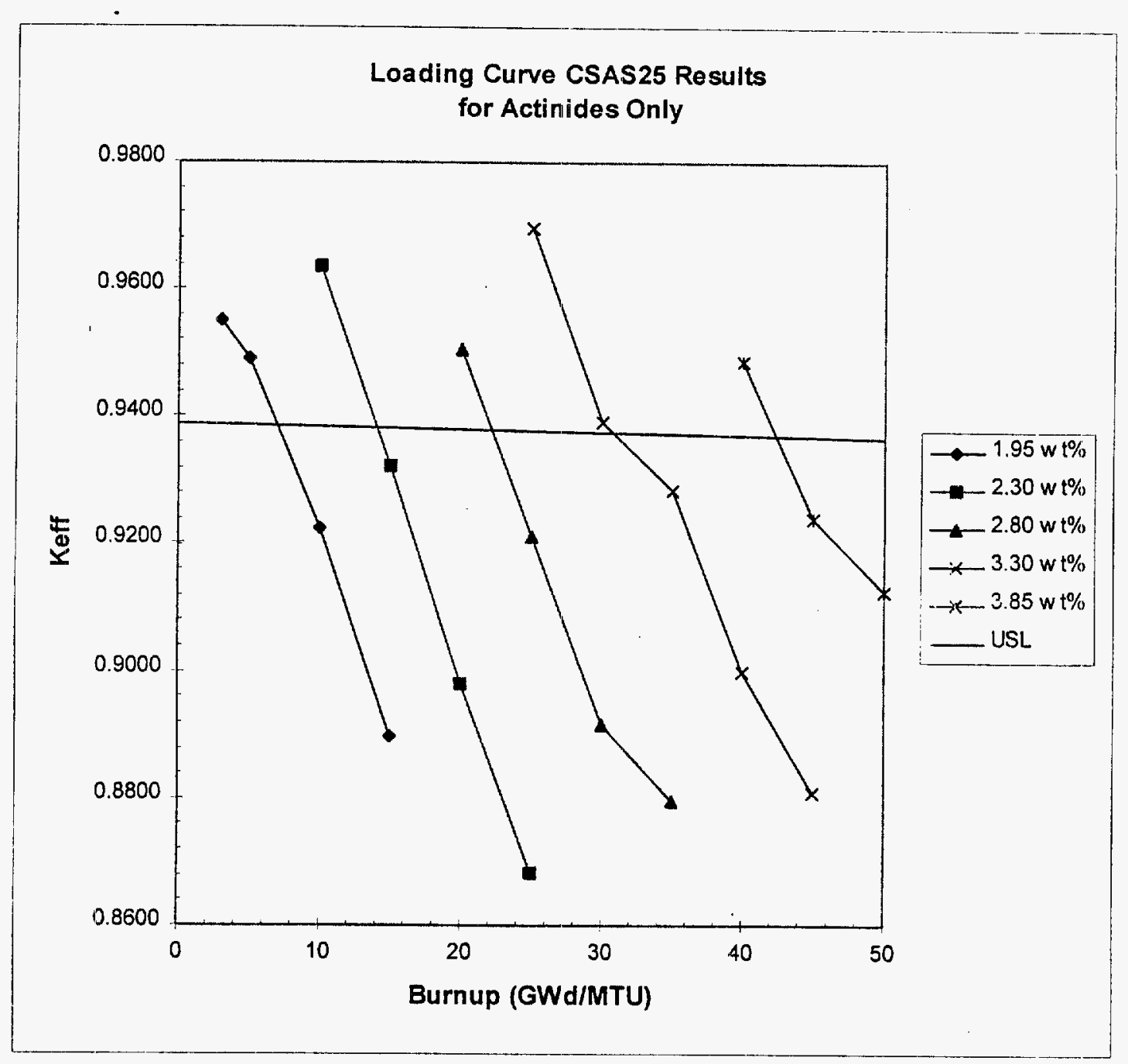

Table A.3-7 TN-40 Loading Curve Data for Westinghouse $14 \times 14$ Fuel (Actinides Only)

\begin{tabular}{|c|c|c|}
\hline $\begin{array}{c}\text { Initial } \\
\text { Enrichment } \\
\text { (wt\%) }\end{array}$ & $\begin{array}{c}\text { Burnup } \\
\text { (GWD/MTU) }\end{array}$ & USL \\
\hline 1.95 & 0 (fresh fuel) & 0.9388 \\
\hline 1.95 & 8.32 & 0.9388 \\
\hline 2.3 & 13.92 & 0.9388 \\
\hline 2.8 & 22.00 & 0.9367 \\
\hline 3.3 & 30.43 & 0.9367 \\
\hline 3.85 & 42.42 & 0.9366 \\
\hline
\end{tabular}




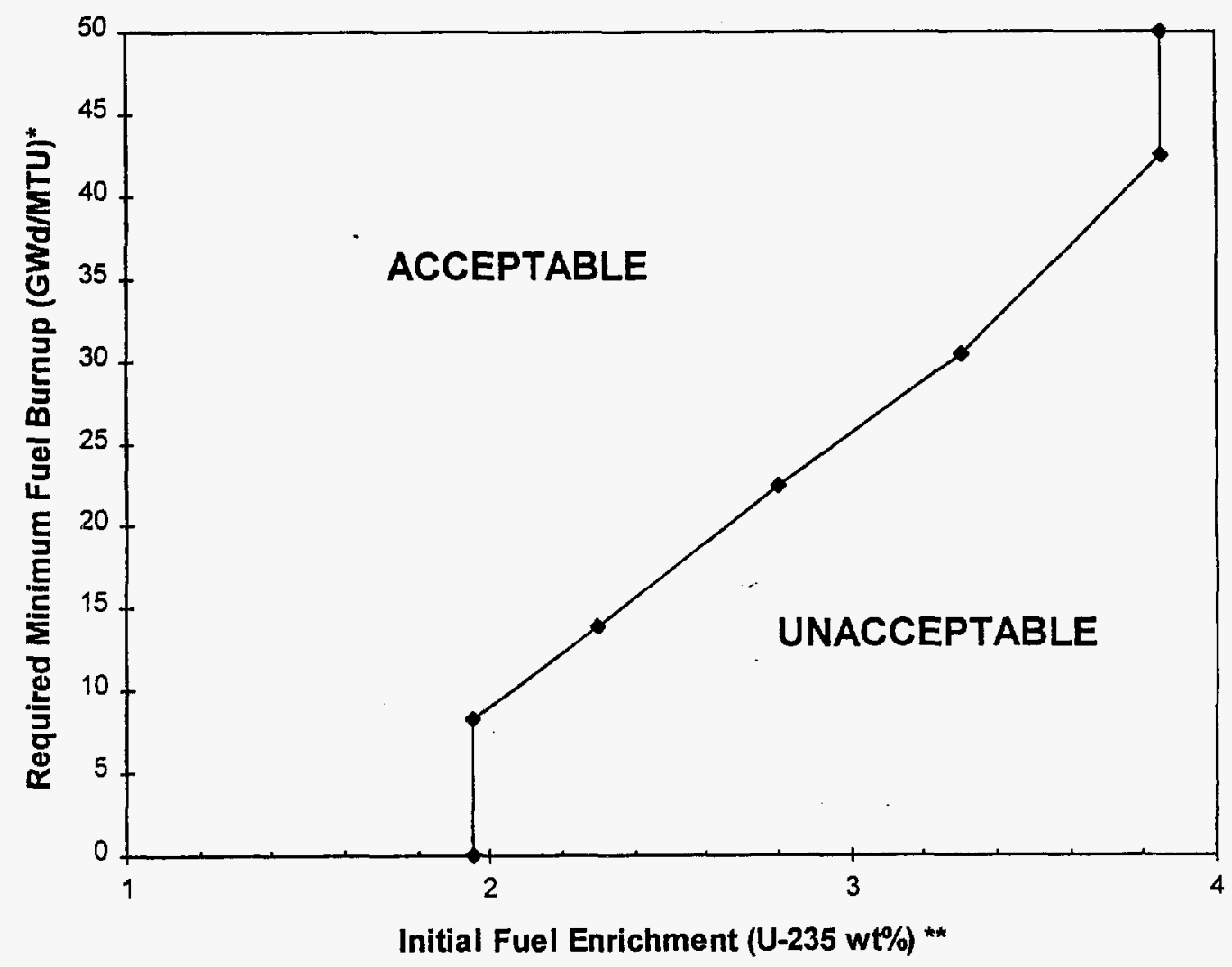

Assembly Design:

Minimum Cooling Time: $15 \mathrm{yr}$

Maximum Number of Removable Burnable Absorber Rods:

Note: This loading curve was generated with the following generic assumptions: Maximum Cycle Average ppm Boron of 650 , Maximum Core Outlet

Temperature of $570^{\circ} \mathrm{K}$, and the Maximum Pellet Average Temperature of $900^{\circ} \mathrm{K}$.

* The nominal burnup must be reduced by the utility so there is a $95 \%$ confidence level of meeting the Required Minimum Fuel Burnup.

** If the assembly has more than one enrichment, the highest enrichment must be used.

Figure A.3-5 Development of Burnup Credit Loading Curve for the TN-40 Spent Fuel Cask 
APPENDIX A.4

VECTRA NUHOMS-MP187 


\section{A.4 NUHOMS ${ }^{\circledR}$-MP187 SAMPLE BURNUP CREDIT ANALYSIS}

This Appendix demonstrates the application of the methodology described in Chapters 2 through 7 to VECTRA's NUHOMS ${ }^{\circledR}$-MP187 multi-purpose cask. This demonstration will be accomplished by developing a sample loading curve for the cask as described below.

\section{A.4.1 CASK DESCRIPTION}

The NUHOMS ${ }^{\circledR}$-MP187 cask is the transportation overpack for the NUHOMS ${ }^{\circledast}$ Multi-Purpose Canister (MPC) system. The cask, along with three PWR spent fuel canisters, was submitted to the U.S. NRC for storage and transportation licensing in September 1993. Details of the cask and canisters can be found in, "Safety Analysis Report for the NUHOMS ${ }^{\circledR}$-MP187 MultiPurpose Cask," Docket 71-9255. The cask itself, shown in Figure A.4-1, provides an overpack for the fuel canisters d ring onsite transfer, onsite storage (as an alternate to the NUHOMS ${ }^{\circledR}$ concrete horizontal stciage modules), and offsite transportation. The cask body consists of stainless steel inner and outer shells, stainless steel top and bottom forgings, a lead gamma shield layer, and a Bisco NS-3 neutron shield layer. An opening in the cask bottom end allows fuel canisters to be handled either horizontally or vertically. The cask exterior has a length of 201.5 inches and a diameter of 92.5 inches. The cask cavity length is 187 inches and the cavity diameter is 68 inches.

The 24 element PWR fuel canister is shown in Figure A.4-2. The basket assembly consists of steel spacer discs, support rods, and guide sleeves. Each guide sleeve includes neutron absorber sheets which form flux traps between adjacent assemblies. The spacer discs and support rods serve to maintain the gaps between the fuel assemblies. The canister basket is surrounded by a welded stainless steel shell which includes shielding at both ends to minimize occupational exposures during handling. Each fuel "cell" has an open width of 8.9 inches and a length of either 167 inches or 173 inches depending on the canister type.

The current license applications for the MP187 cask are based on a fresh fuel enrichment of $3.43 \mathrm{wt} \%$ U-235. While this enrichment bounds most of the fuel currently stored in plant fuel pools, it will not bound a large portion of the fuel being discharged either currently or in the future. As shown in the remainder of this Appendix, applying a burnup credit analysis to the existing cask/canister designs will easily allow fuel with maximum initial enrichments of up to $5 \mathrm{wt} \% \mathrm{U}-235$ to be stored/transported in the MP187 cask. Future work will include removing absorber sheets to reduce the canister costs and new canister designs with increased payloads.

This sample analysis was performed using the ORNL SCALE 4.3 code package, available from the Radiation Shielding Information Center, installed on a personal computer. With the exception of the fuel assemblies, the KENO analytical model is identical to that described in Chapter 6 of Revision 3 of the MP187 SAR. Parameters identical to those in the MP187 SAR include the package geometry (including worst case tolerances) and material compositions. For 
consistency with the isotopic data obtained from the DOE, a Westinghouse $17 \times 17$ fuel assembly is used in this sample calculation which differs from the $B \& W 15 \times 15$ assembly which represents the design basis for the MP187 package. Table A.4-1 provides the Westinghouse 17x17 fuel specifications.

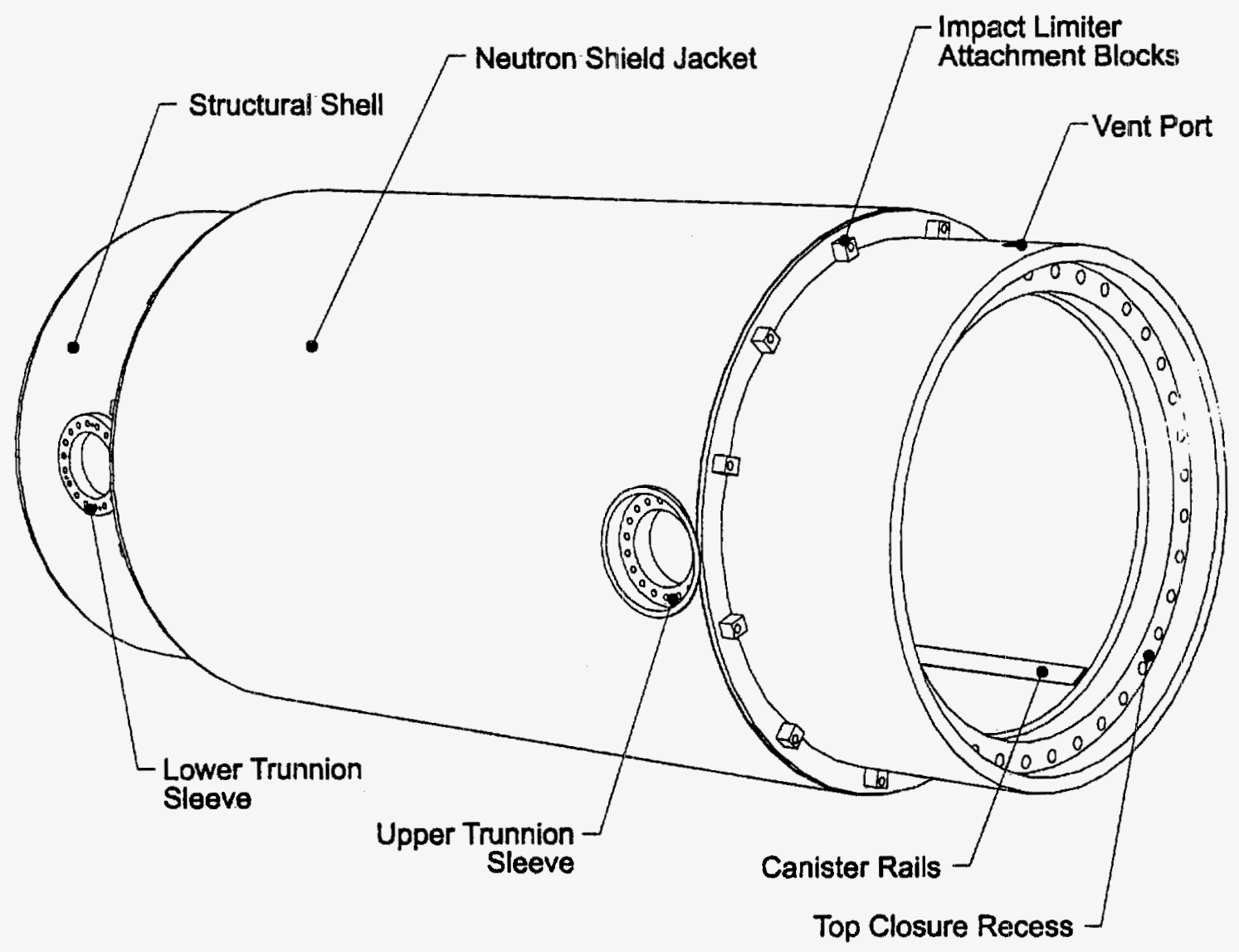

Figure A.4-1: NUHOMS ${ }^{\circledR}$-MP187 Multi-Purpose Cask 


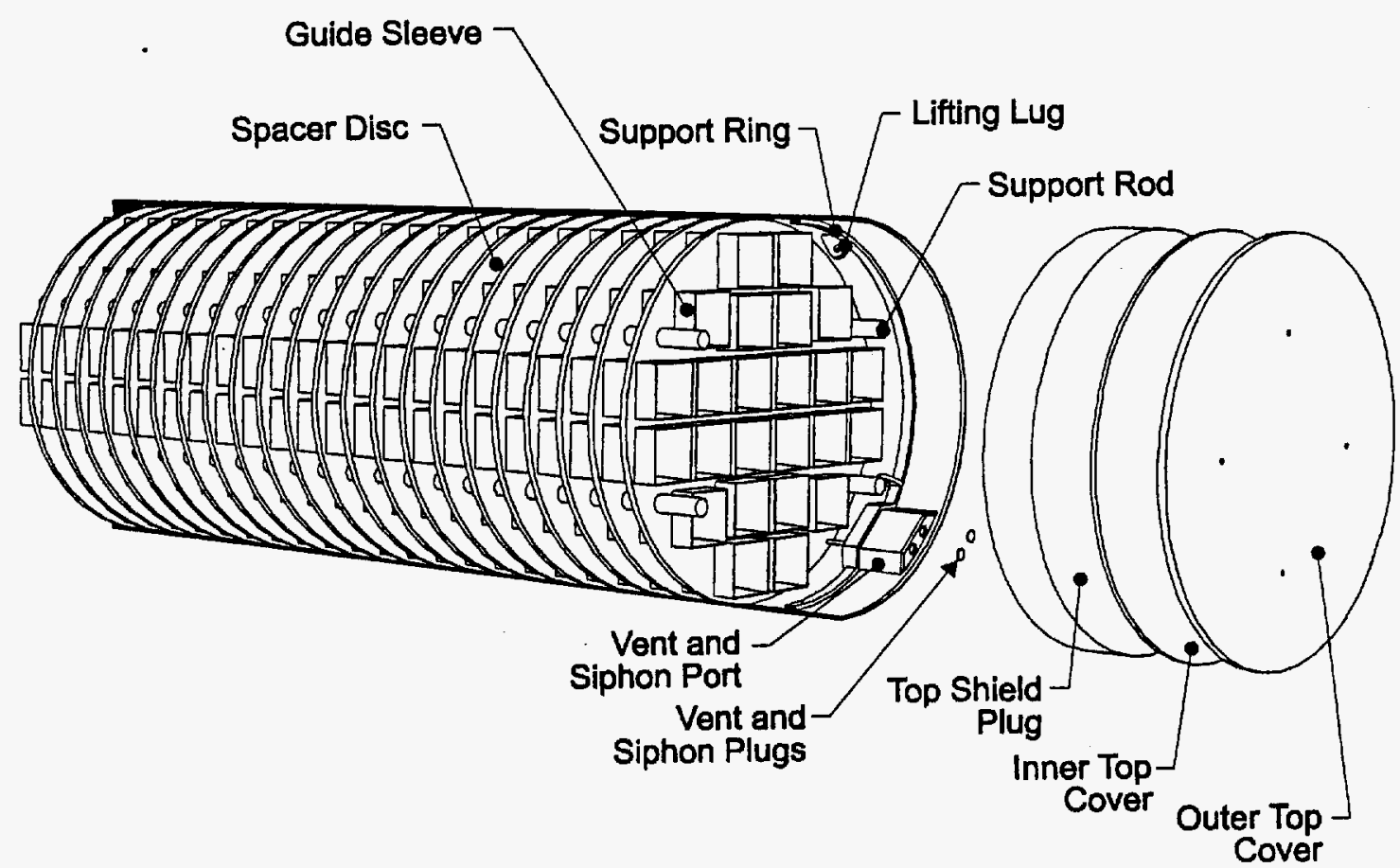

Figure A.4-2: NUHOMS ${ }^{\circledR} 24$ Element PWR Canister

Table A.4-1: Westinghouse 17x17 Fuel Assembly Model Parameters

\begin{tabular}{|l|c|}
\hline \multicolumn{1}{|c|}{ Description } & Value \\
\hline Number of Fuel Rod Positions & 289 \\
\hline Number of Fueled Rods & 264 \\
\hline Number of Water Filled Guide/lnstrument Tubes & 25 \\
\hline Number of Burnable Absorber/Control Rods & 0 \\
\hline Active Fuel Length & 144 in \\
\hline Fuel Material & $\mathrm{UO}_{2}$ \\
\hline Fuel Rod Pitch & 0.496 in \\
\hline Clad Material & Zircaloy-4 \\
\hline Rod Diameter & 0.374 in \\
\hline Clad Thickness & 0.0225 in \\
\hline Fuel Diameter & 0.3225 in \\
\hline Guide/Instrument Tube Material & Zircaloy-4 \\
\hline
\end{tabular}




\section{A.4.2 ISOTOPIC VALIDATION}

This evaluation was performed using the SCALE criticality sequences with the 27BURNUPLIB cross-section library. Because this code and library are specifically addressed in the body of this report, no additional isotopic validation is required for this sample calculation.

\section{A.4.3 CRITICALITY VALIDATION}

This evaluation was performed using the SCALE criticality sequences with the 27BURNUPLIB cross-section library. Because this code and library are specifically addressed in the body of this report, no additional criticality validation is required.

\section{A.4.4 LIMITING PARAMETERS}

Chapter 4 discusses many of the limiting parameters required for input to the SAS2H isotopic concentration generation process. Table A.4-2 provides the typical limiting values for the Westinghouse $17 \times 17$ assembly used in the SAS2H model. Other factors or uncertainties such as material and fabrication tolerance, modeling limitations, and clustering of assemblies in baskets that are not unique to burnup credit design were not considered in this sample calculation.

Table A.4-2: Fuel History Parameters for the SAS2H Calculations

\begin{tabular}{|l|c|}
\hline \multicolumn{1}{|c|}{ Description } & Value \\
\hline Specific Power & $60 \mathrm{MW} / \mathrm{MTU}$ \\
\hline Operating History & Single Irradiation Cycle \\
\hline Boron Concentration & $650 \mathrm{ppm}$ \\
\hline Max. Core Outlet Temp. & $570 \mathrm{~K}$ \\
\hline Max. Assembly Avg. Pellet Temp. & $900 \mathrm{~K}$ \\
\hline
\end{tabular}

\section{A.4.5 CONSTRUCTION OF LOADING CURVE}

\section{A.4.5.1 Fresh Fuel Intercept}

The fresh fuel intercept was calculated using a series of CSAS25 (KENO Va) runs and the MP187 cask model. This intercept represents the maximum fresh fuel enrichment that can be safely loaded into the cask. The fuel data presented in Table A.4-1 was used to generate the fresh fuel isotopics as a function of enrichment. The $\mathrm{k}_{\mathrm{eff}}$ results plus $1.645 \sigma$ were then plotted against the Upper Safety Limit (USL) as shown in Figure A.4-3. The fresh fuel (uranium) USL is 0.9388 as discussed in Chapter 3. The intercept of $k_{\text {eff }}+1.645 \sigma$ and the USL falls between $3.25 \mathrm{wt} \%$ and $3.3 \mathrm{wt} \%$. A maximum allowable enrichment of $3.25 \mathrm{wt} \% \mathrm{U}-235$ is, therefore, conservatively used for fresh Westinghouse $17 \times 17$ fuel in the 24 element MP187 package. Note that this fresh fuel enrichment is less than the $3.43 \mathrm{wt} \%$ enrichment for which the cask is currently being licensed. This is due primarily to the use of a USL of 0.95 in the licensing calculations versus 0.9388 in the burnup credit calculations. A sample CSAS25 input file is provided in Table A.4-3 


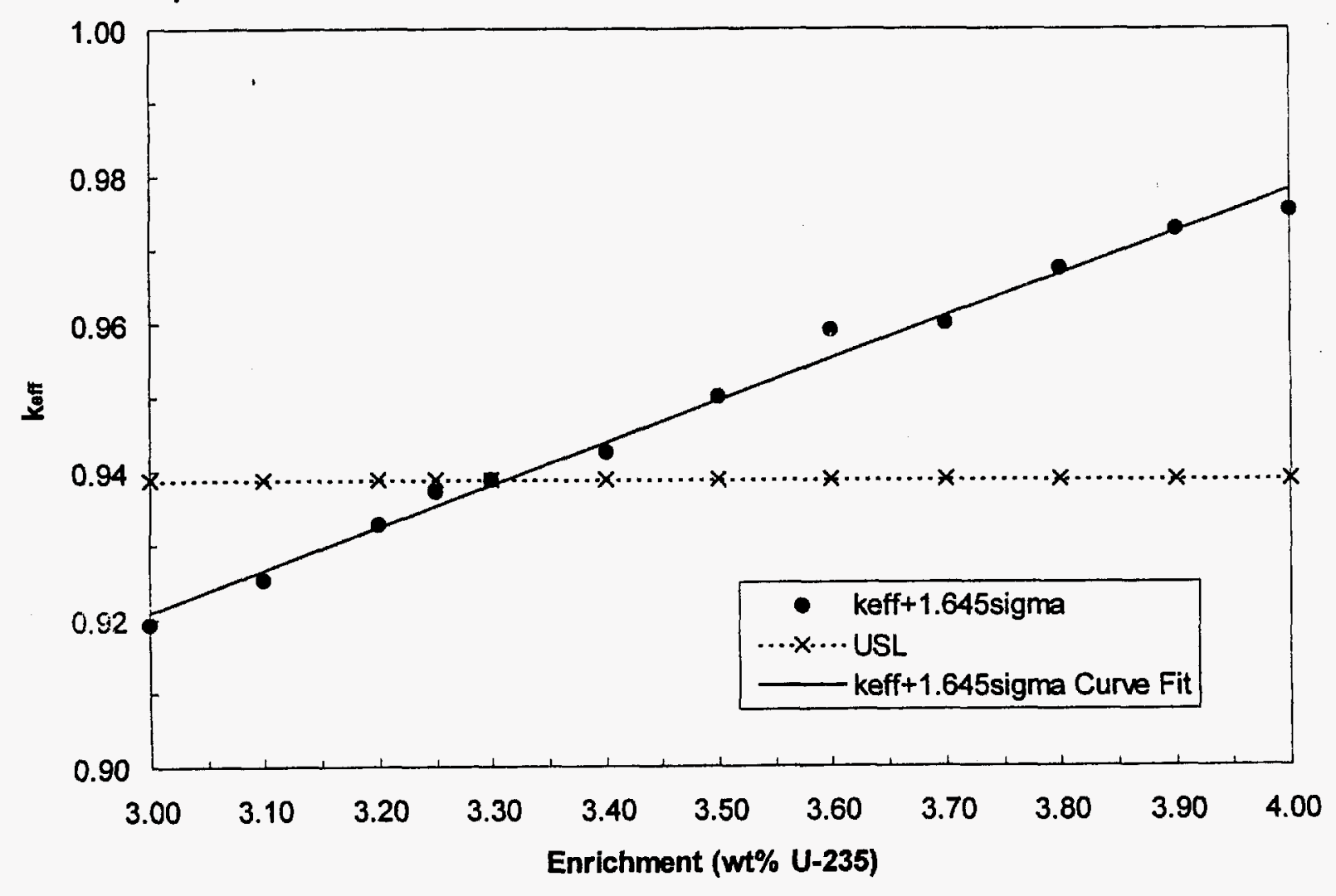

\begin{tabular}{|ccccc|}
\hline Enrichment (\%) & $\mathbf{k}_{\text {eff }}$ & $\sigma$ & $\mathbf{k}_{\text {enf }}+1.645 \sigma$ & USL \\
\hline 3.00 & 0.91692 & 0.00141 & 0.9192 & 0.9388 \\
3.10 & 0.92285 & 0.00146 & 0.9253 & 0.9388 \\
3.20 & 0.93037 & 0.00145 & 0.9328 & 0.9388 \\
3.25 & 0.93480 & 0.00148 & 0.9372 & 0.9388 \\
3.30 & 0.93657 & 0.00144 & 0.9389 & 0.9388 \\
3.40 & 0.94017 & 0.00149 & 0.9426 & 0.9388 \\
3.50 & 0.94760 & 0.00147 & 0.9500 & 0.9388 \\
3.60 & 0.95662 & 0.00147 & 0.9590 & 0.9388 \\
3.70 & 0.95759 & 0.00150 & 0.9601 & 0.9388 \\
3.80 & 0.96499 & 0.00153 & 0.9675 & 0.9388 \\
3.90 & 0.97040 & 0.00140 & 0.9727 & 0.9388 \\
4.00 & 0.97279 & 0.00149 & 0.9752 & 0.9388 \\
\hline
\end{tabular}

Figure A.4-3: Fresh Fuel Loading Results Considering Biases and Uncertainties 
VECTRA Technologies, Inc. San Jose, California

Table A.4-3: CSAS25 Input File for Fresh Fuel Case

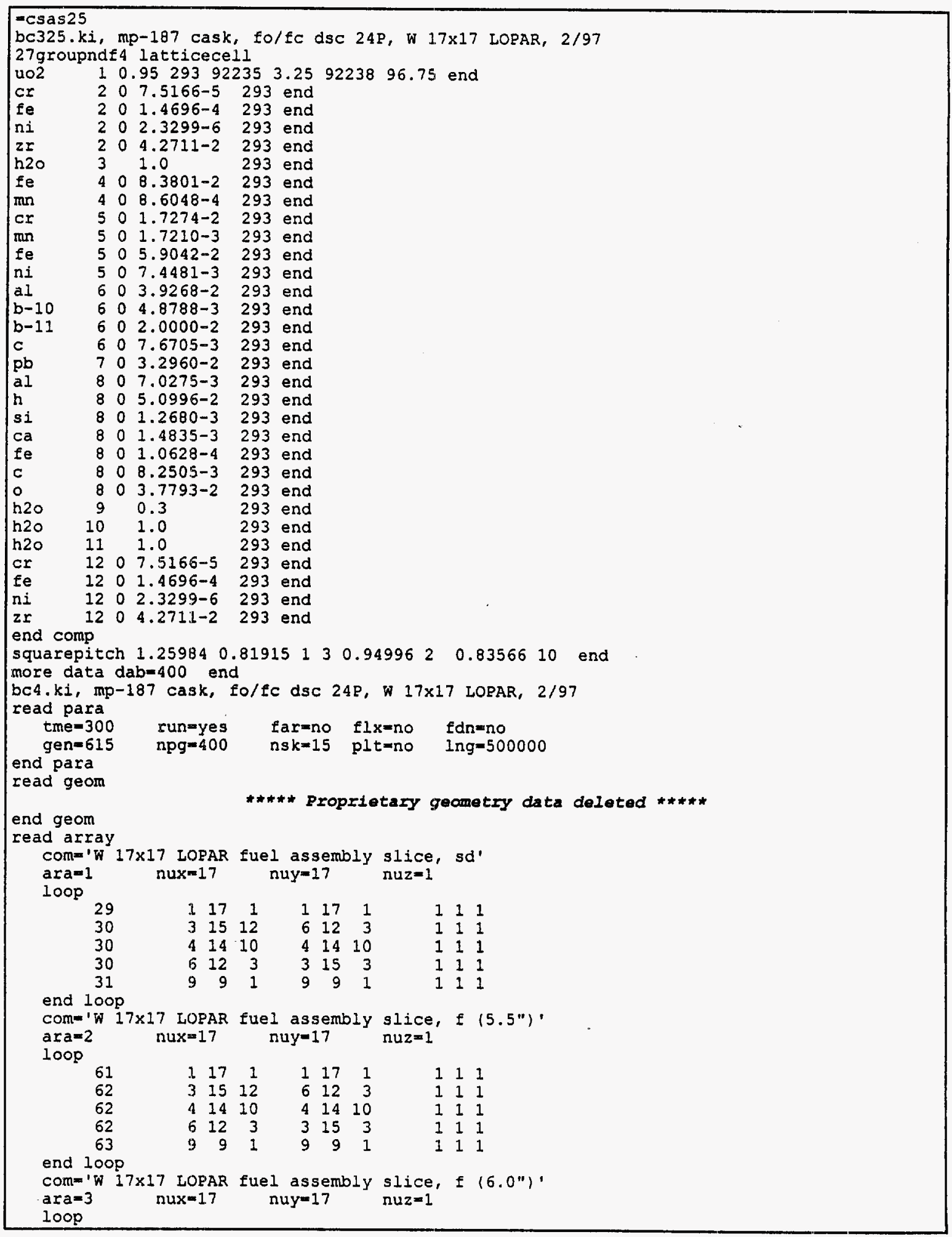




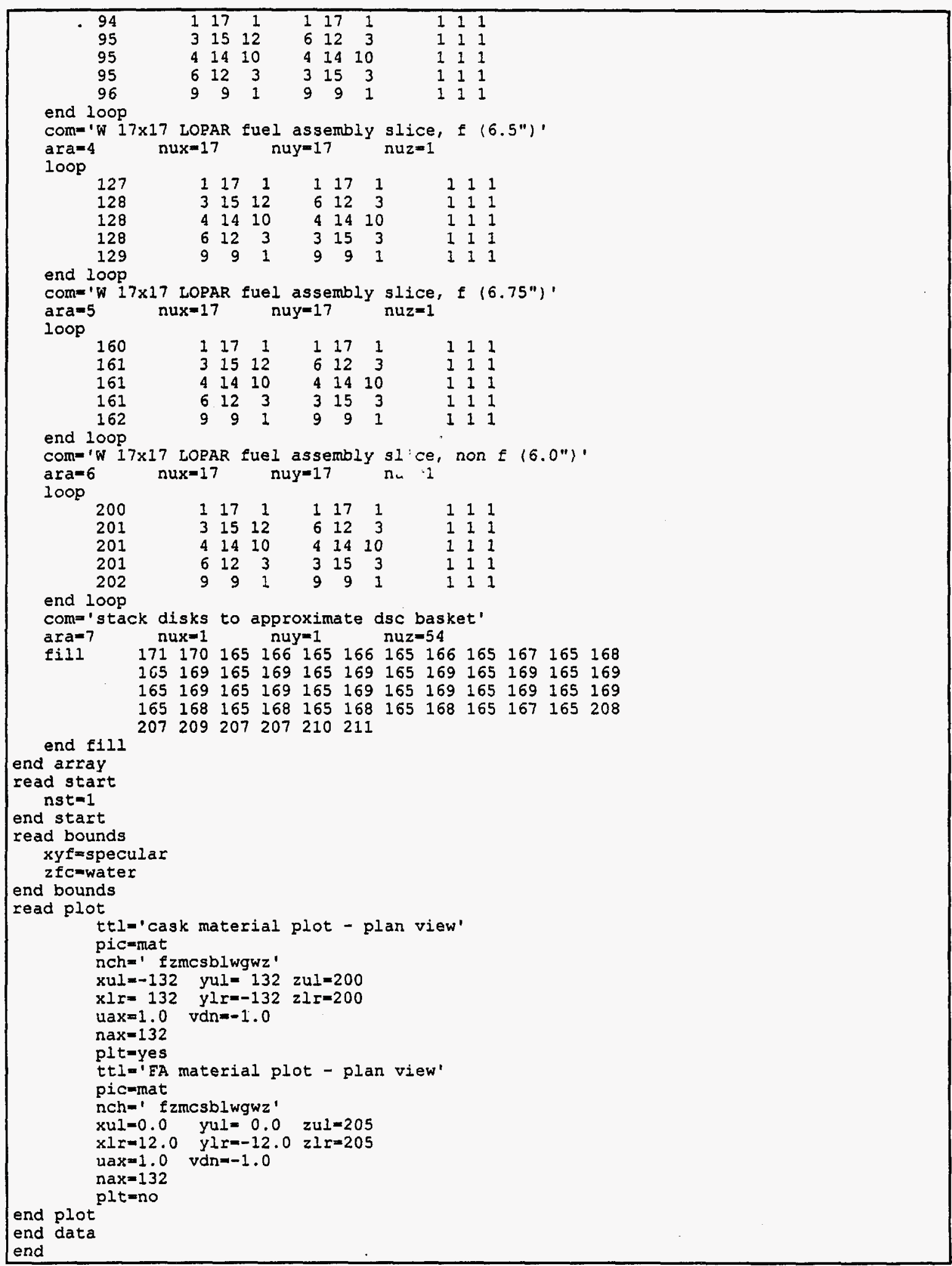




\section{A.4.5.2 Spent Fuel Composition}

Spent fuel compositions for the Westinghouse $17 \times 17$ assemblies were calculated as a function of initial enrichment and burnup using linear interpolations of the SAS2H results provided by DOE.

\section{A.4.5.3 Spent Fuel Criticality Calculations}

The spent fuel criticality calculations were performed by modifying the fresh fuel CSAS25 models described above to include the fuel isotopics as a function of initial enrichment and burnup. Two burnup regions were defined for each fuel assembly as shown in Figure A.4-4 to account for radial burnup tilt. Although several assembly orientations were analyzed to determine the worst case basket configuration, a more detailed evaluation will be required for a final licensing application. For average fuel burnups less than $20 \mathrm{GWd} / \mathrm{MTU}$, the isotopics in the two fuel region. are based on burnup variations of $\pm 33 \%$. For average fuel burnups greater than or equal to $2 \mathrm{C} \mathrm{GWd/MTU}$, the isotopics are based on burnup variations 0 f $\pm 20 \%$.

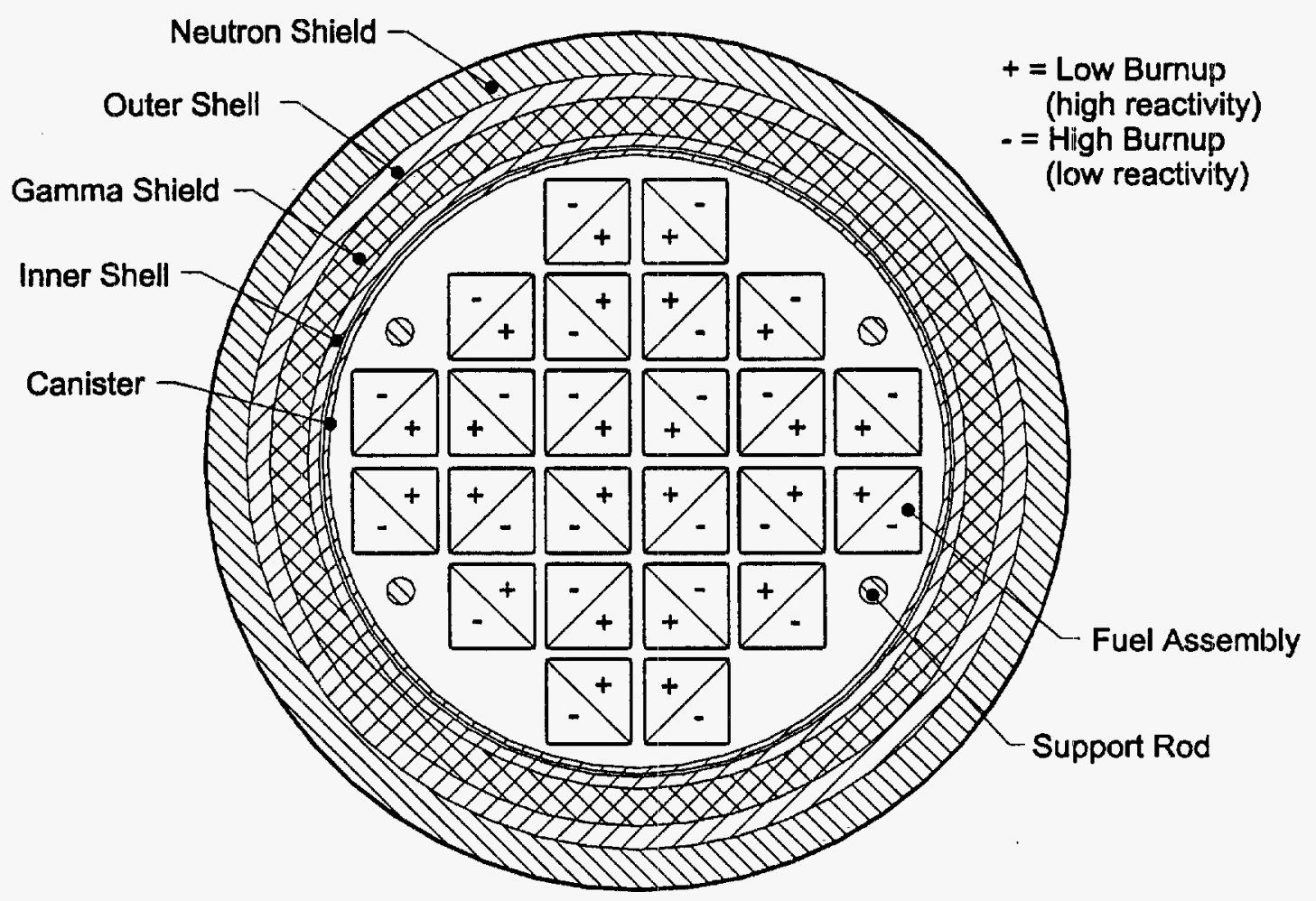

Figure A.4-4: Cross-Section of KENO Model Showing Radial Tilts 
Two CSASN models were run for each case to generate the resonance corrected working libraries for the two assembly burnup regions. SCALE's WAX module was then used to combine the working libraries for use by the CSAS25 model, which calculates $k_{\text {eff. }}$ The Average Lethargy for Absorption (ALA) was determined for each case from the CSAS25 output and used to calculate the USL as described in Chapter 3.

Table A.4-4 shows the results for the calculated enrichment and burnup pairs that went into the loading curve determination. The enrichments shown in Table A.4-4 are in wt\% U-235 and the burnups in GWd/MTU. The values of $\mathrm{k}_{\mathrm{eff}}$ and $\sigma$ are taken directly from the CSAS25 output. The final value of $\mathrm{k}_{\mathrm{eff}}$ which is compared to the USL includes the calculated $\mathrm{k}_{\mathrm{eff}}$ plus $1.645^{*} \sigma$ plus the end effects bias $\left(k_{\text {bias }}\right)$. The end effects bias is calculated as discussed in the body of this report. This data is shown graphically on Figure A.4-5.

Figure A.4-6 plots the final required burnup versus initial enrichment. As explained in Chapter 5, any spent fuel assemblies with a bumup and initial enrichment under the loading curve (unacceptable region) will not be qualified for loading into the MP187 cask. Spent fuel assemblies with a burnup and initial enrichment above the curve (acceptable region) san be safely loaded into the cask.

\section{A.4.5.4 Low-Density Moderation Effects}

This analysis was not performed for this sample calculation because, as discussed in Chapter 6 of the MP187 SAR, a water density of 1.0 is limiting for the NUHOMS ${ }^{\circledR}$-MP187 package. 
VECTRA Technologies, Inc. San Jose, California

Table A.4-4: Spent Fuel Calculational Results - Actinide Only

\begin{tabular}{|c|c|c|c|c|c|c|}
\hline Enrichment & Burnup & $k_{\text {eff }}$ & $\sigma$ & ALA & $k_{\text {eff }}+1.645 \sigma+k_{\text {blas }}$ & USL \\
\hline \multirow[t]{3}{*}{3.25} & 1 & 0.94435 & 0.00120 & 17.62 & 0.94632 & 0.93650 \\
\hline & 5 & 0.92790 & 0.00120 & 17.60 & 0.92987 & 0.93642 \\
\hline & 10 & 0.90636 & 0.00124 & 17.59 & 0.90840 & 0.93636 \\
\hline \multirow[t]{3}{*}{3.50} & 5 & 0.94403 & 0.00131 & 17.57 & 0.94618 & 0.93629 \\
\hline & 8 & 0.93222 & 0.00118 & 17.56 & 0.93416 & 0.93623 \\
\hline & 15 & 0.89496 & 0.00120 & 17.57 & 0.89693 & 0.93628 \\
\hline \multirow[t]{4}{*}{4.00} & 10 & 0.94611 & 0.00123 & 17.52 & 0.94813 & 0.93601 \\
\hline & 13 & 0.93503 & 0.00118 & 17.50 & 0.93697 & 0.93594 \\
\hline & 14 & 0.92957 & 0.00124 & 17.50 & 0.93161 & 0.93595 \\
\hline & 20 & 0.90196 & 0.00116 & 17.52 & 0.90387 & 0.93604 \\
\hline \multirow[t]{3}{*}{4.50} & 15 & 0.95066 & 0.00123 & 17.45 & 0.95268 & 0.93570 \\
\hline & 20 & 0.92940 & 0.00121 & 17.47 & 0.93139 & 0.93579 \\
\hline & 25 & 0.91009 & 0.00116 & 17.48 & 0.91476 & 0.93584 \\
\hline \multirow[t]{4}{*}{5.00} & 20 & 0.95060 & 0.00115 & $1: 71$ & 0.95249 & 0.93549 \\
\hline & 25 & 0.93160 & 0.00125 & 1.43 & 0.93642 & 0.93560 \\
\hline & 26 & 0.92761 & 0.00120 & 17.43 & 0.93290 & 0.93562 \\
\hline & 30 & 0.90962 & 0.00122 & 17.44 & 0.91715 & 0.93567 \\
\hline
\end{tabular}

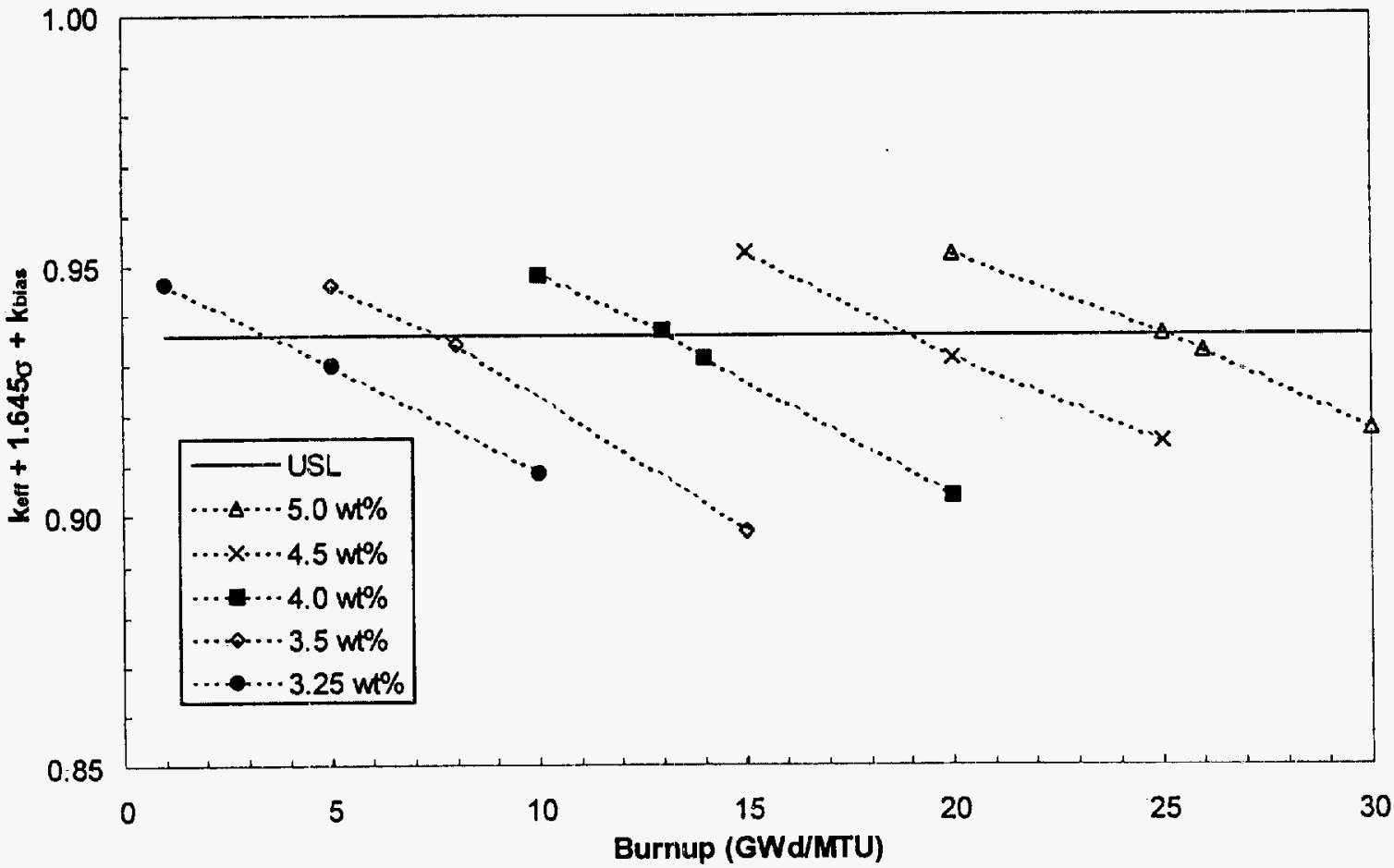

Figure A.4-5: Calculational Results Used to Generate the Loading Curve 


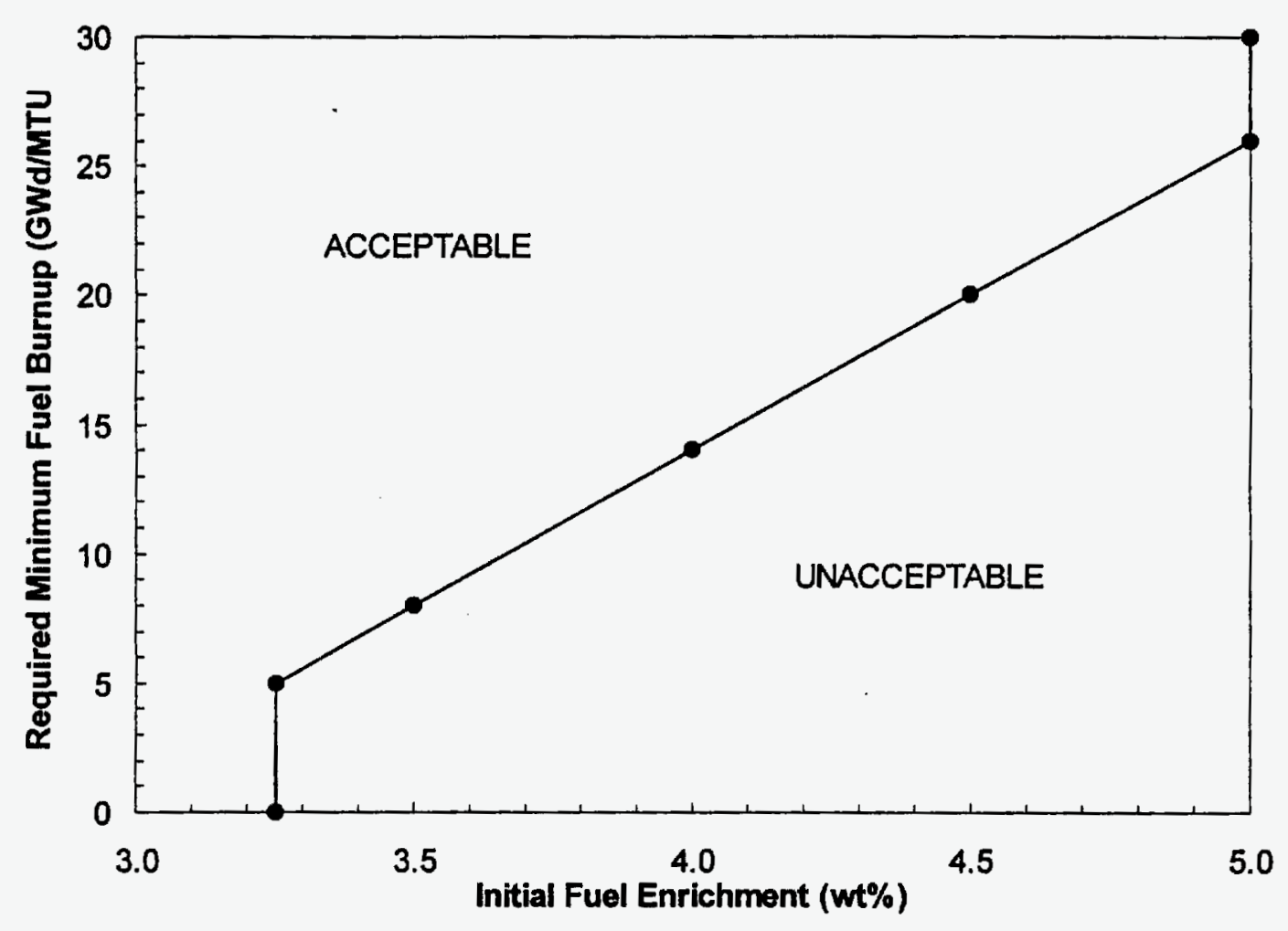

Assembly Design: Westinghouse $17 \times 17$

\section{Minimum Cooling Tlme: 5 years}

\section{Maximum Number of Removable Burnable Poison Rods: $\quad 0$}

Note: This loading curve was generated with the following assumptions: Maximum Cycle Average Boron of $650 \mathrm{ppm}$, Maximum Core Outlet Temperature of $570 \mathrm{~K}$, and Maximum Pellet Average Temperature of $900 \mathrm{~K}$.

* The nominal bumup must be reduced by the utility so there is a $95 \%$ confidence level of meeting. the Required Minimum Fuel Burnup.

** If the assembly has more than one enrichment, the highest enrichment must be used.

Figure A.4-6: Loading Curve for WE 17x17 Fuel Assemblies in the NUHOMS ${ }^{\circledR}$-MP187 Cask 
APPENDIX B

BURNUP MEASUREMENT SYSTEMS 


\section{BURNUP MEASUREMENT SYSTEMS}

The following are descriptions of burnup measurement systems as provided by the vendor. Appendix B.1 is a description of the BNFL FuelMaster. Appendix B.2 is a description of EPRI's Fork+ system. 
APPENDIX B.1

BNFL'S FuelMaster $^{\text {TM }}$ 


\section{BNFL INSTRUMENTS BURNUP MEASUREMENT SYSTEM}

\section{B.1.1 Introduction}

Spent fuel burnup monitoring is being offered as a service using an instrument system based on high resolution gamma spectrometry (HRGS). The system, known as FuelMaster ${ }^{T M}$ (formerly Spent Fuel Monitor (SFM)) has been designed using experience gained by the development and use of a series of instruments for the support of operations at the Sellafield nuclear fuel reprocessing facility in the United Kingdom. Industrial robustness with low maintenance and high reliability have been key attributes of these instruments and have allowed the successful measurement of more than 1 million fuel items since the 1970s.

As part of the FuelMaster ${ }^{\mathrm{TM}}$ development program a demonstration system was produced in 1996. Using this system, measurements were made on 55 PWR assemblies in a US utility spent fuel pool during April 1996. The measurements presented the opportunity to provide the utility with their required burnup verification data and to simultaneously demonstrate the BNFL Instruments system to the US Department of Energy (USDOE) and the Nurlear Regulatory Commission (NRC). Subsequently a commercial contract was awarded by tie same utility to measure an additional campaign of more than 300 PWR assemblies. A pre.iminary report on these measurements has been published under the auspices of the Electric Power Research Institute (EPRI) ${ }^{1}$. The report concluded that HRGS measurements using the FueMaster ${ }^{\top M}$ could provide accurate determination of burnup and cooling time. Based on a dependent calibration the correlation between measured and reactor records burnup was shown to have a $1 \sigma$ error of between 3 and $5 \%$.

\section{B.1.2 Design}

A schematic illustration of the demonstration FuelMaster ${ }^{\mathrm{TM}}$ is shown in figure B.1-1. The simplicity of design allows ease of installation, removal and decontamination, and is intended to minimise disruption to other operations in the pool during its use. This configuration is pool wall mounted and fuel assemblies are brought to it for measurement. Movement of fuel to the monitoring system for measurement was considered appropriate as fuel measurements may be co-ordinated with other operations such as fuel inspection or fuel transfer to either dry storage/transport casks or to a segregated area for measured assemblies. The principal mechanical components comprise:

(i) A vertical re-entrant tube that is fixed to the pool wall. The re-entrant tube allows the insertion and removal of the high resolution gamma detector within a carriage. This approach to detector delivery, in which the detector is segregated from the pool, provides direct access to the detector for maintenance and prevents any risk of contamination from the pool water. 
(ii) A detector carriage. This acts to protect the detector from mechanical damage and ensures its correct positioning with respect to the gamma collimator axis.

(iii) A shielded detector enclosure. This minimises the magnitude of any background radiation reaching the detector and aids optimisation of gamma spectral quality.

(iv) A horizontal collimator. This defines and controls the detector's field of view at the fuel assembly.

(v) A v-shaped fuel location fixture. This permits simultaneous views of two faces of the assembly and provides a means for accurate and reproducible positioning of the fuel assembly during measurement.

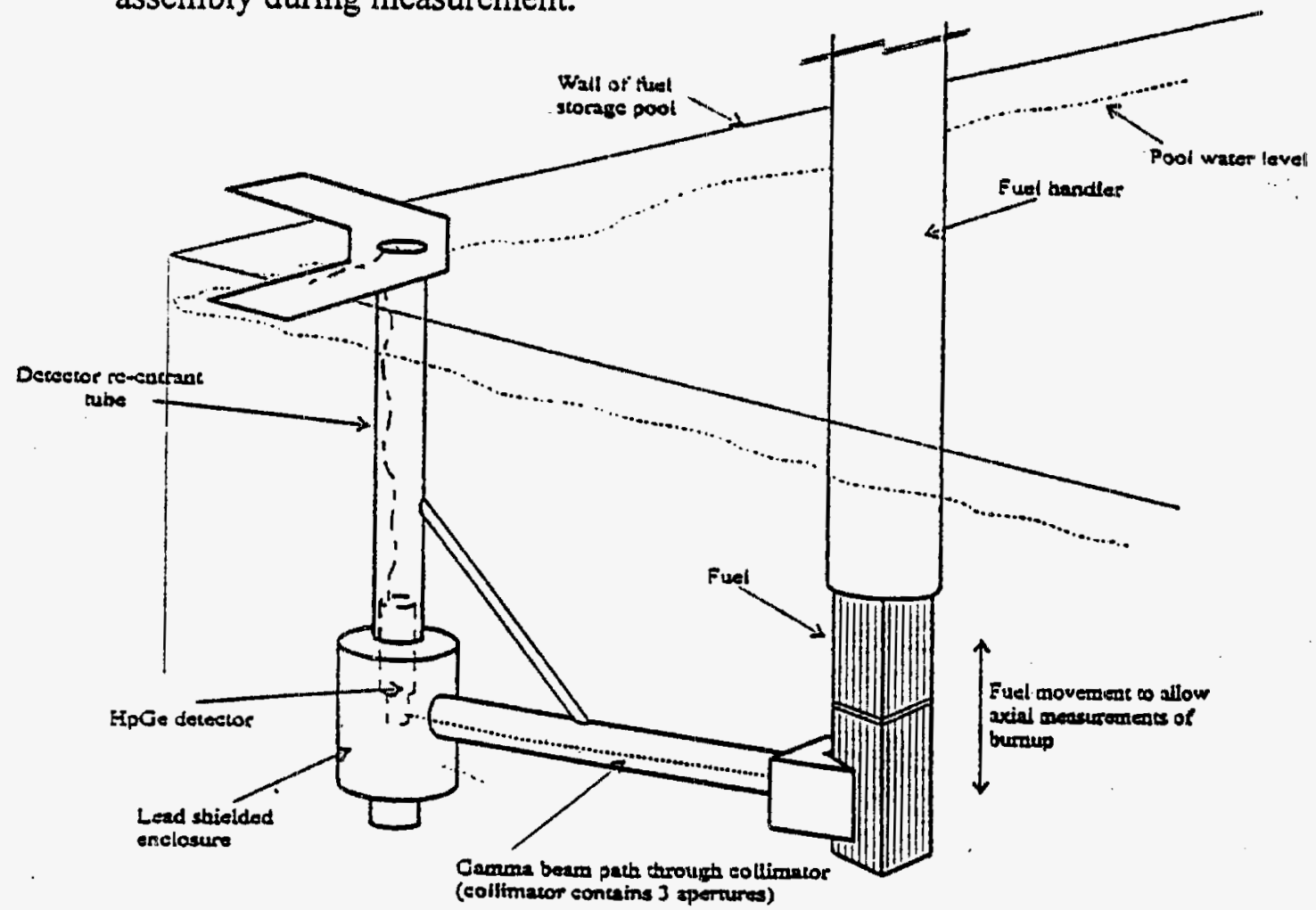

Figure B.1-1 Demonstration FuelMaster ${ }^{\mathrm{TM}}$ schematic arrangement.

Photographs of the demonstration system are shown in figures B.1-2 and B.1-3. Figure B.1-2 shows the HRGS high purity intrinsic germanium (HpGe) detector being inserted into the reentrant tube at the pool side. Figure B.1-3 shows a plan view of the collimator pointing from the pool corner to a fuel assembly held in the fuel handling machine. The fuel is shown as it approaches the v-shaped fixture on the end of the gamma collimator. Both the pond wall fixing plate arrangement, visible in figure B.1-2, and the collimator length may be tailored to suit the local conditions at specific utilities. Adaptations of the FuelMaster ${ }^{\mathrm{TM}}$ design could also be used in dry, out of pool, conditions.

All electrical service and signal cables are fed back from the detector to the radiometric, control and data storage electronics through the re-entrant tube. This again allows easy maintenance and eliminates equipment contamination risks. 


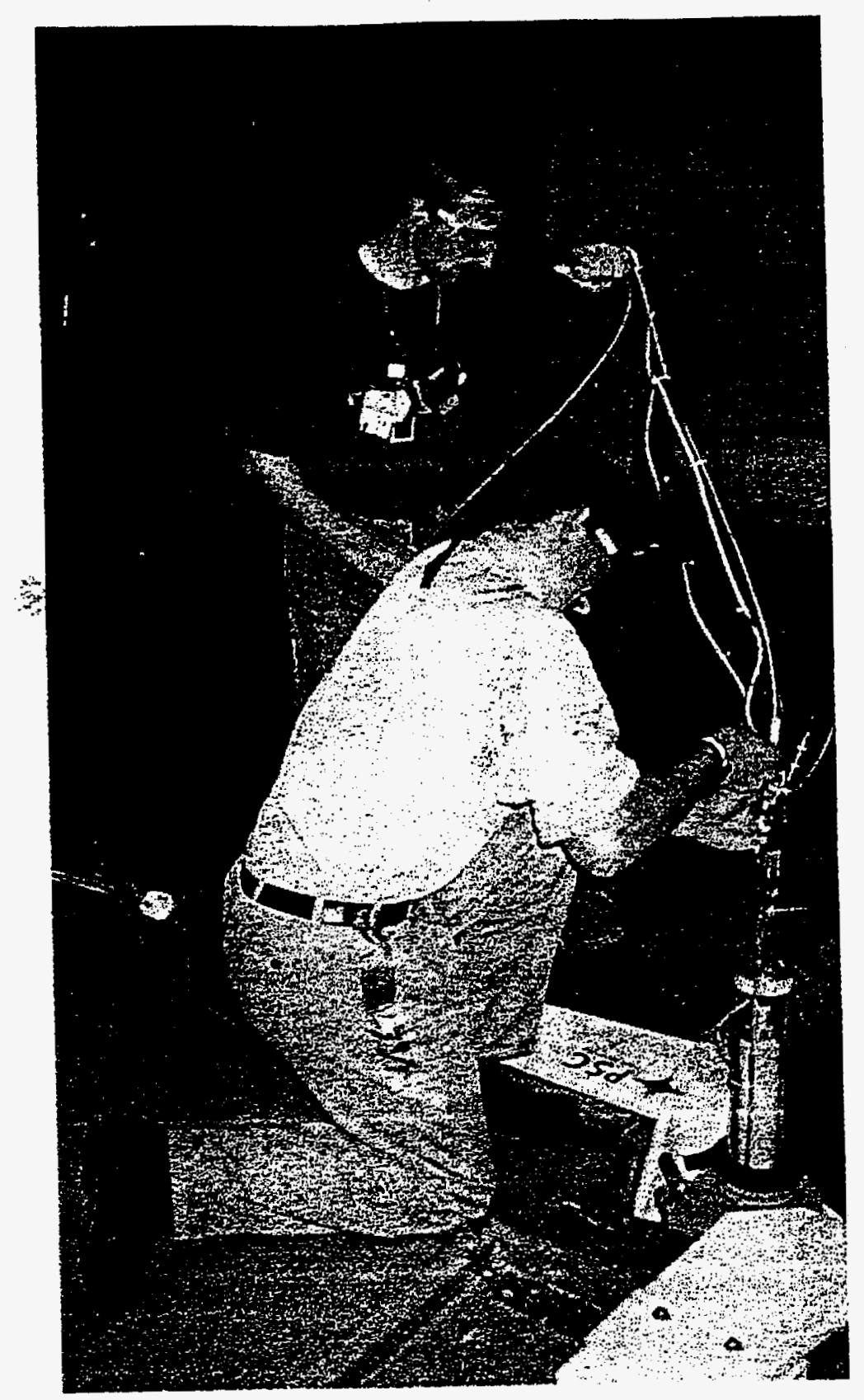

Figure B.1-2 Loading of gamma detector into re-entrant tube. 


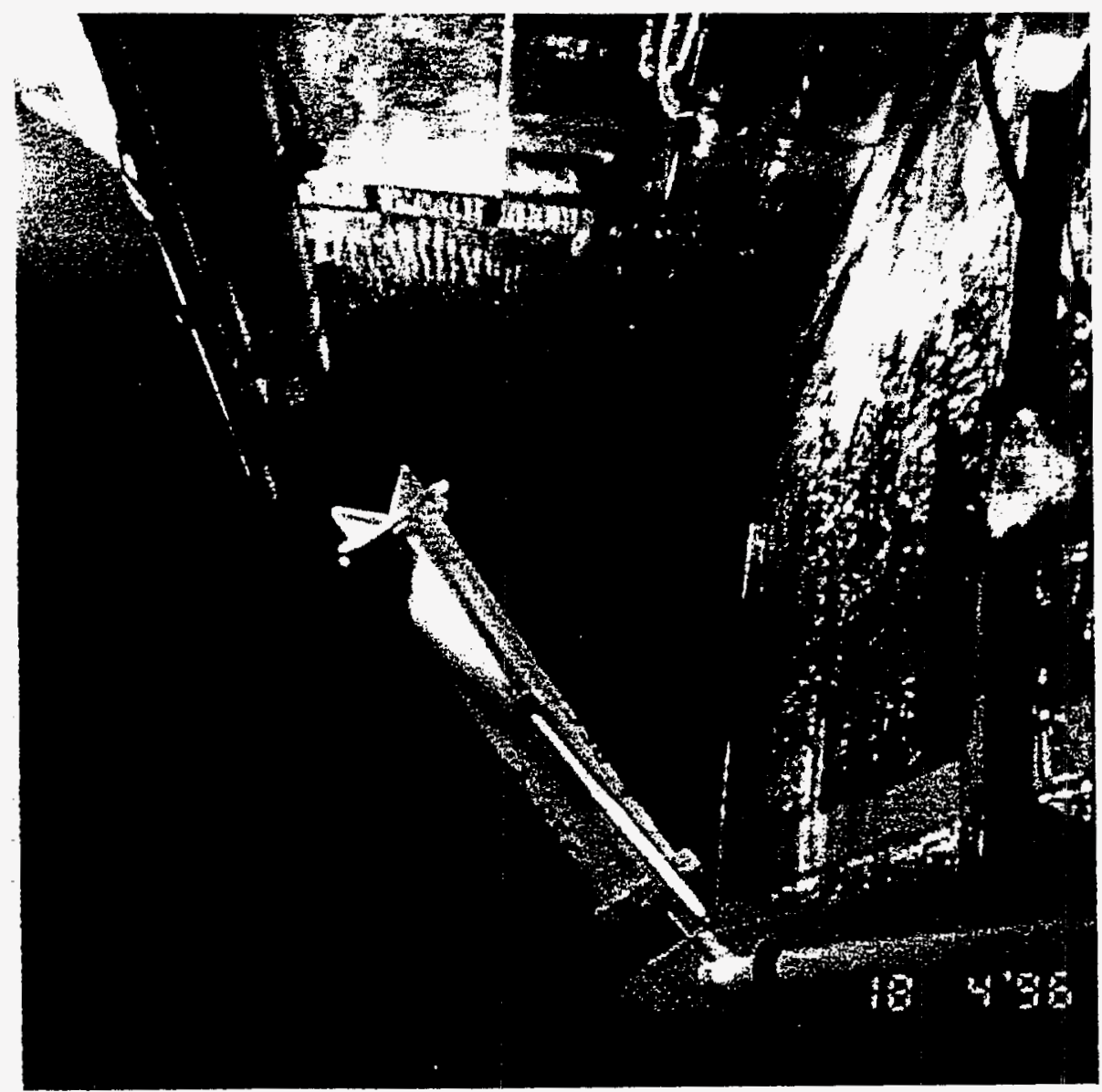

Figure B.1-3 Plan view of gamma collimator and fuel handling machine. 


\section{B.1.3 Theory of Operation}

The high resolution gamma spectrometric measurements offered by the FuelMaster ${ }^{\mathrm{TM}}$ gives the system the ability to resolve and quantify a variety of gamma rays emitted by fission and activation products present in the spent fuel. Radio-isotopes that may be measured by the detection of their gamma emissions include Cs-137, Eu-154, Cs-134, Ce-144 and Ru-106. Individually or in combination the quantities of these isotopes, built up during irradiation, can be correlated with burnup. As such they are often referred to as "burnup indicators". However, for spent fuel with cooling times in the range 5 to 40 years of which 20 years is typical for US fuels, some of the shorter lived isotopes (Ru-106 and Ce-144) may have decayed away. This leaves Cs137 as the primary burnup indicator via its $\beta$ decay daughter $\mathrm{Ba}_{\mathrm{m}}-137,661.66^{*} \mathrm{keV}$ gamma ray.

Cs- 137 has a half life of 30 years and is a direct fission product with an almost identical fission yield from both uranium and plutonium. It has a linear relationship with burnup when corrected for cooling time and is insensitive to variations in U-235 enrichment, reactor power rating and dwell times. In addition its long half life means it can easily be measured in fuel cooled to more than 100 years. These characteristics make Cs-137 a particularly good indicator of burnup.

The linear relationship can be expressed in the standard way;

$$
\text { Cs- } 137=a+b . B U
$$

where Cs-137 is the count rate of the $661.66 \mathrm{keV}$ gamma ray corrected to zero cooling time, and "a" and "b" are constants in the linear correlation with burnup BU.

The cooling time, required to correct for the decay of the Cs-137 content in the time between reactor shutdown or discharge from the reactor and measurement, also can be measured by the spectroscopy system using isotopic activity ratios. This additional capability to measure cooling time can be used as a check on the reactor records cooling time and thereby give further confidence in the assembly's irradiation history data.

An example of a typical gamma spectrum, produced on a multichannel analyser (MCA), is shown in figure B.1-4. The log ordinate, counts per channel, is shown against the channel numbers calibrated in energy (keV). The dominance of the $661.66 \mathrm{keV}$ photopeak is shown clearly even on the log scale.

Other algorithms based on HRGS measurements may be brought into use as additional measures of burnup but these are seen, for the reasons given below, as of only secondary importance compared to the Cs-137 technique. The alternative techniques include the use of the activity ratios Cs-134/Cs-137 and Ru-106 x Cs-137/(Cs-134) ${ }^{2}$. These techniques, for shorter cooled fuels where all the required isotopes are measurable, offer the advantage that they do no not rely on an absolute measurement as is required for Cs-137. Consequently errors arising from variations in detection efficiency due to changes in detector or electronics performance or in the precise

\footnotetext{
* Reference: Table of Isotopes, Richard B Firestone (Virginia S Shirley Editor) Eighth Edition, John Wiley \& Sons Inc. 1996.
} 
positioning of the fuel relative to the detector should be of less importance. The disadvantages are, however, for the first ratio Cs-134/Cs-137 (a) the ratio has a 2.2 year half life and needs a significant cooling time correction, (b) its correlation with burnup is influenced by the initial U$235 \mathrm{wt} . \%$ enrichment and by the reactor power rating and (c) its application is limited to fuel with cooling times of about 20 years or less due to the decay and disappearance of the shorter lived component, Cs-134.

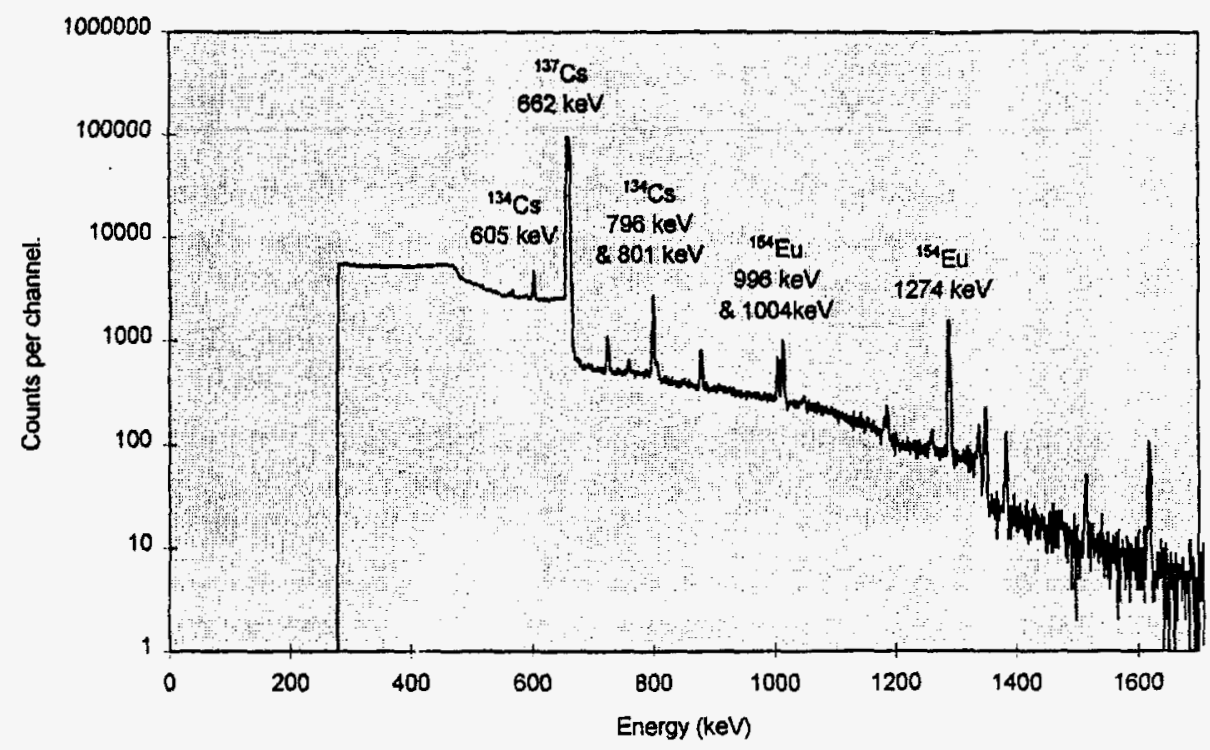

Figure B.1-4 Example of a typical MCA gamma spectrum.

The second activity ratio, Ru-106 x Cs-137/(Cs-134), has the advantage of being an activity ratio method, (i.e. it is insensitive to geometry) but unlike the Cs-134/Cs-137 ratio it is virtually independent of enrichment and rating and is therefore subject to lower systematic errors. The half life of the ratio is 22 years, giving it a relatively low sensitivity to cooling time correction errors. However due to the decay of the short half life component $\mathrm{Ru}-106$, this ratio technique can be used only on fuel that has a cooling time of less than about 8 or 9 years. Its general application to a large proportion of US spent fuel is therefore not possible.

\section{B.1.4 Calibration}

B.1.4.1 Dependent Calibration. A dependent method of calibration is proposed for burnup measurement systems in the Actinide Only Burnup Credit Topical Report (AOBCTR), Revision 1, March 30, 1997. This approach to calibration has been adopted traditionally for monitoring systems that are used to confirm the consistency of a data set, i.e. to indicate the presence of any outliers. This is considered appropriate for burnup reactor records in which the general accuracy and precision of the data set under test is assumed and that any isolated errors due, for instance, to paper errors would be apparent. These could then be corrected or eliminated from the calibration set. Similarly errors of this type could be corrected or removed from any subsequent measurement set. No account is taken for the possible occurrence of systematic errors or biases in the calibration data sets. The calibrations are, therefore, dependent on the quality of the burnup 
records of those spent fuel assemblies selected for the calibration measurement campaigns. Benefits of the dependent approach are that the calibration assemblies are of the same geometry as the fuel to be measured consequently some systematic effects in the measurement system are accounted for.automatically. As mentioned above it is possible that with an HRGS measurement system other fuel parameters such as cooling time can be determined independently to provide supporting validation of the reactor records.

The test proposed in the AOBCTR to qualify the measurement system and to some degree the reactor records uses the following test expression for expected burnup uncertainty, $\mathrm{CBU}$;

$$
C B U=t_{\alpha / 2, n-2} \sqrt{\left(\frac{n+1}{n}+\frac{(x-\bar{x})^{2}}{S_{x x}}\right) \frac{S S_{R}}{n-2}}
$$

where;

$S_{x x} \equiv \sum_{i=1}^{n}\left(x_{i}-\bar{x}\right)^{2}=$ the sum of differences squared in reactor records burnup about the mean reactor records burnup for the sample population and, $S S_{R} \equiv \sum_{i=1}^{n}\left(y_{i}-y_{s t}\right)^{2}=$ the sum of differences squared in measured burnup from the linear regression value for the sample population.

With the rejection criterion imposed that the CBU is to be less than $10 \%$ to a $95 \%$ confidence limit and the reactor records uncertainty is assumed to be $5 \%$ for $2 \sigma$, the measurement system must also offer a measurement uncertainty of better than $5 \%$ for $2 \sigma$. An assessment has been undertaken to test the results of a recent measurement campaign of 40 assemblies against the dependent system rejection criterion. This is presented in the Measurement Data Section.

B.1.4.2 Independent Calibration. There is interest in using methods of calibrating monitoring systems which are independent of reactor records data. An independent approach, that can be implemented by the FuelMaster ${ }^{T M}$ HRGS system, is to determine the correlation between burnup indicators and burnup by the use of computer burnup inventory codes such as ORIGEN and FISPIN ${ }^{2}$. These codes, established for many years and validated by comparison with experimental destructive analysis data ${ }^{3,4}$, provide inventories of fission products and transuranic nuclides as a function of irradiation history.

Examples of the correlation between two key burnup indicators from both ORIGEN and FISPIN are given in figures B.1-5 and B.1-6. The data is for generic PWR fuel of 5 years cooling time and initial enrichments of 2, 2.5, 3, and $3.5 \mathrm{U}-235 \mathrm{wt} . \%$.

Figure B-1.5 shows that there is good agreement between the two codes for the content of the primary burnup indicator Cs-137. Its magnitude has been shown to be consistently predicted by

\footnotetext{
* Note that $t$ distribution tables are required to evaluate $t_{\alpha / 2, n-2}$ at the 2 sigma level of significance (i.e. a two tailed significance test).
} 
the different codes and has been validated satisfactorily by destructive analysis to an uncertainty to $1 \sigma$ of less than $1 \%$. If the measurement geometry and detection efficiency are well known and are reproducible, Cs-137 can be used to provide a calibration fully independent of operator irradiation history data. In addition the cooling time needed to correct for the decay of Cs-137 can also be measured independently using gamma spectrometry. The only data required, therefore, for the calibration are the structural details of the fuel assembly which are available to a high quality from the fuel manufacturer.

It is crucial in this approach, however, that no changes occur between the calibration conditions and the measurement conditions. Such changes could include variations in; (i) the detection efficiency, (ii) the measurement geometry, and (iii) the fuel assembly geometry. A measurement procedure that uses this approach should, therefore, include suitable checks to eliminate systematic errors from these possible variations.

5 years Cooled

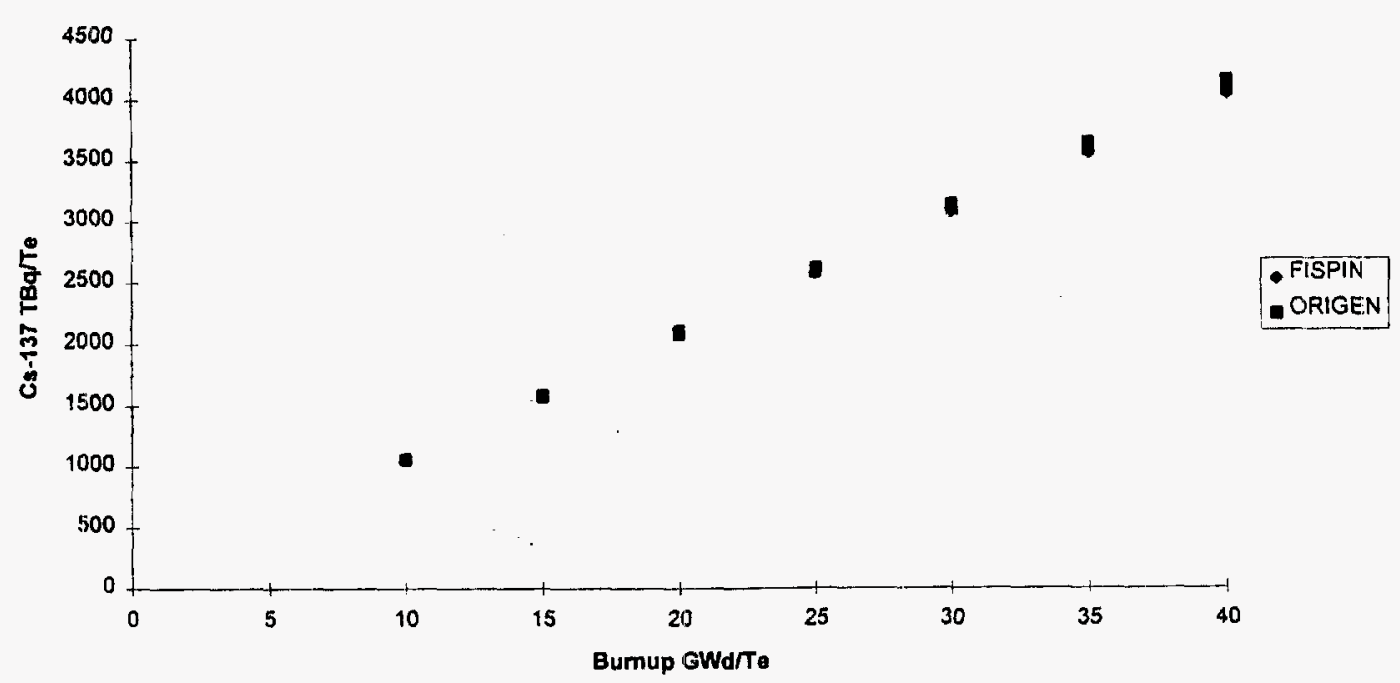

Figure B.1-5 Inventory code derived Cs-137 content per unit uranium mass as a function of bumup.

Figure B.1-6 shows an example of an alternative burnup indicator, Cm-244. This is the primary burnup indicator used by neutron measurement systems via its spontaneous neutron emission. As shown there is a clear disagreement between the two codes, also the correlation between $\mathrm{Cm}-244$ and burnup is not linear and there is a strong dependency on the U-235 wt.\% initial enrichment. For this reason and because neutron based measurement systems are sensitive to the presence of neutron poisons in the measurement pool an independent calibration using $\mathrm{Cm}-244$ would be difficult to implement.

In order to achieve an independent calibration based on the preferred burnup indicator, Cs-137, a calibration procedure that is more involved than for a dependent method is still a basic 
requirement however. For example an accurate knowledge and understanding is required of (i) the fuel assembly parameters, (ii) the gamma attenuation between the source of the gamma emission in the fuel, (iii) the collimator design (iv) the detector intrinsic efficiency and (v) the radiometric electronics performance characteristics.

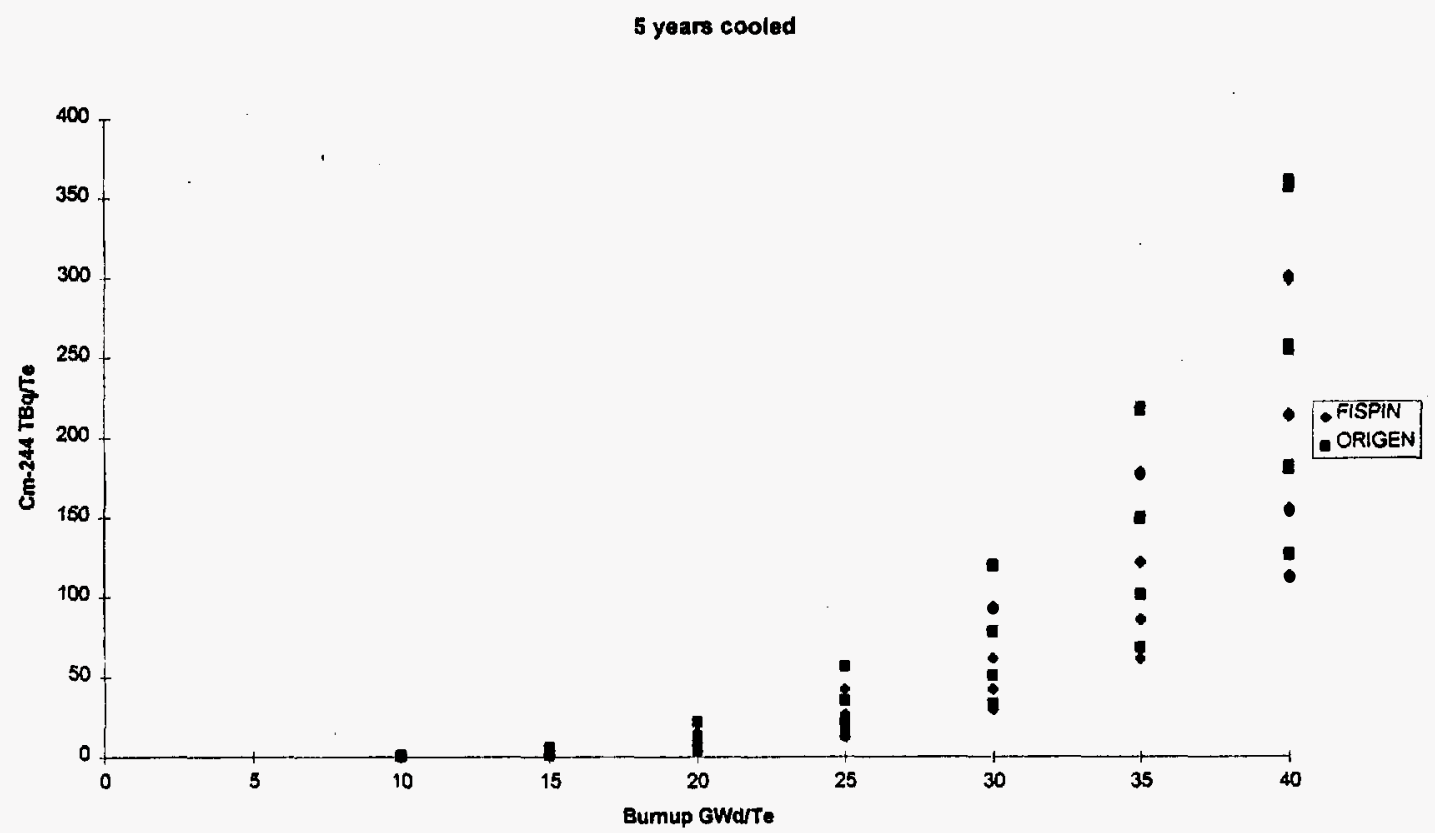

Figure B.1-6 Inventory code derived $\mathrm{Cm}-244$ content per unit uranium mass as a function of burnup.

Considered in the fuel assembly parameters are the Cs-137 activity as a function of burnup at zero cooling time, the activity per unit volume of the fuel assembly, the branching ratio of the Cs-137 $661.66 \mathrm{keV}$ gamma ray and the cooling time of the fuel at measurement. The influence of the fuel structure and the collimator design on the attenuation of gamma rays from the fuel also need to be taken into account. Finally assessment of the combined effects of the above and the detector and radiometrics electronics performance are necessary to correctly link the measured gamma ray count rate, the quantity of burnup indicator Cs-137 in the fuel to give a measure of burnup. A mixture of analytical calculations and Monte Carlo modelling techniques are likely to be required to satisfactorily carry out this process.

In practice these processes would be applied by calibrating the collimator and associated counting chain using a National Laboratory traceable gamma sealed source whilst both the quantity of Cs-137 and its gamma escape probability in spent fuel would be modelled.

\section{B.1.6 Measurement Procedure}

The fuel measurements during 1996 using the demonstration version of the FuelMaster ${ }^{\top M}$ were made in a cask loading pit adjacent to a fuel storage pool. 
The daily measurement procedure included; (i) detector operational tests using a standardization source prior to the day's fuel measurements, (ii) background radiation measurements, (iii) axial burnup profile and point gamma spectrometry measurements at several positions along the length of each selected assembly.

In order to minimize systematic errors due to radial burnup profile or radial tilt, the measurement procedure includes turning each fuel assembly through 180 degrees and taking measurements along the assembly on the opposite corner. This allows the measurement of all four faces of the assembly and calculation of the "correct horizontal average". After completion of the measurements each assembly was returned its original rack location.

Measurements from each position were subsequently combined to determine assembly average values of burnup and cooling time. The standard assembly measurement time was approximately 30 minutes.

As the burnup determination is based on the absolute measurement of the Cs-137 $661.66 \mathrm{keV}$ gamma ray count rate. it is crucial that the procedures and geometrical arrangement ensure reproducible positioning of the fuel assembly and consistent detector and associated electronics performance throughout a measurement campaign. To achieve this, the measurement procedure includes suitable checks to eliminate the possibility of systematic errors from these detection efficiency related parameters.

Two methods used to monitor for these effects were (i) confirmation of the detection efficiency of the radiometric system by the measurement of the gamma standardisation source, and (ii) daily measurement of a local reference assembly chosen from additional assemblies available in the same pool. This latter method is very important as it would reveal any changes in the detector/electronics performance, detector positioning in the re-entrant tube and very importantly fuel positioning in the field of view of the gamma collimator.

\section{B.1.7 Measurement Data}

Published results from the US utility PWR measurements using the demonstration FuelMaster ${ }^{\mathrm{TM}}$ system include a set of 55 demonstration measurements made in April and a campaign of 40 assemblies carried out under contract in August of 1996. The measurement results presented below are from this first contracted measurement campaign. The results of other commercial measurement made to date have not yet been published. The reactor records data for the first campaign assemblies is given in Table B.1-1.

In accordance with the procedures given above a reference assembly was chosen and measured each day to confirm the stability of the measurement system and reproducibility of detector and fuel positioning. Table B.1-2 shows the results of these repeat Cs-137 measurements taken over the duration of the measurement campaign. 
Table B.1-1 Measured Assemblies - Operator reactor records data.

\begin{tabular}{|c|c|c|c|c|c|}
\hline $\begin{array}{l}\text { Fuel } \\
\text { Ident } \\
\text { Number } \\
\text { num }\end{array}$ & $\begin{array}{l}\text { Discharge } \\
\text { Date }\end{array}$ & $\begin{array}{l}\text { Meas } \\
\text { Date } \\
\\
\end{array}$ & $\begin{array}{l}\text { Cooling } \\
\text { Time } \\
\text { Days }\end{array}$ & Burnup & $\begin{array}{c}\text { Initial } \\
\text { Enrich, } \\
\mathrm{U}-235 \mathrm{wt} \%\end{array}$ \\
\hline $\mathrm{NJ} 1 \mathrm{A02}$ & 27-Jan-77 & 10-Aug-96 & 7135 & 17010 & 2.050 \\
\hline NJ1A03 & $27-\operatorname{Jan}-77$ & 14-Aug-96 & 7139 & 17930 & 2.053 \\
\hline NJ1A05 & 27-Jan- 77 & 09-Aug-96 & 7134 & 16930 & 2.053 \\
\hline NJIA06 & 27-Jan- 77 & 11. Aug-96 & 7136 & 17640 & 2.055 \\
\hline NJ1A07 & 27-Jan-77 & 09-Aug-96 & 7134 & 16850 & 2.052 \\
\hline NJ1A08 & $27-\operatorname{Jan}-77$ & 11.Aug-96 & 7136 & 17650 & 2.056 \\
\hline NJIA09 & $27-J \operatorname{an}-77$ & 12-Aug-96 & 7137 & 17920 & 2.054 \\
\hline NJIAI0 & 27-Jan-77 & 11.Aug-96 & 7136 & 17050 & 2.056 \\
\hline NJIAII & 27-Jan-77 & 10-Aug-96 & 7135 & 17040 & 2.055 \\
\hline NJ1A12 & 27-Jan-77 & 09-Aug-96 & 7134 & 16850 & 2.050 \\
\hline NJ1A13 & $27-\operatorname{Jan}-77$ & 11.Aug-96 & 7136 & 17160 & 2.053 \\
\hline NJIA14 & 27-Jan-77 & 09-Aug-96 & 7134 & 16850 & 2.055 \\
\hline NJIAI5 & 27-Jan-77 & 08-Aug-96 & 7133 & 16400 & 2.057 \\
\hline NJ1A16 & 27-Jan-77 & 11.Aug-96 & 7136 & 17650 & 2.056 \\
\hline NJ1A17 & 27-Jan-77 & 14-Aug-96 & 7139 & 17980 & 2.057 \\
\hline NJ1A18 & $27-\operatorname{Jan}-77$ & 10-Aug-96 & 7135 & 16980 & 2.059 \\
\hline NJIA19 & 27-Jan- 77 & 11.Aug-96 & 7136 & 17740 & 2.057 \\
\hline NJ1A21 & $27-\operatorname{Jan}-77$ & 10-Aug-96 & 7135 & 17020 & 2.055 \\
\hline NJ1A22 & 27-Jan-77 & 14-Aug-96 & 7139 & 17930 & 2.057 \\
\hline NJ1A24 & 27-Jan-77 & 10-Aug-96 & 7135 & 16980 & 2.053 \\
\hline NJ1A25 & 27-Jan-77 & 10-Aug-96 & 7135 & 17010 & 2.054 \\
\hline NJ1A27 & 27-Jan-77 & -09-Aug-96 & 7134 & 16940 & 2.056 \\
\hline NJlA42 & 27-Jan-77 & 12-Aug-96 & 7137 & 17920 & 2.050 \\
\hline NJIA43 & 27-Jan-77 & 14-Aug-96 & 7139 & 17920 & 2.060 \\
\hline NJ1A44 & 27-Jan-77 & 09-Aug-96 & 7134 & 16850 & 2.052 \\
\hline NJ1A45 & 27-Jan-77 & 11.Aug-96 & 7136 & 17640 & 2.060 \\
\hline NJ1A50 & 27-Jan-77 & 11.Aug-96 & 7136 & 17060 & 2.059 \\
\hline NJ1A52 & 27-Jan-77 & 10-Aug-96 & 7135 & 17040 & 2.057 \\
\hline NJ1A55 & 27-Jan-77 & 11.Aug-96 & 7136 & 17400 & 2.055 \\
\hline NJ1B03 & $02-\mathrm{Feb}-78$ & 14-Aug-96 & 6768 & 28315 & 2.724 \\
\hline NJ1B18 & $02-\mathrm{Feb}-78$ & 13-Aug-96. & 6767 & 28336 & 2.724 \\
\hline NJ1B19 & $02-$ Feb-78 & 14-Aug-96 & 6768 & 28322 & 2.725 \\
\hline NJ1B28 & 02-Feb-78 & 13-Aug-96 & 6767 & 28129 & 2.730 \\
\hline NJ1B36 & 02-Feb-78 & 14-Aug-96 & 6768 & 28301 & 2.727 \\
\hline NJ1B47 & $02-$ Feb-78 & 14-Aug-96 & 6768. & 28302 & 2.727 \\
\hline NJ1A41 & 02-Jan-81 & 14-Aug-96 & 5703 & 23885 & 2.061 \\
\hline NJo0WT & 08-Nov-82 & 13-Aug-96 & 5027 & 31876 & 3.011 \\
\hline NJ00WU & 08-Nov-82 & 13-Aug-96 & 5027 & 31517 & 3.011 \\
\hline NJ00X6 & 08-Nov-82 & 13-Aug-96 & 5027 & 31495 & 3.010 \\
\hline NJ00X8 & $08-N o v-82$ & 13-Aug-96 & 5027 & 31328 & 3.010 \\
\hline
\end{tabular}


The small variations of the measured count rates, of less than $1 \%$ for each point compared to the mean arise from (i) the statistical error associated with the measured Cs-137, $661.66 \mathrm{keV}$, count rate, (ii) the combined detector performance and electronics drift and (iii) variations in the positioning of the detector in the re-entrant tube and in the fuel assembly with respect to the gamma collimator. This ability to reproducibly measure the burnup indicator, Cs-137, within a small error of less than $1 \%$ demonstrates the quality that the system configuration and the measurement procedures introduce.

Table B.1-2 Cs-137, 661.66 keV count rate measurements from reference assembly NJ00WS.

\begin{tabular}{|c|c|c|}
\hline Measurement Date and Time & $\begin{array}{c}\text { Cs-137 661.66 keV } \\
\text { photopeak count rate } \\
\text { (cps) }\end{array}$ & $\begin{array}{c}\text { Variation from mean } \\
(\%)\end{array}$ \\
\hline $09 / 08 / 9616: 03$ & $5220 \pm 9$ & +0.1 \\
\hline $10 / 08 / 9607: 25$ & $5221 \pm 8$ & +0.1 \\
\hline $11 / 08 / 9607: 34$ & $5243 \pm 9$ & +0.5 \\
\hline $12 / 08 / 9618: 27$ & $5200 \pm 8$ & -0.3 \\
\hline $12 / 08 / 9619: 20$ & $5198 \pm 8$ & -0.3 \\
\hline $13 / 08 / 9607: 32$ & $5247 \pm 11$ & +0.6 \\
\hline $14 / 08 / 9617: 43$ & $5179 \pm 13$ & -0.7 \\
\hline
\end{tabular}

As all the fuel assemblies being measured in the campaign were to be returned to their original storage racks it was possible to use all 40 both to test the correlation between the measured and reactor records burnup and as a calibration set. The assembly average Cs-137, $661.66 \mathrm{keV}$ count rate was plotted against the reactor records burnup to establish a correlation curve. From this curve an empirical calibration was determined to give measured burnup as a function of the reactor burnups. A plot based on this calibration giving measured against reactor burnup is shown in figure B.1-7. Note: (i) a single linear curve has been fitted to all the data and (ii) the scatter of the data points about the fitted curve are from the combination of both reactor records and measurements errors.

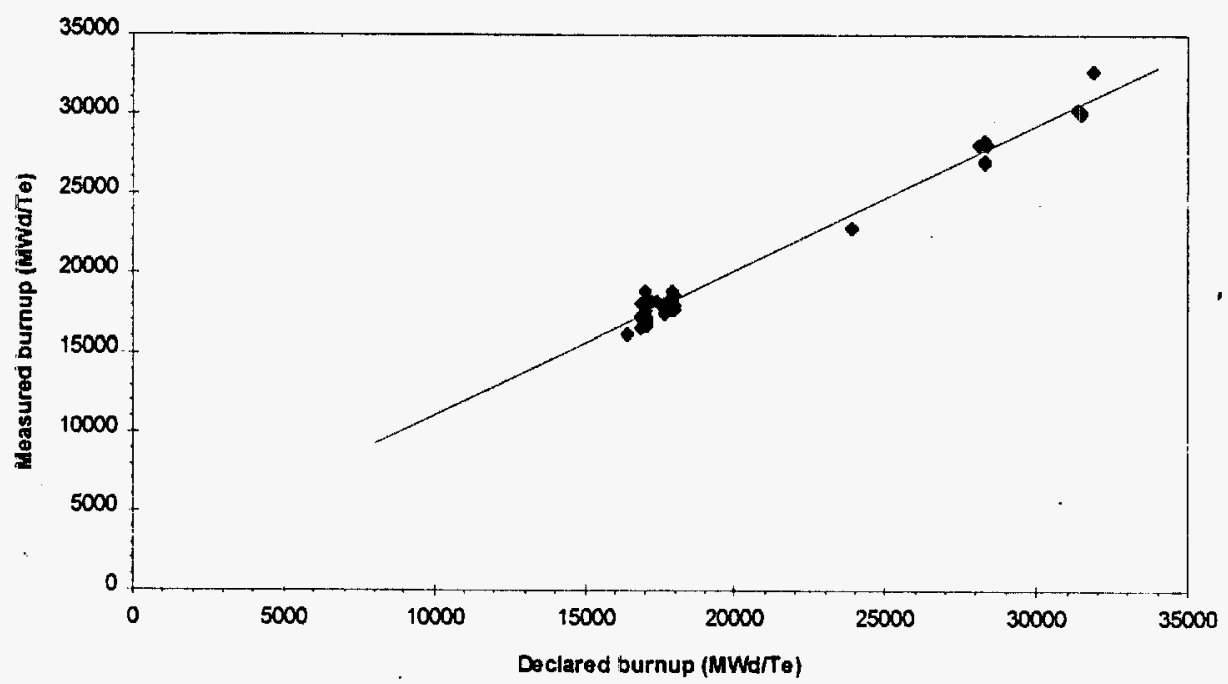

Figure B.1-7 Measured versus reactor records declared burnup for a campaign of 40 assemblies. 
The expected burnup uncertainty, $\mathrm{CBU}$, from this dependent calibration system has been calculated using the two tailed $t$ test function as described in the Calibration Section. The CBUs for the 40 assemblies were found to pass the proposed rejection criterion, i.e. the expected burnup uncertainty was found to be less than $10 \%$ of the reactor records assembly burnup in all cases. The individual measured burnup and CBU values are presented in Table B.1-3.

Table B.1-3 Measured burnup and CBU rejection criteria test results.

\begin{tabular}{|c|c|c|c|}
\hline $\begin{array}{l}\text { Reactor Records } \\
\text { Bumup } \\
(\mathrm{MWd} / \mathrm{Te})\end{array}$ & $\begin{array}{l}\text { Measured } \\
\text { Bumup } \\
(\mathrm{MWd} / \mathrm{Te})\end{array}$ & $\mathrm{CBU}$ & $\% \mathrm{CBU}$ \\
\hline 31876 & 32740 & 1557 & 4.88 \\
\hline 31517 & 30004 & 1517 & 4.81 \\
\hline 31495 & 30124 & 1519 & 4.82 \\
\hline 31328 & 30282 & 1521 & 4.85 \\
\hline 17010 & 18886 & 1458 & 8.57 \\
\hline 17930 & 18542 & 1459 & 8.14 \\
\hline 16930 & 17982 & 1461 & 8.63 \\
\hline 17640 & 18111 & 1461 & 8.28 \\
\hline 16850 & 17225 & 1464 & 8.69 \\
\hline 17650 & 17445 & 1463 & 8.29 \\
\hline 17920 & 17683 & 1462 & 8.16 \\
\hline 17050 & 17206 & 1465 & 8.59 \\
\hline 17040 & 16744 & 1467 & 8.61 \\
\hline 16850 & 17248 & 1464 & 8.69 \\
\hline 17160 & 18238 & 1460 & 8.51 \\
\hline 16850 & 16551 & 1468 & 8.71 \\
\hline 16400 & 16169 & 1470 & 8.97 \\
\hline 17650 & 17871 & 1462 & 8.28 \\
\hline 17980 & 17736 & 1462 & 8.13 \\
\hline 16980 & 17615 & 1463 & 8.61 \\
\hline 17740 & 18247 & 1460 & 8.23 \\
\hline 17020 & 18180 & 1460 & 8.58 \\
\hline 17930 & 17887 & 1461 & 8.15 \\
\hline 16980 & 18035 & 1461 & 8.60 \\
\hline 17010 & 18007 & 1461 & 8.59 \\
\hline 16940 & 17946 & 1461 & 8.63 \\
\hline 23885 & 22845 & 1459 & 6.11 \\
\hline 17920 & 18298 & 1460 & 8.15 \\
\hline 17920 & 18839 & 1458 & 8.14 \\
\hline 16850 & 18105 & 1461 & 8.67 \\
\hline 17640 & 17662 & 1462 & 8.29 \\
\hline 17060 & 16911 & 1466 & 8.59 \\
\hline 17040 & 16652 & 1467 & 8.61 \\
\hline 17400 & 18194 & 1460 & 8.39 \\
\hline 28315 & 26958 & 1484 & 5.24 \\
\hline 28336 & 28056 & 1495 & 5.27 \\
\hline 28322 & 28175 & 1496 & 5.28 \\
\hline 28129 & 28089 & 1495 & 5.31 \\
\hline 28301 & 28361 & 1498 & 5.29 \\
\hline 28302 & 27084 & 1485 & 5.25 \\
\hline
\end{tabular}


The results show that the performance of the burnup measurement system successfully meets the dependent rejection criterion for this sample population. On this basis the measurement system qualifies for use and would provide confirmation of the reactor record burnups to allow their use with the appropriate burnup curves for cask loading.

\section{B.1.8 Quality Assurance}

BNFL Instruments has third party accreditation to ISO 9001 which imposes a thorough control of all company processes. In order to demonstrate consistency with the requirements of the relevant CFRs (10-CFR-50, 10-CFR-71 and 10-CFR-72) a compliance index is being produced for the production FuelMaster ${ }^{\mathrm{TM}}$ measurement services for 1997 . The index will identify areas where any adaptation of current procedures and instructions relevant to the FuelMaster ${ }^{\mathrm{TM}}$ service $^{- \text {F }}$ may be required to be fully compliant with the CFRs.

The Quality Assurance Program will address a number of organisational and procedural issues including;

The company organisation

Design control

Document control

Instructions, procedures and drawings

Control of purchased material, equipment and services

Identification and control of materials, parts and components

Control of special processes

Inspection

Test control

Control of measuring and test equipment

Handling, storage and shipping

Inspection, test and operating status

Nonconforming materials, parts or components

Corrective action

Quality assurance records

Audits.

\section{B.1.9 Summary and Conclusions}

The BNFL Instruments FuelMaster ${ }^{\mathrm{TM}}$ has demonstrated the practicality of making measurements on spent fuel within a utility's spent fuel pool. Furthermore, this work was carried out with equipment that required a simple equipment installation procedure and with minimal disruption to utility operations.

The results of the measurements have been shown to be compliant with the specified measurement accuracy and rejection criteria proposed in the USDOE OCRWM Topical Report on Actinide Only Burnup Credit. 
It can be concluded, therefore, that the FuelMaster ${ }^{T M}$ measurement system is well suited for the verification of reactor records assembly burnup data.

Further information on spent fuel monitoring is available in references 6-10 and on the Web http: Ilwww.bnflinsts.co.uk।

\section{References}

1. Chesterman A S et al, Preliminary Report on Arkansas Nuclear One PWR Spent Fuel Measurements 1996, BNFL Instruments, Presented to an EPRI meeting, EPRI Conference Centre, Palo Alto, California, October 1.2, 1996.

2. Burstall R F, FISPIN - A computer code for nuclide inventory calculations, United Kingdom Atomic Energy Authority, ND-/R/328(R), October 1979.

3. Alldred B, Quayle G A \& Whittaker A, Validation of the FISPIN Code Version 6 for PWR Calculations Using New Data Libraries Derived Predominant ${ }^{i n}$ from JEF-1., BNFL plc, August 1991.

4. Adachi Takeo et al \& Inoue Shin, Comparison of Calculated Values and Measured Values on the Amount of TRU and FP Nuclides Accumulated in Gadolinium Bearing PWR Spent Fuels. Department of Chemistry and Fuel Research, Japan Atomic Energy Research Institute \& The Kansai Electric Power Co., Journal of Nuclear Science and Technology, October 1994.

5. D Lancaster, B Lake \& E Fuentes Technical Exchange on PWR Actinide-Only Burnup Credit, January, 1997.

6. Beggs W J, Statistics for Nuclear Engineers and Scientists, Part 1, Basic Statistical Inference, Bettis Atomic Power Laboratory, WAPD-TM-1292, February 1981.

7. Electric Power Research Institute, Burnup Verification Measurements on Spent Fuel Assemblies at Oconee Nuclear Station, Final Report, EPRI TR-103591, January 1994.

8. Chesterman A S and Clark P A, Spent Fuel and Residue Measurement Instrumentation at the Sellafield Nuclear Reprocessing Facility, INMM 36th Annual Meeting Proceedings, Palm Desert, California, July 9-12, 1995.

9. Chesterman A S et al, PWR Spent Fuel Burnup Determination by Gamma Spectroscopy, BNFL Instruments, Presented to the meeting between Pajarito Scientific Corporation \& BNFL Instruments Ltd, and the U.S Nuclear Regulatory Commission, Headquarters, Rockville, MD, June 1996.

10. Chesterman A S and Clark P A, Radiometric Instrumentation for Burnup Credit, safeguards and Waste Charcterisation of Spent Fuel, INMM 37th Annual Meeting Proceedings, Palm Desert, California, July 28-31, 1996. 
APPENDIX B.2

EPRI's Fork+ 


\section{Application of the Fork+ radiation measurement system to the verification of burnup records.}

\section{B.2.1 Summary}

The Fork+ system provides a definitive verification of reactor records for burnup by measuring the residual radiation (gamma-rays and neutrons) from spent fuel assemblies. The Fork+ system incorporates gamma-ray spectroscopy capabilities to provide a determination of assembly burnup that is independent of the reactor records for burnup and initial enrichment. The Fork+ system is an extension of the Fork system, designed at Los Alamos National Laboratory for use by the International Atomic Energy Agency. The Fork+ system retains the overall design of the Fork system to take advantage of the demonstrated operational simplicity and sensitivity of the Fork system. Applications of the Fork system to verification of burnup records at U.S. commercial reactors are described in References 1-3. This appendix is intended to supplement the information in the references.

Gamma-ray spectroscopy permits the identification of a fission product, cesium-137, by its characteristic gamma-ray. Measurement of a fission product can be directly related to the burnup without reference to the reactor record. The Fork+ also has the capability to rapidly measure the gamma-ray yield along the length of an assembly to determine a burnup profile that is used to reduce the uncertainty in the independent measurement of burnup. Analysis of the neutron yield is used to identify with high sensitivity any disagreements between the neutron measurement and the reactor record for burnup of individual assemblies. The Fork+ system fulfills the measurement system design requirements of the Topical Report on Actinide-Only Burnup Credit for PWR Spent Nuclear Fuel Packages (DOE/RW-0472). The Fork+ system is in the final stages of development by Sandia National Laboratories with the support of the Electric Power Research Institute.

\section{B.2.2 Theory}

While undergoing irradiation in the reactor the fuel assemblies become highly radioactive due to the formation of fission products and neutron capture reactions. After removal from the reactor, the radiation emitted from the assembly decays with the characteristic half-lives of the many radioactive isotopes. The spent fuel assemblies that will be analyzed using the Fork+ have been out of the reactor for over 5 years, which simplifies the analysis of the radiation. After five years of cooling time cesium-137 is the major gamma-ray emitter. Cesium-137 is produced as a fission product in about six percent of the fissions that occur in the assembly. The burnup (heat output) of the assembly is directly determined by the number of fissions that occurred in the assembly, which is directly related to the cesium- 137 content of the assembly at the time of discharge. After five years of cooling time the only significant neutron emitter is curium-244, which is formed during irradiation by successive neutron capture beginning with uranium-238, and produces neutrons by spontaneous fission. The production of curium-244 is found to increase with about the fourth power of the burnup. The neutron emission is therefore very 
sensitive to variations in burnup.

\section{B.2.3 Measurement of Cesium-137}

Cesium-137 decays with a half-life of 30 years, resulting in the emission of a gamma-ray of energy $662 \mathrm{keV}$ in 85 percent of the decays. The $662 \mathrm{keV}$ gamma-ray is identified by analyzing the energy spectrum of the gamma-rays emitted from a spent fuel assembly. Standard spectroscopy techniques are employed to produce the gamma-ray energy spectrum, and identify the $662 \mathrm{keV}$ gamma-ray. The concentration of cesium-137 in the spent fuel assembly is determined from the observed intensity by calibration of the spectroscopy system with standard sources of cesium-137 and by calculation of geometric constraints and gamma-ray scattering. The total amount of cesium-137 in the assembly is determined by measuring the relative gammaray intensity along the length of the assembly and by integrating the observed concentration. The relative gamma-ray intensity is measured using ion chambers that are collimated to accept gamma-rays from only a small section of the assembly. The cooling time record for the assembly is then employed to extrapolate the total assembly content of cesium-137 back to the content at the time of discharge. The cooling time record is used because there is no direct radiation measurement available to independently determine an accurate cooling time that is effective over the entire cooling interval of interest in spent fuel verification ( 5 to 50 years).

\section{B.2.4 Independent Calculation of Burnup}

The burnup for the assembly can be determined from the total cesium-137 content of the assembly at the time of discharge and its irradiation history. The total number of fissions that have occurred in the assembly are calculated from the known ratio of fissions to cesium- 137 (about 16) and the energy released per fission (about $200 \mathrm{MeV}$ ). The result is the total amount of energy released from the assembly by fission. That result divided by the total amount of uranium in the assembly yields the burnup in the usual units of energy produced per mass of uranium. The irradiation history of the assembly is used to correct for the decay of cesium-137 while in the reactor and for any time out of the reactor between irradiation cycles.

\section{B.2.5 Neutron Yield}

The relative neutron yield is measured to provide a sensitive and rapid detection of assemblies for which the neutron yield does not agree with the reactor record for burnup (anomalous assemblies). The sensitivity of this measurement is due to the strong dependence of the neutron yield on the burnup (about the fourth power). The cesium-137 gamma-ray intensity increases as the first power of the burnup, and therefore is not as sensitive as neutrons to variations in burnup. After the assembly has been out of the reactor for 5 years the only significant neutron emitter is curium-244, which is formed in the reactor by successive neutron capture beginning with uranium-238. Curium-244 emits neutrons by spontaneous fission with a half-life of 18 
years. The production of curium increases with about the fourth power of the burnup. The yield of neutrons is correlated with burnup by calculated correction factors that make use of the reactor records for burnup, cooling time, and initial enrichment. When the corrected neutron yield is fit to the burnup records with a least-squares power law, the internal variation of burnup is accurately measured, and deviations indicate anomalous assemblies with great sensitivity.

\section{B.2.6 Description of Measurement System}

The Fork+ system is similar in design and operation to the Fork system, described in detail in References 1-3. In both systems, Fork and Fork+, gamma-ray and neutron measurements are made simultaneously on two opposite sides of the assembly, with detectors in each of the two arms (or tines of the "fork"). In the Fork+ system, each arm contains a neutron detector in the form of a fission chamber embedded in polyethylene, and a gross gamma-ray detector consisting of an ion chamber. The outputs of the two neutron detectors are added together to average the burnup distribution across the assembly. The two ion chambers are read individually to allow adjustment of the single gamma-ray spectrometer measurement for burnup variations across the assembly. One arm of the detector includes a spectrometer to analyze the energy distribution of the gamma-rays. A cadmium-zinc-tellurium crystal provides the necessary energy resolution to identify the gamma-ray from cesium-137. The gamma-ray sensors are each collimated with tungsten shielding to closely define the field of view on the assembly. Standard commercially available electronic control and readout systems are employed to analyze the detector outputs.

\section{B.2.7 Operation of the Fork+ System}

The Fork + detector is suspended from the fuel handling bridge and immersed in the spent fuel pool at a location just above the fuel rack. The array is moved to the location of the spent fuel assembly to be analyzed. The assembly is raised part way out of the rack until the Fork+ detector is in position for a measurement. The detector is swiveled into contact with assembly and the measurements performed. The assembly is then lowered back into its position in the rack. In general, the neutron and the gamma-ray spectroscopy measurements are performed near the center point of the assembly. A "burnup profile" is obtained using the ion chambers at several locations along the length of the assembly by raising or lowering the assembly.

\section{B.2.8 Proposed Verification Procedure Campaign}

The proposed verification procedure would perform neutron and ion chamber measurements at the center level of each assembly. Four assemblies, selected to bracket a range of burnups, are first measured to establish an initial calibration for the neutron system. Gamma-ray spectroscopy and burnup profile measurements would be performed on the four calibration assemblies, and on a sampling basis thereafter to provide the independent measurements of burnup. The sampling could involve a regular pattern, i.e., every ten assemblies, or a selected 
pattern to satisfy a particular statistical model. Anomalous assemblies identified by the neutron measurements would also be analyzed by gamma-ray spectroscopy and burnup profile. measurements.

\section{B.2.9 Fulfilling the Measurement System Design Requirements}

The Fork+ system combines both the "dependent" (neutron-based) and "independent" (gammaray spectroscopy based) measurement systems. The neutron measurements provide a rapid determination of relative burnup and screen for anomalous assemblies with great sensitivity. The more time consuming independent determinations of burnup would be performed on the calibration and sampling assemblies, assemblies for which the burnup is suspect or crucial (as would be the case for burnup near the loading curve), and anomalous assemblies detected by the neutron measurements. Additional internal calibration is available through the intercomparison of the neutron and gross gamma-ray yield measurements. The neutron measurements are used to check internal consistency, for intercomparison with calibration assemblies, and to detect anomalous assemblies. The accuracy requirement of $10 \%$ in burnup is met by the gamma-ray based measurements by careful control of geometry and by calibration with standard sources.

\section{B.2.10 Conclusions}

The Fork+ system consists of three measurement units: neutron detection, gross gamma-ray detection, and gamma-ray spectroscopy. Neutron detection is used to determine the internal variability of the reactor records for burnup, and to detect anomalous assemblies. Gamma-ray spectroscopy is used for the independent determination of the assembly burnup. The gross gamma-ray detectors are used to determine a relative burnup profile along the length of the assembly, to specify the side-to-side horizontal variation in burnup, and for intercomparison of the assemblies with and without gamma-ray spectroscopy data. 


\section{References}

1. Ewing, R.I., G.E. Bosler, R. Siebelist, and Gary Walden. 1994."Burnup Verification Measurements on Spent Fuel Assemblies at Oconee Nuclear Station", published by the Electric Power Research Institute, EPRI Report TR-103591, January, 1994.

2. Ewing, R.I., D.R. Bronowski, G.E. Bosler, R. Siebelist, J. Priore, and S. Sullivan. 1996. "Burnup Verification Measurements on Spent Fuel Assemblies at Arkansas Nuclear One, Unit 1", published by the Electric Power Research Institute, EPRI Report TR-106305, March, 1996.

3. Ewing, R.I., D.R. Bronowski, G.E. Bosler, R. Siebelist, J. Priore, C.H. Hansford, and S. Sullivan, 1997, "Measurements on Spent Fuel Assemblies at Arkansas Nuclear One Using the Fork System", Sandia National Laboratories Report SAND96-1364, UC-810, March, 1997. 
APPENDIX C

\section{ACRONYMS}




\section{ACRONYMS}

AEG Average Energy Group causing Fission

ALA Average Lethargy for Absorption

ALC Average Lethargy for Capture

ALF Average Lethargy for Fission

ANS American Nuclear Society

ANSI American National Standards Institute

ATM Approved Testing Materials

\begin{tabular}{|c|c|}
\hline BAR & Burnable Absorber Rod \\
\hline BCL & Battle Columbus Laboratory \\
\hline BUC & Burnup Credit \\
\hline $\mathrm{CE}$ & Combustion Engineering \\
\hline CFR & Code of Federal Regulations \\
\hline CRWMS & Civilian Radioactive Waste Management System \\
\hline DOE & Department of Energy \\
\hline
\end{tabular}

EPRI Electric Power Research Institute

Gwd/MTU Gigawatt Day Per Metric Tons Uranium

HEDL Hanford Engineering Development Laboratory

HLW High Level Radioactive Waste

IFBA Integral Fuel Burnable Absorber

LPB Lower Prediction Band

LWR Light Water Reactor

MCC Materials Characterization Center

MOX Mixed Oxide

MPC Multi-Purpose Canister

MW/MTU MegaWatt Per Metric Tons Uranium

NRC Nuclear Regulatory Commission

NWPA Nuclear Waste Policy Act of 1982, as amended

OCRWM Office of Civilian Radioactive Waste Management

ORNL Oak Ridge National Laboratory

PNL Pacific Northwest Laboratories

ppmb Parts per Million Boron

PUP Plutonium Utilization Program

PWR Pressurized Water Reactor 
QA Quality Assurance

QARD Quality Assurance Requirements and Description

RG Regulatory Guide

RSIC Radiation Shielding Information Center

SAR Safety Analysis Report

SCALE Standardized Computer Analyses for Licensing Evaluation

SNF Spent Nuclear Fuel

SNL Sandia National Laboratories

USL Upper Safety Limit 
APPENDIX D

\section{GLOSSARY}




\section{GLOSSARY}

27BURNUPLIB - The SCALE 4.227 group burnup library containing ENDF/B-IV (actinides) and ENDF/B-V (fission products) neutron cross section data. The cross sections are used in SAS2H fuel depletion and CSAS25 criticality analysis sequence calculations.

Absorber - A neutron-capture material. Absorber nuclides have a large neutron absorption cross section relative to their fission cross section.

Actinide-Only Burnup Credit - Credit for the reactivity change from fresh fuel to spent fuel accounting only for the change in actinide isotopic concentrations. Credit for the addition of fission product absorbers is not taken.

Actinides - A chemical group which contains, for the purpose of this report, $\mathrm{U}, \mathrm{Np}, \mathrm{Pu}, \mathrm{Am}$, and 'Cm.

Areas of Applicability - The ranges of material compositions and geometric arrangements within which the bias of a calculational method is established.

Assembly Identifier - A unique string of alphanumeric characters which identifies an assembly, bundle, or canister from a specific reactor in which it has been irradiated. Must be consistent with other submissions to the DOE/NRC; that is, Annex B, previous Form RW-859, and DOE/NRC Form 741.

Axial Burnup Distribution - The variability in SNF burnup along the length of an assembly. Typically, burnup is highest in the center region and lowest at the ends.

Basket - The internal component of a spent fuel storage, transportation, or disposal package that provides structural support for individual spent fuel assemblies and assures a subcritical geometry. The basket also functions to provide thermal conductivity to remove spent fuel decay heat.

Benchmark (noun) - A well-specified experiment that can be used to validate analytical methods. Accurate descriptions of the experimental configurations and materials are provided along with method descriptions and detailed results (including uncertainties and tolerances).

Benchmark (verb) - Verification of the area(s) of applicability and bounds of an analysis method by comparison to either experimental results or the results of another analysis method that has been verified experimentally.

Bias - A measure of the systematic disagreement between the results calculated by a method and experimental data. The uncertainty in the bias is a measure of both the precision of the calculation and the accuracy of the experimental data. 
BONAMI-S - A SCALE 4.2 module that performs resonance self-shielding calculations for isotopes that have Bondarenko data associated with their cross sections. The module is called by the SAS2H fuel depletion and CSAS25 criticality analysis sequences.

Burnable Absorbers - Absorbers placed in selected locations in a reactor core, external to the fuel rods, to enhance reactivity and power distribution control. Burnable absorbers are manufactured from materials that include a neutron absorber, which is converted to a nuclide with low absorption cross section as a result of neutron absorption. Similar reactor core reactivity control benefits are achieved with integral fuel burnable absorbers, which are added to the fuel matrix during fuel manufacture.

Burnup - 1) the process of fuel being consumed by fissioning; 2) a measure of the amount of energy obtained from fuel as the fuel fissions, which is expressed as the amount of energy produced per unit of fuel weight or the percentage of fissile atoms consumed during irradiation.

Burnup Credit (BUC) - The process of accounting for the operating history of spent nuclear fuel in criticality safety calculations and fuel loading operating procedures and controls.

Burnup Credit Isotopes - The isotopes selected to represent the composition of spent fuel in the burnup credit method.

Burnup Credit Loading Curve - A line plotted on an X-Y graph through limiting combinations of fuel assembly initial enrichment and required minimum burnup established using the burnup credit method. The curve specifies the criticality control design criteria and serves as the operational limit for selecting fuel assemblies for loading into a burnup credit SNF package.

Burnup Credit Method - The mathematical equations, approximations, assumptions, associated numerical parameters (e.g., cross sections), and calculational procedures that yield the burnup credit loading curve.

Burnup Credit Package - A storage, transportation, or disposal package designed to incorporate the operating history of spent nuclear fuel in criticality safety calculations and fuel loading operating procedures and controls.

Candidate Assembly - A spent fuel assembly determined by procedure to meet minimum burnup and any other requirements specified by a burnup credit SNF package Certificate of Compliance and the supporting Safety Analysis Report.

Cooling Time - The time since a spent fuel assembly is permanently discharged from the operating reactor.

Critical - A nuclear system is critical when the total number of fission neutrons produced during a time interval is equal to the total number of neutrons lost by absorption and leakage during the same interval (i.e., $\mathrm{k}_{\mathrm{eff}}=1$ ). 
CSAS - SCALE 4.2 sequences that perform criticality analysis calculations. CSAS analysis sequences are standardized automated procedures that process SCALE 4.2 cross sections using BONAMI-S and NITAWL-S, and perform a criticality analysis using KENO V.a.

Depletion - Isotopic transmutations occurring while the fuel is in the reactor core and producing power.

Double Contingency Principle - As adapted from ANSI/ANS-8.1, criticality control systems and procedures should, in general, incorporate sufficient factors of safety to require at least two unlikely, independent, and concurrent changes in conditions or failures in procedural controls before a criticality accident is possible.

End Effect - The $\mathrm{k}_{\text {eff }}$ difference between an axially burnup-dependent criticality calculation and an axially uniform criticality calculation.

Enrichment - A measure of the atom or weight percent of a particular isotope when it is increased above its abundance as found in nature.

Fissile Isotope - An isotope that is capable of fissioning when bombarded by a thermal neutron.

Fission Products - The bi-product nuclei resulting from fission events.

Fresh Fuel - Nuclear fuel that has not been exposed to any significant neutron sources.

Fresh Fuel Assumption - A term used to describe the historic method of modeling fuel for criticality analysis where it is assumed that the fuel is at its initial enrichment.

$\mathbf{H} / \mathbf{U}$ - The ratio of hydrogen to uranium in a system containing uranium fuel and hydrogeneous moderator.

Independent Burnup Verification - An accurate, relative indication of spent fuel assembly burnup correlated from neutron and gamma emission measurements and reactor records for assembly initial enrichment and cooling time since final discharge from the reactor.

Intact Fuel Assemblies - "As-received" by a reactor operator, in those characteristics important to the criticality safety analysis; i.e., all original fuel pins are present and assembly array characteristics, including pin pitch, and guide and instrument tube characteristics are unaltered from the original as-manufactured design configuration. The presence of irradiated burnable absorber rods in the guide tube locations is specifically identified as an "intact" assembly. Intact Fuel Assemblies are potential candidates for loading into a burnup credit package. The presence of fuel pins in guide or instrument tube locations is specifically identified as "not intact" and not acceptable for loading in a burnup credit package.

Integral Fuel Burnable Absorbers - Burnable absorbers integral to the fuel pin. These include Gd or Er mixed in the pellet or a boron compound coating on the pellet. 
$\mathbf{k}_{\text {eff }}$, Effective Multiplication Factor - The ratio of the neutron production rate by fission in a nuclear system to the rate of neutron loss by leakage and absorption

$\mathbf{k}_{\infty}$, Infinite Multiplication Factor - The ratio of the neutron production rate from fission in an infinite nuclear system to the rate of neutron loss by absorption (i.e., leakage is zero).

KENO V.a - A SCALE 4.2 module that performs a 3-D multigroup Monte Carlo criticality analysis. The module is called by the CSAS 25 criticality analysis sequence.

Loading Criteria - Fuel loading requirements, limits, and controls specified by a burnup credit SNF package Certificate of Compliance and the supporting Safety Analysis Report.

Modeling Parameters - Material and geometric characteristics of a system necessary to describe the system for calculational purposes, which, when varied, influence the margin of subcriticality.

Moderator - Material incorporated into a nuclear system to slow neutrons to lower energy levels ,by collision processes.

Neutron Cross Section - A proportionality constant describing the extent to which neutrons interact with nuclei of a material.

NITAWL-S - A SCALE 4.2 module that applies a Nordhiem resonance self-shielding correction to isotopes having resonance parameters. The module is called by the SAS2H fuel depletion and CSAS25 criticality analysis sequences.

Non-specification Assembly - A spent fuel assembly determined by procedure to not meet minimum burnup or other requirements specified by a burnup credit SNF package Certificate of Compliance and the supporting Safety Analysis Report.

ORIGEN-S - A SCALE 4.2 module that performs both isotope generation and depletion calculations for a specified reactor fuel history. ORIGEN-S is called by the SAS2H analysis sequence.

Package - The shielded container together with its radioactive contents as prepared for storage, transport, or disposal.

Package Capacity - The number of individual spent fuel assemblies that can be physically inserted into a particular transportation package.

Qualified Assembly - A spent fuel assembly determined by procedure to meet minimum burnup requirements specified by a burnup credit SNF package Certificate of Compliance and the supporting Safety Analysis Report, and verified by measurement to exhibit characteristics consistent with reactor records with regard to initial enrichment, burnup, and cooling time.

Reactivity - A measure of the departure of a nuclear system from critical. 
Reactor Records - Utilization facility records pertaining to spent nuclear fuel manufacture, irradiation history, and current storage location.

SAS2H - A SCALE 4.2 sequence that performs fuel isotope generation and depletion analysis calculations and analysis of spent fuel packages. The SAS2H analysis sequence is a standardized automated procedure which processes SCALE 4.2 cross sections using BONAMI-S, NITAWL-S, XSDRNPM-S and COUPLE, and performs a fuel nuclide generation, depletion and decay analysis using ORIGEN-S.

SCALE 4.2 - A modular Code System for Performing Standardized Computer Analysis for Licensing Evaluation, NUREG/CR-0200, Rev. 4 (ORNL/NUREG/CSD-2/R4), Vols, I, II, and III. Available from Radiation Shielding Information Center, Oak Ridge National Laboratory, as CCC545.

Special Nuclear Material - 1) Plutonium, uranium 233, uranium enriched in isotope 233 or isotope 235 , and any other material determined as special nuclear material pursuant to section 51 of the Atomic Energy Act, but does not contain source material or 2) any material artificially enriched by any of the foregoing, but does not include source material.

Specific Power (MW/MTU) - The amount of power produced per metric ton of uranium originally in the fuel.

Spent Nuclear Fuel - Burned fuel that has been permanently withdrawn from a nuclear reactor.

Spent Nuclear Fuel Package - This is a general term to encompass transportation casks, storage containers, waste packages, or a multi-purpose canister.

Staged Fuel Assembly - A qualified fuel assembly that is physically positioned in preparation for SNF package loading consistent with the package loading procedure.

Subcritical - A nuclear system is subcritical when the total number of fission neutrons produced during a time interval is less than the total number of neutrons lost by absorption and leakage during the same interval (i.e., $\mathrm{k}_{\text {eff }}<1$ ).

Thermal Neutrons - Neutrons that are in substantial thermal equilibrium with the core material and are the primary means for inducing fission in fissile material.

Upper Safety Limit (USL) - The highest value of $\mathbf{k}_{\text {eff }}$ allowed so that subcriticality is ensured. This limit accounts for all the biases, uncertainties, administrative margins, and licensing assumptions.

Validation - A process to demonstrate that analytical methods meet predetermined requirements. 
INTENTIONALLY LEFT BLANK 